\author{
UNIVERSIDADE DE SÃO PAULO \\ INSTITUTO DE ENERGIA E AMBIENTE \\ PROGRAMA DE PÓS-GRADUAÇÃO EM ENERGIA
}

JOSÉ RAFAEL RODRÍGUEZ BENAVIDES

A AUDITORIA ENERGÉTICA COMO FERRAMENTA PARA O APROVEITAMENTO DO POTENCIAL DE CONSERVAÇÃO DA ENERGIA: O CASO DAS EDIFICAÇÕES DO SETOR EDUCACIONAL 
JOSÉ RAFAEL RODRÍGUEZ BENAVIDES

\section{A AUDITORIA ENERGÉTICA COMO FERRAMENTA PARA O APROVEITAMENTO DO POTENCIAL DE CONSERVAÇÃO DA ENERGIA: O CASO DAS EDIFICAÇÕES DO SETOR EDUCACIONAL}

Dissertação apresentada ao programa de PósGraduação em Energia da Universidade de São Paulo para obtenção do título de Mestre em Ciências.

Orientador: Prof. Dr. Geraldo Francisco Burani 


\section{AUTORizo A REPRODUÇÃo E DIVULGaÇÃo TOTAL OU PARCIAL DESTE TRABALHO, POR QUALQUER MEIO CONVENCIONAL OU ELETRÔNICO, PARA FINS DE ESTUDO E PESQUISA, DESDE QUE CITADA A FONTE.}

FICHA CATALOGRÁFICA

Benavides, José Rafael Rodriguez.

A auditoria energética como ferramenta para o aproveitamento do potencial de conservação da energia: o caso das edificações do setor educacional./ José Rafael Rodriguez Benavides; orientador: Geraldo Francisco Burani. - São Paulo, 2014.

136 f.: il.; $30 \mathrm{~cm}$.

Dissertação (Mestrado - Programa de Pós-Graduação em Energia) EP / FEA / IEE / IF da Universidade de São Paulo.

1. Eficiência energética. 2. Iluminação. 3. Cogeração. I. Título. 


\section{UNIVERSIDADE DE SÃO PAULO \\ PROGRAMA DE PÓS-GRADUAÇÃO EM ENERGIA}

\section{JOSE RAFAEL RODRIGUEZ BENAVIDES}

“A auditoria energética como ferramenta para o aproveitamento do potencial de conservação da energia: o caso das edificações do setor educacional"

Dissertação defendida e aprovada pela Comissão Julgadora:

Prof. Dr. Geraldo Francisco Burani - PPGE/USP

Orientador e Presidente da Comissão Julgadora

Prof. Dr. Hédio Tatizawa- PPGE/USP

Prof. Dr. Marco Antonio Saidel- EP/USP 


\section{DEDICATÓRIA}

Dedico esse trabalho aos meus Pais e Avós, por seu apoio incondicional e grande exemplo na minha vida. Para vocês, muito obrigado. 


\section{AGRADECIMENTOS}

Ao Professor Geraldo Francisco Burani por sua amizade, ajuda, e contribuição para finalizar com sucesso o mestrado.

Aos Professores e pesquisadores, Prof. Dr. José Roberto Simões Moreira, Dr. Alessandro Barghini, Dr. Kleiber Tadeu Soletto, Msc. Jose Gil Oliveira, Doutorando Arthur Cursino dos Santos, e Doutorando Rinaldo Caldeira pelo acompanhamento em diversas etapas da dissertação.

Ao Dr. Elvo Calixto Burini Jr. por sua colaboração constante em temas da área da Iluminação.

Aos Professores do Programa de Pós-Graduação em Energia do Instituto de Energia e Ambiente por suas lições importantes para o meu desenvolvimento como profissional.

A minha esposa, Natalia Ribeiro, pela ajuda durante a totalidade do meu trabalho e principalmente por ser minha grande companheira de vida durante minha estadia no Brasil.

Aos colegas e amigos do Instituto de Energia e Ambiente por sua amizade, ajudas e incontáveis momentos gratos.

A minha família e amigos na Costa Rica por sempre estarem presentes neste tempo que morei longe.

Ao Consejo Nacional para Investigaciones Científicas y Tecnológicas (CONICIT) do Governo da Costa Rica pelo apoio financeiro.

A Organização de Estados Americanos (OEA), o Grupo Coimbra de Universidades Brasileiras (GCUB) e a Universidade de São Paulo (USP), pela bolsa de estudo e principalmente a oportunidade de viver esta experiência. 


\section{RESUMO}

\section{RODRIGUEZ BENAVIDES, J.R.-" A auditoria energética como ferramenta para o}

aproveitamento do potencial de conservação da energia: o caso das edificações do setor educacional".2014. 132f. Dissertação submetida para obtenção do título de Mestre em Ciências do Instituto de Energia e Ambiente da Universidade de São Paulo. São Paulo, USP, 2014.

O consumo de energia nos diferentes setores da economia cresce continuamente devido aos hábitos de consumo, aumento da população e necessidades tecnológicas atuais; considerando o efeito deste aumento de consumo sobre os recursos naturais, a conscientização da importância do uso racional da energia é cada dia um tópico de maior relevância em todo o mundo. Ante a crescente necessidade de reduzir o consumo energético das edificações, algumas metodologias apresentam-se como ferramentas úteis para o alcance deste fim, uma delas é a auditoria energética. A auditoria energética é um mecanismo para entender o desempenho energético de edifícios, através dela é possível detectar problemas operacionais, aumentar o conforto dos ocupantes e otimizar o uso da energia. O presente estudo utilizou uma metodologia de auditoria energética para conhecer o comportamento energético de diferentes prédios do setor terciário especificamente do setor educacional, pertencentes a Universidade de São Paulo (USP). A metodologia foi aplicada em diferentes edificações do setor, e a mesma incluiu a utilização de medições de variáveis elétricas, medições de iluminação segundo as normas preconizadas, software para estudo de usos finais e ferramentas de simulação computacional como o software Dialux e o EnergyPlus. As melhores oportunidades de eficiência energética foram avaliadas técnica e economicamente, comparando cenários para a execução de estratégias com diferentes tecnologias comercialmente disponíveis no mercado. A avaliação econômica incluiu a utilização de figuras de mérito como o tempo de payback, a taxa interna de retorno (TIR), o custo de ciclo de vida (LCC), o custo de ciclo de vida anualizado (ALCC) e o custo da energia conservada (CEC). Os resultados validam a auditoria energética como método para tomada de decisões no sentido de eleger as melhores ações de eficiência energética para uma edificação.

Palavras-Chave: Auditoria Energética, Simulação computacional, Eficiência energética, Sistemas de iluminação, Cogeração. 


\begin{abstract}
RODRIGUEZ BENAVIDES, J.R.-" The energy audit as a tool for harnessing the potential for energy conservation: the case of education sector buildings ". 2014.
\end{abstract} 132f. Dissertation submitted to obtain the title of Master of Science at the Institute of Energy and Environment, University of São Paulo. São Paulo, USP, 2014.

The energy consumption in different sectors of the economy grows continuously due to consumption habits, increase in population and current technological needs; considering the negative effect of this increased consumption the environment, awareness of the significance of rational use of energy is a topic of great importance worldwide. Faced with the growing need to optimize the energy consumption of buildings, some methodologies are presented as useful tools for achieving this goal, one of them is the energy audit. The energy audit is a mechanism to understand the energy performance of buildings and facilities, through it is possible to detect operational problems, increase occupant comfort and optimize energy use. The present study used a methodology of energy audit to understand the energy performance of different buildings of the tertiary sector and specifically in educational sector buildings belonging to the University of São Paulo ( USP ). The methodology was applied in different buildings of this sector, and it included the use of power measurements, lighting measurements according to the standards, energy end-use software and computer simulation tools such as Dialux and EnergyPlus software .The best opportunities for energy efficiency were evaluated by comparing scenarios for the implementation of strategies with different technologies commercially available. The economic evaluation included the use of financial analysis tools such as payback time, the internal rate of return (IRR ), the Life Cycle Cost (LCC), the Annualized Life Cycle Cost (ALCC) and the Cost of Saved Energy (CSE) . The results validate energy audit as a method for decision making in order to select the best energy efficiency strategies for a building.

Key Words : Energy Audit, Computer Simulation, Energy Efficiency, Lighting Systems, Cogeneration 


\section{LISTA DE FIGURAS}

Figura 1- Metodologia Geral para Auditoria Energética. .24

Figura 2- Carga de Iluminação em relação á Demanda máxima das instalações..........26

Figura 3- Esquema funcionamento de sistema centralizado com

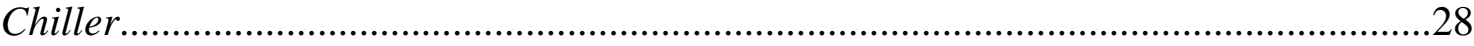

Figura 4- Usos Finais da Energia nas edificações acadêmicas nos USA (A); no Reino Unido (B); na Arábia Saudita (C); na Grécia (D) e no Brasil (E)..................................31

Figura 5- Equipamentos trifásicos de medição de energia utilizados..............................36

Figura 6- Luximetro digital utilizado nas medições de iluminância...............................37

Figura 7- Questionário Eventos de Consumo para levantamento dos usos finais..........38

Figura 8- Tabela de decisão para curva de demanda de um evento..............................39

Figura 9- Software de simulação de iluminação DIALUX..........................................41

Figura 10- Arquivos fotométricos para diferentes luminárias.....................................42

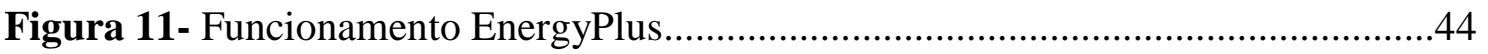

Figura 12- Procedimento típico de calibração de modelo de simulação

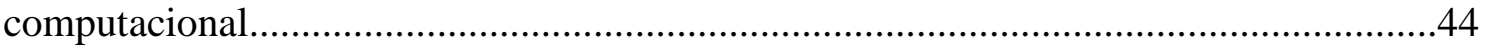

Figura 13- Posicionamento do Prédio da Administração do IEE..................................45

Figura 14- Imagens do exterior e do interior do Prédio Administração IEE/USP.........46

Figura 15- Imagens do sistema fotovoltaico Prédio Administração IEE/USP...............47

Figura 16- Influência da produção do sistema fotovoltaico na curva de carga do Prédio da Administração.

Figura 17- Fotos do sistema de iluminação do Prédio "Fazendinha" do IEE................49

Figura 18- Medição da potência ativa entre 1 de junho e 30 de junho...........................50

Figura 19- Medição da potência ativa de um dia típico no horário comercial................51

Figura 20- Medição da potência ativa de um dia de final de semana...........................51

Figura 21- Usos finais da energia Prédio Administração no Inverno............................54

Figura 22- Usos finais da energia Prédio da Administração no Verão............................55 
Figura 23- Curva de demanda de energia por uso final,para um dia típico da semana no inverno, segundo o PUFE.

Figura 24- Curva de demanda de energia por uso final para dia típico de final de semana no inverno, segundo o PUFE.

Figura 25- Modelo Computacional Biblioteca--Escritórios (A) Modelo Computacional Biblioteca-Sala Leitura (B). Modelo Computacional Biblioteca-Sala Acervo (C). 60

Figura 26-Modelo Computacional Escritório-Contratos (A) Modelo Computacional Escritórios-Administrativo (B). Modelo Computacional Direitoria (C).......................62

Figura 27- Posicionamento do Prédio de Energia do IEE .65

Figura 28- Imagens do exterior e do interior do Prédio de Energia do IEE...................66

Figura 29- Fotos do sistema de iluminação do Prédio de Energia do IEE....................68

Figura 30- Medição da potência ativa entre 11 de maio e 05 de julho............................70

Figura 31- Medição da potência ativa e energia de um dia típico horário comercial.....70

Figura 32- Medição da potência ativa de um dia típico de final de semana..................71

Figura 33- Usos finais da energia Prédio de Energia no Inverno.................................73

Figura 34- Usos finais da energia Prédio de Energia no Verão....................................74

Figura 35- Curva de demanda de energia por uso final para um dia típico da semana no inverno, segundo o PUFE. .75

Figura 36- Curva de demanda de energia por uso final para dia típico de final de semana no inverno, segundo o PUFE. .76

Figura 37- Modelo Computacional Sala Professor 1 (A) Modelo Computacional

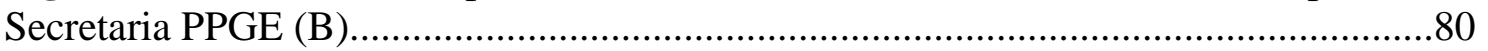

Figura 38- Posicionamento do Prédio do Laboratório de Conservação de Energia do IEE. .83

Figura 39- Imagens do exterior e do interior do Prédio "Fazendinha" IEE/USP...........85

Figura 40- Fotos do sistema de iluminação do Prédio "Fazendinha" do IEE.................86

Figura 41- Medição da potência ativa entre 7 de junho e 17 de julho............................87

Figura 42- Medição da potência ativa e energia de um dia típico da semana no horário comercial. 
Figura 43- Medição da potência ativa e energia de um dia típico de final de semana...88

Figura 44- Medição da potência ativa e energia no CPD entre os dias 08 e 16 de agosto de 2013.

Figura 45- Medição da potência ativa e energia de um dia típico de semana no CPD..90

Figura 46- Medição da potência ativa e energia de um dia típico de final de semana no CPD. .90

Figura 47- Usos finais da energia Prédio "Fazendinha" no Inverno.............................92

Figura 48- Usos finais da energia Prédio "Fazendinha" no Verão.

Figura 49- Curva de demanda de energia por uso final para dia típico de semana no inverno, segundo o PUFE

Figura 50- Curva de demanda de energia por uso final para dia típico final de semana em inverno, segundo o PUFE. 95

Figura 51- Modelo Computacional Sala Professor 1 (A) Modelo Computacional Secretaria PPGE (B). .99

Figura 52- Posicionamento do Prédio CCE USP.........................................................102

Figura 53- Posicionamento do Prédio CCE USP.......................................................... 103

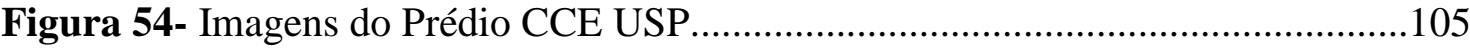

Figura 55- Chiller, Fan Coils e duto de circulação de ar no CPD do CCE...................106

Figura 56- Fotos do sistema de iluminação do CCE...................................................106

Figura 57- Medição da potência ativa e energia ativa do dia 21/07 ao 18/08 de

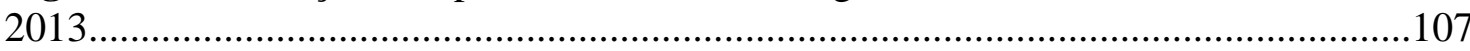

Figura 58- Medição da potência ativa de um dia típico comercial (06/08/2013).........108

Figura 59- Medição da potência ativa deum final de semana (03/08/2013)................108

Figura 60- Usos finais da energia Prédio CCE/USP no Inverno................................110

Figura 61- Usos finais da energia Prédio CCE/USP no Verão....................................111

Figura 62- Usos finais da energia Prédio CCE/USP no Inverno................................112

Figura 63- Usos finais da energia CCE/USP no Verão...........................................113 
Figura 64- Curva de demanda de energia por uso final para um dia típico de semana no

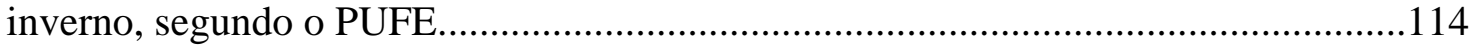

Figura 65- Curva de demanda de energia por uso final para um dia típico de final de semana no inverno, segundo o PUFE............................................................................. 115

Figura 66- Modelo computacional en Google Sketchup para simulação em

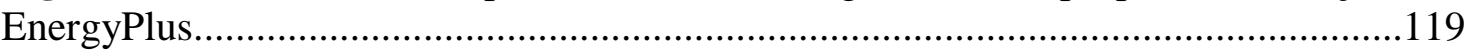

Figura 67- Simulação computacional da carga térmica do CPD num dia de inverno e de verao. 119

Figura 68- Cogeração com Ciclo Topping. 120

Figura 69- Nova curva de demanda elétrica para um dia típico inverno, energia gerada pelo motogerador e energia comprada a concessionária.

Figura 70- Carga térmica do datacenter e capacidade de geração térmica motogerador e microturbina em dia típico de inverno 


\section{LISTA DE TABELAS}

Tabela 1- Uso da energia no setor terciário em diferentes países

Tabela 2- Iluminância média recomendada para iluminação artificial em áreas do ambiente acadêmico.

Tabela 3- Densidade de potência de iluminação recomendada nas edificações acadêmicas segundo ASHRAE.

Tabela 4- Usos Finais da Energia nas edificações acadêmicas. .30

Tabela 5- Indicadores de consumo energético para as edificações do setor terciario .40

Tabela 6- Indicadores de consumo energético especifico de diferentes sistemas..........40

Tabela 7- Funcionários e Atividades do Prédio da Administração IEE/USP .46

Tabela 8- Medições de Iluminância Média e efeito da iluminação natural no total......52

Tabela 9- Comparação valores existentes com os requeridos nas normas .53

Tabela 10- Dados utilizados para o cálculo dos indicadores energéticos......................58

Tabela 11- Indicadores Energéticos baseados na medição...........................................58

Tabela 12- Indicadores Energéticos baseados no PUFE............................................58

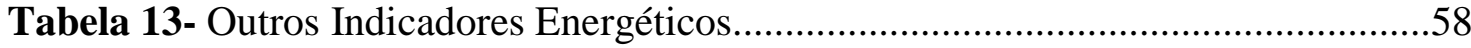

Tabela 14- Simulações no Dialux para as salas da Biblioteca do Prédio Administração.

Tabela 15- Simulações no Dialux para as salas de escritórios do Prédio Administração.

Tabela 16- Custos Equipamentos e Mão de Obra 63

Tabela 17- Avaliação econômica da substituição das lâmpadas atuais por lâmpadas da tecnologia T5 e LED.

Tabela 18- Funcionários e Atividades do Prédio de Energia IEE/USP .66

Tabela 19- Medições de Iluminância Média e efeito da iluminação natural no total.....72

Tabela 20- Comparação valores existentes com os requeridos nas normas. .72 
Tabela 21- Dados utilizados para o cálculo dos indicadores energéticos

Tabela 22- Indicadores Energéticos baseados na medição..........................................77

Tabela 23- Indicadores Energéticos baseados no PUFE...............................................

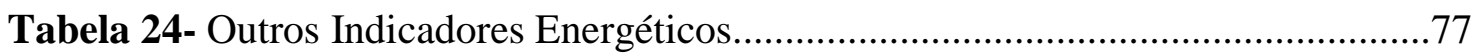

Tabela 25- Simulações no Dialux para salas representativas do Prédio Energia...........80

Tabela 26- Custos Equipamentos e Mão de Obra............................................................. 81

Tabela 27- Avaliação econômica da sustitução das lâmpadas atuais com lâmpadas da

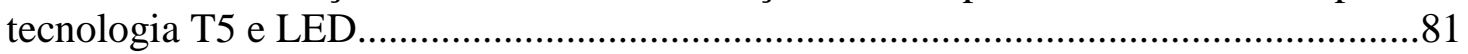

Tabela 28- Funcionários e Atividades do Prédio Fazendinha IEE/USP.......................84

Tabela 29- Medições de Iluminância Média e efeito da iluminação natural no total....91

Tabela 30- Comparação valores existentes com os requeridos nas normas...................91

Tabela 31- Dados utilizados para o cálculo dos indicadores energéticos.....................96

Tabela 32- Indicadores Energéticos baseados na medição...........................................96

Tabela 33- Indicadores Energéticos baseados no PUFE..........................................97

Tabela 34- Indicadores Energéticos CPD........................................................... 97

Tabela 35- Outros Indicadores Energéticos.................................................................

Tabela 36- Simulações no Dialux para salas representativas do Prédio "Fazendinha".99

Tabela 37- Custos Equipamentos e Mão de Obra.........................................................100

Tabela 38- Avaliação econômica da sustitução das lâmpadas atuais por lâmpadas da

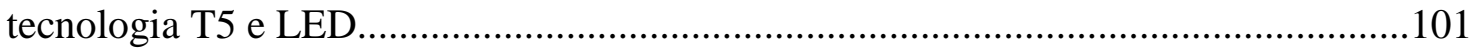

Tabela 39- Divisões e Atividades do Prédio CCE USP...........................................103

Tabela 40- Comparação valores existentes com os requeridos nas normas..................109

Tabela 41- Dados utilizados para o cálculodos indicadores energéticos.....................116

Tabela 42- Indicadores Energéticos baseados na medição CCE/USP........................116

Tabela 43- Indicadores Energéticos baseados no PUFE.........................................116

Tabela 44- Indicadores Enérgeticos CPD do CCE/USP.........................................117 
Tabela 45- Outros Indicadores Energéticos.

Tabela 46. Cálculos Energia Térmica Motogerador 200kW...............................................121

Tabela 47. Cálculos Geração Térmica Chiller de Absorção................................................122

Tabela 48- Cálculos Energia Térmica Microturbina 190kW................................................122

Tabela 49- Cálculos Geração Térmica Chiller de Absorção....................................................123

Tabela 50- Custo Equipamentos, instalação e manutenção anuais estimados..........................124

Tabela 51. Custo mensal de eletricidade comprada a concessionária.................................125

Tabela 52- Custo mensal do gás natural para geração elétrica nos diferentes cenários. $\quad$....... 125

Tabela 53- Avaliação Econômica da implementacao de cogeração no CCE.............................126 


\section{LISTA DE SIGLAS}

AHU Air Handling Units

ALCC Annualized Life Cycle Cost

ASHRAE American Society of Heating, Refrigerating and Air Conditioning Engineers

BLAST Building Loads Analysis and Thermodynamics

CCE Centro de Computação Eletronica

CEC Custo Energia Conservada

CERTUSP Organismo de Certificação de Produtos

COP Coeficiente de Performance

CPD Centro de Processamento de Dados

DOE Department of Energy

DPI Densidade de Potência de Iluminação

HVAC Heating, Ventilation and Air Conditioning

IEE Instituto de Energia e Ambiente

ISO International Organization for Standarization

LCC Life Cycle Cost

LED Light Emitting Diodes

NBR Norma Brasileira

NPD Densidade de Potência Normalizada de Iluminação

PPGE Programa de Pós Graduação em Energia

PROCEL Programa Nacional de Conservação de Energia Elétrica

PUE Power Usage Effectiveness ( Datacenter)

PUFE Programa Usos Finais da Energia

PVC Policloreto de vinila 
TIR Taxa Interna de Retorno

USD $\quad$ United States Dollars

USP Universidade de Sao Paulo

VRV Variable Refrigerant Volume 


\section{SUMÁRIO}

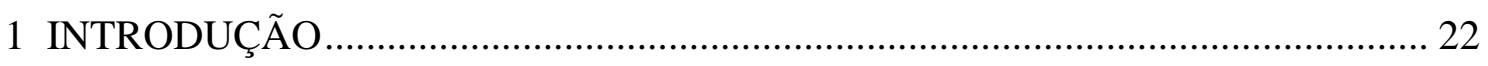

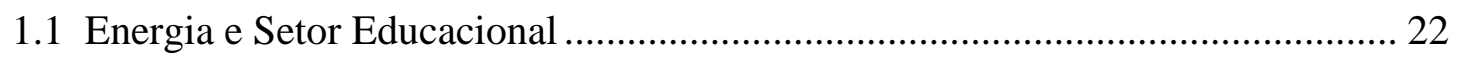

1.2 Eficiência Energética e Auditorias.................................................................. 23

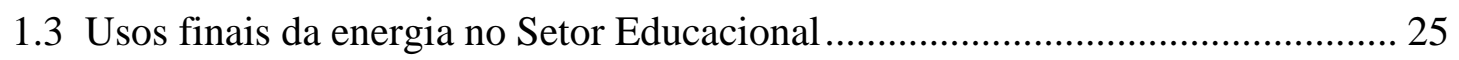

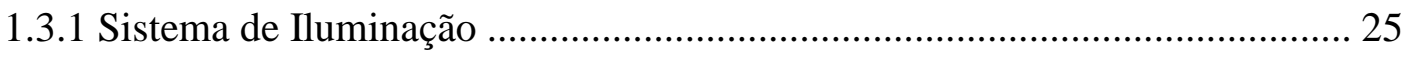

1.3.2 Sistema de Condicionamento Ambiental .................................................. 28

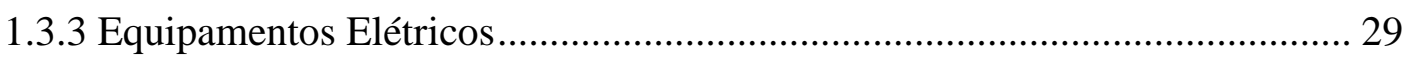

1.4 Auditorias energéticas no Setor Educacional ................................................. 30

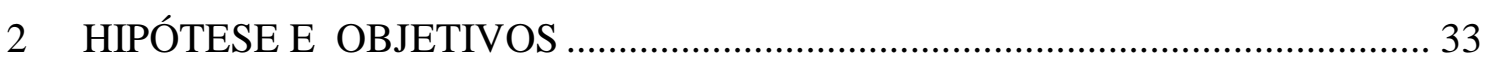

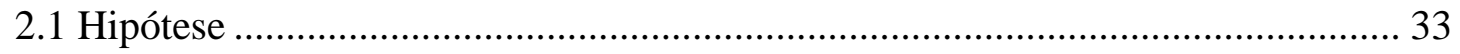

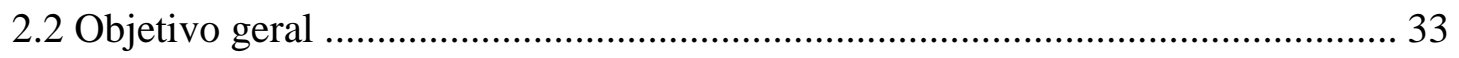

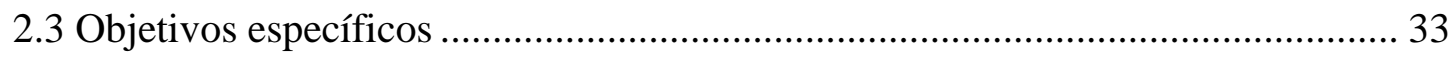

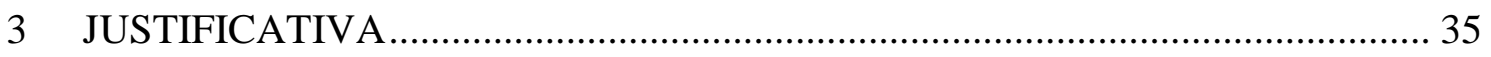

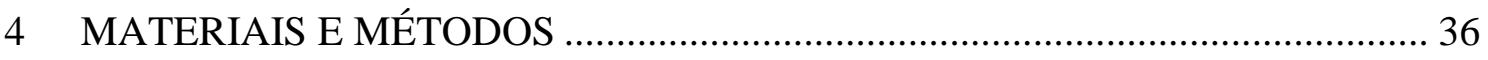

4.1 Medições de consumo energético ..................................................................... 36

4.2 Medições e avaliação de iluminância segundo a norma NBR 5382. ................... 37

4.3 Levantamento dos usos finais da energia. ...................................................... 37

4.4 Construção de curvas de demanda e cálculo de indicadores. ............................. 39

4.5 Proposta de cenários de conservação de energia e melhoria da iluminação......... 41

4.6 Comprovação de cenários com modelos de simulação computacional. ............... 41

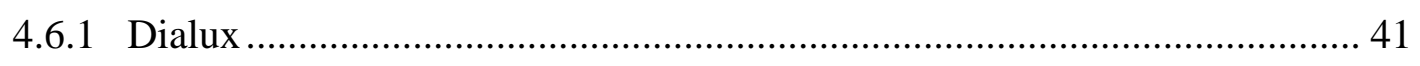

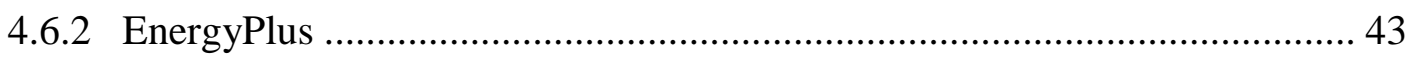

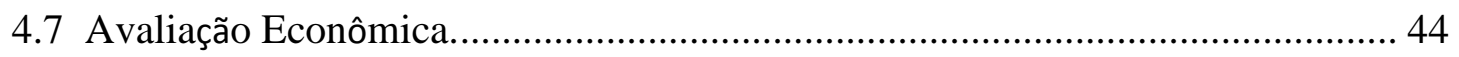

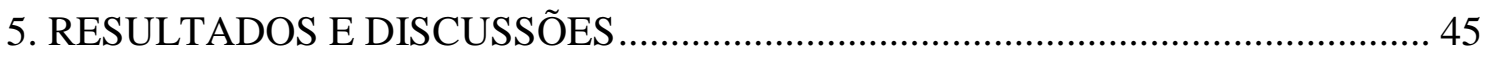

5.1 Prédio de Administração- Instituto de Energia e Ambiente ................................. 45

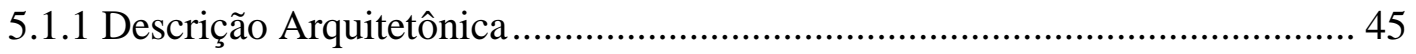

5.1.2 Características Especiais: Sistema Fotovoltaico Conectado à Rede ............. 46

5.1.3 Descrição Geral dos Sistemas Energéticos ............................................... 48

5.1.3.1 Condicionamento Ambiental ............................................................ 49 


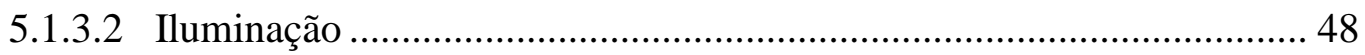

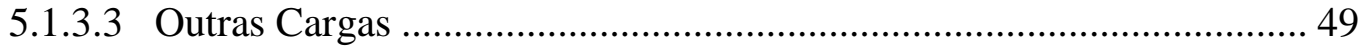

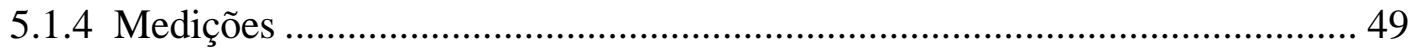

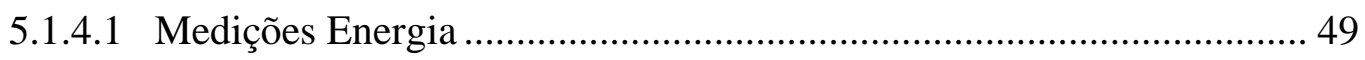

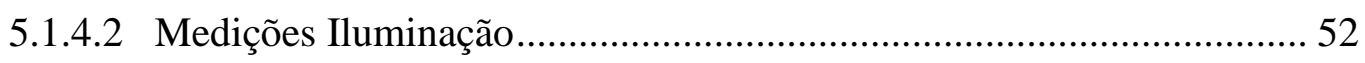

5.1.5 Levantamento Usos Finais da Energia (PUFE).......................................... 53

5.1.5.1 Distribuição dos Usos Finais ......................................................... 53

5.1.5.2 Curva de Carga por Uso Final ....................................................... 55

5.1.6 Cálculos e Dados Paramétricos ................................................................... 57

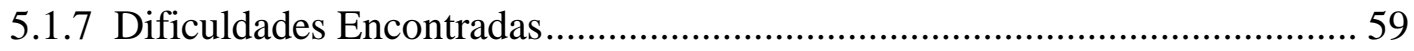

5.1.8 Proposta de cenários de conservação de energia e melhoria iluminação ...... 59

5.1.9 Substituição do sistema de iluminação atual .............................................. 59

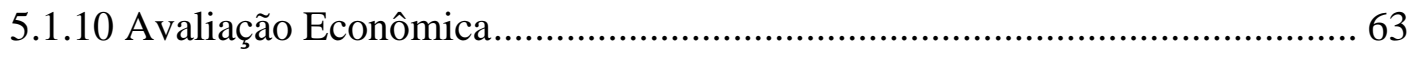

5.2 Prédio de Energia- Instituto de Energia e Ambiente …................................... 65

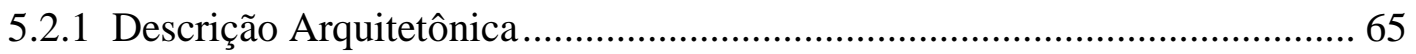

5.2.2 Descrição Geral dos Sistemas Energéticos .............................................. 67

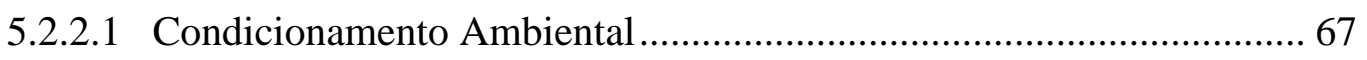

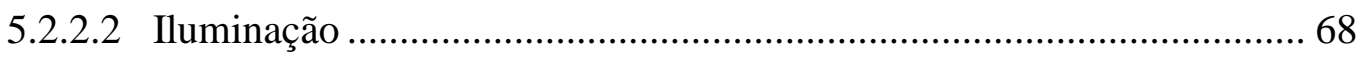

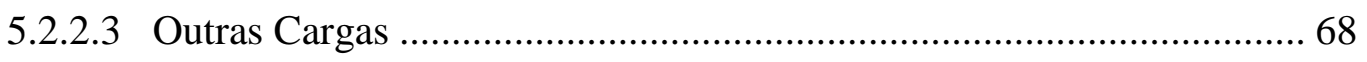

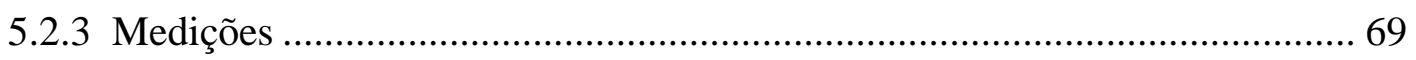

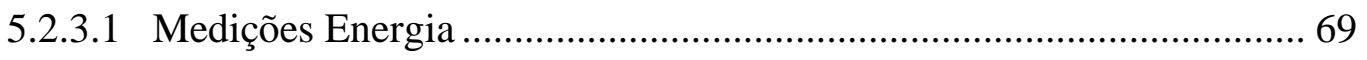

5.2.3.2 Medições Iluminação.................................................................... 71

5.2.4 Levantamento Usos Finais da Energia (PUFE)........................................ 73

5.2.4.1 Distribuição dos Usos Finais .............................................................. 73

5.2.4.2 Curva de Carga por Uso Final .......................................................... 75

5.2.5 Cálculos e Dados Paramétricos .............................................................. 76

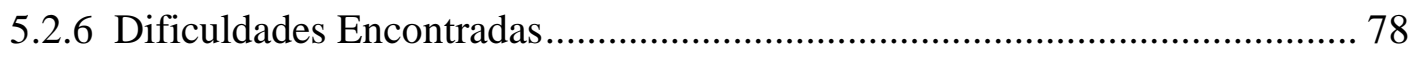


5.2.7 Proposta de cenários de conservação de energia ou melhoria da iluminação 78

5.2.8 Substituição do sistema de iluminação atual ............................................ 79

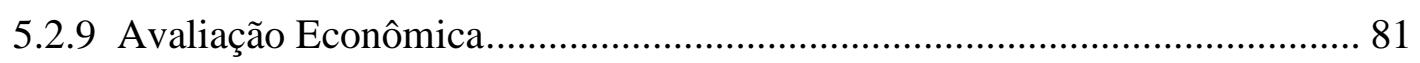

5.3 Prédio de Laboratorios ("Fazendinha”) - Instituto de Energia e Ambiente ..... 83

5.3.1 Descrição Arquitetônica..................................................................... 83

5.3.2 Descrição Geral dos Sistemas Energéticos ............................................... 85

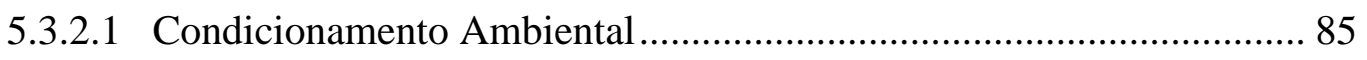

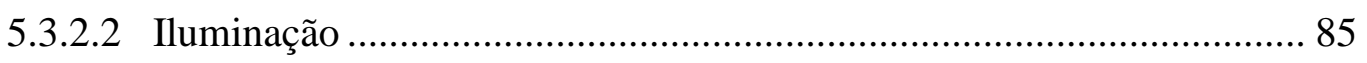

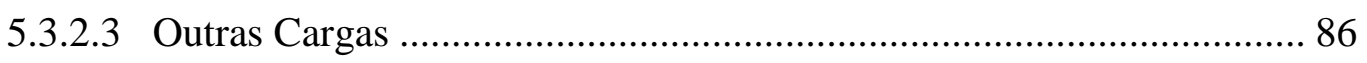

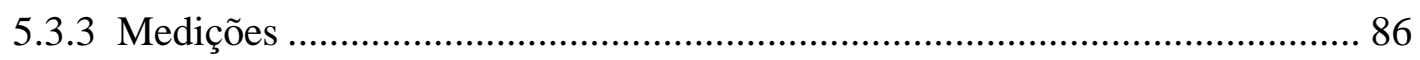

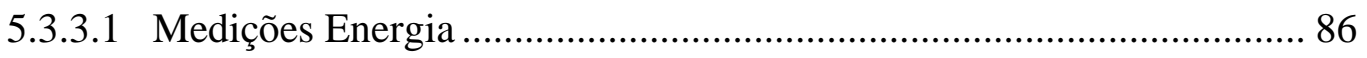

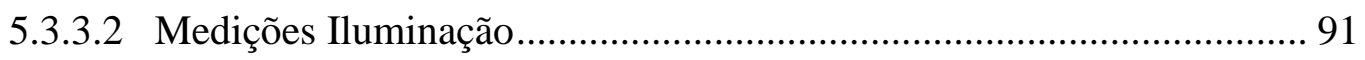

5.3.4 Levantamento Usos Finais da Energia (PUFE) ....................................... 92

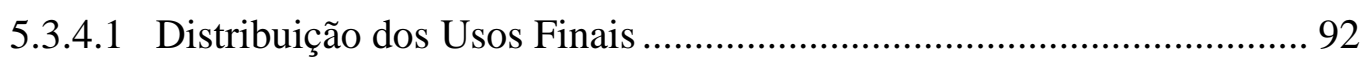

5.3.4.2 Curva de Carga por Uso Final ........................................................ 94

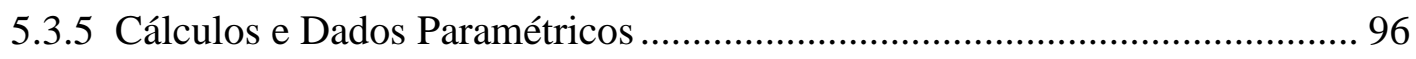

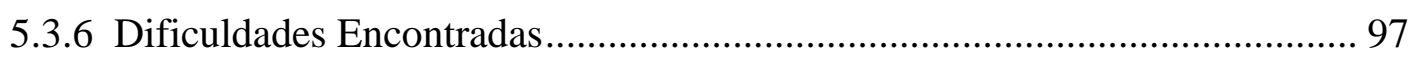

5.3.7 Proposta de cenários de conservação de energia e melhora iluminação ....... 98

5.3.8 Substituição do sistema de iluminação atual ............................................. 99

5.3.9 Avaliação Econômica........................................................................... 100

5.4 Centro de Computação Eletrônica (CCE/USP) …............................................ 102

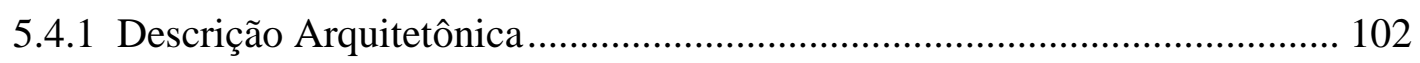

5.4.2 Descrição Geral dos Sistemas Energéticos ............................................. 105

5.4.2.1 Condicionamento Ambiental ........................................................ 105

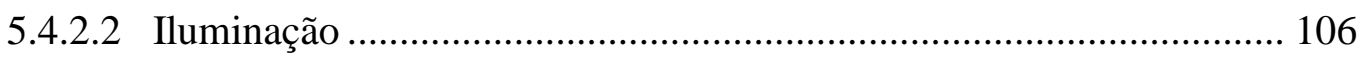

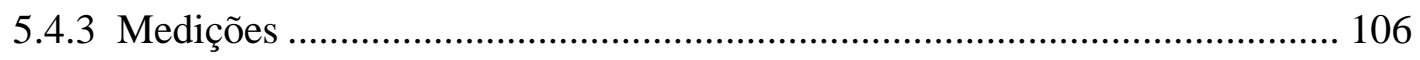

5.4.3.1 Medições Energia .......................................................................... 106

5.4.3.2 Medições Iluminação...................................................................... 109 
5.4.4 Levantamento Usos Finais da Energia (PUFE)....................................... 109

5.4.4.1 Distribuição dos Usos Finais ............................................................. 109

5.4.4.2 Curva de Carga por Uso Final ....................................................... 113

5.4.5 Cálculos e Dados Paramétricos ............................................................. 115

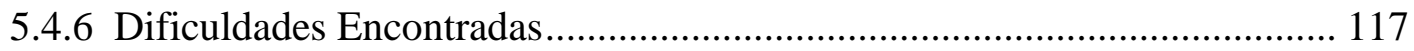

5.4.7 Proposta de cenários de conservação de energia e melhora iluminação ..... 118

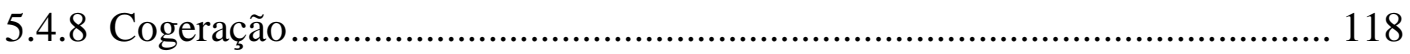

5.4.9 Avaliação Económica ...................................................................... 124

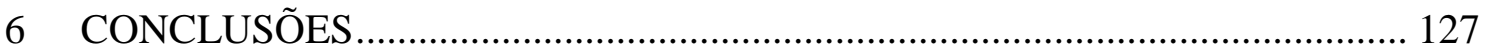

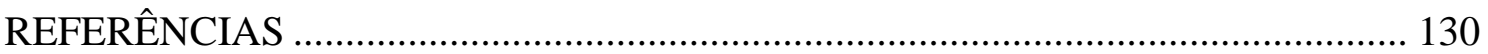

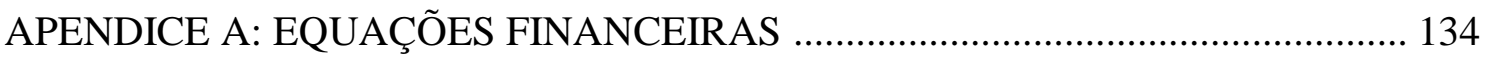




\section{INTRODUÇÃO}

\subsection{Energia e Setor Educacional}

O consumo de energia nos diferentes setores da economia cresce continuamente devido aos hábitos de consumo, aumento na população e necessidades tecnológicas atuais; considerando o efeito deste aumento de consumo sobre os recursos naturais e o meio ambiente, a conscientização da importância do uso racional e eficiente da energia é cada dia um tópico de maior relevância em todo o mundo.

Nas últimas décadas, principalmente após a crise do petróleo de 1973, observase um enfoque mundial na redução do consumo da energia em todos os setores da sociedade (Krarti, 2011) e nesse sentido, intervenções no setor terciário (Comércio e Serviços) são consideradas um ponto importante para alcançar reduções significativas nos gastos com energia. No Brasil, o consumo deste setor corresponde a $4,5 \%$ do consumo total de energia e o consumo de eletricidade deste setor corresponde a $24 \%$ do consumo de energia elétrica total (EPE, 2013).

As edificações do setor educacional são parte do setor terciário, as mesmas são compostas por diversas categorias de edificação como pré-escolar, ensino fundamental e ensino superior que, por sua vez, são divididas em outras categorias como edificações de ensino, pesquisa, bibliotecas, laboratórios, escritórios administrativos entre outros.

Perez-Lombard et al (2008) avaliaram o consumo energético nos diferentes subsetores do setor terciário em diferentes partes do mundo; os autores observaram que o setor educação representa uma porcentagem considerável do uso final da energia deste setor (Tabela 1).

Tabela 1- Uso da energia no setor terciário em diferentes países. Fonte: Perez-Lombard (2008).

\begin{tabular}{cccc}
\hline Tipo de Edifiçao & USA (\%) & Espanha (\%) & UK (\%) \\
\hline Varejo & 32 & 22 & 22 \\
Escritórios & 18 & 33 & 17 \\
Hotéis e Restaurantes & 14 & 30 & 16 \\
Educacão & $\underline{\mathbf{1 3}}$ & $\underline{\mathbf{4}}$ & $\underline{\mathbf{1 0}}$ \\
Hospitais & 9 & 11 & 6 \\
Lazer & 6 & - & 6 \\
Outros & 8 & & 23 \\
\hline
\end{tabular}


A redução do consumo de energia nas edificações do setor educacional possui implicações importantes; por ser o aceso à educação um direto humano fundamental, os governos necessitam investir seus recursos para proporcionar a melhor educação possível às pessoas e fortalecer as instituições de ensino. Para se ter uma idéia, nos Estados Unidos o gasto financeiro em energia para as instituições de ensino superior é estimado em $\$ 14$ bilhões ao ano, correspondente a 0,09\% do Produto Interno Bruto (EERE, 2012); portanto, a economia de energia através da aplicação de medidas de eficiência energética poderia diminuir o gasto das edificações do setor educacional, permitindo assim investir o orçamento poupado em diferentes programas de educação, cultura, bibliotecas, melhoras na infraestrutura, e em geral melhorar a qualidade do ensino oferecido à população.

\subsection{Eficiência Energética e Auditorias}

Na década de 70, os projetos de eficiência energética em edificações consistiam em ações simples como desligar a iluminação, baixar a temperatura nos sistemas de aquecimento e aumentar a temperatura nos sistemas de ar condicionado; atualmente a gestão da energia nas edificações inclui uma avaliação mais global e analítica de praticamente todos os sistemas energéticos utilizados.

A auditoria energética é um mecanismo para entender o desempenho energético de edifícios e instalações, através dela é possível detectar problemas operacionais, aumentar o conforto dos ocupantes e reduzir o consumo da energia (Alajmi, 2012; Jayamaha,2007). Além disso, é possível obter as curvas de demanda elétrica e térmica, seja por medição ou por software, o que possibilita propor soluções de eficiência energética numa lista de oportunidades de conservação de energia, as quais podem ser verificadas antes da execução das mesmas utilizando modelos de simulação energética.

Para efetuar uma auditoria energética, diferentes tarefas devem ser realizadas dependendo do tipo de auditoria e do tamanho ou a função da edificação. Algumas tarefas podem precisar ser repetidas várias vezes e outras eliminadas, dependendo dos resultados de outras tarefas, portanto a execução de uma auditoria energética é muitas vezes um processo não linear e iterativo (Krarti, 2011).

As tarefas de uma auditoria energética podem variar consideravelmente dependendo do objetivo do trabalho, portanto as metodologias são flexíveis a variações. Na Figura 1, uma metodologia geral de auditoria energética de 7 etapas é apresentada. 


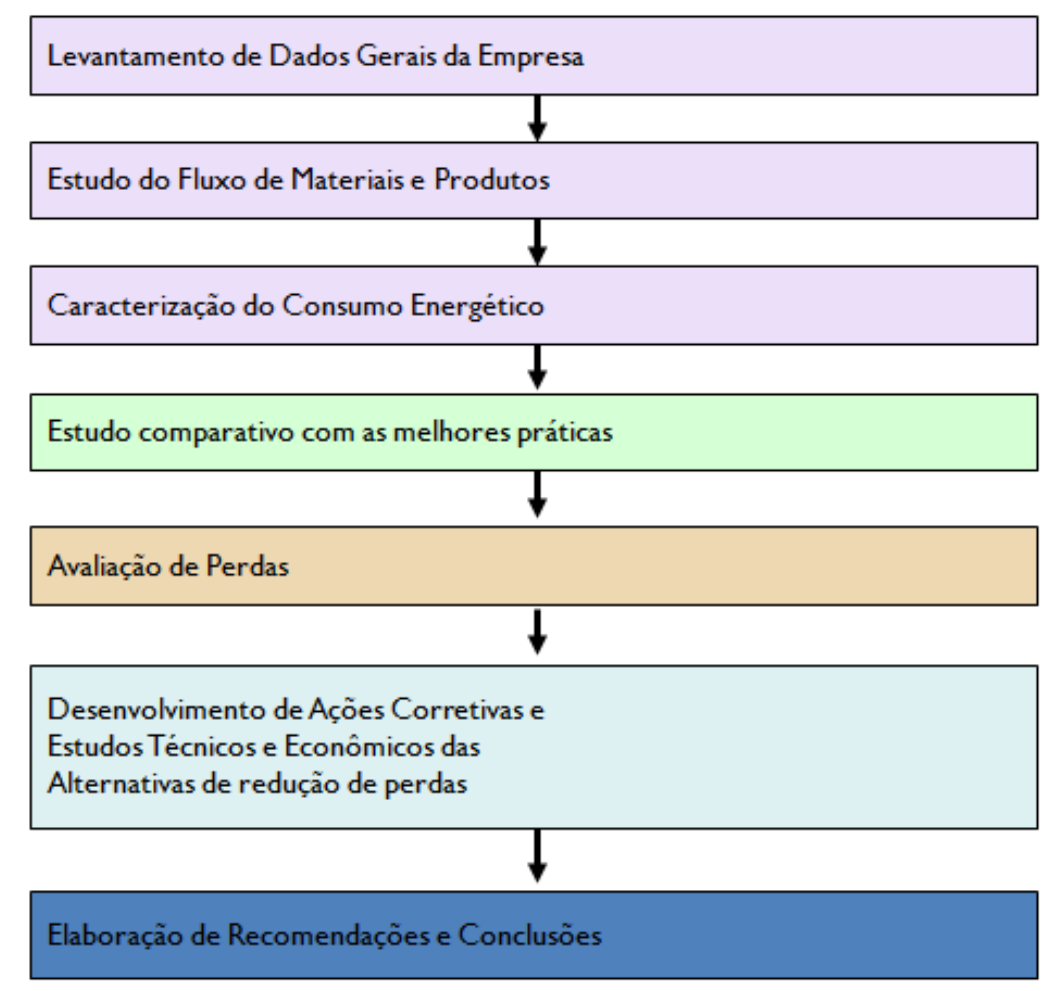

Figura 1- Metodologia Geral para Auditoria Energética. Fonte: Sauer (2012).

Nas primeiras etapas da auditoria, o objetivo é entender a operação da instalação; as características de consumo e de uso final dos equipamentos; os insumos utilizados e as tarifas correspondentes; o balanço energético da instalação; entre outras tarefas que permitam à equipe de auditoria energética se familiarizar com a instalação.

Para caracterizar o comportamento do consumo energético de uma edificação é necessário entender como a energia é usada na mesma. A informação do consumo por uso final é a base do estudo energético e permite avaliar o consumo dos usos finais. Desta forma, tendo em vista os principais fatores que influenciam o consumo de energia nas edificações estudadas é possível desenvolver estratégias de conservação da mesma.

No estudo comparativo com as melhores práticas, os dados obtidos nas primeiras etapas são usados para calcular indicadores energéticos que possam ser comparados com os de outras instalações e padrões de eficiência energética nacional e internacional. Na seguinte etapa as perdas da instalação são avaliadas e as oportunidades de melhorias na eficiência energética são determinadas.

$\mathrm{Na}$ parte final da auditoria as informações coletadas e calculadas anteriormente são utilizadas para definir diferentes cenários para as ações corretivas que são avaliadas técnica e economicamente para elaborar as recomendações de melhorias na instalação. 
A avaliação técnica dos cenários pode incluir estudos de simulação computacional que permitam predizer o comportamento energético de determinado sistema, por exemplo, simulações energéticas com o software EnergyPlus ou simulações do sistema de iluminação com o software Dialux.

\subsection{Usos finais da energia no Setor Educacional}

A missão das edificações da área educacional é proporcionar um ambiente adequado para a aprendizagem, pesquisa e o desenvolvimento profissional e pessoal da comunidade. Deste modo, os usos finais encontrados nas edificações deste setor visam atender estas necessidades cumprindo assim sua finalidade.

Alguns usos finais com maior impacto sobre o consumo das edificações deste setor serão melhor descritos a seguir.

\subsubsection{Sistema de Iluminação}

Para que as atividades acadêmicas de ensino e pesquisa, assim como as administrativas, sejam desempenhadas, é indispensável contar com níveis de iluminância que cumpram com as normas vigentes; de modo que os estudantes, professores, pesquisadores e pessoal universitário possam desfrutar de total conforto visual para atender suas demandas acadêmicas e laborais. Na tabela 2 são mostrados os valores de iluminância recomendadas pela norma NBR 5413 Iluminância de Interiores para diferentes atividades,

Tabela 2- Iluminância média recomendada para iluminação artificial em áreas do ambiente acadêmico. Fonte: Elaboração própria baseada em Norma NBR 5413 (1992).

\begin{tabular}{cc}
\hline Tipo de Atividade & Iluminancia Norma NBR 5413 (Lux) \\
\hline Biblioteca-Sala de Leitura & 500 \\
Biblioteca- Recinto das Estantes & 300 \\
Biblioteca- Fichário & 300 \\
Salas de Aula & 300 \\
Salas Trabalhos Manuais & 300 \\
Laboratórios-Iluminação geral & 200 \\
Laboratórios-Iluminação local & 500 \\
Anfiteatros e Auditórios- Plateia & 200 \\
Anfiteatros e Auditórios- Tribuna & 500 \\
Salas de Reuniões & 200 \\
Corredores & 100 \\
Escritório & 500 \\
\hline
\end{tabular}


Na Figura 2 observa-se a importância da iluminação como uso final nas instituições de ensino no Brasil, ao representar $18 \%$ da demanda máxima da instalação (Procel, 2005).

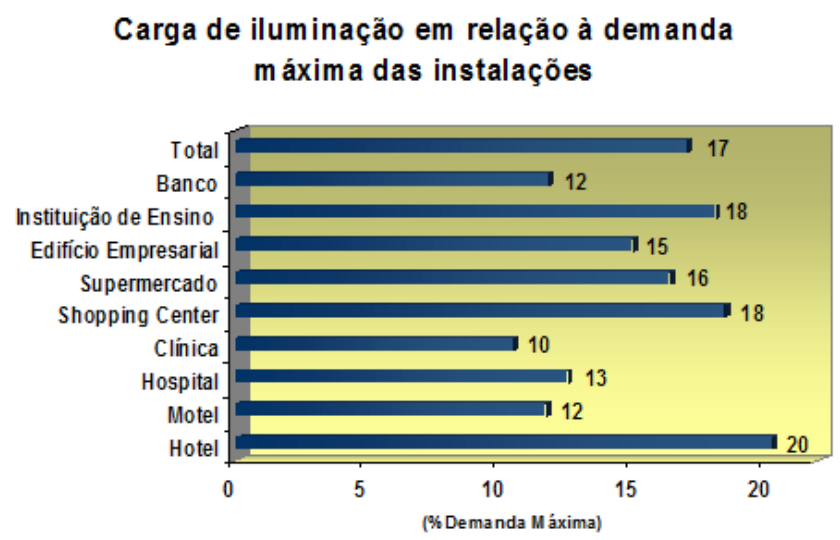

Figura 2- Carga de Iluminação em relação á demanda máxima das instalações. Fonte: Procel (2005)

Nestes prédios, as luminárias normalmente encontradas são as que utilizam lâmpadas fluorescentes tubulares, as mesmas podem ser agrupadas pelo diâmetro, largura ou potência elétrica (Lin, 2005). O diâmetro do fluorescente tubular é dado pela letra ' $\mathrm{T}$ ' (de tubular) seguido por um número que se refere ao diâmetro medido em oitavos de uma polegada, assim, por exemplo, uma lâmpada T8 tem um diâmetro de 2,54cm ou 8/8 de polegada, e uma lâmpada T5 tem um diâmetro de 1,59 cm ou 5/8 de polegada (Mahlia et al, 2011).

As lâmpadas fluorescentes tubulares mais utilizadas atualmente são as T8 e nos últimos anos também as T5. Estas tecnologias de luminárias fluorescentes (T8 e T5) competem tecnicamente com as luminárias lineares LED (Light Emitting Diodes), que são componentes em estado sólido, capazes de transformar eletricidade diretamente em luz monocromática com um baixo consumo de potência elétrica (Sauer, 2012). A tecnologia LED apresenta vantagens em eficiência energética mas tem um impacto na qualidade da iluminação (Ryckaert, 2012).

Existe uma série de opções de conservação da energia que podem ser implementadas nos sistemas de iluminação das edificações do setor terciário em geral; as principais são a otimização do sistema de iluminação conectado, a integração da iluminação natural e a utilização de controles de ocupação nas diferentes áreas da edificação (ASHRAE, 2011). 
Para a otimização do sistema de iluminação conectado é importante examinar indicadores próprios dos sistemas de iluminação. Os mais utilizados são a densidade de potência de iluminação e a densidade de potência normalizada de iluminação. A densidade de potência de iluminação (DPI) é um indicador amplamente utilizado para determinar a eficiência energética de um sistema de iluminação, é definida como a máxima potência de iluminação por unidade de área da classificação, pela função do espaço de uma edificação e medido em W/m² (ASHRAE, 2007).

A norma ASHRAE 90.1 para a energia nas edificações define duas metodologias para o cálculo da DPI, uma utiliza a área da edificação completa e a respectiva demanda de energia elétrica para iluminação e a outra sugere um estudo separando espaço por espaço da edificação. A primeira é mais flexível porque permite variações da DPI entre os diferentes espaços enquanto não supere o valor definido de DPI total para edificação.

$\mathrm{Na}$ tabela 3 encontra-se representado os valores recomendados de DPI para as edificações da área educacional pelo método da área da edificação completa e pelo método de espaço por espaço.

Tabela 3- Densidade de potência de iluminação recomendada nas edificações do setor educacional segundo ASHRAE. Fonte: Elaboração própria baseada em ASHRAE (2007).

\begin{tabular}{cc}
\hline \multicolumn{2}{c}{ Método Área Edificação Completa } \\
\hline Tipo de Edificação & DPI (W/m2) \\
Biblioteca & 14,1 \\
Escola/Universidade & 13,0 \\
Escritórios & 10,9 \\
\hline \multicolumn{1}{c}{ Método Espaço por Espaço } \\
\hline Espaço & DPI (W/m2) \\
Escritório & 11,8 \\
Sala Conferencia & 14,0 \\
Sala de Aula & 15,1 \\
Laboratórios & 15,1 \\
Catalogo Biblioteca & 11,8 \\
Acervo Biblioteca & 18,3 \\
Leitura Biblioteca & 12,9 \\
Corredores & 9,6 \\
\hline
\end{tabular}

A Densidade de Potência Normalizada de Iluminação está expressa em $\mathrm{W} / \mathrm{m}^{2 \cdot} 1001 \mathrm{x}$ e representa a potência necessária por metro quadrado para atingir uma iluminância média no plano horizontal de 100 lux. É calculada como a densidade de potência entre a iluminância média mantida num plano de referência, sendo melhor indicador para realização de comparações entre espaços com diferentes requerimentos de iluminância. Dubois et al (2011) definiram que dependendo do tamanho e refletância 
da superfície da sala, fonte de iluminação e aplicação; o valor da Densidade de Potência Normalizada de Iluminação para uma instalação eficiente, com lâmpadas fluorescentes e boa manutenção deve ser entre 1,9 e $2,3 \mathrm{~W} / \mathrm{m}^{2} 100 l u x$.

\subsubsection{Sistema de Condicionamento Ambiental}

Os sistemas de condicionamento ambiental ou HVAC (Heating, Ventilation and Air Conditioning) devem proporcionar um ambiente adequado todos os dias em todas as horas, por essa razão o desafio é como fornecer sistemas HVAC confiáveis que atendam todas as normativas utilizando a menor quantidade de energia possivel (ASHRAE,2012).

Nos climas tropicais estes sistemas estão focados principalmente no condicionamento de ar. As edificações utilizam diferentes sistemas de ar condicionado como sistemas centralizados, sistemas independentes como os Split ou janela e, sistemas de volume variável de refrigerante (VRV). Os sistemas de resfriamento, como os comentados anteriormente são caracterizados pelo Coeficiente de Performance (COP), o qual pode ser definido como a razão do calor extraído, dividido pela energia de entrada requerida (Krarti, 2011).

Os sistemas centralizados são os mais utilizados nas edificações de grande porte. Nestes sistemas, o evaporador do chiller resfria a água e esta água resfriada é bombeada até as unidades de tratamento de ar (AHU) e unidades de fan-coil localizadas em diferentes partes da edificação. Estas unidades possuem ventiladores que sopram o ar através de trocadores de calor para transferir o calor do ar à água e, portanto resfriarem o ar. A água resfriada, depois de absorver o calor das unidades, é bombeada de volta ao evaporador do chiller para ser resfriada novamente completando o ciclo (Jayamaha, 2007).

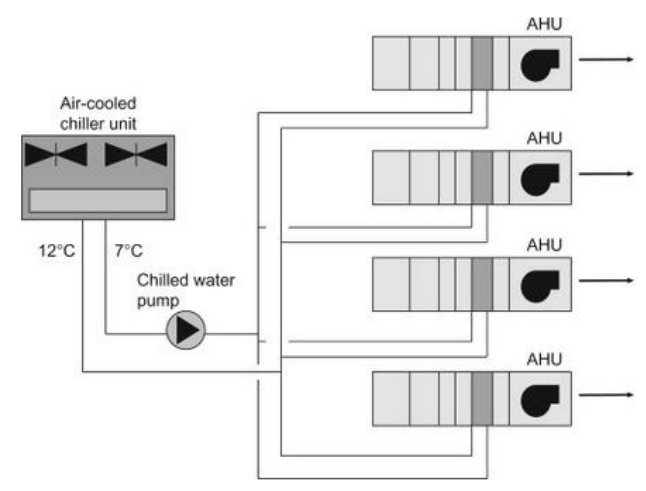

Figura 3- Esquema funcionamento de sistema centralizado com chiller. Fonte: Beggs (2009). 
Existem diversas tecnologias de chillers, os quais podem ser elétricos, de absorção ou motorizados. Os chillers elétricos usam o ciclo de compressão a vapor e podem utilizar compressores centrífugos, recíprocos ou rotatórios. Os chillers de absorção utilizam um ciclo de concentração - diluição para mudar o nível de energia do líquido refrigerante, usando brometo de lítio para, alternadamente, absorver calor a baixa temperatura e rejeitar calor a altas temperaturas. A absorção pode se dar por queima direita ou por queima indireta. Os chillers motorizados são similares aos chillers elétricos, porém os compressores são alimentados por turbinas ou motores a gás natural (Krarti,2011).

Os equipamentos de ar condicionado possuem um importante potencial de redução do consumo energético principalmente quando aplicadas algumas estratégias: substituição do sistema de ar condicionado por um de maior eficiência, melhora dos sistemas de operação e controle existentes e utilização de sistemas alternativos de resfriamento (Krarti, 2011).

\subsubsection{Equipamentos Elétricos}

As edificações do setor terciário e especificamente do setor educacional possuem uma grande e diversa quantidade de equipamentos elétricos. Entre estes equipamentos encontram-se aparelhos de escritório como computadores, equipamentos de telecomunicações, copiadoras ou impressoras; podem também ser encontrados aparelhos de laboratório dependendo da área de pesquisa do mesmo, além de equipamentos próprios do funcionamento da edificação como motores, bombas ou elevadores; e sistemas de segurança e detecção de incêndios (ASHRAE, 2011).

Alguns dos equipamentos citados necessitam carga continua e sem alteração ao longo do tempo como servidores, roteadores, equipamentos de refrigeração e segurança; porém outros destes equipamentos possuem potencial para conservação da energia (ASHRAE, 2012).

Os motores elétricos são outro tipo de equipamento a serem considerados, nos Estados Unidos eles podem representar mais de 50\% da carga de uma de edificação do setor comercial (Krarti, 2011).Os motores convertem energia elétrica em energia mecânica e são utilizados para movimentar maquinas dos sistemas de ventilação, 
bombeamento, elevadores, e compressão de gases como o ar e para refrigeração entre outras aplicações.

\subsection{Auditorias energéticas no Setor Educacional}

As edificações do setor educacional normalmente são compostas de sistemas energéticos complexos, com requerimentos técnicos exigentes, que precisam brindar aos usuários o maior conforto e segurança para realização dos labores acadêmicos. $\mathrm{O}$ consumo energético por usos finais das edificações variam conforme as necessidades próprias da mesma, possuindo uma importante influência as condições climáticas do lugar da instalação, o nível de conforto requerido e as atividades nela executadas. Por essa razão, definir os usos finais da energia para edificações do setor educacional de um país ou cidade é complicado e nem sempre é totalmente correto, contudo permite ter uma ideia do comportamento das mesmas.

A Tabela 4 e Figura 4 apresentam o estudo dos usos finais da energia em países como Estados Unidos, Reino Unido, Arábia Saudita, Grécia e Brasil, países com diferentes características climáticas, culturais, e de metodologias construtivas nas edificações.

Tabela 4- Usos Finais da Energia nas edificações acadêmicas. Fonte: Elaboração própria baseada em Energy Information Agency (2003), Department of Energy and Climate Change (2010), Sait (2013), Santamouris (1993), Alvarez (1998).

\begin{tabular}{ccccccc}
\hline & Estados Unidos & UK & Arábia Saudita & Grécia & Brasil EE & Brasil Zoologia \\
\hline Aquecimento Espaço & $47 \%$ & $55.12 \%$ & - & $72 \%$ & - & - \\
Ar Condicionado & $10 \%$ & $0.47 \%$ & $83 \%$ & $2 \%$ & $37 \%$ & $28 \%$ \\
Ventilação & $10 \%$ & - & - & - & - & - \\
Aquecimento de Agua & $7 \%$ & $12.50 \%$ & - & - & - & - \\
Iluminação & $14 \%$ & $14.79 \%$ & $5 \%$ & $17 \%$ & $46 \%$ & $41 \%$ \\
Cocção & $1 \%$ & - & - & - & - & - \\
Refrigeração & $2 \%$ & - & - & - & - & - \\
Equipamentos de Escritório & - & - & $6 \%$ & - & - & - \\
Computação & $4 \%$ & $3.52 \%$ & - & - & - & - \\
Equipamentos de Laboratóric & - & - & $1 \%$ & - & - & - \\
Equipamentos Elétricos & - & - & $5 \%$ & $9 \%$ & - & - \\
Alimentação & - & $8.91 \%$ & - & - & - & - \\
Outros & $5 \%$ & $4.69 \%$ & - & - & - & - \\
\hline
\end{tabular}


Usos Finais da Energia Edificações

Setor Educacional

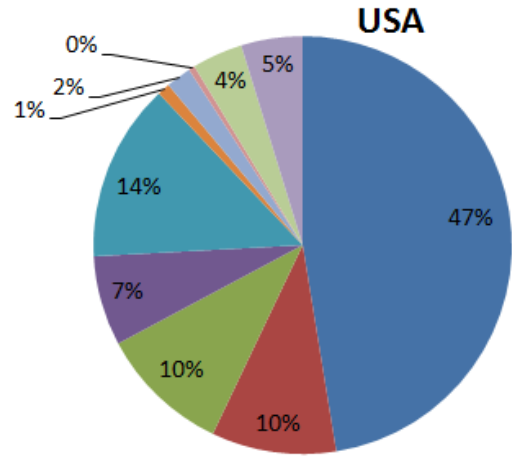

A

Usos Finais da Energia Edificações

Setor Educacional

Arabia Saudita

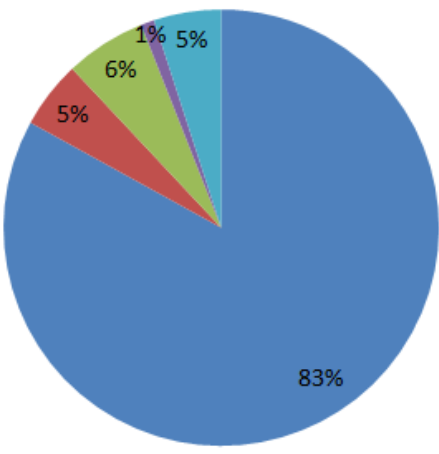

ar Condicionado

E.luminação

Equipamentos de Escritório

Equipamentos de Laboratório

C

Usos Finais da Energia Edificações Engenharia Elétrica POLI-USP

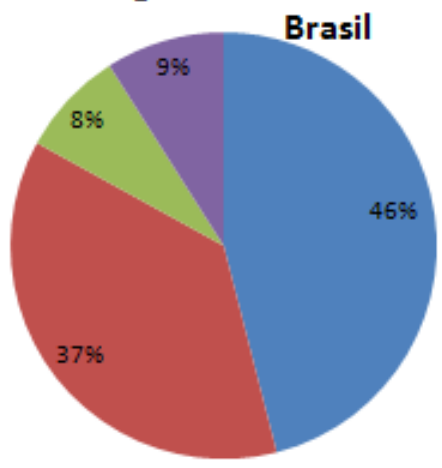

E
Usos Finais Energia Edificaçoes Setor Educacional

UK

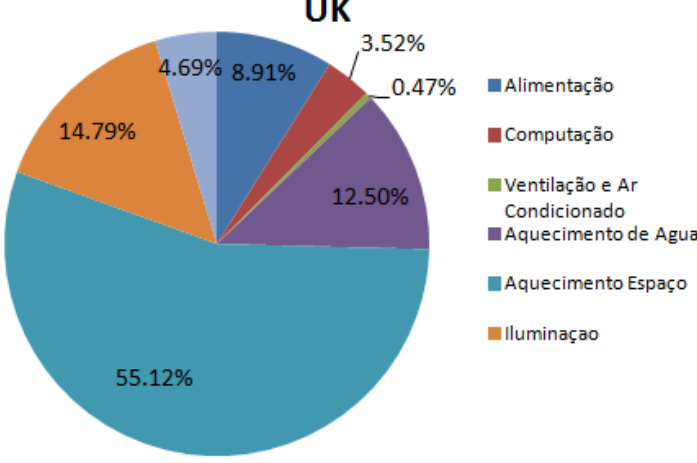

B

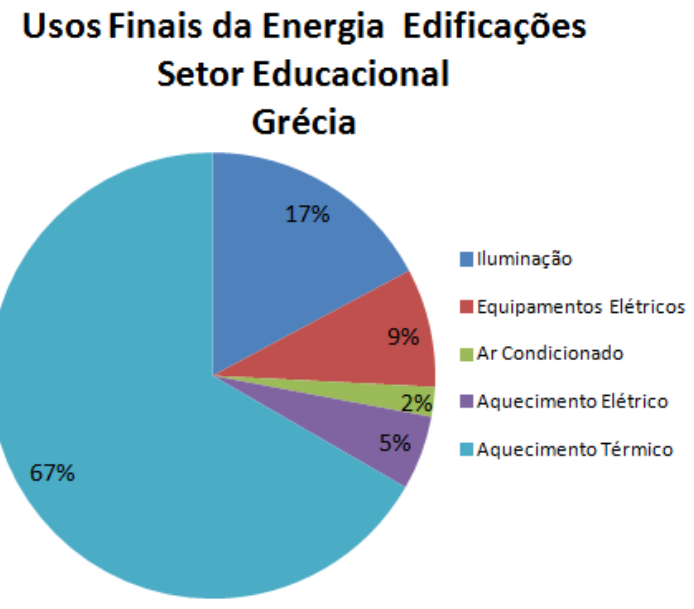

D

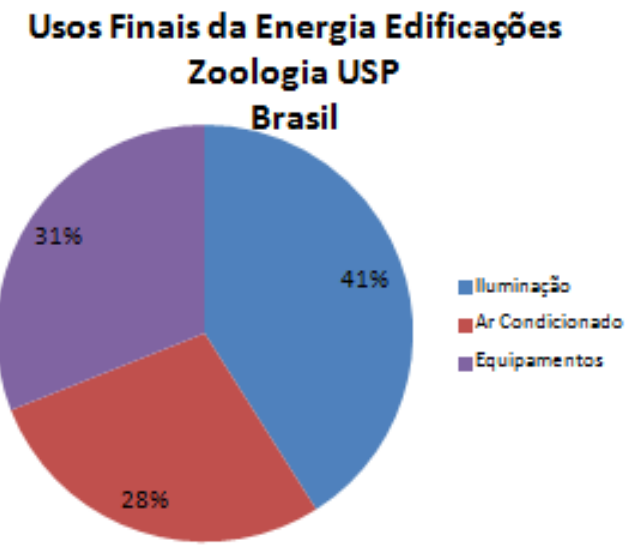

$\mathbf{F}$

Figura 4- Usos Finais da Energia nas edificações acadêmicas nos USA (A) Fonte: Elaboração própria baseada em: Energy Information Agency (2003); no Reino Unido (B). Fonte: Elaboração própria baseada em: Department of Energy and Climate Change (2010); na Arábia Saudita (C) Fonte: Elaboração própria baseada em: Sait (2013); na Grécia (D). Fonte: Elaboração própria baseada em: Santamouris (1993) e no Brasil (E)(F). Fonte: Elaboração própria baseada em: Alvarez (1998). 
Em (A) encontram-se representados os diferentes usos finais da energia para as edificações do setor educacional nos EUA segundo a Energy Information Agency desse país. Observa-se que os usos finais relacionados com o condicionamento ambiental; como aquecimento do espaço (47\%), ar condicionado (10\%), e ventilação (10\%) juntos, representam o maior uso final das edificações do setor educacional neste país; além disso, a iluminação possui também uma importante participação com 14\% do consumo energético destas edificações.

No caso do Reino Unido (B), o uso final mais importante é de novo o aquecimento do espaço com o 55,12\% do consumo, seguido da iluminação com o $14,79 \%$ e o aquecimento de água com o $12,50 \%$. Neste caso é importante notar como a ventilação e o ar condicionado representam somente $0,47 \%$ do consumo de energia da edificação (Department of Energy and Climate Change, 2012).

Já a Arábia Saudita (C) apresenta-se como um caso bastante diferente, por apresentar condições climáticas de calor extremo, o ar condicionado é a carga de maior consumo com $83 \%$, o restante das cargas possuem um consumo similar, com $5 \%$ de iluminação; $5 \%$ dos elevadores, bombas e outros; $6 \%$ de equipamentos de escritório e $1 \%$ de equipamentos de laboratório (Sait,2013).

A auditoria energética de 238 edificações do setor educacional na Grécia (D) determinou os usos finais da energia destas edificações nesta localidade. Pode-se notar o importante papel do aquecimento do espaço no consumo energético das edificações acadêmicas com $83 \%$ do consumo total, a participação da iluminação e outros equipamentos elétricos próprios das atividades possuem $13 \%$ cada um, e um baixo consumo de energia para condicionamento ambiental de 1\% (Santamouris, 1993).

No Brasil (E, F), Alvarez (1998) desenvolveu uma metodologia para a determinação do potencial de conservação da energia nas edificações de ensino na Universidade de São Paulo (USP). O estudo determinou que os principais usos finais nas edificações estudadas são a iluminação com aproximadamente $40 \%$ do consumo, o ar condicionado com aproximadamente $30 \%$ e o restante para equipamentos e microcomputadores. 


\subsection{Hipótese}

Visto que as auditorias permitem conhecer o comportamento energético de determinadas instalações, a hipótese deste trabalho é que a aplicação de uma metodologia de auditoria energética nas edificações do setor terciário e especificamente no setor educacional permitiria conhecer os padrões de uso, detectar problemas operacionais, encontrar oportunidades de conservação da energia, e, portanto, reduzir o consumo das edificações deste setor, permitindo alcançar importante economia de energia e dinheiro.

\subsection{Objetivo geral}

O presente trabalho teve como objetivo utilizar uma metodologia de auditoria energética para realizar um estudo dos usos finais da energia em edificações da Universidade de São Paulo- USP e, baseado nas informações obtidas, descrever o comportamento energético atual dos diferentes sistemas destas edificações, a qualidade dos mesmos, identificar oportunidades de conservação da energia e simular diferentes cenários de uso de estratégias de eficiência energética que possam ser avaliados tecnicamente.

\subsection{Objetivos específicos}

Os objetivos específicos deste trabalho foram:

- Realizar um levantamento completo das características de potência e modo de uso dos equipamentos, e a variação da ocupação das edificações estudadas.

- Avaliar por meio de medições de iluminância segundo a norma "NBR 5382: Verificação de Iluminância de Interiores", o sistema de iluminação atual das edificações estudadas.

- Construir, a partir do comportamento dos usos finais da energia, as curvas de demanda energética das edificações, com o software PUFE (Programa Usos Finais da Energia). 
- Obter os índices de intensidade energética das edificações analisadas $\left(\mathrm{kWh} / \mathrm{m}^{2}\right.$, kWh/funcionário, etc.).

- Determinar as oportunidades de conservação da energia baseados nos dados da auditoria energética e os resultados do estudo de usos finais.

- Propor cenários de eficiência energética que permitam reduzir o consumo da edificação.

- Comprovar a viabilidade técnica e econômica dos diferentes cenários de eficiência energética com os software Dialux e EnergyPlus. 


\section{JUSTIFICATIVA}

O crescimento da população mundial e das necessidades tecnológicas acarreta um consumo desmedido dos recursos naturais finitos, por isso é importante descobrir e desenvolver novas formas de administrar os recursos do planeta. A diminuição do consumo da energia nas edificações é uma forma de proteger o meio ambiente e ao mesmo tempo gerar economia.

A diminuição do consumo de energia nas edificações do setor terciário, e em especial no setor educacional, é um tópico importante para as autoridades de educação, pois permitiria, entre outras coisas, aplicar o orçamento anteriormente gasto em energia em outras atividades educacionais, culturais e esportivas. Além disso, essas edificações eficientes poderiam elas mesmas servir como modelo e laboratório para ensinar as novas gerações sobre os princípios básicos do uso racional da energia.

Esta situação poderia ser extrapolada para a maioria dos países do mundo com situações similares, interessados em criar políticas de conscientização do uso racional da energia, diminuindo assim os impactos causados ao meio ambiente e os gastos em energia. Portanto, o presente trabalho poderia ser utilizado como base para futuros programas de eficiência energética ou pesquisas em outras latitudes.

Este trabalho também pretende incentivar uma cultura de economia de energia e sustentabilidade na sociedade, através da auditoria energética, apresentando este conceito como um processo comprovado para diagnosticar problemas energéticos nas instalações e propor soluções adequadas, que possam reduzir a intensidade energética e os custos associados numa edificação, sendo possível ser reproduzida em diferentes localidades. 
O estudo da auditoria energética como uma ferramenta para o aproveitamento das oportunidades de conservação da energia, contemplou inicialmente uma etapa de revisão bibliográfica e outras experiências relacionadas com a familiarização com o consumo energético nas edificações, além do estudo das diferentes ferramentas utilizadas como os software PUFE, Dialux e EnergyPlus. Vencida esta etapa, a metodologia do trabalho foi desenvolvida de acordo com as etapas comentadas a seguir.

\subsection{Medições de consumo energético}

Utilizando medidores eletrônicos de energia, de tipo trifásico, foram realizadas medições de diferentes parâmetros elétricos das edificações estudadas. No caso dos prédios de Administração IEE, Energia IEE e Fazendinha IEE, foi utilizado o medidor modelo SAGA 1000. No caso das medições no prédio do CCE/USP, o medidor utilizado foi o Reliable Power Meter- Modelo 1500.

Os medidores amostraram os parâmetros durante cinco minutos e registraram a média/máxima/mínima durante este período. Os parâmetros obtidos foram potência ativa, potência reativa, energia, tensão por fase, corrente por fase, distorção harmônica por fase e fator de potência.

O valor de potência ativa e energia forem plotados para obter a curva de demanda da instalação e a energia consumida num período de tempo determinado.

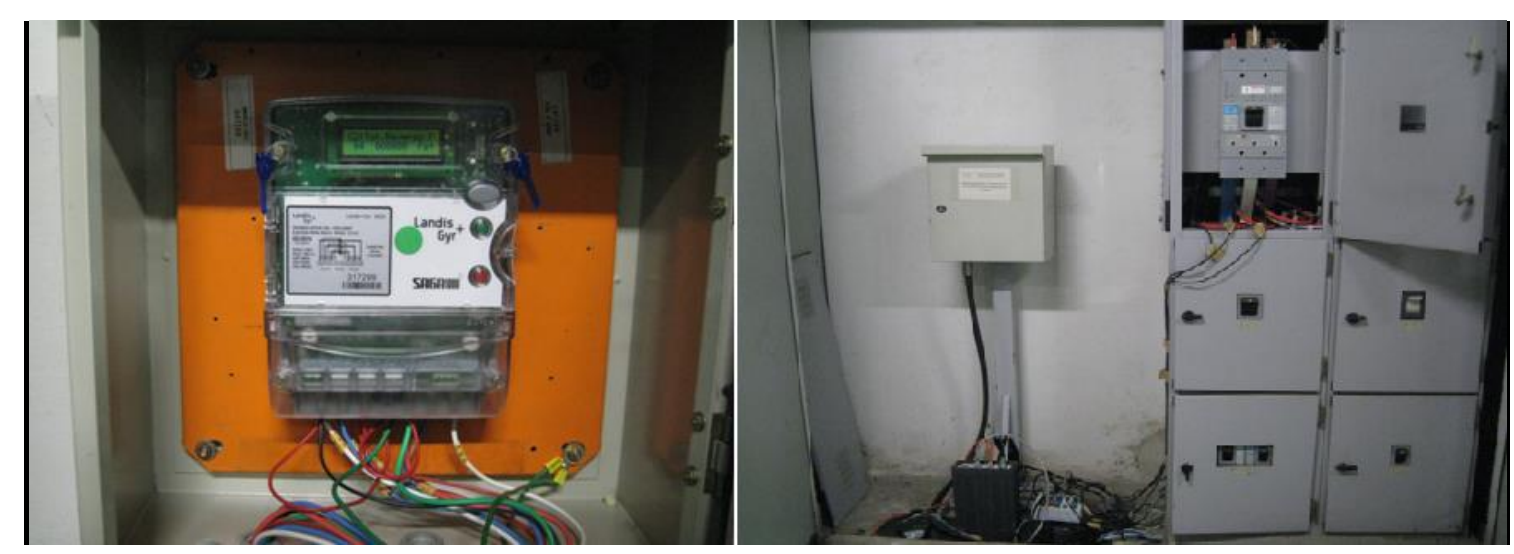

Figura 5- Equipamentos trifásicos de medição de energia utilizados. 


\subsection{Medições e avaliação de iluminância segundo a norma NBR 5382.}

Foram realizadas medições de iluminância em diferentes salas dos prédios estudados no trabalho. As medições foram realizadas segundo a norma NBR 5382: Verificação de Iluminância de Interiores. Esta norma determina a forma de cálculo da Iluminância Média de um determinado espaço; os diferentes pontos entre as medições são computados para se obter uma média ponderada do valor da iluminância média. Todas as medições foram realizadas a uma altura de 0,75 metros, utilizando um luxímetro digital modelo ICEL LD-500 como o da Figura 6.

Um importante aspecto a ser considerado é que as medições, nas salas com janelas, foram realizadas em duas diferentes situações: com iluminação natural (luminárias desligadas) e com as luminárias acesas. A razão disso foi possibilitar a observação do efeito da iluminação natural e somente da iluminação artificial na iluminância total das salas para futuras comparações.

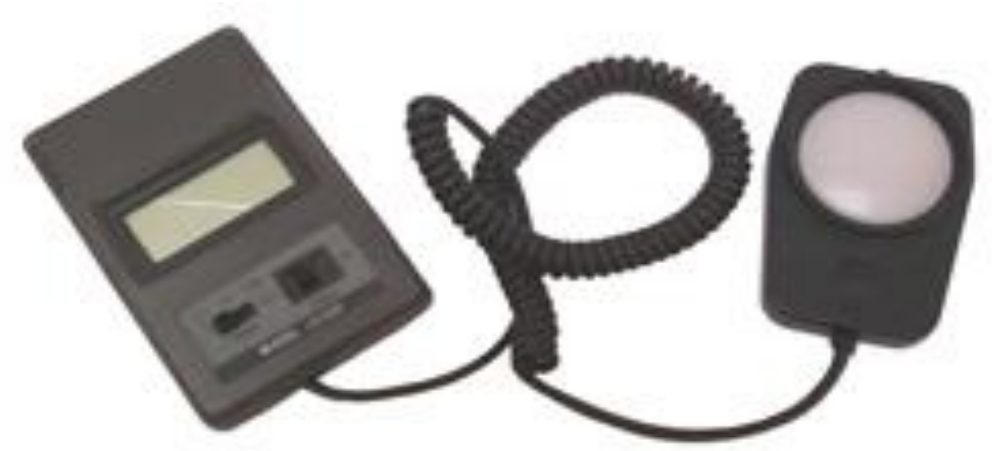

Figura 6- Luxímetro digital utilizado nas medições de iluminância. Fonte: Servitenge (2013)

\subsection{Levantamento dos usos finais da energia.}

O levantamento dos usos finais de energia incluiu diferentes visitas às edificações para realização do mapeamento das mesmas. Esta etapa foi adaptada da metodologia apresentada por Barghini (1996), a qual assume o consumo de energia da edificação como determinado pela quantidade e potencia dos equipamentos presentes, e o modo de uso dos mesmos.

Esta metodologia tem sido empregada em diversos estudos de planejamento energético na América Latina. A mesma trata do processo da pesquisa de campo, que visa obter informações sobre posse de equipamentos de energia elétrica, hábitos de uso desses equipamentos e sobre os serviços energéticos utilizados pela população estudada. 
As informações obtidas permitem conhecer a demanda de serviços energéticos e a junção dessas informações com dados estatísticos e demográficos permite o estudo do atendimento a necessidades de eletricidade (Sentelhas, 2004).

Alguns dos tópicos importantes nesta metodologia são o levantamento de dados socioeconômicos sobre a localidade estudada, análise da rede elétrica e seus principais problemas, análise de tarifas e do processo de faturamento, análise do cadastro, seleção da amostra e a preparação da pesquisa de campo entre outras.

A utilização desta metodologia neste trabalho está relacionada com a pesquisa de campo para o levantamento dos usos finais da energia através de visitas às edificações e aplicação de questionários sobre os eventos de consumo energético. Diferentes informações importantes para definir o evento como: o tipo de equipamento, a quantidade, a potência instalada, potência útil, tensão, hora de início, hora de término, hora mais provável, a estação do ano e a frequência de uso são levantadas no questionário para inserir os dados no software PUFE (Programa de Usos Finais de Energia) e construir a curva de demanda. Na Figura 7 encontra-se o questionário sobre os eventos de consumo energético utilizado.

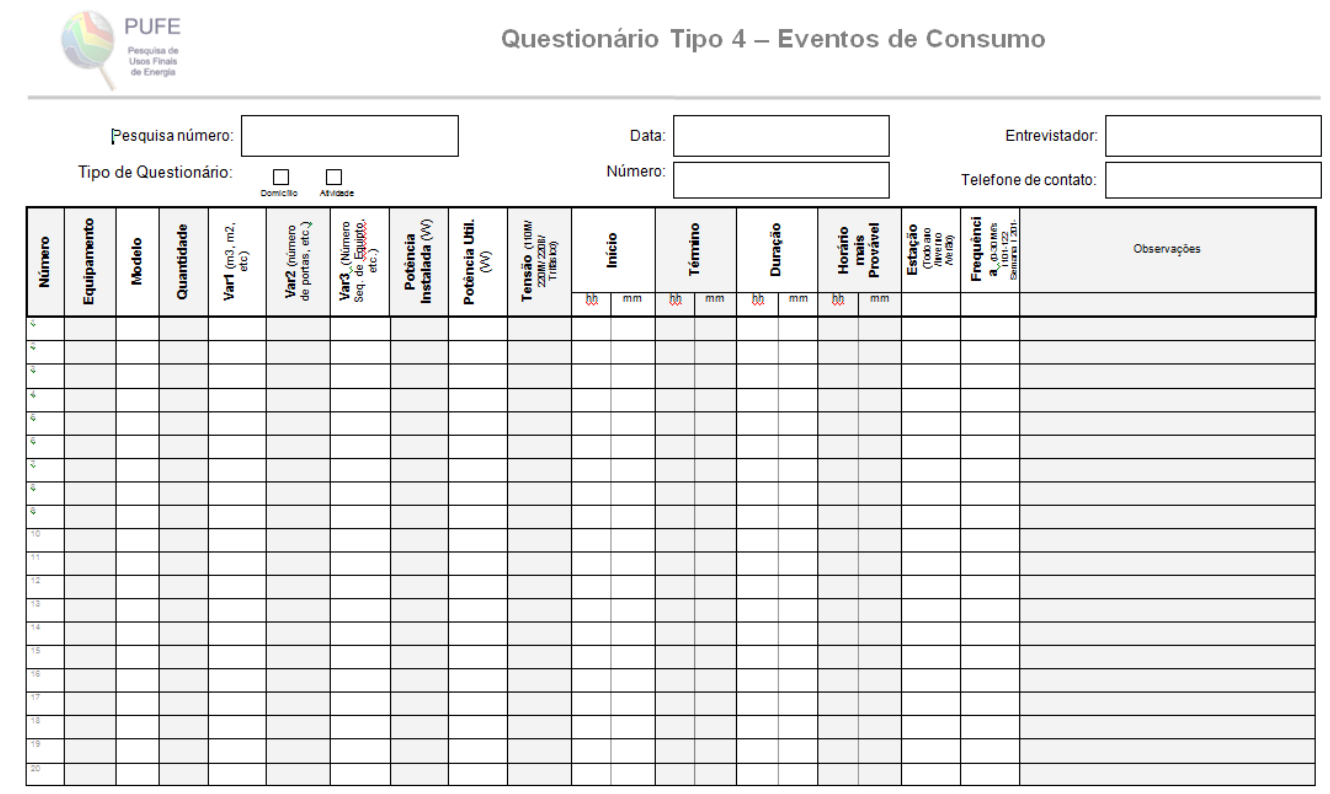

Figura 7- Questionário Eventos de Consumo para levantamento dos usos finais. Fonte: Sentelhas (2004). 


\subsection{Construção de curvas de demanda e cálculo de indicadores.}

Com a informação coletada no levantamento dos usos finais da energia, foi construída a curva de demanda da instalação com o software Programa de Usos Finais de Energia (PUFE) e foram calculados indicadores energéticos.

O PUFE é um software que foi desenvolvido por Barghini e Sentelhas em 1990 e tem sido utilizado para dar apoio às pesquisas de usos finais de energia elétrica. $\mathrm{O}$ software é um sistema computacional web, dedicado a administrar pesquisas destinadas a identificar e descrever de forma estatística os usos da energia elétrica para fins residenciais, comerciais, industriais e de serviços (PUFE,2013, Sentelhas, 2004).

Cada evento de consumo corresponde a um hábito de utilização de um equipamento elétrico de um ou mais funcionários em uma atividade. Os eventos permitem localizar no tempo as demandas de energia e construir a curva de demanda requerida para um transformador, subestação ou toda a rede que atende o local pesquisado. A curva decorrente de cada evento depende da duração do evento e da hora mais provável da ocorrência do mesmo. Na seguinte figura são mostradas diferentes situações e a curva tipo correspondente (Sentelhas,2004).

\begin{tabular}{|c|c|c|c|c|}
\hline & Condições & & & ddos \\
\hline Duração : Intervalo & Duração : Intervalo/2 & Horário mais provável & Rotina & Curva tipo \\
\hline$=$ & & & 1 & \\
\hline$<$ & & Sem hora mais provável & 2 & \\
\hline \multirow{6}{*}{$<$} & \multirow{3}{*}{$<$} & Início do intervalo & 3 & \\
\hline & & Meio do intervalo & 4 & \\
\hline & & Término do intervalo & 5 & \\
\hline & \multirow{3}{*}{$>=$} & Início do intervalo & 6 & \\
\hline & & Meio do intervalo & 7 & \\
\hline & & Término do intervalo & 8 & \\
\hline
\end{tabular}

Figura 8- Tabela de decisão para curva de demanda de um evento Fonte: Sentelhas (2004)

Com os dados obtidos no levantamento dos usos finais e as medições das etapas anteriores, foram calculados os indicadores energéticos das edificações. Os indicadores de consumo energético são utilizados para conhecer o consumo de energia de uma 
edificação e possibilitam a comparação com o consumo de outras edificações de referência ou com os valores definidos nas normas. Diferentes tipos de indicadores de consumo energético foram utilizados para avaliar o consumo de energia nas edificações, alguns deles são mostrados na Tabela 5.

Tabela 5- Indicadores de consumo energético para as edificações setor terciario Fonte: Elaboração própria baseada em: Saidel et al (2005).

\begin{tabular}{|c|c|c|}
\hline Indicador & Definição & Unidade \\
\hline Intensidade Energética por área & $\begin{array}{l}\text { Razão entre o consumo energético mensal da edificação e a } \\
\text { área construída em } \mathrm{m} 2 .\end{array}$ & $\mathrm{kWh} / \mathrm{m} 2$ \\
\hline Intensidade Energética por funcionário & $\begin{array}{l}\text { Razão entre o consumo energético mensal da edificação e o } \\
\text { numero de funcionários da unidade }\end{array}$ & kWh/funcionário \\
\hline Demanda Máxima Mensal por área & $\begin{array}{l}\text { Razão entre a máxima demanda registrada mensalmente e a } \\
\text { área construída em } \mathrm{m} 2 .\end{array}$ & $\mathrm{kW} / \mathrm{m} 2$ \\
\hline
\end{tabular}

Os indicadores também podem ser específicos dos usos finais como iluminação, condicionamento ambiental, aquecimento da água entre outros. A Tabela 6 mostra alguns indicadores específicos calculados neste trabalho.

Tabela 6- Indicadores de consumo energético especifico de diferentes sistemas Fonte: Elaboração própria baseada em: Avelar (2014), ASHRAE (2007)

\begin{tabular}{ccc}
\hline Indicador & Definição \\
\hline $\begin{array}{c}\text { Densidade de Potência de Iluminação } \\
\text { Densidade de Potência Normalizada de } \\
\text { Iluminação }\end{array}$ & $\begin{array}{c}\text { Razão entre a Potência dos equipamentos de iluminação da } \\
\text { edificação e a área construída em m2 }\end{array}$ \\
$\begin{array}{c}\text { Razão entre a Potência dos equipamentos de iluminação da } \\
\text { edificação para produzir } 100 \text { lux, e a área construída em m2 }\end{array}$ & $\begin{array}{c}\text { W/m2·100lux } \\
\text { Condicionado }\end{array}$ \\
& $\begin{array}{c}\text { Razão entre o consumo energético de ar condicionado da } \\
\text { edificação e a área construída em m2 } \\
\text { Indicador de Eficiência em Datacenters, é a razão entre a } \\
\text { Potência total instalada do datacenter (Ar Condicionado, } \\
\text { iluminação, servidores, roteadores, No-breaks) e a Potência } \\
\text { instalada para equipamentos de IT. }\end{array}$ \\
\hline
\end{tabular}




\subsection{Proposta de cenários de conservação de energia e melhoria da iluminação.}

Utilizando como base as informações recolhidas nas etapas anteriores como as medições, o levantamento dos usos finais e os indicadores energéticos, foi determinada a principal oportunidade de conservação de energia nas edificações estudadas. Para o aproveitamento desta oportunidade principal de conservação de energia, propostas de cenários de eficiência foram formuladas.

\subsection{Comprovação de cenários com modelos de simulação computacional.}

Após determinada a melhor proposta de conservação de energia, uma série de ferramentas computacionais permitem analisar a viabilidade técnica da implementação desta proposta. Estas ferramentas podem variar na sua complexidade e precisão, podendo incluir métodos de cálculo simples ou programas de simulação computacional como o Dialux, para sistemas de iluminação; ou o EnergyPlus, para simulação térmica de edificações.

\subsubsection{Dialux}

O software Dialux é um programa de simulação luminotécnica amplamente utilizado atualmente por engenheiros e projetistas da área de iluminação. O mesmo é de aceso livre e foi desenvolvido na Alemanha no ano 1994, na sua primeira versão. A versão utilizada neste trabalho foi a 4.11.03 (Dial, 2013).

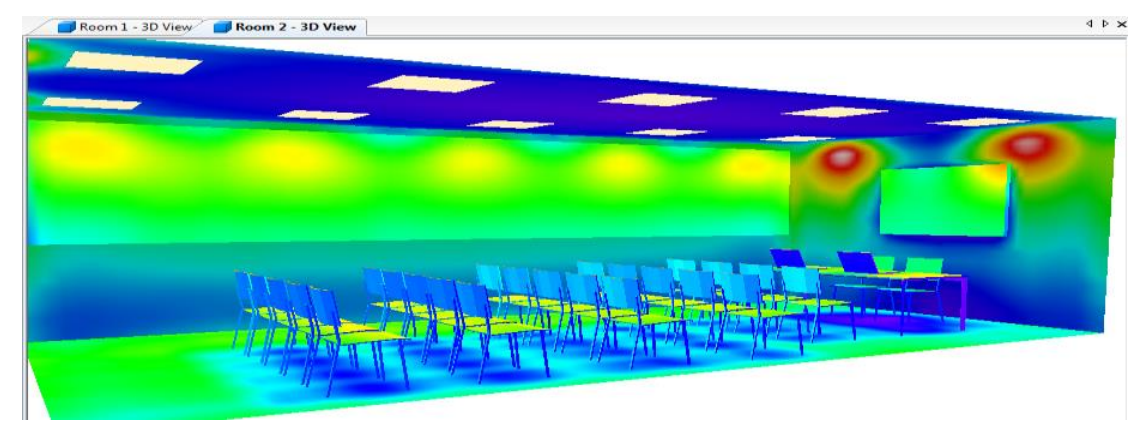

Figura 9- Software de simulação de iluminação DIALUX. Fonte: Elaboração própria.

Esta ferramenta de planejamento da iluminação permite reproduzir fisicamente diversos ambientes, a fim de avaliar características e parâmetros luminotécnicos de 
diferentes distribuições e modelos de luminárias e lâmpadas. O software permite realizar avaliações em ambientes internos de uma edificação e também em ambientes externos como para iluminação pública.

As diferentes empresas fabricantes de lâmpadas e luminárias no mercado internacional publicam constantemente os arquivos fotométricos dos produtos fabricados, os quais podem ser utilizados no Dialux para as simulações. Os arquivos fotométricos possuem a extensão ".ies" e contêm a informação do comportamento do fluxo luminoso de determinada luminária, possibilitando que o software calcule valores específicos para a iluminância, luminancia, uniformidade, entre outros valores de importância no estudo luminotécnico. Diferentes arquivos fotométricos com imagens do comportamento do fluxo luminoso são mostrados na Figura 10.

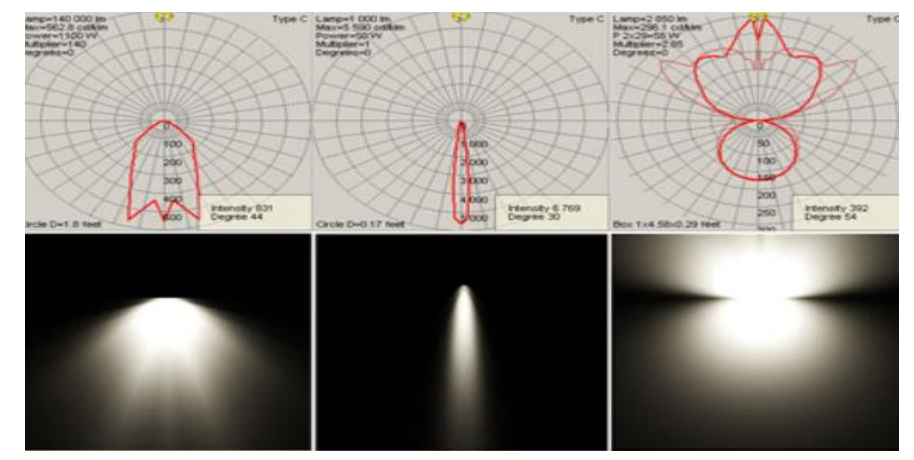

Figura 10- Arquivos fotométricos para diferentes luminárias. Fonte: ART (2013).

A influência da iluminação natural é também avaliada com o Dialux, inserindo no modelo computacional a localização de janelas, a transmitância do vidro, a localização geográfica da edificação, entre outras informações; o software constrói cenários correspondentes a uma determinada hora do dia. O cenário pode incluir grupos de controle para a integração da iluminação artificial e natural ao "dimmerizar" as luminárias utilizadas no projeto (Dialux-Help, 2013).

A otimização energética do projeto de iluminação é outra das características importantes do Dialux. Este software permite estimar o consumo energético nas etapas iniciais do projeto e é uma ferramenta para identificar a melhor opção energetica por considerar não só a potência e uso das luminárias, mas também as opções de controle e integração de iluminação natural comentadas anteriormente. 


\subsubsection{EnergyPlus}

A simulação energética permite modelar uma edificação antes de ser construída ou reformada. A mesma permite que diferentes alternativas sejam investigadas e comparadas com outras, otimizando o projeto e os processos. Esta ferramenta possui a vantagem de ser muito mais barato e rápida que a experimentação, evitando gastos e perda de tempo (GARD, 2003).

A característica mais importante dos modelos de simulação energética é sua capacidade de abranger diversos parâmetros cruciais para predizer de forma precisa o uso da energia, especialmente em edificações com uma considerável carga térmica (Krarti, 2011).

O software EnergyPlus é um programa de simulação computacional distribuído pelo Departamento de Energia dos Estados Unidos (DOE), desenvolvido para a simulação de carga térmica e análise energética de edificações e seus sistemas. O mesmo está baseado nos softwares BLAST (Building Loads Analysis and Thermodynamics) e DOE-2, os quais surgiram após crise do petróleo dos anos 70 (DOE, 2013).

Algumas características do programa o diferenciam de outros programas similares, como o uso de "time-step" de cálculo menor que uma hora, sistema modular, possibilidade de cálculo de infiltração de ar para cada zona térmica, cálculos de iluminação natural, índices de conforto térmico e integração de novas tecnologias como sistemas fotovoltaicos, aquecimento solar, células combustíveis, entre outras (Melo et al, 2013).

A Figura 11 mostra o funcionamento do EnergyPlus. O software gerencia as simulações de diferentes módulos que contém os algoritmos para simulação de elementos como janelas, iluminação natural, sombreamentos, equipamentos, infiltração de ar, entre outros; e fornece os resultados da simulação. O EnergyPlus permite utilizar interfaces externas, de maior facilidade para o usuário, como o DesignBuilder, o Ecotect, e o OpenStudio de Sketchup. Este último foi o utilizado na realização deste trabalho. (Attia, 2011;DOE, 2013). 


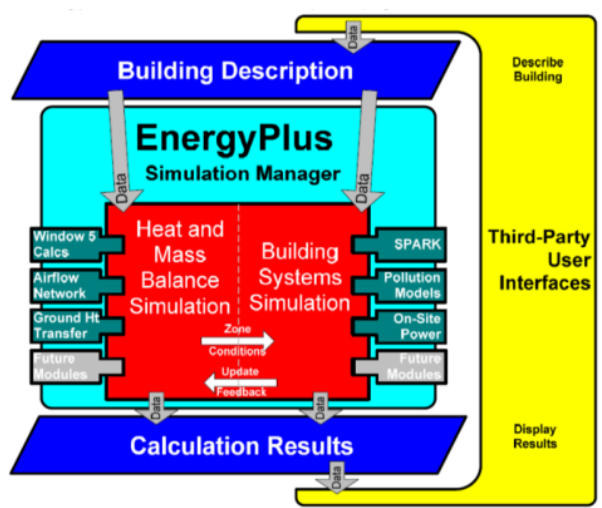

Figura 11- Funcionamento EnergyPlus .Fonte: DOE (2013).

Para uma correta estimação dos valores calculados, as ferramentas de simulação computacional devem ser validadas utilizando-se medições ou dados precisos da instalação. Não existe atualmente um consenso sobre o processo geral de validação para qualquer tipo de edificação, e esta validação é mais considerada uma arte baseada no conhecimento e na experiência do auditor energético (Krarti, 2011). Na figura 12 é apresentado um processo de calibração típica para modelos de simulação energética em edificações.

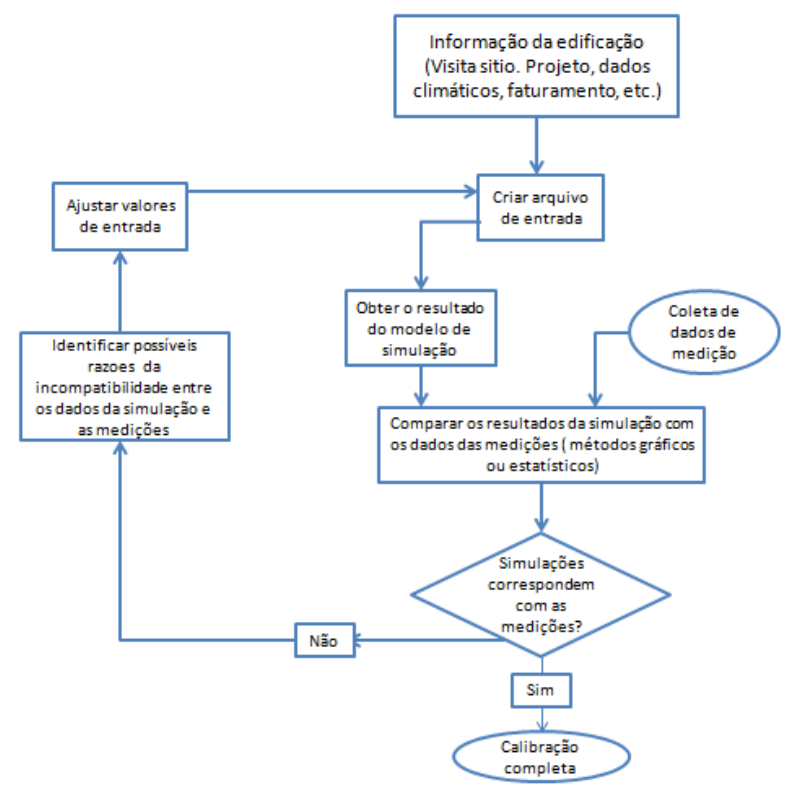

Figura 12- Procedimento típico de validação de modelo de simulação computacional. Fonte: Elaboração própria baseada em: Krarti (2011).

\subsection{Avaliação Econômica}

A avaliação econômica incluiu a utilização de figuras de mérito como o tempo de payback, a taxa interna de retorno (TIR), o custo de ciclo de vida (LCC), o custo de ciclo de vida anualizado (ALCC) e o custo da energia conservada (CEC). As equações matemáticas para os cálculos aparecem no Apêndice A. 


\section{RESULTADOS E DISCUSSÕES}

\subsection{Prédio de Administração-Instituto de Energia e Ambiente}

\subsubsection{Descrição Arquitetônica}

O Prédio da Administração do Instituto de Energia e Ambiente (IEE) da Universidade de São Paulo (USP) consiste em um edifício térreo localizado ao nordeste do Instituto, contiguo à entrada do mesmo, como mostra a Figura 13.

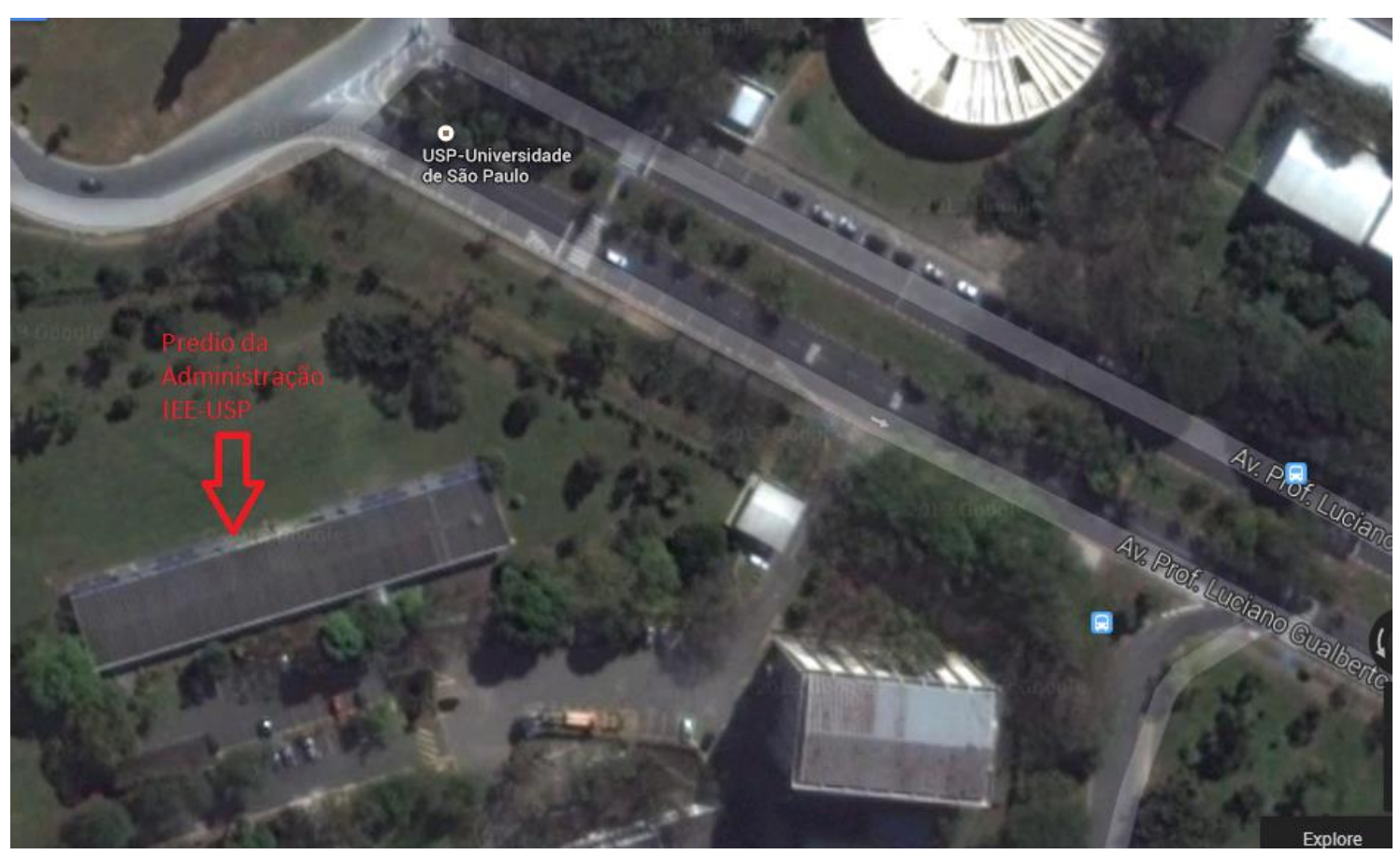

Figura 13- Posicionamento do Prédio da Administração do IEE.

A distribuição arquitetônica possui 21 ambientes, contando com uma biblioteca, escritórios da diretoria, salas administrativas, sala de reuniões, copa, banheiros e almoxarifado entre outras. Sua área total corresponde a $1040 \mathrm{~m}^{2}$ e possui uma modulação com um corredor central de circulação e salas nos setores norte e sul da edificação

As atividades desenvolvidas neste prédio são variadas e incluem principalmente tarefas de escritório; o mesmo é organizado de acordo com os usos mostrados na Tabela 7. 
Tabela 7- Funcionários e Atividades do Prédio da Administração IEE/USP.

\begin{tabular}{|c|c|c|}
\hline & Quantidade Funcionários & Atividades \\
\hline Pavimento Unico & 32 & $\begin{array}{l}\text { - Direitoria IEE/USP. } \\
\text { - Biblioteca Professor Fonseca Telles. } \\
\text { - Divisão Administrativa - IEE } \\
\text { - Manutenção de Micros / Editoração }\end{array}$ \\
\hline
\end{tabular}

A edificaçao possui um pé direito estrutural de $3,82 \mathrm{~m}$ e apresenta uma arquitetura racional com formas retangulares. As fachadas norte e sul possuem amplas janelas que cobrem aproximadamente $36 \%$ da sua área. Além disso, na fachada norte observa-se um sistema fotovoltaico conectado à rede, cujos modulos também servem para proteger as janelas da irradiação solar direta.

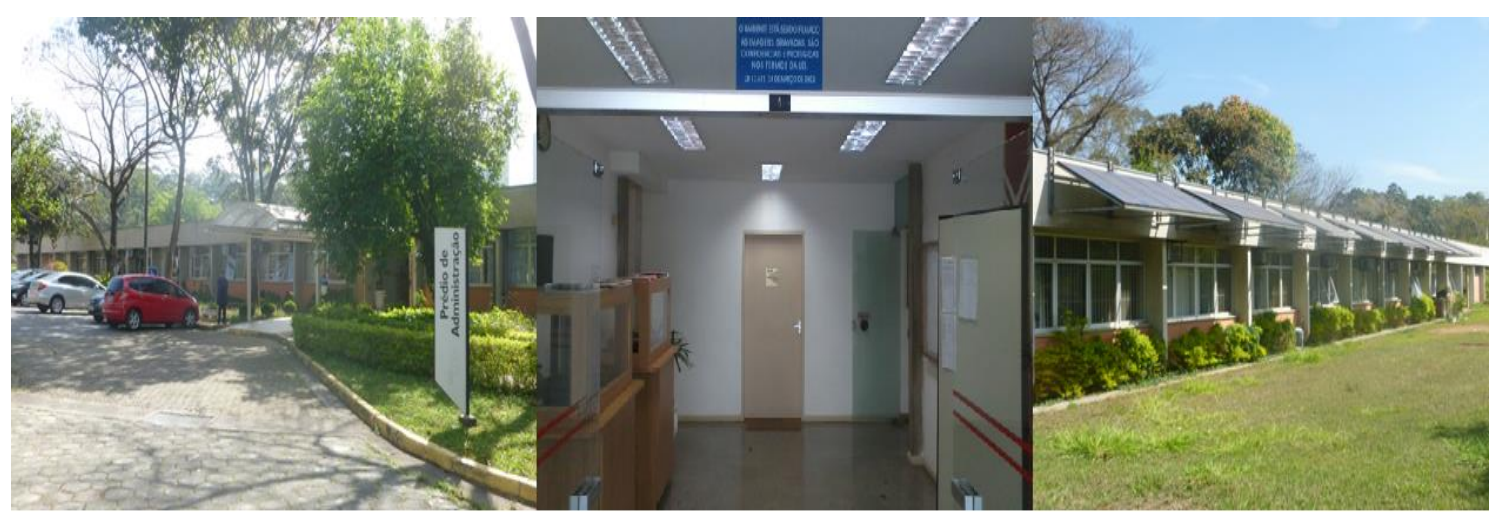

Figura 14- Imagens do exterior e do interior do Prédio Administração IEE/USP.

\subsubsection{Características Especiais: Sistema Fotovoltaico Conectado à Rede}

O Prédio da Administração do IEE/USP possui um sistema fotovoltaico conectado à rede que fornece energia ao prédio durante o dia e exporta o excedente para a rede elétrica. O sistema foi constituído em várias etapas, inicialmente com os geradores instalados nos brises da fachada norte e posteriormente com a instalação de geradores acima do telhado do prédio. 


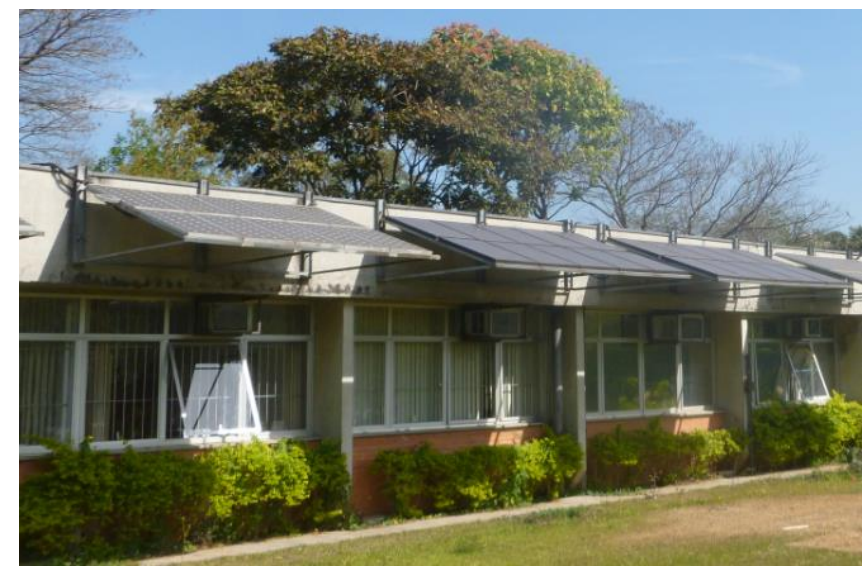

Figura 15- Imagens do sistema fotovoltaico Prédio Administração IEE/USP

A implementação deste sistema teve início no ano de 2001 com um sistema de $6,3 \mathrm{kWp}$ instalado na fachada do prédio. No ano de 2006 houve uma ampliação do sistema que passou a ser composto por aproximadamente $12,3 \mathrm{kWp}$, na fachada norte do Prédio da Administração (Figura 15). Por fim, no ano 2014 foram instalados geradores acima do telhado do prédio, que alcançam uma potência de $75 \mathrm{kWp}$.

Os geradores nos brises, instalados faceando o norte, protegem as janelas da incidência direta da radiação solar, reduzindo portanto a carga térmica da edificação e o uso dos sistemas de ar condicionado. Na figura 16 observa-se a curva de demanda de um dia típico no Prédio da Administração e a influência da produção do sistema fotovoltaico no total.

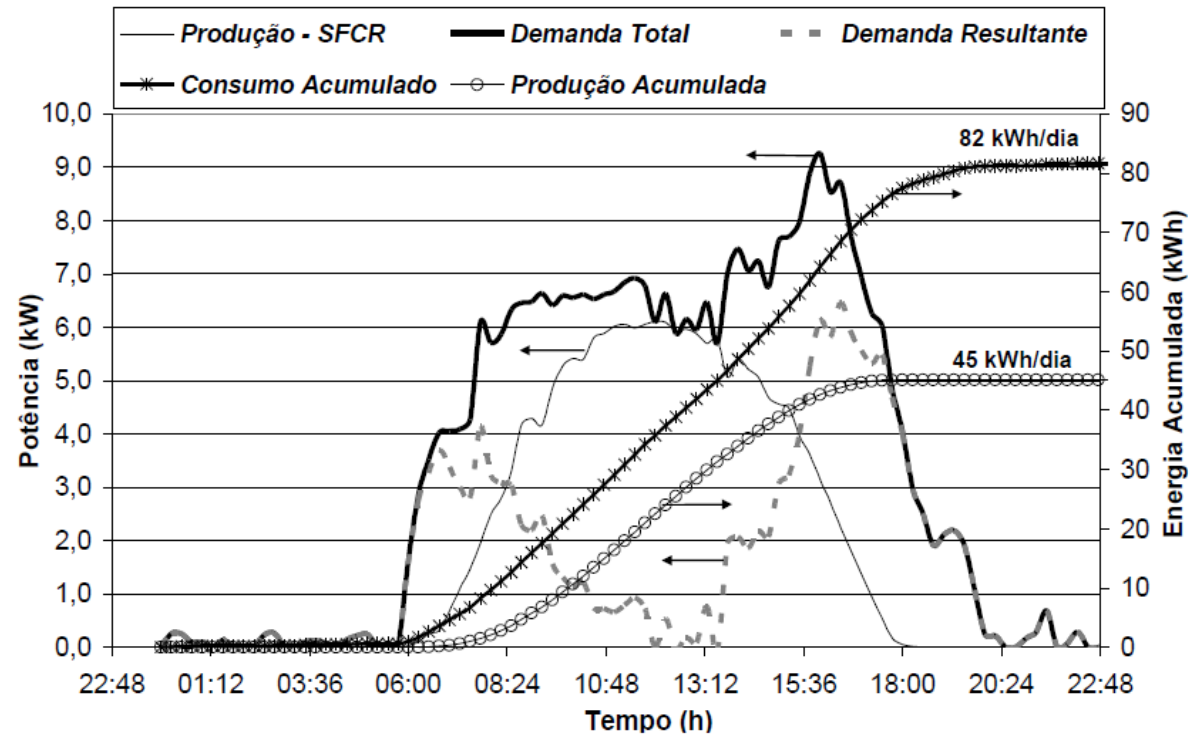

Figura 16- Influência da produção do sistema fotovoltaico na curva de carga do Prédio da Administração. Fonte: Zilles (2013). 
No gráfico acima nota-se que em um dia ensolarado, a demanda de energia da rede elétrica diminui consideravelmente, chegando inclusive próximo a zero ao meio dia. Além disso, observa-se que o sistema fotovoltaico consegue gerar $56 \%$ do total de energia para o funcionamento do prédio.

Adicionalmente, nas áreas adjacentes ao prédio encontram-se usinas solares para injeção na rede elétrica ( não fornecem a energia do prédio da administração). Uma das usinas possui $156 \mathrm{kWp}$ de potência instalada e está localizada na grama da fachada norte do prédio, já a outra usina possui $150 \mathrm{kWp}$ de potência instalada e está localizada em uma estrutura acima dos estacionamentos.

\subsubsection{Descrição Geral dos Sistemas Energéticos}

\subsubsection{Condicionamento Ambiental}

A edificação possui sistemas de ar condicionado nas principais áreas como escritórios, áreas administrativas e biblioteca. Os equipamentos são do tipo janela e em alguns casos do tipo split, o uso ocorre principalmente no verão e durante o horário comercial do escritório das $7 \mathrm{~h}$ às $17 \mathrm{~h}$ mas com uso variavel.

\subsubsection{Iluminação}

O sistema de iluminação é composto por lâmpadas T12 de $40 \mathrm{~W}$ e T8 de 32 W. A iluminação é mantida ligada no período de atividade da edificação, principalmente entre as $7 \mathrm{~h}$ e $18 \mathrm{~h}$ de forma variável.

Nos corredores, áreas comuns, biblioteca e algumas áreas administrativas as luminárias não possuem refletor, causando uma grande perda de fluxo luminoso dos tubos fluorescentes. Já nas áreas da Diretoria, as luminárias com refletor geram um melhor aproveitamento do fluxo luminoso disponível pelos tubos.

$\mathrm{Na}$ figura 17 pode-se apreciar alguns elementos do sistema de iluminação instalado na edificação. 


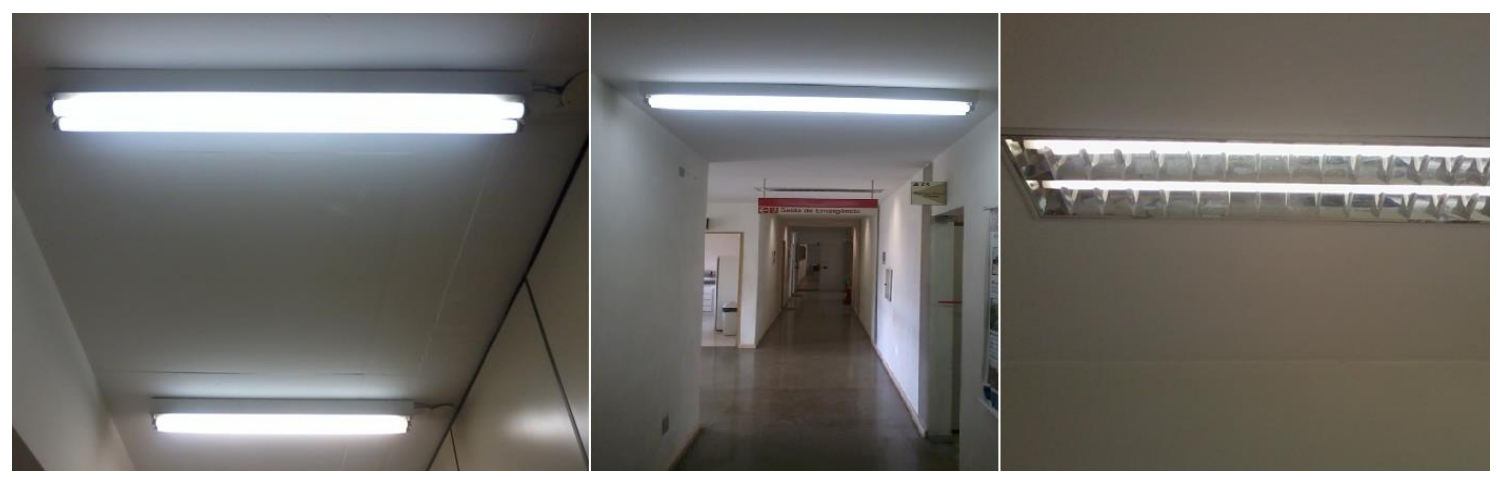

Figura 17- Fotos do sistema de iluminação do Prédio da Administração IEE/USP.

\subsubsection{Outras Cargas}

O Prédio da Administração apresenta um uso de escritório importante, com um uso constante de equipamentos como computadores, impressoras, copiadoras entre outros. Estes equipamentos são utilizados principalmente no horário comercial da edificação das $7 \mathrm{~h}$ às $18 \mathrm{~h}$.

Alem disso, há o uso de outras cargas de equipamentos pelos funcionários como geladeira, bebedouros, micro-ondas, entre outros.

\subsubsection{Medições}

\subsubsection{Medições Energia}

As medições das variáveis elétricas forem realizadas dos dias 17 de maio a 01 de julho de 2013. As medições permitem conhecer o comportamento energético do prédio e validar o modelo criado no software de usos finais (PUFE).

A Figura 18 apresenta os dados completos obtidos nas medições nestas datas. Neste gráfico se observa que a curva de carga para o prédio, de rotina pautada por atividades administrativas, apresenta um padrão de comportamento estável, com uma carga basal entre 1,0 e 2,0 kW e uma carga em dias úteis e horário comercial entre 7,0 e $10,0 \mathrm{~kW}$. 


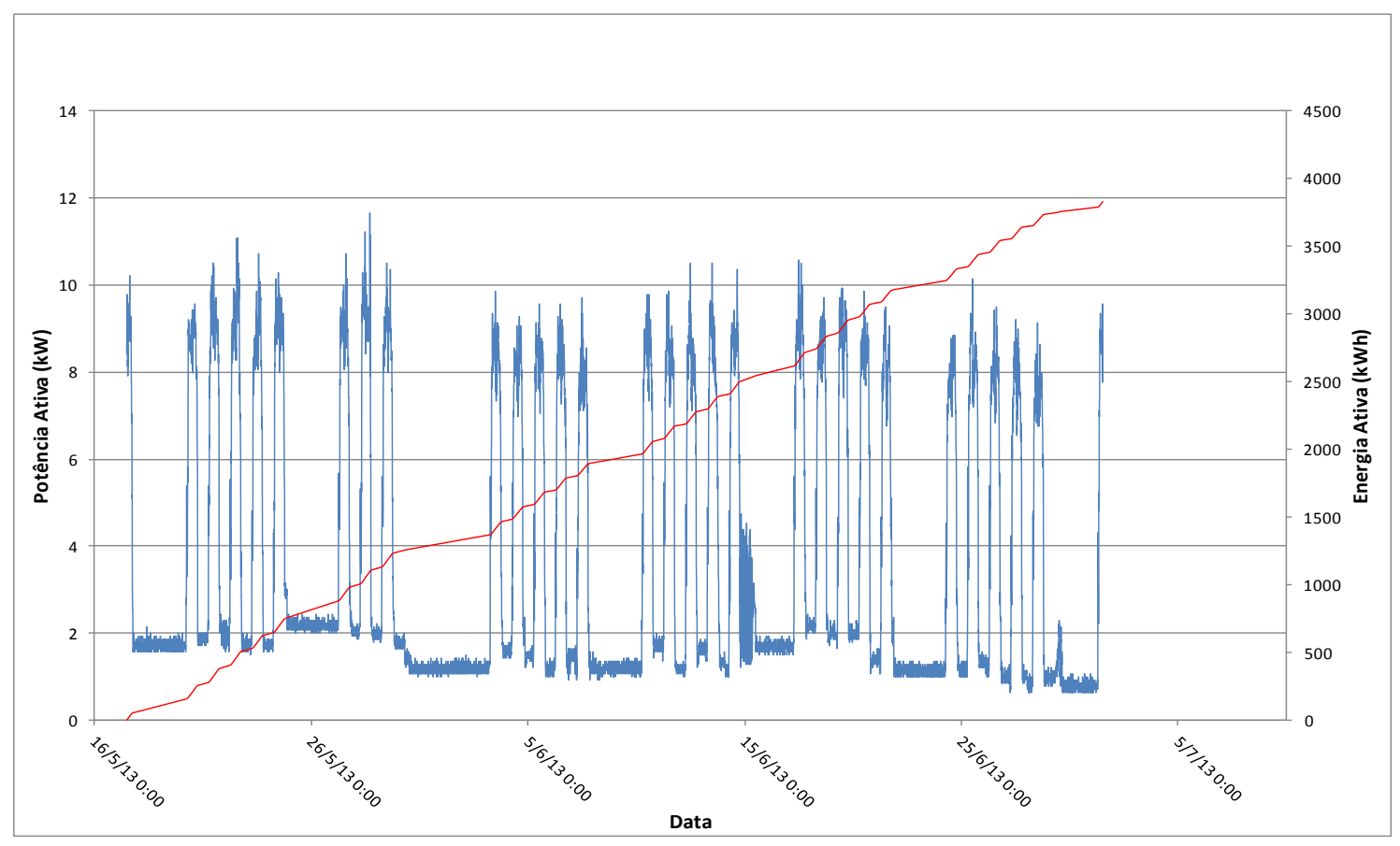

Figura 18- Medição da potência ativa entre 1 de junho e 30 de junho.

As figuras 19 e 20 apresentam as medições de um dia comercial típico e as medições de um dia de final de semana, quando a ocupação do prédio é mínima.

Na Figura 19 encontra-se o comportamento de carga de um dia útil típico, onde se observa que o delineamento da curva de consumo segue os padrões de atividade executadas no prédio. A faixa horária entre as $6 \mathrm{~h}$ e as $7 \mathrm{~h} 30 \mathrm{~h}$ consiste no horário de chegada e começo das atividades da equipe de faxina. Já a maioria das atividades administrativas está delimitada pelo horário comercial das 7:30h às 16:30h, com pausa de 1 hora para o almoço ao meio-dia. Os serviços bibliotecários estendem-se até às $18 \mathrm{~h}$. Às $20 \mathrm{~h}$ ocorre o apagar das luzes internas e o fechamento do prédio, realizado pelos seguranças do instituto. 


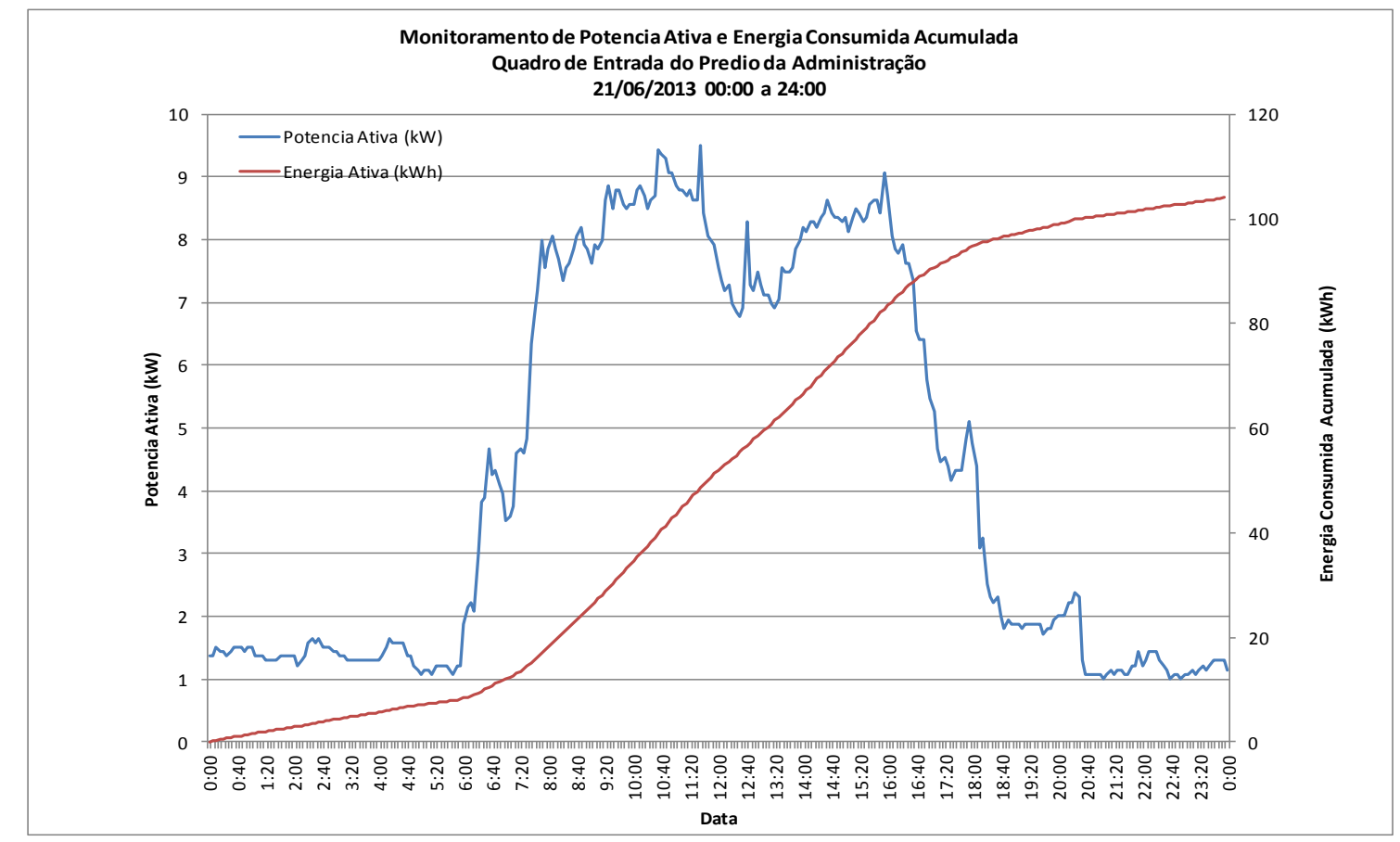

Figura 19- Medição da potência ativa dia de semana.

Finalmente a Figura 20 apresenta o comportamento da carga típico de um dia de final de semana. Neste caso, as variações cíclicas da carga estão relacionadas aos equipamentos de refrigeração como geladeiras, frigobares e bebedouros.

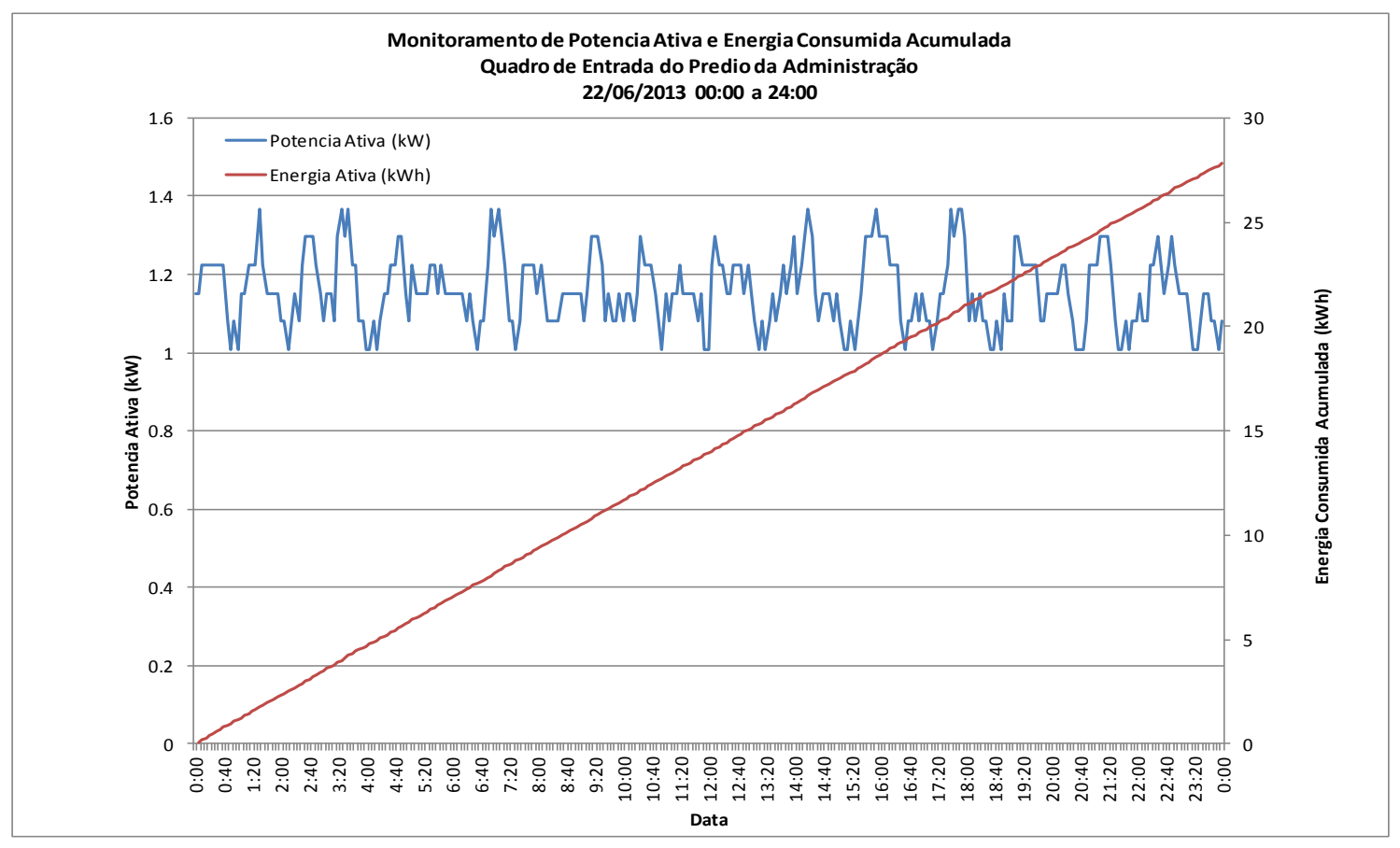

Figura 20- Medição da potência ativa dia típico final de semana. 


\subsubsection{Medições Iluminação}

As medições de iluminância das diferentes áreas do Prédio da Administração forem feitas baseados na norma NBR 5382: Verificação de Iluminância de Interiores. As mesmas foram realizadas no dia 6 de setembro de 2013 pela tarde e com céu claro, com as luminárias ligadas e desligadas a fim de avaliar o efeito da iluminação natural na iluminância média e a iluminância própria do sistema de iluminação artificial. Na tabela 8 encontram-se os valores de iluminância média total das áreas selecionadas e a participação da iluminação natural no total.

Tabela 8- Medições de Iluminância Média e efeito da iluminação natural no total.

\begin{tabular}{cccc}
\hline & $\begin{array}{c}\text { Iluminância } \\
\text { Media Total } \\
(\text { Lux })\end{array}$ & $\begin{array}{c}\text { Iluminância } \\
\text { Media Natural } \\
\text { (Lux) }\end{array}$ & $\begin{array}{c}\text { \% Iluminância } \\
\text { Natural do Total }\end{array}$ \\
\hline BIBLIOTECA- SALA DE LEITURA & 418 & 198 & $47.4 \%$ \\
BIBLIOTECA-ESTANTES ACERVO & 225 & 34 & $15.1 \%$ \\
BIBLIOTECA-FICHARIO /ESCRITORIOS & 358 & 140 & $39.1 \%$ \\
ESCRITORIO CONTRATOS & 444 & 171 & $38.5 \%$ \\
RECEPÇÃO & 638 & 346 & $54.2 \%$ \\
ESCRITORIO ADMINISTRATIVO & 651 & 288 & $44.2 \%$ \\
DIRETORIA & 504 & 229 & $45.4 \%$ \\
SALA DE REUNIÕES & 539 & 60 & $11.1 \%$ \\
\hline
\end{tabular}

A participação da iluminação natural no Prédio da Administração é muito importante. Todas as áreas estudadas, com exceção da sala de acervo na Biblioteca e da Sala de Reuniões, possuem mais de 38\% de iluminância natural no total. Nestas salas, integrar um controlador para dimerizar a iluminação artificial dependendo da iluminação natural pode ser uma estratégia interessante de redução do consumo.

O valor de iluminância média, sem se considerar a iluminação natural, e a potência de iluminação das diferentes áreas estudadas foi comparada com os valores recomendados nas normas de iluminação e eficiência energética para edificações. Os resultados são mostrados na Tabela 9. 
Tabela 9- Comparação valores existentes com os requeridos nas normas .

\begin{tabular}{|c|c|c|c|c|c|c|c|}
\hline & Área (m2) & $\begin{array}{c}\text { Iluminância } \\
\text { media } \\
\text { (Lux) }\end{array}$ & $\begin{array}{c}\text { Iluminância } \\
\text { Norma NB R5413 } \\
\text { (Lux) } \\
\end{array}$ & $\begin{array}{c}\text { Potência } \\
\text { Iluminação } \\
(W)\end{array}$ & $\begin{array}{c}\text { DPI } \\
(\mathbf{W} / \mathbf{m} 2) \\
\end{array}$ & $\begin{array}{c}\text { DPI } \\
\text { ASHRAE } \\
(\text { W/m2) } \\
\end{array}$ & $\begin{array}{c}\text { NPD } \\
(\mathrm{W} / \mathrm{m} 2 \cdot \mathbf{1 0 0 l u x}) \\
\end{array}$ \\
\hline BIBLIOTECA-SALA DE LEITURA & 20 & 220 & 500 & 304 & 15.20 & 12.90 & 6.91 \\
\hline BIBLIOTECA-ESTANTES ACERVO & 154 & 191 & 300 & 1920 & 12.47 & 18.30 & 6.53 \\
\hline BIBLIOTECA-FICHARIO/ESCRITORIOS & 20 & 218 & 300 & 448 & 22.40 & 11.80 & 10.28 \\
\hline ESCRITORIO CONTRATOS & 20 & 273 & 500 & 416 & 20.80 & 11.80 & 7.62 \\
\hline RECEPÇÃO & 24 & 292 & 100 & 320 & 13.33 & 9.61 & 4.57 \\
\hline ESCRITORIO ADMINISTRATIVO & 24 & 363 & 500 & 128 & 5.33 & 11.80 & 1.47 \\
\hline DIRETORIA & 26 & 275 & 500 & 256 & 9.85 & 11.80 & 3.58 \\
\hline SALA DE REUNIÕES & 60 & 479 & 200 & 768 & 12.80 & 11.80 & 2.67 \\
\hline
\end{tabular}

No Prédio da Administração o sistema de iluminação não atinge a norma para iluminância de interiores em todas as salas, com exceção da recepção; portanto, uma nova tecnologia ou distribução deve ser integrada a fim de aumentar os níveis de iluminância.

A avaliação da eficiência energética do sistema de iluminação demonstrou que o mesmo possui um DPI maior que o recomendado pelo ASHRAE em várias salas, devido principalmente a presença de luminárias com lâmpadas de tecnologia T12 de 40 W. Também ao considerar a parte luminotécnica pode se notar como em algumas salas o indicador é bastante alto principalmente nas salas da biblioteca e do escritório de contratos.

\subsubsection{Levantamento Usos Finais da Energia (PUFE)}

\subsubsection{Distribuição dos usos finais da energia}

O levantamento dos equipamentos e hábitos de uso permitiu definir a participação dos diferentes usos finais da energia no total do consumo do Prédio da Administração. Na figura 21 são amostrados os diferentes usos finais da energia durante o inverno. 


\section{Prédio de Administração IEE/USP- Inverno}

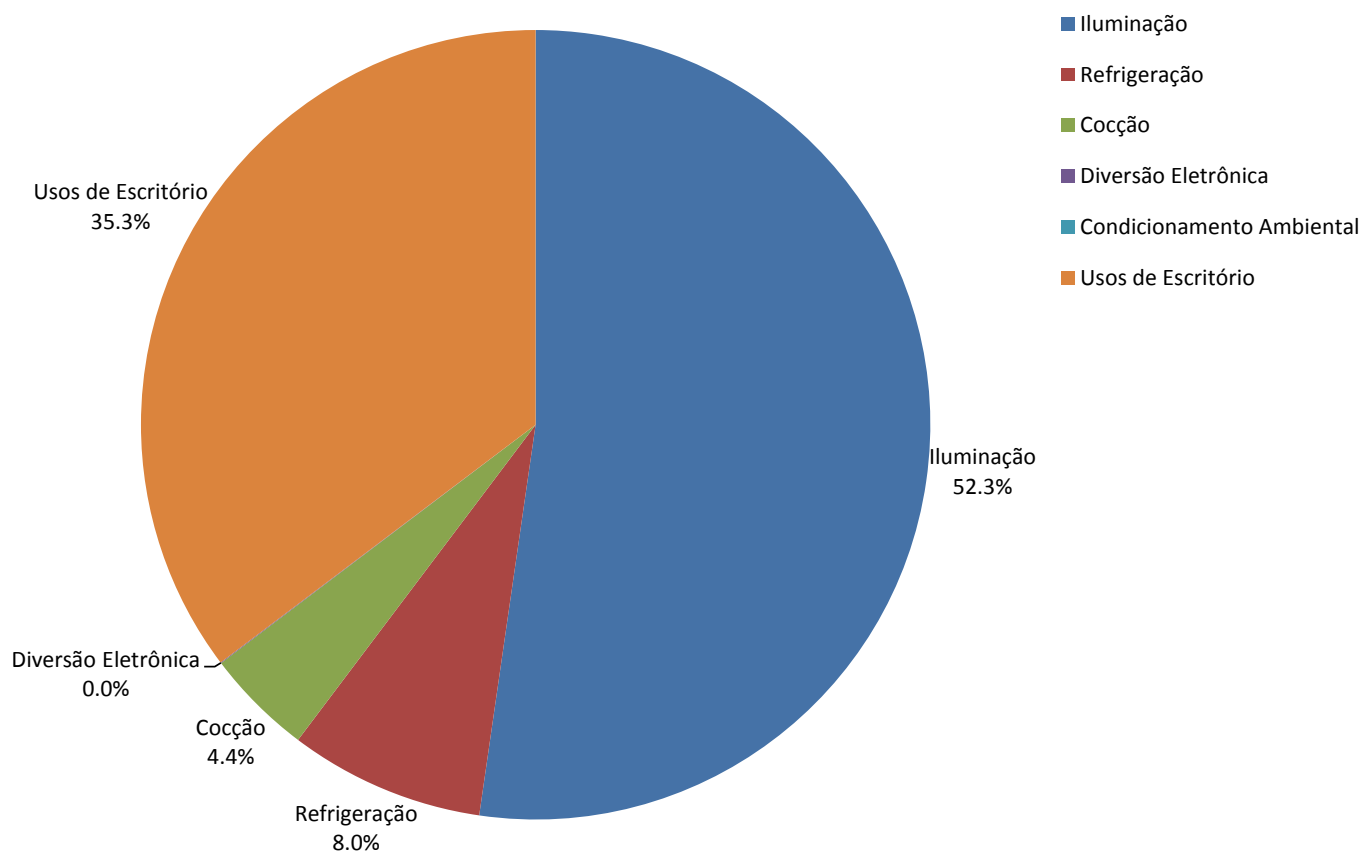

Figura 21- Usos finais da energia Prédio Administração no Inverno.

O uso final mais importante do Prédio da Administração durante o inverno é a iluminação, representando $52,3 \%$ do total do prédio. Os usos de escritório representam o segundo uso final em importância com 35,3\%. Devidos as características deste prédio, em que a grande parte das tarefas desenvolvidas são administrativas, é compreensível que suas principais cargas durante o inverno sejam a iluminação e os usos de escritório. O restante dos usos finais estão relacionados com o próprio conforto dos funcionários nas horas laborais e são: a refrigeração com $8 \%$, a cocção com 4,4\% e equipamento de diversão eletrônica, principalmente rádios com $0,03 \%$ do total.

$\mathrm{Na}$ figura 22 encontram-se representados diferentes usos finais da energia durante o período do verão no Prédio da Administração; neste caso é possível distinguir a importância do uso final condicionamento ambiental que passa a ser o uso final de maior importância durante esta época do ano, em que existe o aumento das temperaturas, representando $38,3 \%$ do total. 


\section{Prédio de Administração IEE/USP- Verão}

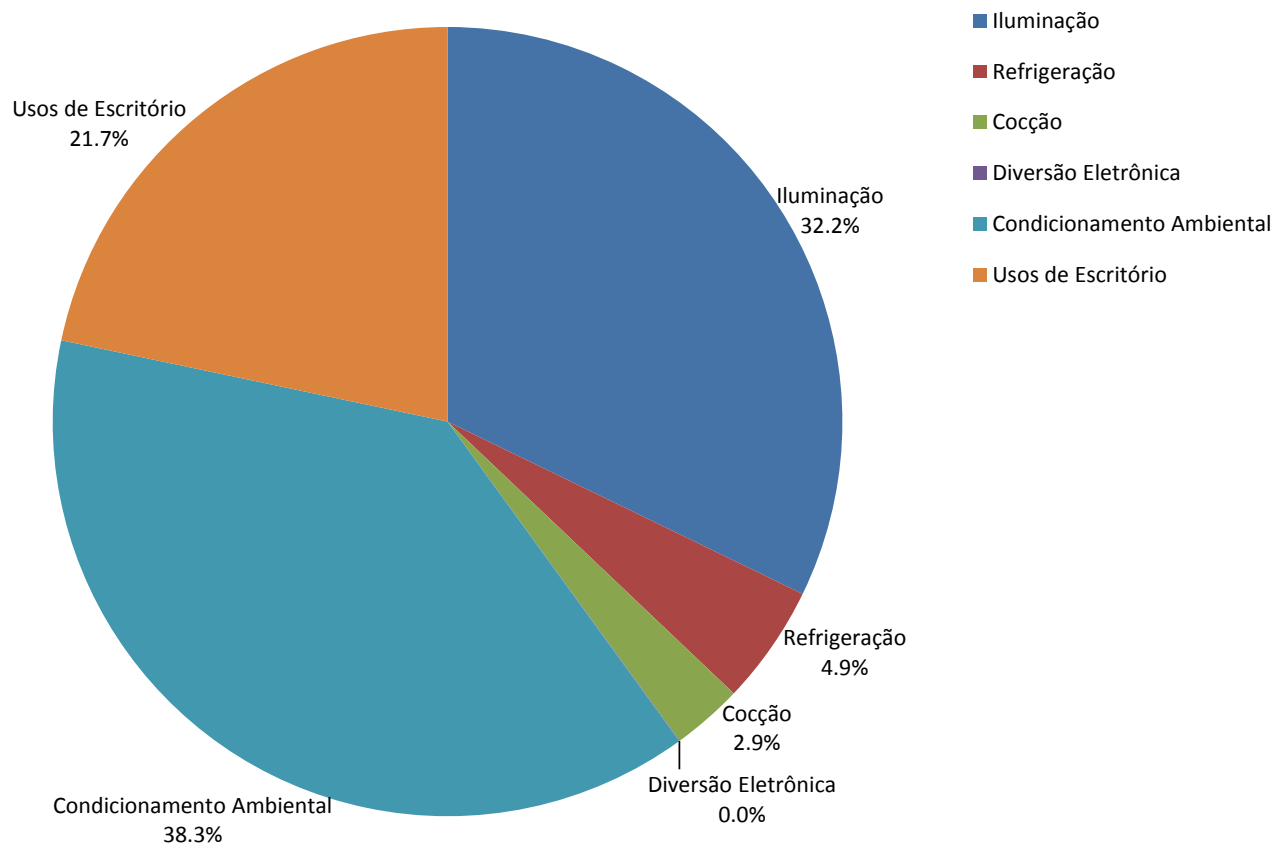

Figura 22- Usos finais da energia Prédio da Administração no Verão.

O uso do condicionamento ambiental durante o verão produz uma variação nas porcentagens dos outros usos finais da edificação. A iluminação passa a ser o segundo uso final em importância com 32,2\%, seguido pelos usos de escritório com 21,7\%. No caso dos usos finais minoritários a refrigeração representa 4,9\%, a cocção 2,9\% e os equipamentos de diversão eletrônica $0,02 \%$.

\subsubsection{Curva de carga de consumo por uso final}

Com base na medição e nos levantamentos presenciais realizados na edificação, foi possível construir a curva de carga de consumo por uso final. As Figuras 23 e 24 apresentam as curvas para um dia comercial típico e para um dia de pouca atividade (final de semana), respectivamente.

Usando as informações dos levantamentos dos equipamentos e os hábitos de consumo foi estimada a curva média de um dia típico de trabalho, que apresenta uma carga base entre 1 e $2 \mathrm{~kW}$ e uma demanda máxima entre 8 e $10 \mathrm{~kW}$. 
A carga base do dia típico é composta por equipamentos de escritório como switch de rede e outros equipamentos que operam em modo stand by, refrigeração e cocção (maquina de café), que ficam ligados o tempo todo. Ao começar o horário laboral, por volta das $6 \mathrm{~h}$, tem início as cargas de iluminação e o aumento das cargas de usos de escritório, que alcançam sua demanda máxima entre 8 e 10kW. Entre às $17 \mathrm{~h}$ e às 19h a carga de iluminação e os usos de escritório começam a diminuir até retornar a carga base.

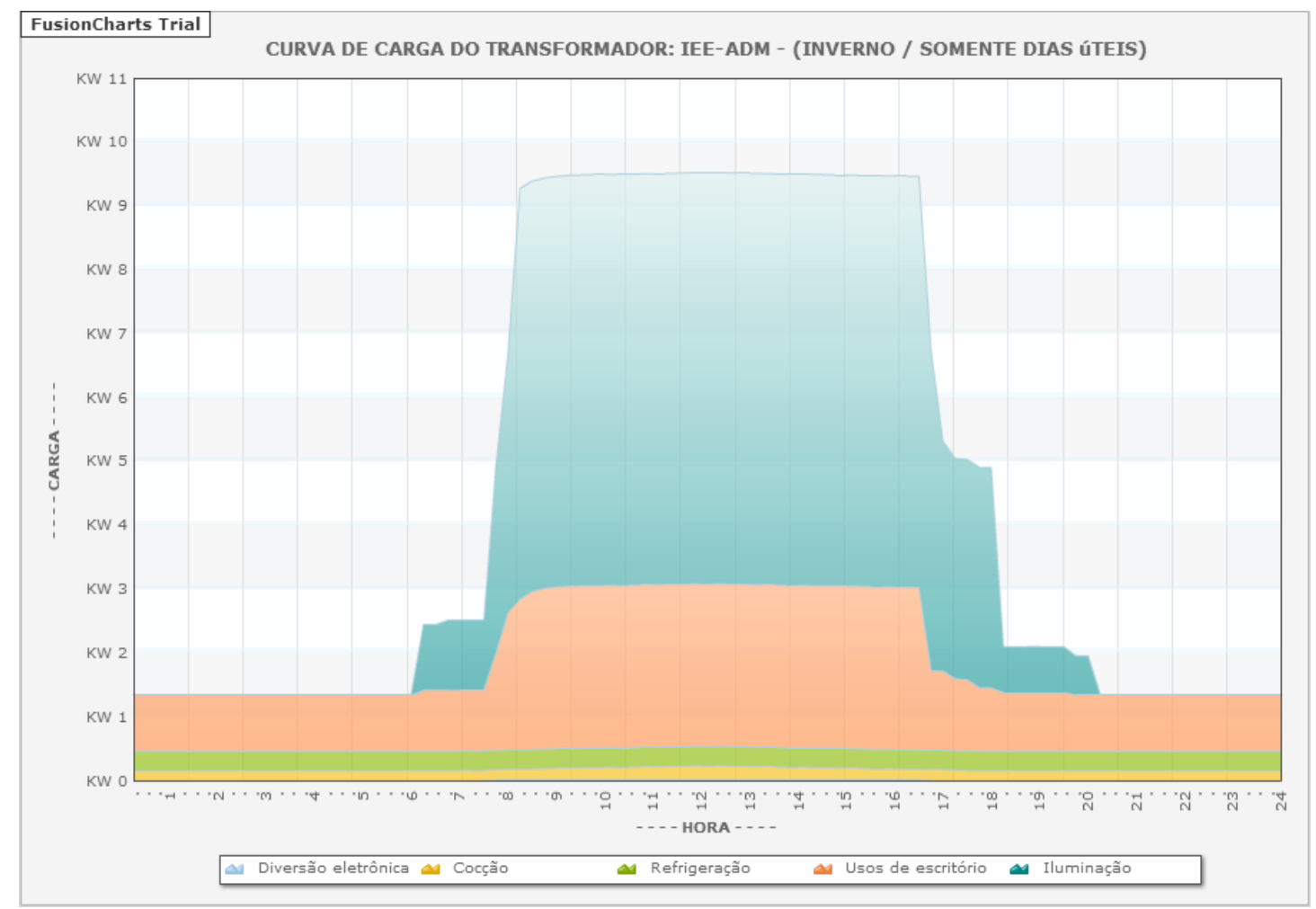

Figura 23- Curva de demanda de energia por uso final para dia típico entre semana em inverno, segundo o PUFE

Já no final de semana, a curva de demanda é composta praticamente pela carga base comentada anteriormente. O comportamento do final de semana no Prédio da Administração pode ser apreciado na Figura 24. 


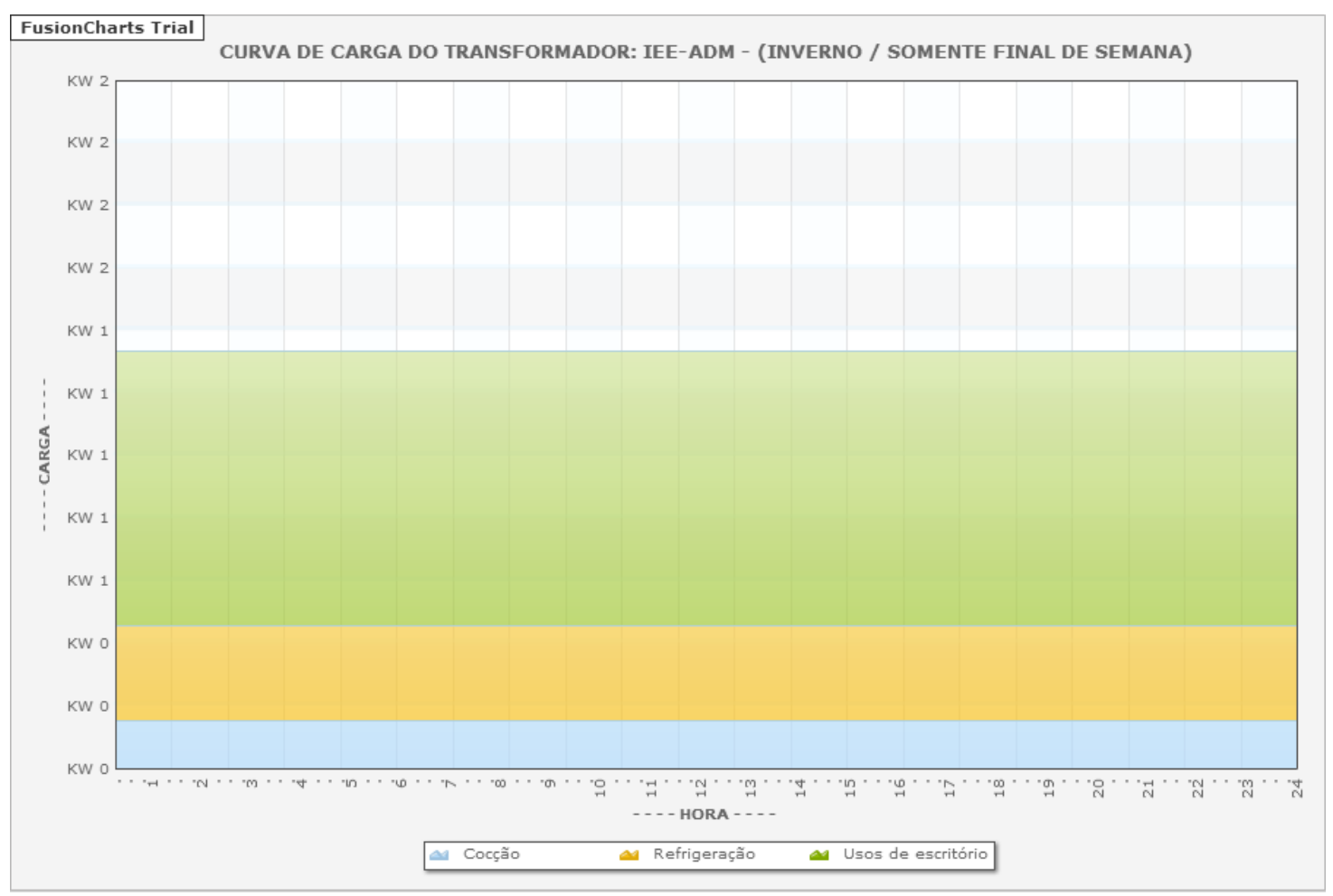

Figura 24- Curva de demanda de energia por uso final para dia típico final de semana em inverno, segundo o PUFE.

\subsubsection{Cálculos e Dados Paramétricos}

O consumo mensal total de energia, segundo a medição, foi de 2 480,23 kWh kWh/mês do dia 01/06/2013 a 30/06/2013, enquanto o consumo mensal total de energia segundo o PUFE foi de $2738,92 \mathrm{kWh} / \mathrm{mês}$. A diferença entre os resultados indica uma variação de $10,4 \%$.

Com base nas medições e na curva de carga construída com o PUFE foi possível definir os dados paramétricos da edificação, fundamentais para a determinação dos padrões de consumo. Os dados também permitiram a identificação de indicadores, que poderiam ser utilizados no futuro para avaliar a eficiência energética da edificação. 
Tabela 10. Dados utilizados para o cálculo dos indicadores energéticos.

\begin{tabular}{lc}
\hline \multicolumn{2}{c}{ Dados para calculo indicadores } \\
\hline Área Total & $1028 \mathrm{~m} 2$ \\
Funcionários & 32 \\
Demanda Máxima Media & $\sigma=0,47$ \\
Consumo Energia Mensal Medido & $2480 \mathrm{kWh} / \mathrm{mês}$ \\
Consumo Energia Inverno (PUFE) & $2739 \mathrm{kWh} / \mathrm{mês}$ \\
Consumo Energia Verão (PUFE) & $4470 \mathrm{kWh} / \mathrm{mês}$ \\
Consumo Ar Condicionado no Inverno & $0 \mathrm{kWh} / \mathrm{mês}$ \\
Consumo Ar Condicionado no Verão & $1704 \mathrm{kWh} / \mathrm{mês}$ \\
Demanda de Potencia para Iluminação & $10,63 \mathrm{~kW}$ \\
\hline
\end{tabular}

Com base nos dados acima foi possível determinar a intensidade energética e a demanda máxima mensal da edificação. Os indicadores foram divididos em três tipos: Indicadores baseados na medição (Tabela 11); Indicadores baseados no PUFE (Tabela 12) e outros indicadores energéticos que poderiam ser de utilidade (Tabela 13).

Tabela 11- Indicadores Energéticos baseados na medição.

\begin{tabular}{lc}
\hline \multicolumn{2}{c}{ Indicadores Energéticos ( Medição) } \\
\hline Intensidade Energética por Área & $2,38 \mathrm{kWh} / \mathrm{m} 2$ \\
Intensidade Energética por Funcionário & $77,5 \mathrm{kWh} / \mathrm{funcionário}$ \\
Demanda Máxima Mensal por Área & $9,4 \mathrm{~W} / \mathrm{m} 2$ \\
Demanda Máxima Mensal por Funcionário & $305 \mathrm{~W} /$ funcionário \\
\hline
\end{tabular}

Tabela 12- Indicadores Energéticos baseados no PUFE.

\begin{tabular}{lc}
\hline \multicolumn{2}{c}{ Indicadores Energéticos (PUFE) } \\
\hline Intensidade Energética por Área (Inverno) & $2,63 \mathrm{kWh} / \mathrm{m} 2$ \\
Intensidade Energética por Funcionário (Inverno) & $85,6 \mathrm{kWh} / \mathrm{funcionário}$ \\
Intensidade Energética por Área (Verão) & $4,3 \mathrm{kWh} / \mathrm{m} 2$ \\
Intensidade Energética por Funcionário (Verão ) & $139 \mathrm{kWh} / \mathrm{funcionário}$ \\
\hline
\end{tabular}

Tabela 13- Outros Indicadores Energéticos.

\begin{tabular}{lc}
\hline \multicolumn{2}{c}{ Outros Indicadores Energéticos } \\
\hline Densidade de Energia do Ar Condicionado (Inverno) & $0 \mathrm{kWh} / \mathrm{m} 2$ \\
Densidade de Energia do Ar Condicionado (Verão) & $1,63 \mathrm{kWh} / \mathrm{m} 2$ \\
Densidade de Potencia de Iluminação & $10,22 \mathrm{~W} / \mathrm{m} 2$ \\
\hline
\end{tabular}




\subsubsection{Dificuldades Encontradas}

Foram encontradas dificuldades para calibrar o modelo de usos finais em relação às medições realizadas. Neste caso, por exemplo, o modelo aponta para uma superestimação do uso de lâmpadas, contabilizadas em aproximadamente 300 pelo levantamento, uma vez que, conferidas numa tarde de inverno, verificou-se a utilização efetiva de menos de $60 \%$ do contingente. Outra possível superestimação está relacionada à rotina de parte da diretoria, uma vez que os diretores não possuem rotina fixa na ocupação de seus escritórios.

Outra dificuldade encontrada foi que para a época da realização deste trabalho, as medições para meses de verão não estavam disponíveis, portanto não foi possível calibrar o modelo de usos finais para o cenário sazonal de verão.

\subsubsection{Proposta de cenários de conservação de energia e melhora iluminação}

O consumo de energia para o sistema de iluminação no prédio da administração do IEE representa, dependendo da estação climática, entre 32 e $52 \%$ do consumo total do prédio. O indicador de Densidade de Potência de Iluminação para o prédio completo apresenta um valor de $10,22 \mathrm{~W} / \mathrm{m}^{2}$, perto do limite aceito por ASHRAE de 10,9 W/m²; contudo a avaliação espaço por espaço (Tabela 8) demonstrou que muitas áreas da edificação possuem DPI maior que o recomendado pelo ASHRAE, além de baixos níveis de iluminância.

Estes fatos permitiram apontar a melhoria do sistema de iluminação como a principal proposta de conservação de energia para este prédio. Esta melhoria poderia se dar através de um retrofit do sistema atual, que compreende um hibrido de T12/40W e T8/32W, por outras tecnologias de menor consumo energético como T5/28W e LED/22W. Esta proposta foi avaliada considerando-se a redução do consumo de energia e os efeitos luminotecnicos que este retrofit poderia trazer.

\subsubsection{Substituição do sistema de iluminação atual}

A substituição do sistema de iluminação atual por tecnologias de menor consumo energético T5 e LED foram primeiro simuladas no software Dialux, para que fosse possível conhecer o comportamento luminotecnico que o sistema apresentaria com o uso das tecnologias comentadas. Para a simulação foram utilizadas lâmpadas T5 de 28 
W (2900 lúmenes) e lâmpadas tubulares LED de 22 W (1900 lúmenes). Os reatores das lâmpadas não foram considerados nas simulações.

As áreas selecionadas foram as que mostraram valores de iluminância baixos na etapa de medições. O fator de manutenção, para considerar a depreciação do fluxo luminoso e sujeira nas lâmpadas, foi de 0,8. As refletividades utilizadas foram: Teto $80 \%$, paredes $50 \%$ e chão $20 \%$.

Em primeira instancia a área da biblioteca, especificamente a sala de leitura, os escritórios e a sala do acervo foram avaliadas. Para isso, as características físicas das salas foram reproduzidas para criar o modelo computacional com o software Dialux. A figura 25 apresenta os modelos computacionais comentados.

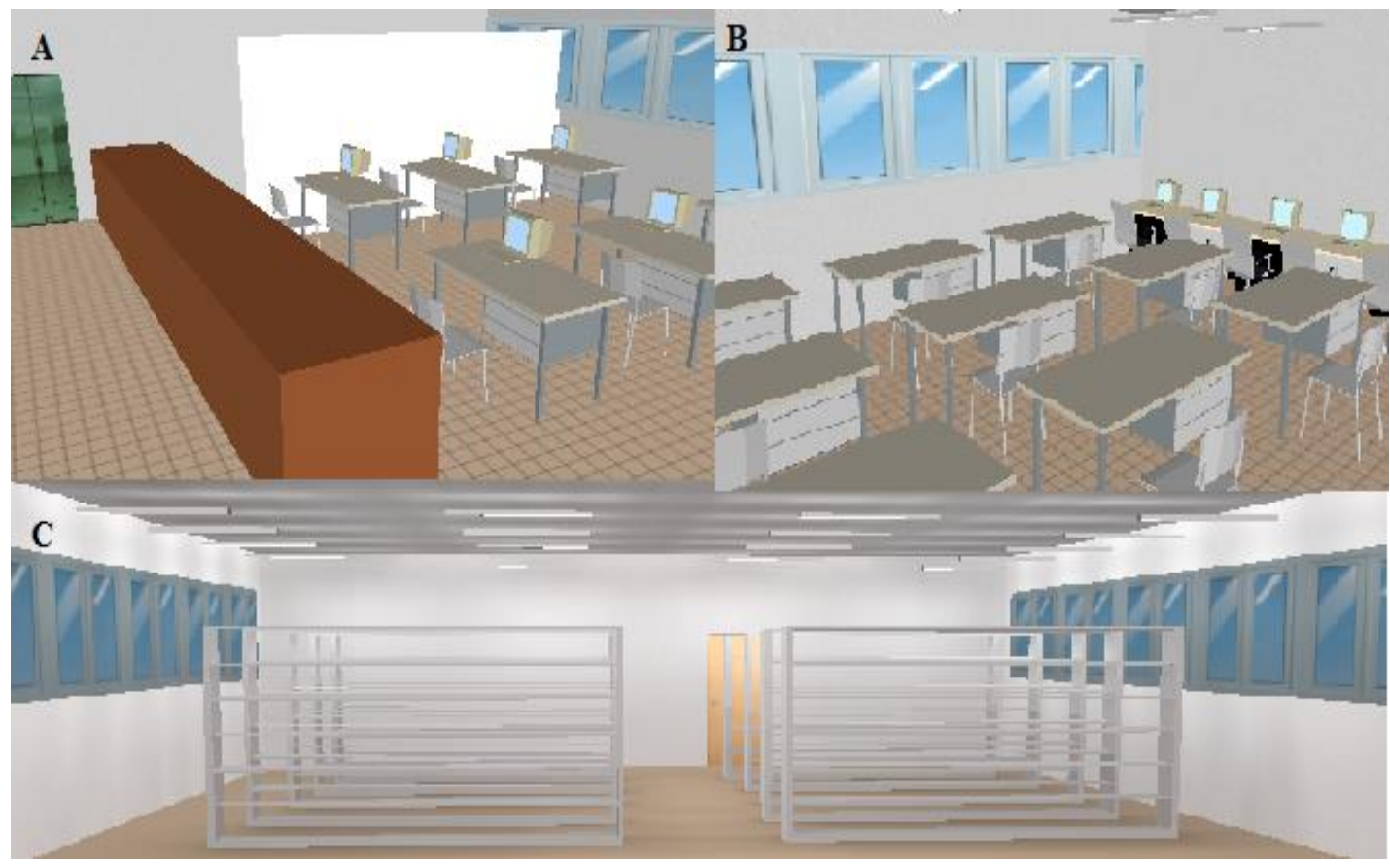

Figura 25- Modelo Computacional Biblioteca--Escritórios (A) Modelo Computacional BibliotecaSala Leitura (B). Modelo Computacional Biblioteca-Sala Acervo (C).

Os resultados das simulações das áreas da biblioteca são apresentados na Tabela 14. 
Tabela 14- Simulacoes no Dialux para as salas da Biblioteca do Prédio Administração.

\begin{tabular}{|c|c|c|c|c|c|c|c|c|c|}
\hline & \multicolumn{3}{|c|}{ B IBLIOTECA-SALA LEITURA } & \multicolumn{3}{|c|}{ BIBLIOTECA-ACERVO } & \multicolumn{3}{|c|}{ BIBLIOTECA-ESCRITORIOS } \\
\hline & Existente & T5 & LED & Existente & T5 & LED & Existente & T5 & LED \\
\hline Área (m2) & 40.00 & 40.00 & 40.00 & 154.00 & 154.00 & 154.00 & 48.00 & 48.00 & 48.00 \\
\hline Iluminância media (Lux) & 220 & 311 & 266 & 191 & 299 & 213 & 218 & 301 & 214 \\
\hline Potência Iluminação (W) & 304 & 224 & 176 & 1920 & 1344 & 1056 & 448 & 336 & 264 \\
\hline DPI (W/m2) & 7.60 & 5.60 & 4.40 & 12.47 & 8.73 & 6.86 & 9.33 & 7.00 & 5.50 \\
\hline NPD $(W / m 2 \cdot 100 l u x)$ & 3.45 & 1.80 & 1.65 & 6.53 & 2.92 & 3.22 & 4.28 & 2.33 & 2.57 \\
\hline Fluxo Luminoso Útil (klm) & 8.80 & 12.44 & 10.64 & 29.41 & 46.05 & 32.80 & 10.46 & 14.45 & 10.27 \\
\hline
\end{tabular}

Os resultados mostram que nas três salas estudadas da área da biblioteca, os sistemas tubular LED possuem a menor DPI e, portanto o menor consumo energético; contudo ao se considerar as qualidades luminotecnicas dos sistemas, a tecnologia T5 apresenta o menor NPD e representaria a opção com o melhor balanço entre eficiência energética e qualidade da iluminação em dois dos três casos estudados. Além disso, as simulações mostram que a iluminância média dos cenários com as diferentes tecnologias estudadas não atingiria o valor solicitado na norma brasileira NBR 5413 (Ver Tabela 2).

Uma solução tecnicamente viável para obter melhorias na iluminação destas salas avaliadas seria a utilização de Task Lighting. Nesta alternativa, a sala possuiria um valor de iluminância basal e cada funcionário poderia ligar a luminária tipo Task Lighting conforme a necessidade, para realizar suas tarefas com conforto visual.

Da mesma forma que com as áreas da biblioteca, foram avaliados, através de simulações computacionais, os parâmetros energéticos e luminotecnicos obtidos após a troca da tecnologia de iluminação de outras áreas que apresentaram níveis de iluminância baixos na etapa de medições .

Os modelos computacionais das salas do escritório de contratos, escritório administrativo e a sala da diretoria estão apresentados na figura 26. 


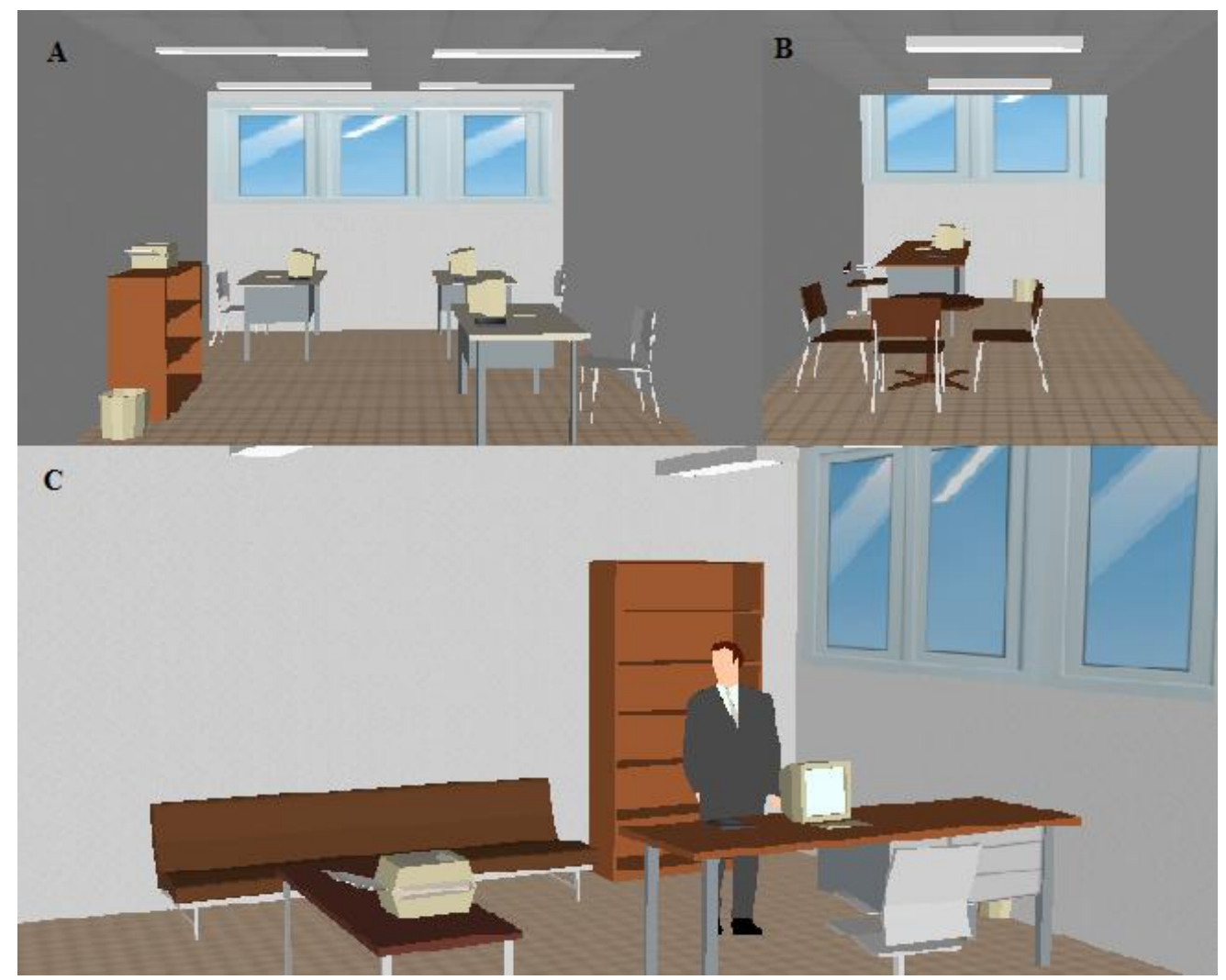

Figura 26- Modelo Computacional Escritorio-Contratos (A) Modelo Computacional EscritoriosAdministrativo (B). Modelo Computacional Direitoria (C).

Os resultados das simulações das áreas de escritório do prédio são apresentadas na Tabela 15.

Tabela 15- Simulacoes no Dialux para as salas de escritorios do Prédio Administracao.

\begin{tabular}{|c|c|c|c|c|c|c|c|c|c|}
\hline & \multicolumn{3}{|c|}{ ESCRITORIO CONTRATOS } & \multicolumn{3}{|c|}{ ESCRITORIO ADMINISTRATIVO } & \multicolumn{3}{|c|}{ DIREITORIA } \\
\hline & Existente & T5 & LED & Existente & T5 & LED & Existente & T5 & LED \\
\hline Área (m2) & 22.00 & 22.00 & 22.00 & 18.00 & 18.00 & 18.00 & 25.00 & 25.00 & 25.00 \\
\hline Iluminância media (Lux) & 273 & 455 & 324 & 320 & 372 & 256 & 275 & 334 & 234 \\
\hline Potência Iluminação (W) & 416 & 336 & 264 & 128 & 112 & 88 & 256 & 224 & 176 \\
\hline DPI $(W / m 2)$ & 18.91 & 15.27 & 12.00 & 7.11 & 6.22 & 4.89 & 10.24 & 8.96 & 7.04 \\
\hline NPD $(W / m 2 \cdot 100 l u x)$ & 6.93 & 3.36 & 3.70 & 2.22 & 1.67 & 1.91 & 3.72 & 2.68 & 3.01 \\
\hline Fluxo Luminoso Útil (klm) & 6.01 & 10.01 & 7.13 & 5.76 & 6.70 & 4.61 & 6.88 & 8.35 & 5.85 \\
\hline
\end{tabular}

De forma similar ao caso das salas da biblioteca, os resultados mostram que nas três salas de escritório estudadas, os sistemas tubular LED tem a menor DPI e portanto o menor consumo energético, porém ao se considerar as qualidades luminotecnicas dos sistemas, a tecnologia T5 apresenta o menor NPD e representaria a opção com o melhor balanço entre eficiência energética e qualidade da iluminação. Além disso, as simulações mostram que a iluminância média dos cenários com as diferentes 
tecnologias, não atinge o valor solicitado na norma brasileira NBR 5413 (Ver Tabela 2). Como no caso das salas da biblioteca, o uso de task lighting seria recomendado para melhorar as condições de iluminação para o usuário.

\subsubsection{Avaliação Econômica}

Utilizando várias figuras de mérito, foi realizada uma análise da economia de energia para determinar se a substituição da distribuição atual de luminárias com sistemas T12 e T8 por sistemas de tecnologia T5 e LED seria economicamente viável.

Para esta análise foram consideradas a totalidade das luminárias do prédio; um tempo de análise de 10 anos; uso diário médio de 6,3 horas; uma taxa de desconto de 12\%; o custo unitário da energia elétrica utilizado foi de USD 0.099/kWh (Custo Médio Mensal Energia Elétrica Campus USP Capital) e um tempo de vida das lâmpadas de 20000h para a T8/T12, 30000h para o sistema T5, e de 40000h para o sistema LED.

Os custos referentes às lâmpadas, reatores e mão de obra para a execução dos projetos de troca de tecnologia de iluminação são apresentados na seguinte tabela.

Tabela 16- Custos Equipamentos e Mão de Obra.

\begin{tabular}{cccc}
\hline & T8/T12 & T5 & LED \\
\hline Custo Lâmpadas (USD) & 608 & 1187 & 12160 \\
Custo Reatores (USD) & 1368 & 1824 & 0 \\
Custo Mão de Obra (USD) & 836 & 1368 & 1216 \\
Custo Total (USD) & $\mathbf{2 8 1 2}$ & $\mathbf{4 3 7 9}$ & $\mathbf{1 3 3 7 6}$ \\
\hline
\end{tabular}

Com os valores comentados anteriormente e os custos da Tabela 16, as figuras de mérito de viabilidade financeira foram calculados. Os resultados são amostrados na tabela 17 .

Tabela 17- Avaliação econômica da sustituição das lâmpadas atuais por lâmpadas da tecnologia T5 e LED.

\begin{tabular}{ccc}
\hline & Retrofit A (Atual vrs T5) & Retrofit B (Atual vrs LED) \\
\hline Economia de Energia Anual (kWh) & 3955,8 & 8817,1 \\
Payback Simple (Anos) & 11,1 & 19,4 \\
TIR (\%) & 25 & 4 \\
LCC (USD) & 9892,8 & 11372,4 \\
ALCC (USD) & 1750,9 & 2012,7 \\
CEC ( USD/kWh) & 0,02 & 0,74 \\
\hline
\end{tabular}


No prédio da Administração foi realizada uma avaliação considerando a totalidade das figuras de mérito estudadas. Os resultados demonstram que o projeto Retrofit A apresenta viabilidade econômica, mesmo com um alto payback, apresentando um TIR aceitável (27\%) e um custo de energia conservada menor que o custo da tarifa elétrica. É importante mencionar que o custo da energia elétrica utilizado possui um valor consideravelmente menor do que a tarifa para um cliente comercial com caraterísticas similares, portanto os resultados são influenciados por esse fato.

Estas figuras de mérito calculadas, permitiram ainda comparar economicamente os dois retrofit e portanto, as duas tecnologias. Neste caso, o Retrofit A (Atual vrs T5) apresenta as melhores condições por possuir o menor LCC (USD 9892,8), ALCC (USD $1750,9)$ e CEC (0,02 USD/kWh). 


\subsection{Prédio de Energia- Instituto de Energia e Ambiente}

\subsubsection{Descrição Arquitetônica}

A Divisão Científica de Energia e Ambiente está localizada a oeste do Instituto próximo a Divisão de Materiais e consiste em um edíficio térreo com mais dois pavimentos, composto por dois volumes interligados. O bloco menor, ao norte, agrupa a circulação vertical, incluindo uma caixa de elevador, sanitários, copa e área de apoio. Ao sul do encontra-se o bloco de atividades. Esta se repete nos três pavimentos, cada pavimento de $552,5 \mathrm{~m}^{2}$, totalizando uma área construída de $1657,5 \mathrm{~m}^{2}$. A Figura 27 apresenta o posicionamento da edificação em relação ao norte.

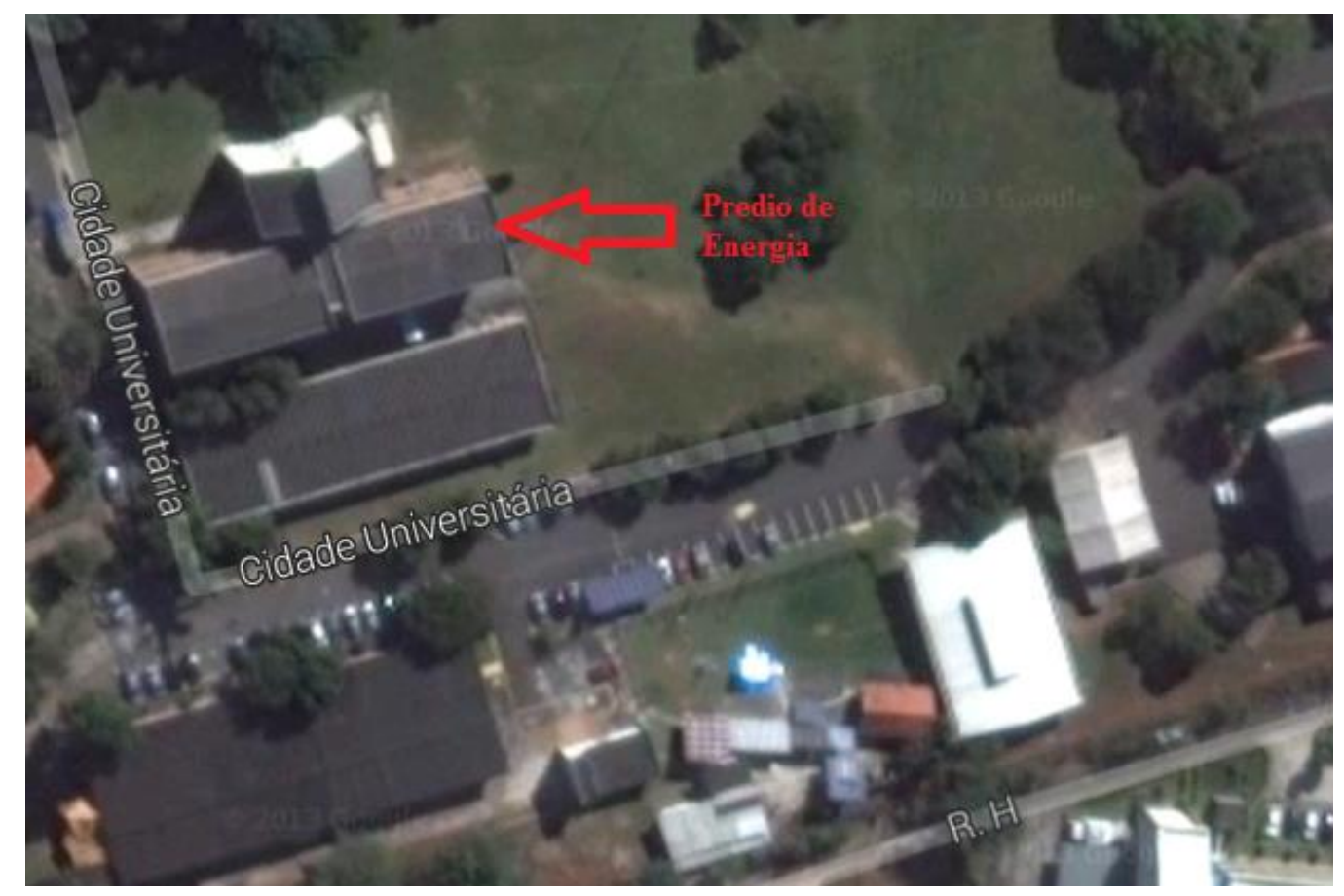

Figura 27- Posicionamento do Prédio de Energia do IEE .

O bloco de atividades é o maior dos volumes e está organizado segundo o usos representados na Tabela 18: 
Tabela 18- Funcionários e Atividades do Prédio de Energia IEE/USP.

\begin{tabular}{|c|c|c|}
\hline & Quantidade Funcionários & Atividades \\
\hline Térreo & 7 & $\begin{array}{l}\text { - Serviço Técnico de Laboratório de Redes Inteligentes, Controlabilidade; } \\
\text { - Qualidade de energia e Descargas Atmosféricas; } \\
\text { - Serviço Técnico de Laboratório de Metrologia }\end{array}$ \\
\hline Primer Andar & 12 & $\begin{array}{l}\text { - Serviço Técnico de Laboratório de Sistema de Iluminação, } \\
\text { Condicionamento Ambiental e Desempenho Energético de Edificações. } \\
\text { - CERTUSP. }\end{array}$ \\
\hline Segundo Andar & 22 & $\begin{array}{l}\text { - Serviço Técnico de Energia e Ambiente. } \\
\text { - Serviço Técnico de Laboratório de Sistemas Fotovoltaicos. } \\
\text { - Serviço Técnico de Assistência Acadêmica. } \\
\text { - Seção de Pós-Graduação. } \\
\text { - Seção de Graduação e Pesquisa. }\end{array}$ \\
\hline
\end{tabular}

A Figura 28 apresenta fotos do interior e exterior da edificação com detalhamento do material construtivo.

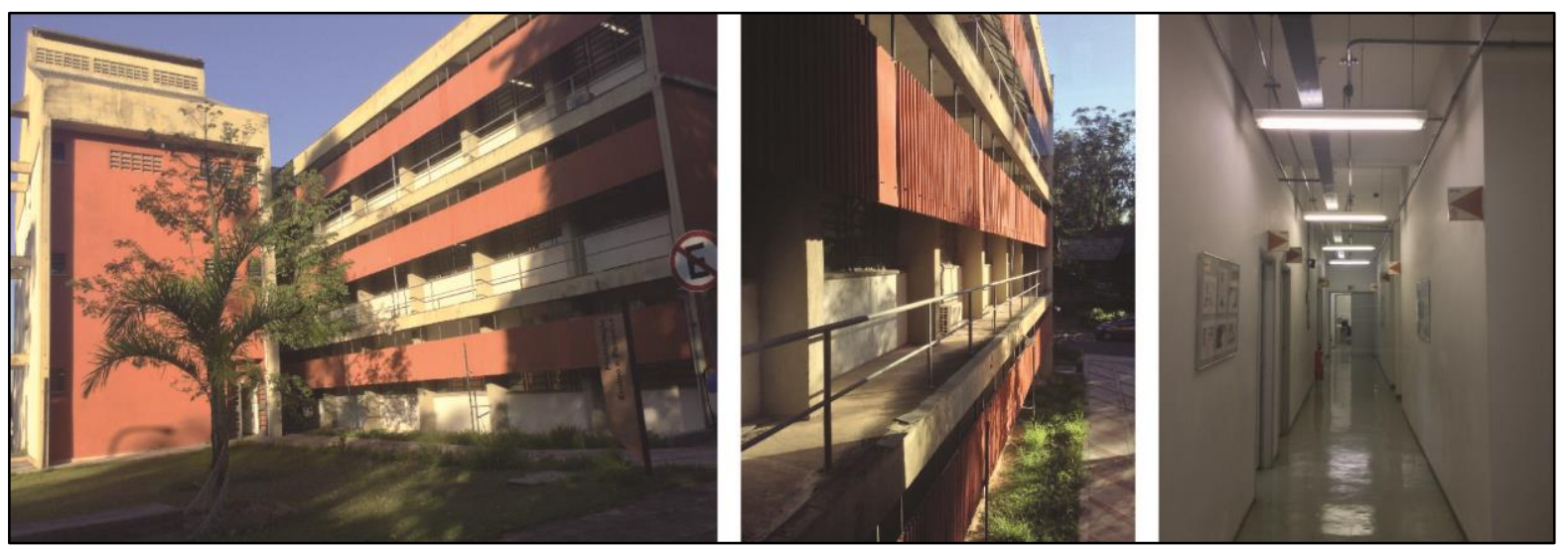

Figura 28- Imagens do exterior e do interior do Prédio de Energia do IEE

A estrutura em concreto armado foi organizada de forma modular e externa às vedações de alvenaria, exercendo também a função de brise soleil vertical. Este sistema de proteção solar é complementada por painéis de telhas de fibrocimento, pintadas na cor vermelho terra, com aproximadamente $1 \mathrm{~m}$ de altura, dispostos de forma vertical, paralelamente às fachadas noroeste e sudoeste. Ao longo de todo o comprimento destas fachadas encontram-se janelas de esquadria de alumínio e vidro transparente simples que cobrem aproximadamente $24 \%$ da área das fachadas. 
A implantação do edifício, com o bloco de apoio ao norte, permite que apenas uma pequena parcela do bloco de atividades, localizado na fachada noroeste, receba insolação no período da tarde. Entretanto, como a solução construtiva para proteção solar é também utilizada na fachada sudeste, que possui pouca radiação direta, o resultado é um edifício que conta com pouca iluminação natural.

Internamente, nos três andares, as salas são distribuídas ao longo de um corredor central no sentido longitudinal do bloco. Algumas adaptações foram feitas para compor salas maiores ou menores, com o uso de divisórias de PVC. As paredes contam com pintura fosca clara e todos os ambientes possuem piso vinílico.

A cobertura do bloco de atividades é composta por telhas de fibrocimento, dispostas em duas águas, rodeadas por platibandas de alvenaria de 1,25 $\mathrm{m}$ de altura, logo acima da laje do último pavimento. No bloco de apoio, a cobertura termina em uma cota mais alta, possivelmente devido a casa de máquinas do elevador, utilizando também telhas de fibrocimento em duas águas.

\subsubsection{Descrição Geral dos Sistemas Energéticos}

\subsubsection{Condicionamento Ambiental}

Os equipamentos de ar condicionado instalados na edificação são apresentados a seguir, de acordo com cada pavimento:

- Térreo - composto basicamente por laboratórios; o ar condicionado permanece ligado por tempo integral devido à existência de uma "pilha padrão". Este local exige uma temperatura constante de $25^{\circ} \mathrm{C}$, desta forma, para garantir a constância da temperatura, além do sistema de resfriamento do ar há também um banco de resistências. Nos laboratórios encontra-se um chiller de água gelada de 10 TR.

- Primeiro andar - Aloja o CERTUSP (Organismo de Certificação de Produtos OCP do IEE/USP) e sala dos engenheiros, configurando uma rotina de escritório e laboratório de fotometria onde são realizados ensaios com periodicidade aleatória, por conta disso o ar condicionado próprio é ligado esporadicamente quando necessário, nas salas que possuem ar condicionado. 
- Segundo andar - As secretarias e as salas dos professores configuram uma rotina de escritório, com certa aleatoriedade na ocupação das salas. Existe ainda um laboratório com utilização frequente e ensaios esporádicos, no qual o ar condicionado é utilizado no verão e algumas vezes durante o inverno para aquecer e manter uma temperatura constante de $25^{\circ} \mathrm{C}$.

\subsubsection{Iluminação}

A iluminação é realizada de forma uniforme em todos os ambientes com luminárias de dois tubos florescentes T8 de 32 watts. Na maioria dos casos a luminária possui apenas os tubos fluorescentes sem refletores, acarretando um desperdício do fluxo luminoso. A iluminação geral é mantida ligada no período de atividade do prédio das $7 \mathrm{~h}$ às $18 \mathrm{~h}$ de forma variável, já nas salas dos professores só é ligada quando os mesmos encontram-se presentes.

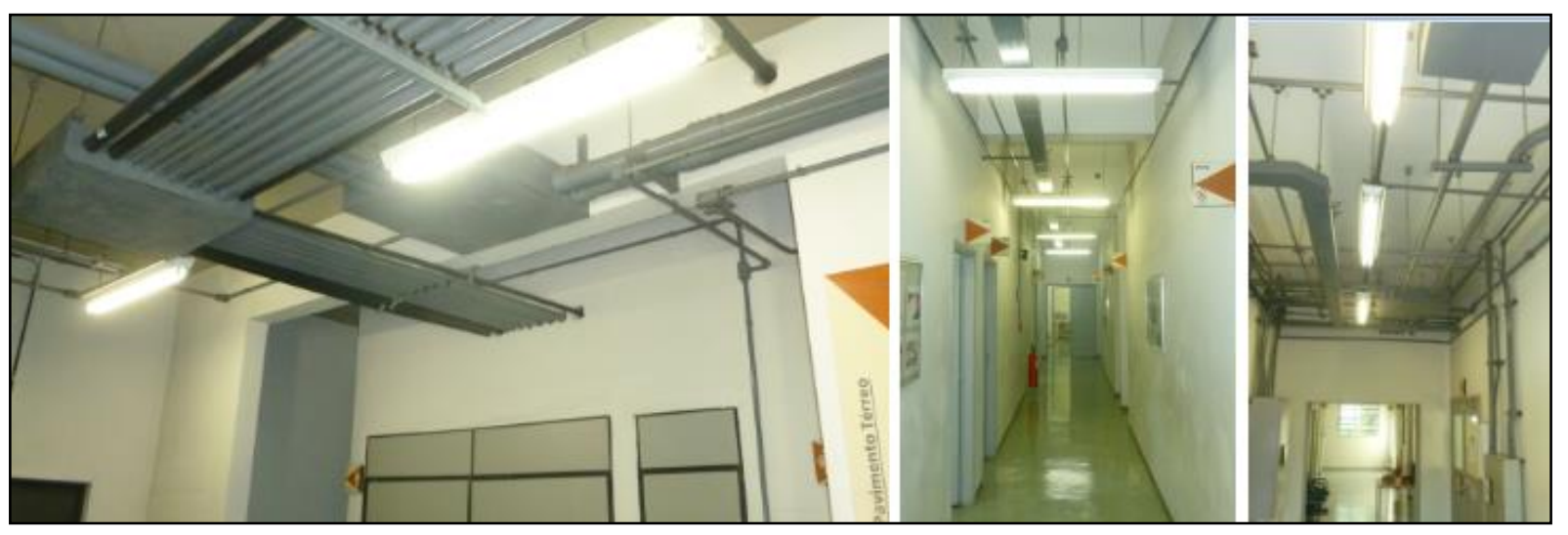

Figura 29- Fotos do sistema de iluminação do Prédio de Energia do IEE

\subsubsection{Outras Cargas}

As cargas definidas como equipamentos de escritório compreendem os computadores, impressoras, copiadoras e outros equipamentos próprios dos labores dos funcionários. Estes equipamentos possuem um período de atividade similar ao da edificação, principalmente entre $7 \mathrm{~h}$ e $18 \mathrm{~h}$, com exceção dos equipamentos das salas dos professores que apresentam rotinas diferentes. 
Outra importante carga do prédio está relacionada aos ensaios de laboratório. Estas cargas entram aleatoriamente ao longo do tempo, de acordo com a demanda de ensaios e os tipos de corpo-de-prova. Por exemplo, no laboratório de medições do térreo a carga pode variar de 0 a $100 \mathrm{kVA}$. No laboratório de iluminação, por sua vez, existe uma sala de sazonamento de lâmpadas que pode somar até $4 \mathrm{~kW}$ de potência se estiver em carga máxima; as demais cargas são aleatórias sendo que, estima-se, que a máxima carga seja de $1 \mathrm{~kW}$.

Já os laboratórios de calibrações possuem uma rotina mais definida e agregam pouca potência, já que as cargas são equipamentos padrões de medições elétricas que consomem relativamente pouca energia. A rigor, para determinar o valor médio de consumo deve se acompanhar o edifício por um período mais longo, talvez um ano, infelizmente não foi possível realizar esse levantamento contínuo no Instituto.

\subsubsection{Medições}

\subsubsection{Medições Energia}

As medições das variáveis elétricas forem feitas no período de 2 de abril a 9 de maio e de 11 de maio a 5 de julho de 2013. As medições permitiram conhecer o comportamento energético do prédio e validar o modelo criado no software de usos finais (PUFE).

A Figura 30 apresenta os dados completos obtidos nas medições do dia 11 de maio a 5 de julho. A Figura 31 apresentam as medições de um dia comercial típico, em que são realizados testes laboratoriais; enquanto a Figura 32 demonstra as medições de um dia de final de semana, quando a ocupação do prédio é mínima.

Na Figura 30 nota-se que o Prédio de Energia possui uma carga base variável entre os diferentes finais de semana e também entre as diferentes semanas do mês, ainda assim é possível definir a carga base da edificação, que se encontra em torno de 5 e 10 $\mathrm{kW}$. Também é possível notar como o consumo de energia nos dias comerciais não tem um comportamento padrão claro. A causa desta diferença é a variabilidade no tipo e horário dos ensaios dos laboratórios, que concentram equipamentos com grandes potências, sem um cronograma típico para acionamento. 


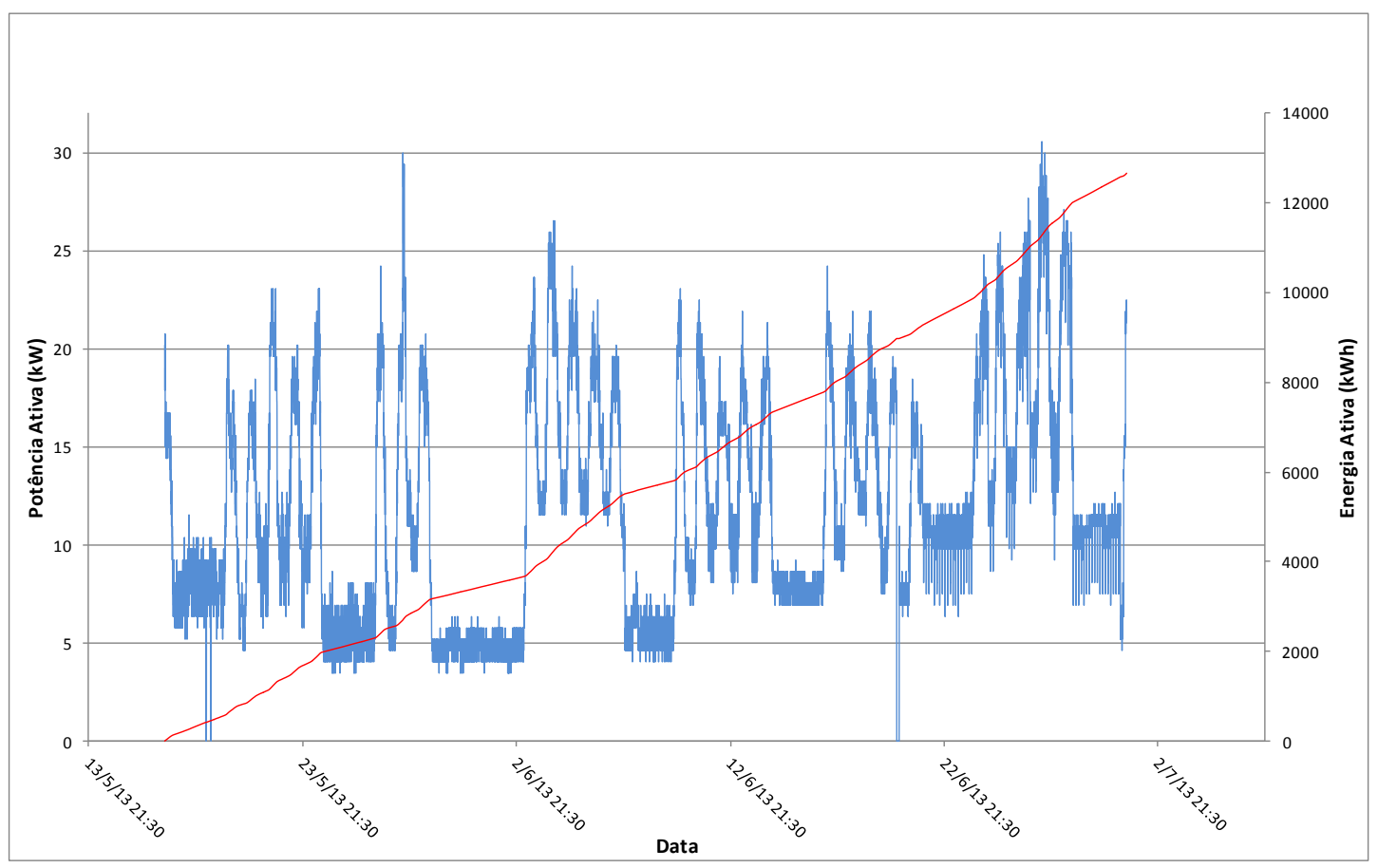

Figura 30- Medição da potência ativa entre 11 de maio e 05 de julho

A Figura 31 apresenta o consumo de energia de um dia típico comercial. Observa-se que no início das atividades, a partir das 6h, há um aumento do consumo, com pico por volta do meio dia e uma carga de $18 \mathrm{~kW}$. O período da tarde apresenta um aumento no consumo de energia causado pala realização dos ensaios laboratoriais. A partir das $17 \mathrm{~h}$ o consumo de energia diminui, até atingir a carga base por volta das $21 \mathrm{~h}$.

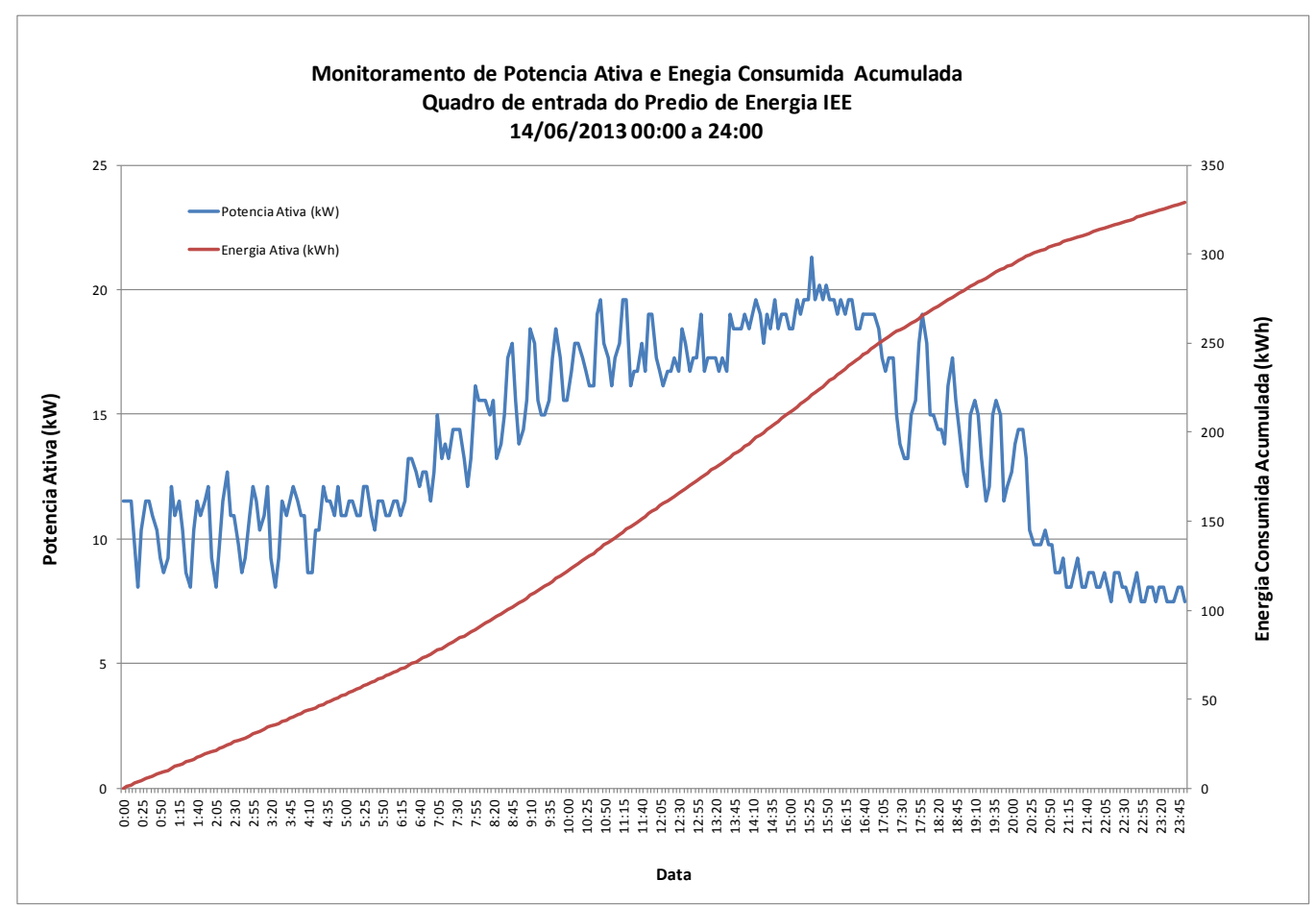

Figura 31- Medição da potência ativa e energia de um dia típico horário comercial. 
Por fim, o comportamento energético dos dias de final de semana é mostrado na Figura 32. Nela é possível observar uma carga base constante de $8 \mathrm{~kW}$, composta principalmente por cargas de refrigeração, ar condicionado, e consumo stand by de equipamentos de escritório.

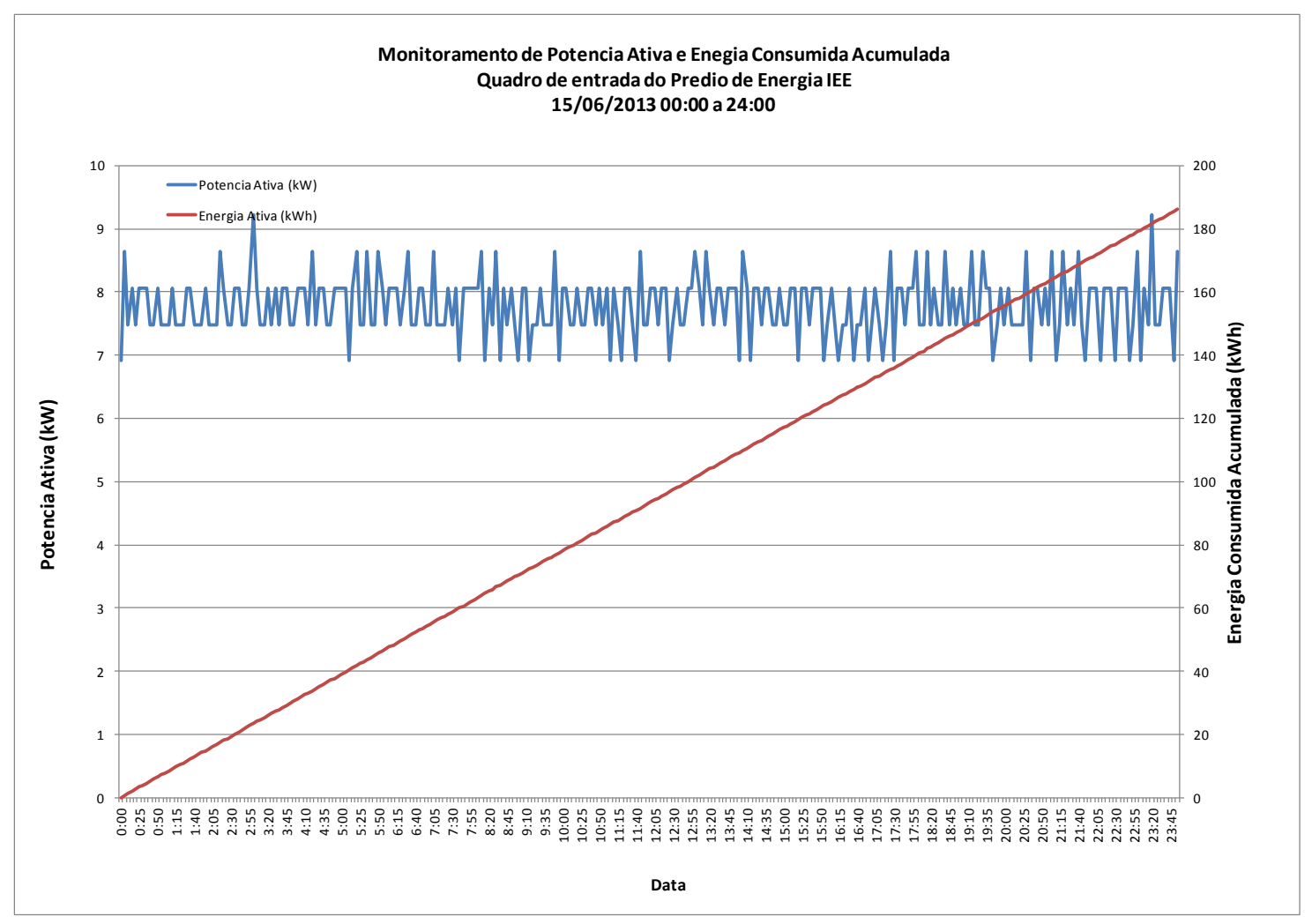

Figura 32- Medição da potência ativa de um dia típico de final de semana.

\subsubsection{Medições Iluminação}

As medições de iluminância das diferentes áreas do prédio de energia forem feitas baseados na norma NBR 5382:Verificação de Iluminância de Interiores. As mesmas forem realizadas no dia 18 de julho de 2013 pela tarde com as luminárias ligadas e desligadas a fim de se avaliar o efeito da iluminação natural, na iluminância média, e também a iluminância própria do sistema de iluminação artificial. Na tabela 19 encontram-se os valores de iluminância média total das áreas selecionadas e a participação da iluminação natural no total. 
Tabela 19- Medições de Iluminância média e efeito da iluminação natural no total.

\begin{tabular}{cccc}
\hline & $\begin{array}{c}\text { Iluminância } \\
\text { Media Total } \\
\text { (Lux) }\end{array}$ & $\begin{array}{c}\text { Iluminância Media } \\
\text { Natural (Lux) }\end{array}$ & $\begin{array}{c}\text { \% Iluminância } \\
\text { Natural do Total }\end{array}$ \\
\hline SECRETARIA PPGE & 325 & 31 & $9.5 \%$ \\
RECEPÇÃO & 237 & 39 & $16.5 \%$ \\
SALA PROFESSOR 1 & 332 & 46 & $13.9 \%$ \\
SALA PROFESSOR 2 & 241 & 41 & $17.0 \%$ \\
SALA PROFESSOR 3 & 323 & 7 & $2.2 \%$ \\
LAB. METROLOGIA & 242 & 0 & $0.0 \%$ \\
SALA LAB. METROLOGIA & 326 & 0 & $0.0 \%$ \\
\hline
\end{tabular}

Pode se observar que a participação da iluminação natural nestas áreas não é muito significativa. A recepção e as sala dos professores 1 e 2 apresentam uma maior participação da iluminação natural no total, contudo, não superam $17 \%$ do total.

Os valores de iluminância média, sem considerar iluminação natural, e a potência de iluminação das diferentes áreas estudadas foi comparada com os valores recomendados nas normas de iluminação e eficiência energética para edificações. Os resultados são mostrados na Tabela 20.

Tabela 20- Comparação valores existentes com os requeridos nas normas .

\begin{tabular}{|c|c|c|c|c|c|c|c|}
\hline & Área (m2) & $\begin{array}{l}\text { Iluminância } \\
\text { media (Lux) }\end{array}$ & $\begin{array}{c}\text { Iluminância Norma } \\
\text { NBR5413 (Lux) }\end{array}$ & $\begin{array}{c}\text { Potência } \\
\text { Iluminação }(\mathbf{W})\end{array}$ & DPI (W/m2) & $\begin{array}{c}\text { DPI ASHRAE } \\
(\mathrm{W} / \mathrm{m} 2)\end{array}$ & $\begin{array}{c}\text { NPD } \\
(\mathrm{W} / \mathrm{m} 2 \cdot 100 l u x) \\
\end{array}$ \\
\hline SECRETARIA PPGE & 24 & 294 & 500 & 640 & 26.67 & 11.80 & 9.07 \\
\hline RECEPÇÃO & 30 & 198 & 100 & 436 & 14.53 & 9.6 & 7.34 \\
\hline SALA PROFESSOR 1 & 12 & 286 & 500 & 192 & 16.00 & 11.80 & 5.59 \\
\hline SALA PROFESSOR 2 & 12 & 200 & 500 & 192 & 16.00 & 11.80 & 8.00 \\
\hline SALA PROFESSOR 3 & 12 & 316 & 500 & 192 & 16.00 & 11.80 & 5.06 \\
\hline LAB. METROLOGIA & 78 & 242 & 200 & 768 & 9.85 & 15.10 & 4.07 \\
\hline SALA LAB. METROLOGIA & 9 & 326 & 500 & 128 & 14.22 & 11.80 & 4.36 \\
\hline
\end{tabular}

Todas as áreas, com exceção da Recepção e do Laboratório de Metrologia, apresentam níveis de iluminância baixos quando comparados com o preconizado pela Norma NBR5413.

Observa-se também que todas as áreas, com exceção do Laboratório de Metrologia, possuem alto DPI, segundo a ASHRAE; o que lhes confere potencial para intervenções de eficiência energética. Da mesma forma, a NPD encontra-se elevada conforme os valores recomendados. 


\subsubsection{Levantamento Usos Finais da Energia (PUFE)}

\subsubsection{Distribuição dos usos finais da energia}

O levantamento dos equipamentos e hábitos de uso permitiu definir a participação dos diferentes usos finais da energia no total do consumo do Prédio de Energia. Na figura 33 são demonstrados os diferentes usos finais da energia durante o inverno.

\section{Prédio de Energia IEE/USP- Inverno}

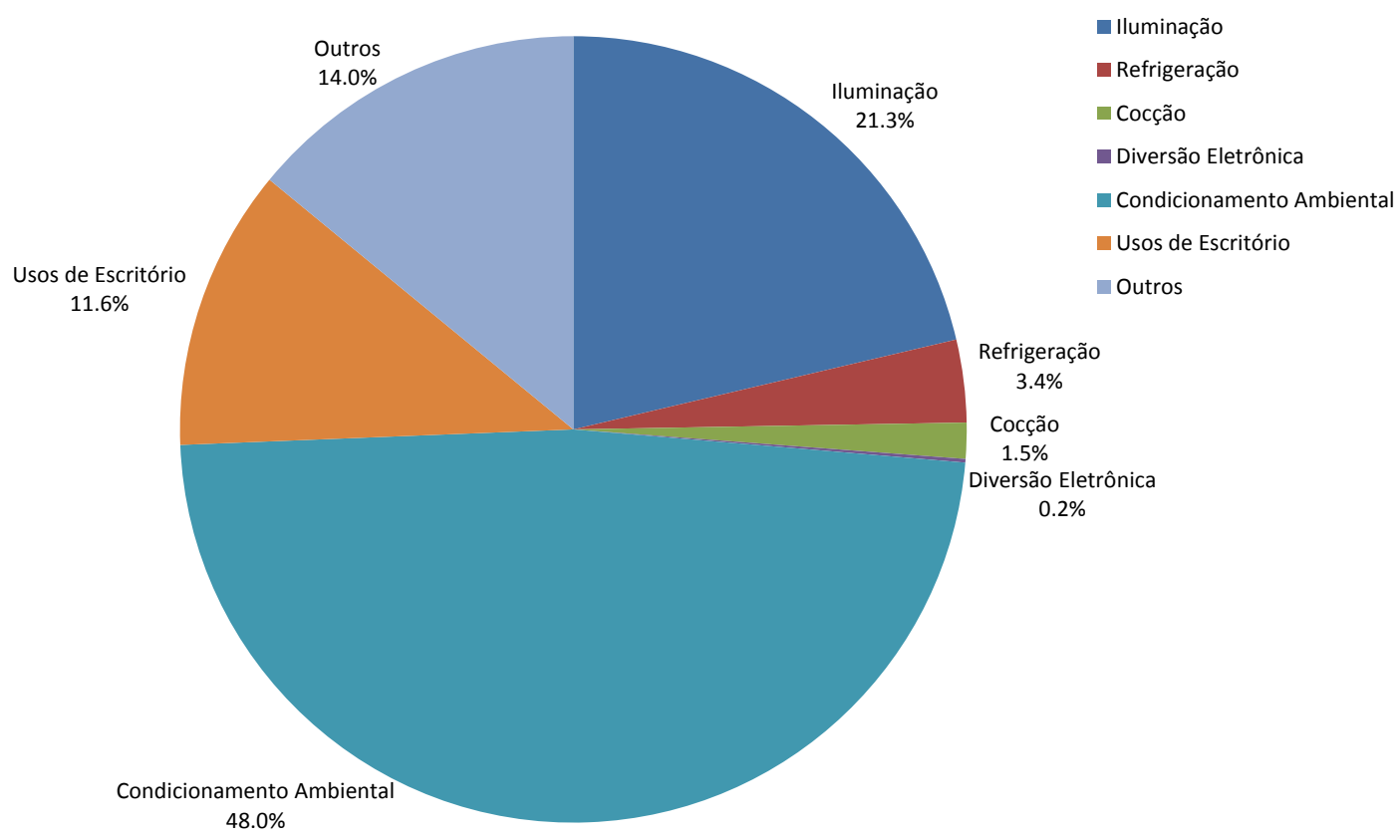

Figura 33- Usos finais da energia Prédio de Energia no Inverno.

O prédio possui um importante consumo de Condicionamento Ambiental, correspondendo a $48 \%$ do total, isto se deve principalmente ao consumo constante de ar condicionado nos laboratórios utilizado para manter a temperatura a $25^{\circ}$ nos ensaios executados. A seguinte carga em importância seria a iluminação, com 21,3\% do total; esta carga permanece ligada aleatoriamente durante o horário comercial gerando um importante consumo. O uso final denominado "Outros" é composto principalmente pelos equipamentos dos laboratórios e do próprio prédio como, por exemplo, o elevador; este uso final apresenta um consumo de 14\%. Os equipamentos de escritório 
como computadores, impressoras e copiadoras representam $11,6 \%$ do consumo. $\mathrm{O}$ restante dos usos finais como refrigeração, cocção e diversão eletrônica (televisores, rádios) representam menos de $5 \%$ do consumo total do prédio no inverno.

A figura 34 apresenta os diferentes usos finais da energia durante o período do verão no prédio de Energia, é possível distinguir um importante aumento, de 6,1\%, no Condicionamento Ambiental quando comparado aos valores obtidos no inverno.

\section{Prédio de Energia IEE/USP- Verão}

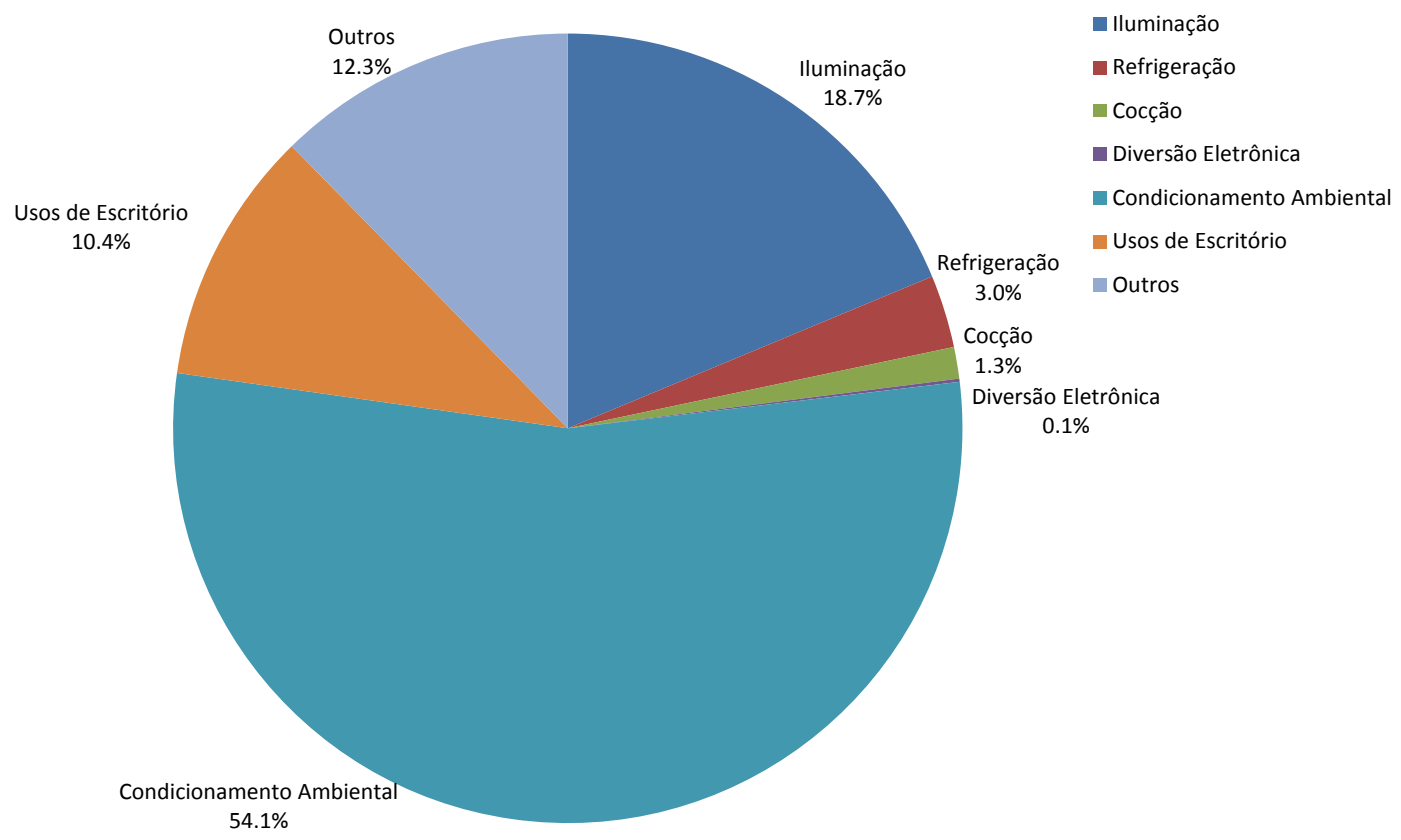

Figura 34- Usos finais da energia Prédio de Energia no Verão.

O consumo de ar condicionado para condicionamento ambiental aumenta de $48 \%$ no inverno para $54,1 \%$ no verão como foi comentado anteriormente, mostrando a importância do uso final condicionamento ambiental na edificação. Os outros usos finais permanecem relativamente similares ao inverno com a iluminação com 18,7\%, Outros (usos laboratórios e do prédio) com 12,3\%, Usos de Escritório com 10,4\% e o restante dos usos finais com um valor menor que $5 \%$ do total. 


\subsubsection{Curva de carga de consumo por uso final}

Com base na medição e nos levantamentos presenciais realizados na edificação, foi possível construir a curva de carga de consumo por uso final. As Figuras 35 e 36 apresentam as curvas para um dia comercial típico e para um dia de pouca atividade (final de semana).

As curvas obtidas são uma média estatística que busca representar o comportamento energético da instalação. Ao se tratar de uma curva média, algumas cargas importantes, como os ensaios de laboratório, são representadas na curva como valores médios e não como pico de consumo (como aparece na curva de medição real).

Devido à variabilidade do uso de energia do prédio, ocasionada por ensaios laboratoriais com cargas variáveis, foi estimado um dia típico com uma carga base entre 6 e 8 kW e uma demanda máxima entre 18 e $22 \mathrm{~kW}$ para a construção da curva.

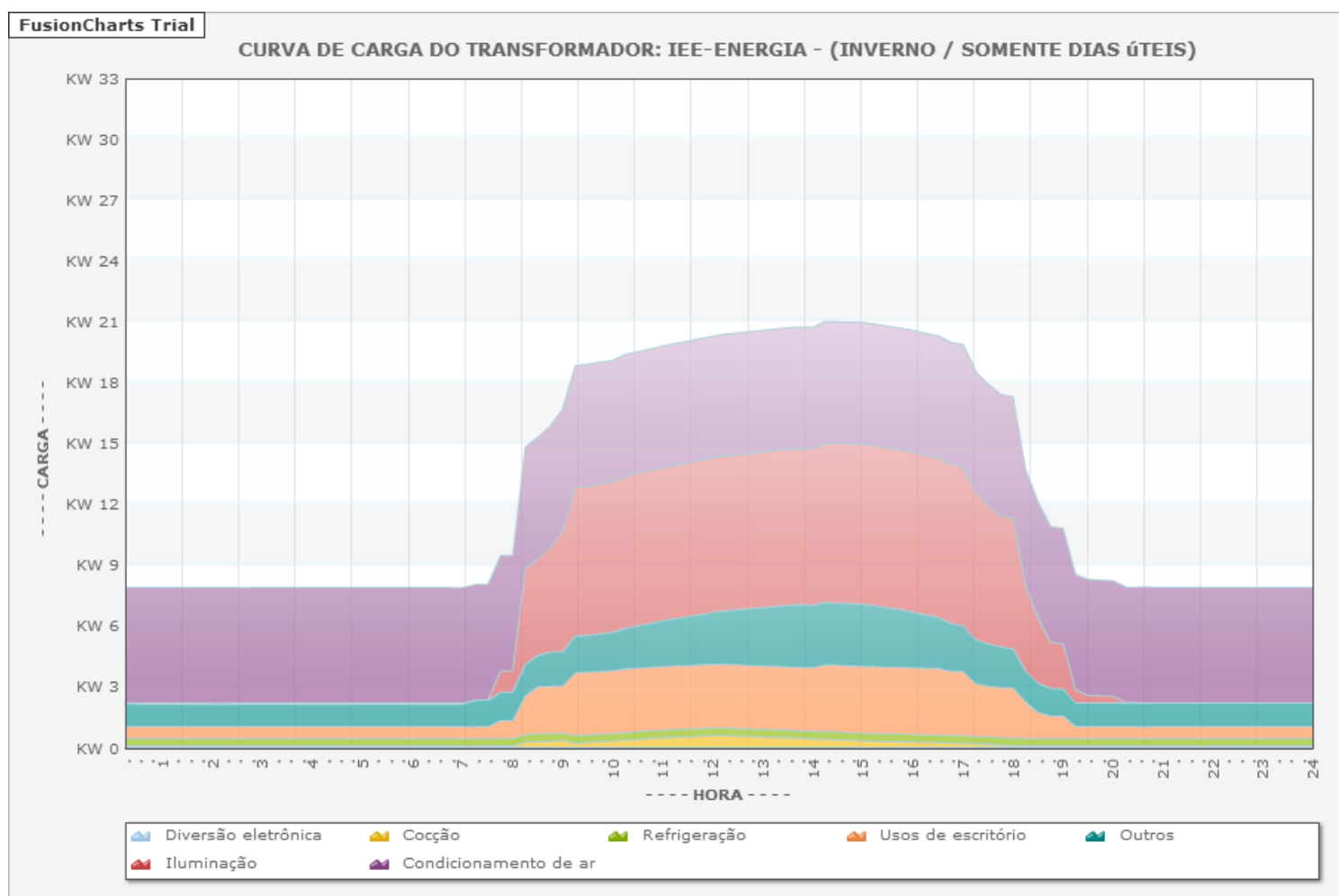

Figura 35- Curva de demanda de energia por uso final para dia típico de semana no inverno, segundo o PUFE

A curva média de um dia de trabalho apresenta uma carga base entre 6 e $8 \mathrm{~kW}$. Essa carga corresponde ao consumo permanente do ar condicionado dos laboratórios e outras cargas menores, como cargas de iluminação para ensaios de vida útil de 
lâmpadas; cargas de refrigeração e cargas de equipamentos de escritório em stand by. Conforme o dia comercial tem início, outras cargas vão se somando ao sistema, como as cargas de iluminação, de equipamentos de escritório e as cargas dos ensaios. Essas cargas somadas apresentam uma demanda máxima média de 18 a $21 \mathrm{~kW}$.

Já o final de semana apresenta características de consumo similares à carga base descrita anteriormente.

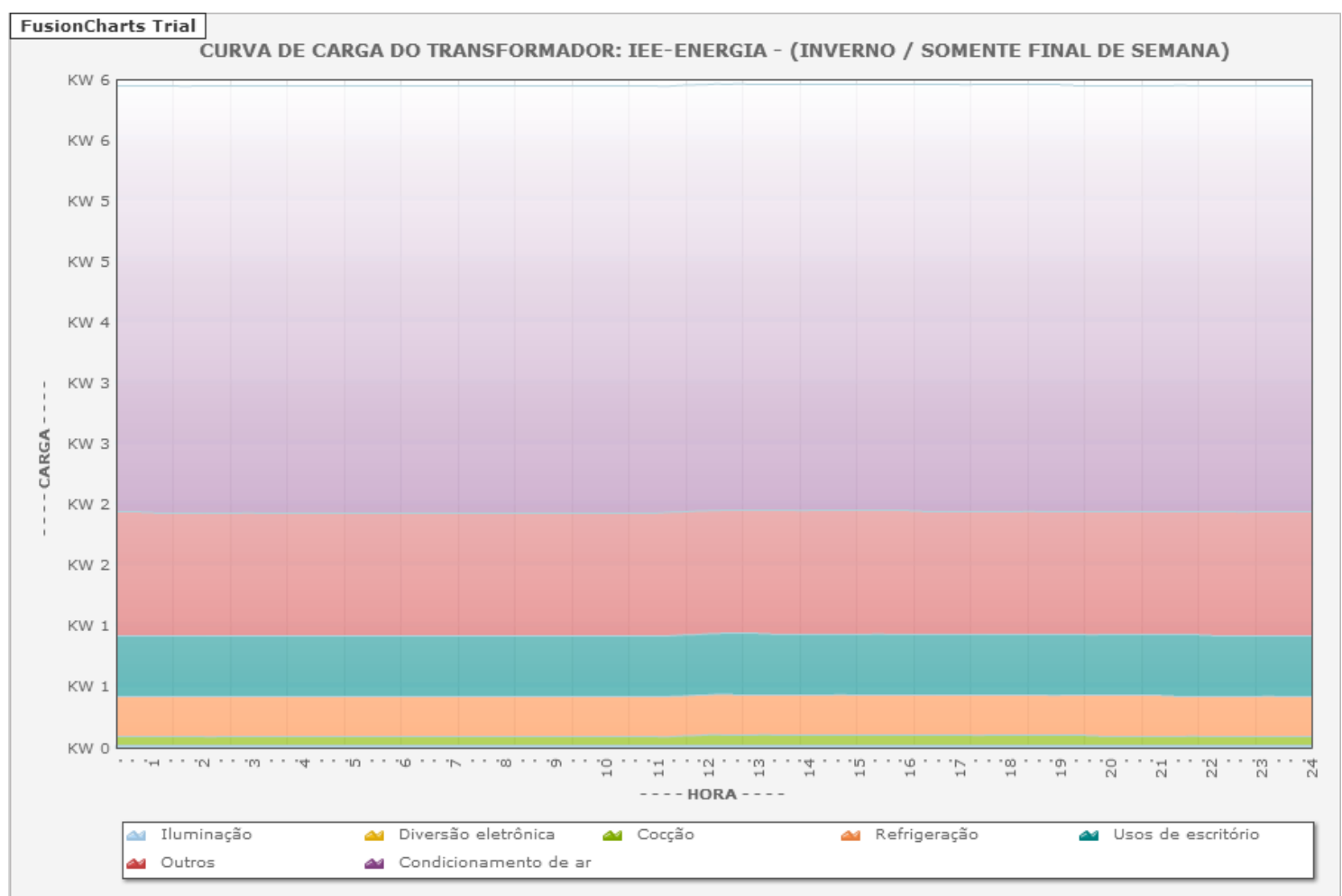

Figura 36- Curva de demanda de energia por uso final para dia típico de final de semana no inverno, segundo o PUFE

\subsubsection{Cálculos e Dados Paramétricos}

O consumo mensal total de energia, segundo a medição, foi de $8983 \mathrm{kWh} / \mathrm{mês}$ de 01/06/2013 a 30/06/2013 e segundo o PUFE foi de $8046 \mathrm{kWh} / \mathrm{mês}$. Estes dados apresentam um erro mensal de 10,4\%, o que é considerado satisfatório.

Com base nas medições e na curva de carga construída com o PUFE foi possível determinar os dados paramétricos da edificação, fundamentais para determinar os padrões de consumo. Os dados também permitiram a identificação de indicadores, que poderiam ser utilizados no futuro para avaliar a eficiência energética da edificação. Os dados para o cálculo dos indicadores são apresentados na Tabela 21. 
Tabela 21- Dados utilizados para o cálculo dos indicadores energéticos.

\begin{tabular}{lc}
\hline \multicolumn{2}{c}{ Dados para calculo dos indicadores } \\
\hline Área Total & $1657,5 \mathrm{~m} 2$ \\
Funcionários & 41 \\
Demanda Máxima Media & $22,17 \mathrm{~kW} \quad \sigma=3,12$ \\
Consumo Energia Mensal Medido & $8983 \mathrm{kWh} / \mathrm{mês}$ \\
Consumo Energia Inverno (PUFE) & $8046 \mathrm{kWh} / \mathrm{mês}$ \\
Consumo Energia Verão (PUFE) & $9137 \mathrm{kWh} / \mathrm{mês}$ \\
Consumo Ar Condicionado no Inverno & $3099,5 \mathrm{kWh} / \mathrm{mês}$ \\
Consumo Ar Condicionado no Verão & $4077,5 \mathrm{kWh} / \mathrm{mês}$ \\
Demanda de Potencia para Iluminação & $12,36 \mathrm{~kW}$ \\
\hline
\end{tabular}

Com base nos dados acima foi possível determinar a intensidade energética e a demanda máxima mensal da edificação. Os indicadores foram divididos em três tipos: Indicadores baseados na medição (Tabela 22); Indicadores baseados no PUFE (Tabela 23) e Outros Indicadores Energéticos que poderiam ser de utilidade (Tabela 24).

Tabela 22- Indicadores Energéticos baseados na medição.

\begin{tabular}{lc}
\hline \multicolumn{2}{c}{ Indicadores Energéticos ( Medição) } \\
\hline Intensidade Energética por Área & $5,32 \mathrm{kWh} / \mathrm{m} 2$ \\
Intensidade Energética por Funcionário & $219,1 \mathrm{kWh} / \mathrm{funcionário}$ \\
Demanda Máxima Mensal por Área & $13 \mathrm{~W} / \mathrm{m} 2$ \\
Demanda Máxima Mensal por Funcionário & $540 \mathrm{~W} / \mathrm{m} 2$ \\
\hline
\end{tabular}

Tabela 23- Indicadores Energéticos baseados no PUFE.

\begin{tabular}{lc}
\hline \multicolumn{2}{c}{ Indicadores Energéticos (PUFE) } \\
\hline Intensidade Energética por Área (Inverno) & $4,76 \mathrm{kWh} / \mathrm{m} 2$ \\
Intensidade Energética por Funcionário (Inverno) & $196 \mathrm{kWh} / \mathrm{funcionário}$ \\
Intensidade Energética por Área (Verão) & $5,41 \mathrm{kWh} / \mathrm{m} 2$ \\
Intensidade Energética por Funcionário (Verão ) & $222,8 \mathrm{kWh} /$ funcionário \\
\hline
\end{tabular}

Tabela 24- Outros Indicadores Energéticos.

\begin{tabular}{lc}
\hline \multicolumn{2}{c}{ Outros Indicadores Energéticos } \\
\hline Densidade de Energia do Ar Condicionado (Inverno) & $1,87 \mathrm{kWh} / \mathrm{m} 2$ \\
Densidade de Energia do Ar Condicionado (Verão) & $2,47 \mathrm{kWh} / \mathrm{m} 2$ \\
Densidade de Potência de Iluminação & $7,76 \mathrm{~W} / \mathrm{m} 2$ \\
Consumo dos Equipamentos Laboratório por Área Lab & $0,41 \mathrm{kWh} / \mathrm{m} 2$ \\
Consumo Ar Condicionado Laboratório por Área Lab & $5,56 \mathrm{kWh} / \mathrm{m} 2$ \\
\hline
\end{tabular}




\subsubsection{Dificuldades Encontradas}

O levantamento das cargas de ar condicionado foi dificultada graças a falta de centralização da documentação necessária. Havia muitos aparelhos de ar condicionado de parede e dois aparelhos de grande porte: um que abastece os laboratórios do térreo e outro que abastece o laboratório de fotometria no primeiro andar. Isto se deve ao fato de que em sua concepção inicial não haveria laboratórios nos andares superiores deste prédio. O ar-condicionado que abastece os laboratórios do térreo fica no sótão e permanece ligado continuamente devido a necessidade de manter a temperatura e umidade dentro de uma faixa controlada e a pilha padrão condicionada. A princípio não era conhecido se este ar estava ligado continuamente, pois o mesmo havia acabado de passar por manutenção, segundo nos foi informado. Porém foi descoberto, analisando a curva (uma potência constante de 5-10 kW ligada continuamente), que este ar já estava ligado de forma contínua.

Outra dificuldade desse edifício foi determinar a rotina de trabalho já que para os laboratórios, as cargas entram aleatoriamente ao longo do tempo de acordo com a demanda de ensaios e os tipos de corpo-de-prova. As salas dos professores no segundo andar também possuem um comportamento aleatório devido a rotina de trabalho dos mesmos.

Outro problema encontrado foi os levantamentos de cargas, que foram anotadas em períodos do dia em que estavam desligadas, sendo então necessário reavaliar a carga inclusive fazendo revisões do levantamento. Mesmo nas áreas de escritório em que a rotina era mais definida, os horários de chegada e saída do pessoal precisaram ser ajustados com precisão de minutos para apresentar um diagnóstico mais real da situação.

\subsubsection{Proposta de cenários de conservação de energia ou melhoria da iluminação}

O consumo de energia para o sistema de iluminação no prédio de Energia do IEE, representa, dependendo da estação climática, entre 18,7 e 21,3\% do consumo total do prédio. O indicador de Densidade de Potência de Iluminação, para o prédio completo, tem um valor de $7,76 \mathrm{~W} / \mathrm{m}^{2}$, o qual é baixo comparado com o de $10,9 \mathrm{~W} / \mathrm{m}^{2}$ recomendado; porém realizando uma avaliação sala por sala (Tabela 18) é possível 
notar como muitas áreas da edificação possuem DPI maior que o recomendado pelo ASHRAE e níveis de iluminância baixos.

Estes fatos permitem definir como uma das principais propostas de conservação de energia para este prédio a melhoria do sistema de iluminação, através de um retrofit do sistema atual, que utiliza luminárias $\mathrm{T} 8 / 32 \mathrm{~W}$, por outras tecnologias de menor consumo energético como T5/28W e LED/22W. Esta proposta foi avaliada do ponto de vista da redução do consumo de energia e dos efeitos luminotécnicos.

Considerando o alto consumo de energia para condicionamento ambiental devido ao uso de ar condicionado nos laboratórios, uma proposta de conservação de energia alternativa seria a troca do chiller existente de 10 TR para os laboratórios do terreo por um de maior eficiência e que consiga atender as necessidades térmicas de todos os laboratórios.

\subsubsection{Substituição do sistema de iluminação atual}

A substituição do sistema de iluminação atual por tecnologias de menor consumo energético T5 e LED foram primeiro simuladas no software Dialux, a fim de se conhecer o comportamento luminotécnico que o sistema teria com as novas tecnologias comentadas. Para a simulação foram utilizadas lâmpadas T5 de 28 W(2900 lúmenes) e lâmpadas tubulares LED de 22 W (1900 lúmenes). Os reatores das lâmpadas não foram considerados nas simulações.

As áreas selecionadas foram aquelas que mostraram valores de iluminância baixos na etapa de medições. $\mathrm{O}$ fator de manutenção, para considerar a depreciação do fluxo luminoso e sujeira nas lâmpadas, foi de 0,8 . As refletividades utilizadas foram: Teto $80 \%$, Paredes $50 \%$, chão $20 \%$.

Para o prédio de Energia as áreas selecionadas são as salas dos professores (uma das salas) e a secretaria do PPGE. Para isso, as características físicas das salas são reproduzidas em um modelo computacional com o software Dialux. A figura 37 apresenta os modelos computacionais comentados. 


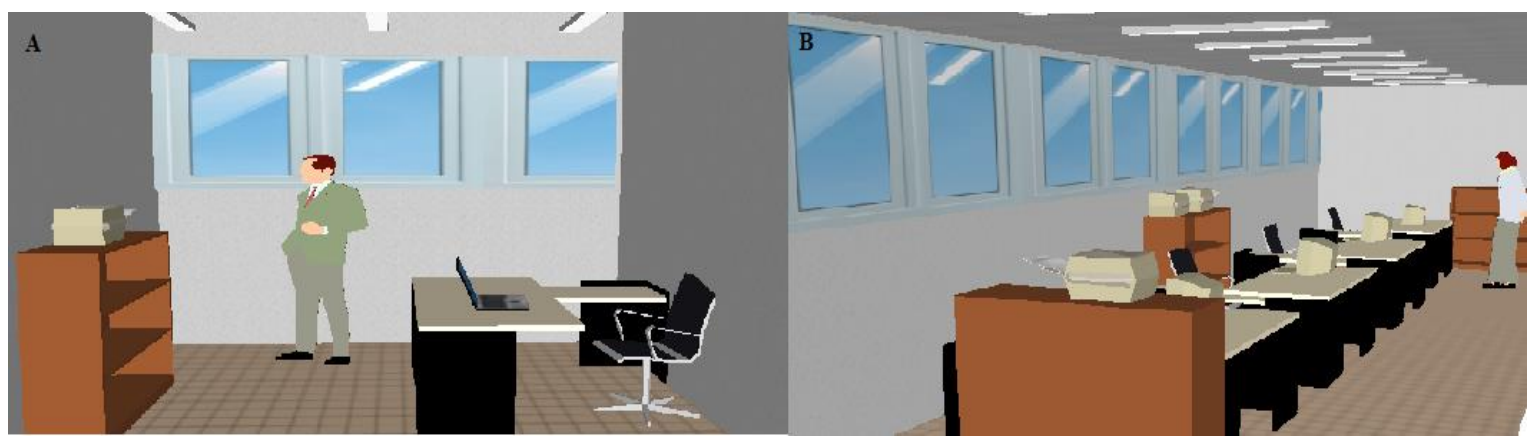

Figura 37- Modelo Computacional Sala Professor 1 (A) Modelo Computacional Secretaria PPGE (B).

Os resultados das simulações das selecionadas são apresentados na Tabela 25.

Tabela 25- Simulações no Dialux para salas representativas do Prédio Energia.

\begin{tabular}{ccccccc}
\hline & \multicolumn{3}{c}{ SECRETARIA PPGE } & \multicolumn{2}{c}{ SALA PROFESSOR 1 } \\
\hline & Existente & T5 & LED & Existente & T5 & LED \\
Área (m2) & 36.00 & 36.00 & 36.00 & 12.00 & 12.00 & 12.00 \\
Iluminância media (Lux) & 294 & 503 & 358 & 286 & 434 & 283 \\
Potência Iluminação (W) & 640 & 504 & 396 & 192 & 168 & 132 \\
DPI (W/m2) & 17.78 & 14.00 & 11.00 & 16.00 & 14.00 & 11.00 \\
NPD (W/m2•100lux) & 6.05 & 2.78 & 3.07 & 5.59 & 3.23 & 3.89 \\
Fluxo Luminoso Útil (klm) & 10.58 & 18.11 & 12.89 & 3.43 & 5.21 & 3.40 \\
\hline
\end{tabular}

Os resultados mostram como nas duas salas estudadas neste prédio os sistemas tubular LED apresentam a menor DPI e, portanto, o menor consumo energético; contudo ao considerar as qualidades luminotécnicas dos sistemas, a tecnologia T5 com o menor NPD representaria a opção com o melhor balanço entre eficiência energética e qualidade da iluminação. Além disso, as simulações mostram que com a utilização da tecnologia T5, a iluminância média atingiria o valor preconizado pela norma brasileira NBR 5413 na secretaria PPGE e ficaria perto no caso da sala de professores. Já com a tecnologia LED ficaria abaixo dos limites da norma.

Como no caso do prédio da administração, uma solução tecnicamente viável seria a utilização de Task Lighting. Desta forma, cada funcionário ao realizar suas tarefas poderia ligar a luminária tipo Task Lighting, conseguindo a iluminação desejada para seu conforto visual. 


\subsubsection{Avaliação Econômica}

Usando várias figuras de mérito, foi realizada uma análise de economia de energia para determinar se a substituição da distribuição atual de luminárias com sistemas T8 por sistemas de tecnologia T5 e LED seria economicamente viável.

Para esta análise foram consideradas a totalidade das luminárias do prédio; um tempo de analise de 10 anos; um uso diário médio de 5,7 horas; uma taxa de desconto de 12\%; o custo unitário da energia elétrica utilizado foi de USD 0.099/kWh (Custo Médio Mensal Energia Elétrica Campus USP Capital); um tempo de vida das lâmpadas de 20000h para a T8, 30000h para o sistema T5, e de 40000h para o sistema LED.

Os custos referentes às lâmpadas, reatores e mão de obra para a execução dos projetos de troca de tecnologia de iluminação são apresentados na seguinte tabela.

Tabela 26- Custos Equipamentos e Mão de Obra.

\begin{tabular}{cccc}
\hline & T8 & T5 & LED \\
\hline Custo Lâmpadas (USD) & 888 & 1732 & 17760 \\
Custo Reatores (USD) & 1988 & 2664 & 0 \\
Custo Mão de Obra (USD) & 1221 & 1998 & 1776 \\
Custo Total (USD) & $\mathbf{4 0 9 7}$ & $\mathbf{6 3 9 4}$ & $\mathbf{1 9 5 3 6}$ \\
\hline
\end{tabular}

Com os valores comentados anteriormente e os custos da Tabela 26 as figuras de mérito de viabilidade financeira foram calculados. Os resultados são amostrados na tabela 27.

Tabela 27- Avaliação econômica da sustituição das lâmpadas atuais por lâmpadas da tecnologia T5 e LED.

\begin{tabular}{ccc}
\hline & Retrofit A (Atual vrs T5) & Retrofit B (Atual vrs LED) \\
\hline Economia de Energia Anual (kWh) & 4268 & 8532 \\
Payback Simple (Anos) & 14,9 & 22,8 \\
TIR (\%) & 12 & 2 \\
LCC (USD) & 13233,3 & 15274,8 \\
ALCC (USD) & 2342,1 & 2703,4 \\
CEC ( USD/kWh) & 0,03 & 1 \\
\hline
\end{tabular}

Fazendo uma avaliação considerando a totalidade das figuras de mérito estudadas, o projeto Retrofit A não apresenta claramente viabilidade econômica por ter um payback alto e tem um TIR muito próximo da taxa de desconto (12\%), mas por outro lado o custo da energia conservada é menor que o custo da tarifa elétrica por tanto teria viabilidade. É importante mencionar que o custo da energia elétrica utilizado possui um valor consideravelmente menor do que a tarifa para um cliente comercial com caraterísticas similares, portanto os resultados são influenciados por esse fato. 
Por tanto, os fatores que influenciaram este resultado foram: pouco uso médio diário (5,7 horas) e custo de energia elétrica baixo, devido a compra em média tensão realizada pela USP.

$\mathrm{O}$ restante das figuras de mérito calculadas permitiram ainda comparar economicamente os dois retrofit e, portanto, as duas tecnologias. Neste caso, o Retrofit A (Atual vrs T5) apresenta as melhores condições ao ter o menor LCC (USD 13233,3), ALCC (USD 2342,1) e CEC (0,03 USD/kWh). 


\subsection{Prédio de Laboratórios ("Fazendinha") - Instituto Energia e Ambiente}

\subsubsection{Descrição Arquitetônica}

O Laboratório de Conservação de Energia do Instituto de Energia e Ambiente (IEE) da Universidade de São Paulo (USP) consiste em um edifício térreo localizado a sudoeste do Instituto, em frente a Divisão de Materiais, como mostra a Figura 38.

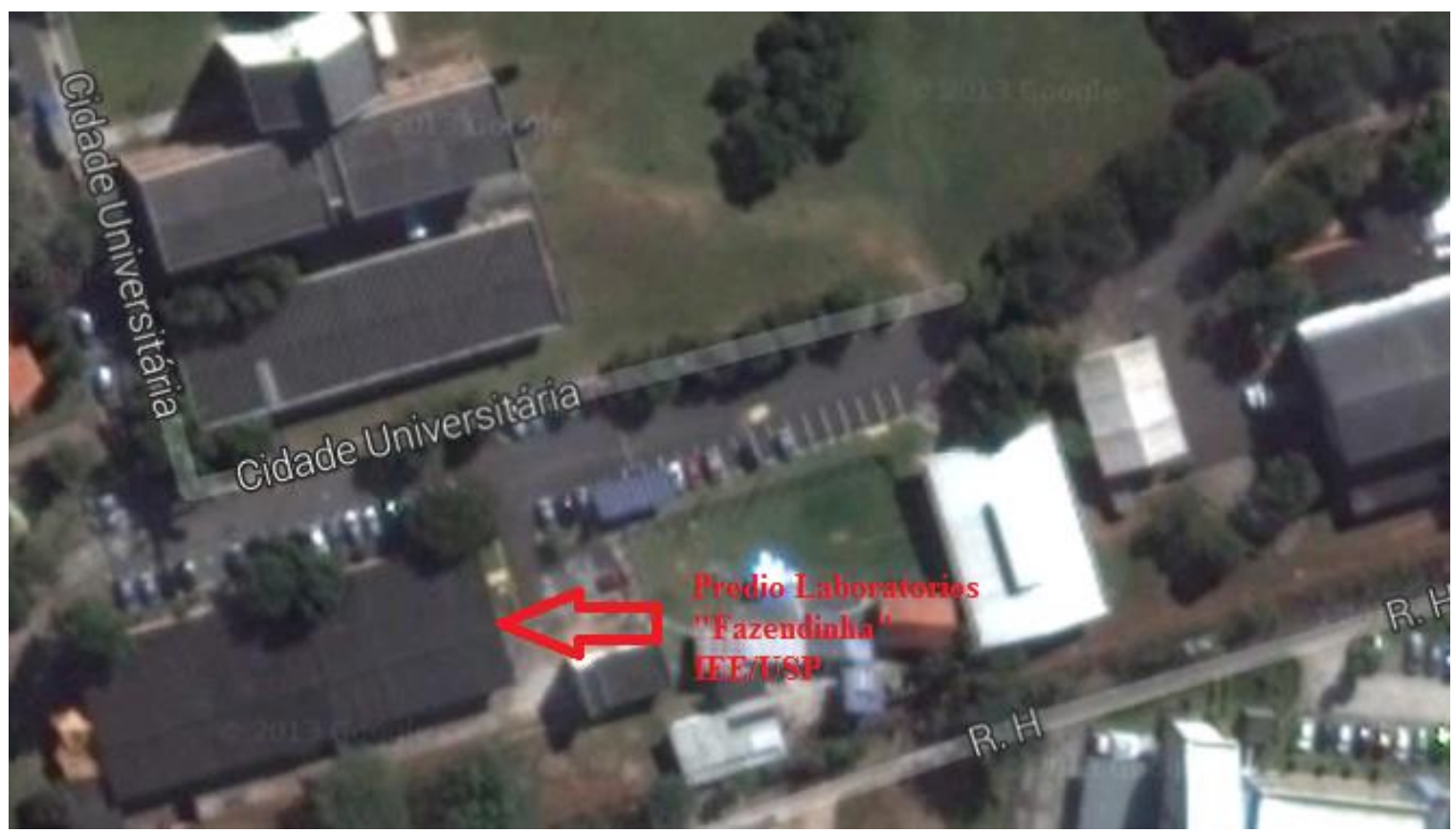

Figura 38- Posicionamento do Prédio do Laboratório de Conservação de Energia do IEE.

Originalmente construído com 23 ambientes para salas, laboratórios e apoio administrativo, mais uma copa e dois sanitários, atualmente o edifício encontra-se redividido em 46 ambientes, com o uso de divisórias em PVC. Sua área total permanece a mesma: $980 \mathrm{~m}^{2}$.

Também chamado no Instituto pelo nome de "Fazendinha", o edifício é organizado de acordo com os usos mostrados na Tabela 28. 


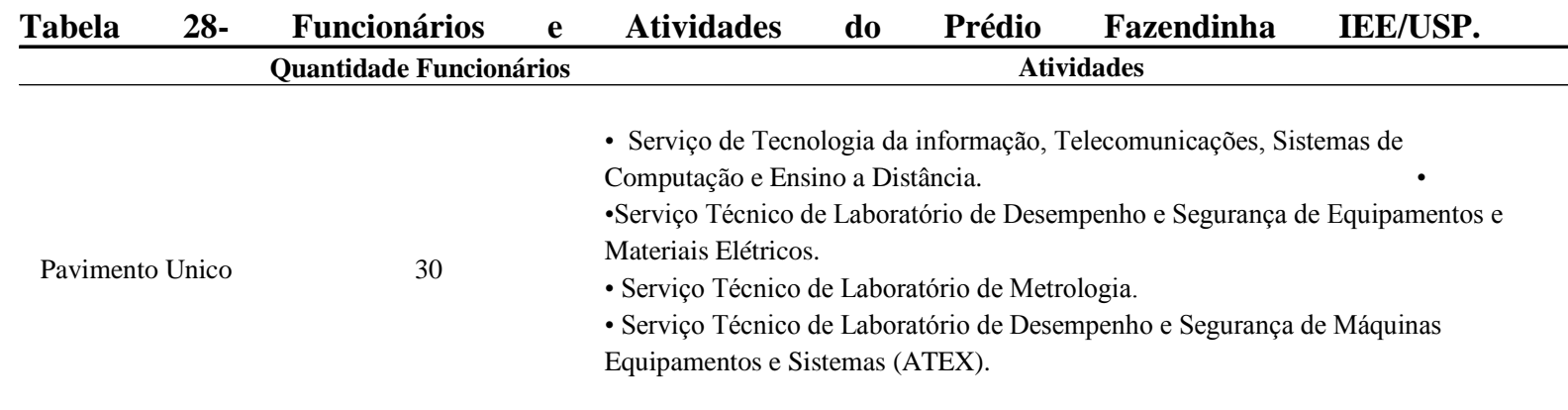

A edificação com estrutura em concreto armado foi organizada de forma modular através de conjuntos de quatro pilares com viga apoiada, gerando dois vãos laterais de $7,20 \mathrm{~m}$ e um vão central de $3,60 \mathrm{~m}$. Cada conjunto é justaposto longitudinalmente com uma distância de 7,20m, gerando uma malha.

Com $4,15 \mathrm{~m}$ de pé direito estrutural, utilizou-se um sistema de forro de poliestireno expandido (EPS) para configurar um pé direito útil de 3,30m nos ambientes e 3,15m na circulação. Com esta solução, obteve-se camadas de ar entre a laje e o forro, variando entre 65 e $80 \mathrm{~cm}$. Acima da laje, uma cobertura de telhas de fibrocimento em duas águas com inclinação de 5,5\% configuram uma segunda camada de ar de 31 a $80 \mathrm{~cm}$ de espessura.

As salas são distribuídas ao longo de um corredor central no sentido longitudinal do edifício. Várias adaptações foram feitas para compor salas maiores ou menores, com o uso de divisórias de PVC, produzindo ambientes sem possibilidade de ventilação e iluminação natural. As paredes contam com pintura fosca clara e os ambientes possuem piso vinílico na cor preta.

Com a inexistência de mecanismos de proteção solar, a fachada principal, orientada para noroeste, apresenta elevado nível de insolação durante o día. Como resultado disso observa-se uma larga utilização de persianas/cortinas e ar-condicionado nas salas com esta orientação (como mostra a Figura 39). Ao longo de todo o comprimento destas fachadas encontram-se janelas de esquadria de ferro e vidro transparente simples que cobrem aproximadamente $40 \%$ da área das fachadas.

A Figura 39 apresenta algumas fotos da edificação que revelam os detalhes citados acima. 


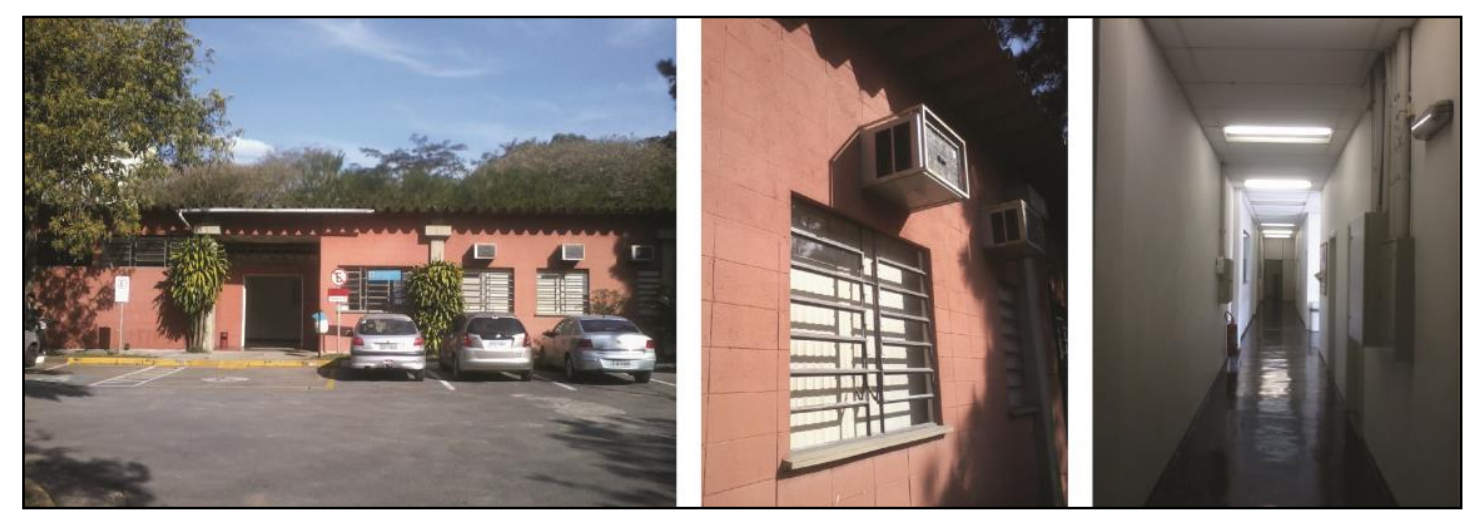

Figura 39- Imagens do exterior e do interior do Prédio Fazendinha IEE/USP.

\subsubsection{Descrição Geral dos Sistemas Energéticos}

\subsubsection{Condicionamento Ambiental}

A edificação possui sistemas de ar condicionado nas suas principais áreas, nos laboratórios e áreas de escritório; os equipamentos são principalmente de janela e em alguns casos tipo split e o uso ocorre principalmente no verão, durante o horário comercial do escritório das $7 \mathrm{~h}$ às $17 \mathrm{~h}$. A edificação possui uma pequena central de computadores conhecida como CPD que apresenta uso constante de ar condicionado durante $24 \mathrm{~h}$, todos os dias do ano. O condicionamento ambiental nessa área é fundamental para dissipar o calor gerado pelos servidores, switchs e computadores.

\subsubsection{Iluminação}

O sistema de iluminação é composto majoritariamente por luminárias com 4 lâmpadas T12 de 40 W e em menor quantidade luminárias de 2 lâmpadas T8 de 32 W. $\mathrm{Na}$ maioria dos casos as luminárias não possuem refletores, gerando um desperdício do fluxo luminoso. A iluminação é mantida ligada no período de atividade da edificação, principalmente entre as $7 \mathrm{~h}$ e $18 \mathrm{~h}$, de forma variável.

No quadro elétrico do edifício também estão ligados os postes de iluminação da área externa do Instituto. Estes postes contam com relés fotoelétricos que ligam à iluminação ao anoitecer. Existem 5 postes com lâmpadas de iluminação pública de aproximadamente $300 \mathrm{~W}$. 


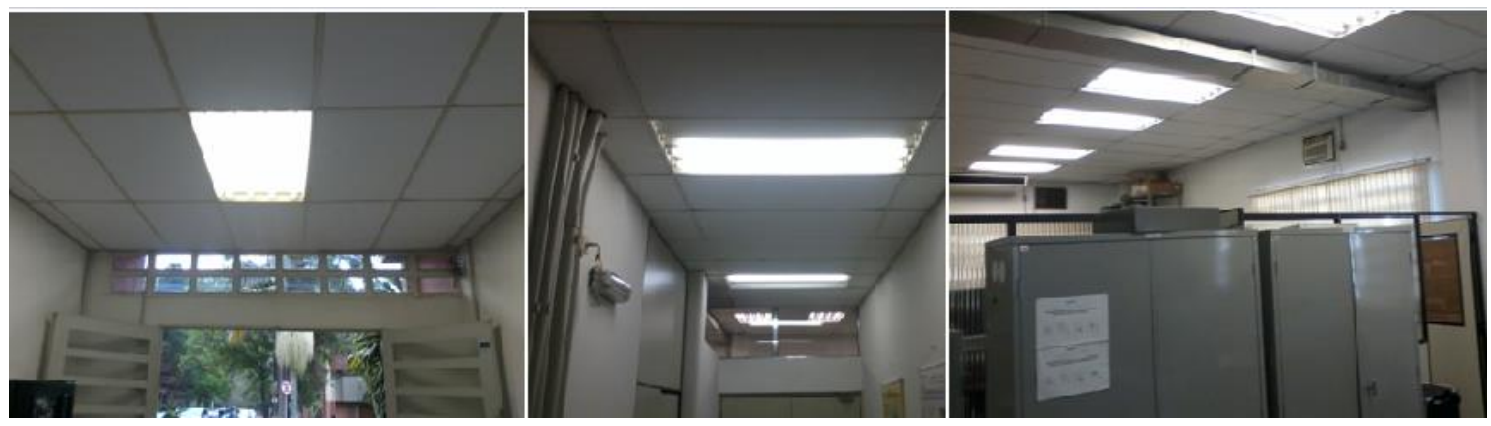

Figura 40- Fotos do sistema de iluminação do Prédio "Fazendinha" do IEE.

\subsubsection{Outras Cargas}

O prédio da "Fazendinha" possui outras importantes cargas a se considerar, sobretudo de equipamentos de escritório e rede, e propriamente os testes realizados nos laboratórios técnicos.

Considerou-se como equipamentos de escritório os computadores, impressoras, copiadoras e outros equipamentos próprios dos labores dos funcionários. Estes equipamentos possuem um período de atividade similar ao da edificação, principalmente das $7 \mathrm{~h}$ às $18 \mathrm{~h}$; com exceção dos equipamentos do centro de computação CPD.

O CPD possui cargas de servidores, switches e computadores que administram a rede computacional do IEE/USP. Estas cargas operam 24 horas por dia e são fornecidas eletricamente por diferentes No-Breaks.

\subsubsection{Medições}

\subsubsection{Medições Energia}

As medições das variáveis elétricas foram feitas entre os dias 07 de junho e 17 de julho de 2013. As medições permitiram observar o comportamento energético do prédio e validar o modelo criado no software de usos finais - PUFE.

A Figura 41 apresenta os dados completos obtidos nas medições nestas datas, enquanto as Figuras 42 e 43 apresentam as medições de um dia comercial típico, e as medições de um dia de final de semana, quando a ocupação do prédio é mínima. 
Na Figura 41 pode se observar que existe uma variação na potência ativa do Prédio da "Fazendinha", que apresenta cargas variáveis entre os diferentes finais de semana e também entre as diferentes semanas do mês. Ainda assim é possível identificar que a carga base da edificação varia entre 5 e $10 \mathrm{~kW}$.

Esta variabilidade no consumo depende do regime dos testes de laboratório na edificação e das atividades externas dos funcionários destas dependências que regularmente realizam atividades externas ao IEE diminuindo assim o consumo do prédio.

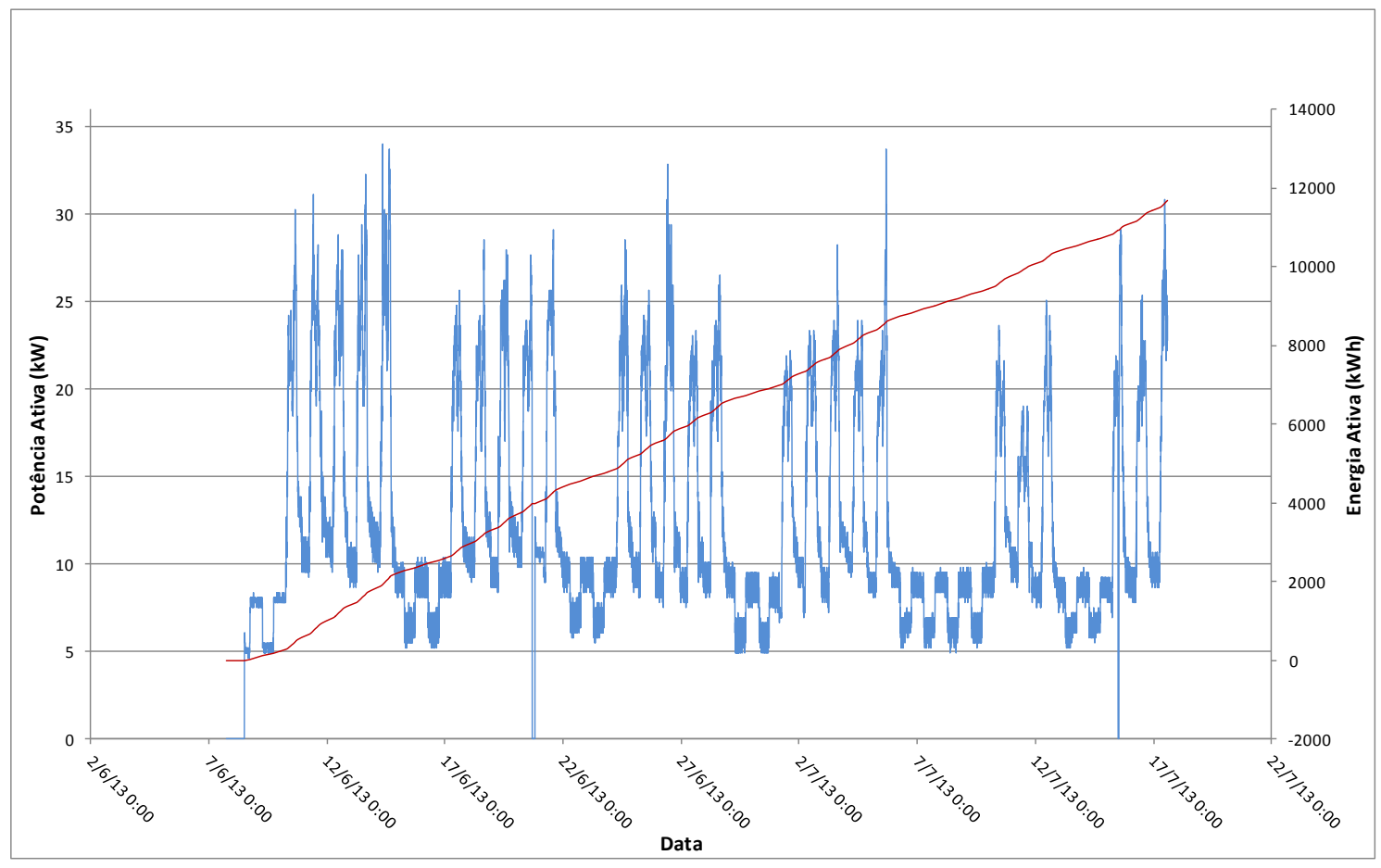

Figura 41- Medição da potência ativa entre 7 de junho e 17 de julho.

Em um dia típico de trabalho, demonstrado na Figura 42, o início das atividades se dá a partir das $6 \mathrm{~h}$, com um pico de consumo de $20 \mathrm{~kW}$ e uma queda de potência por volta do meio dia, usual pela hora de almoço dos funcionários. A partir das $17 \mathrm{~h}$ o consumo de energia começa a diminuir até atingir a carga base por volta das $21 \mathrm{~h}$. 


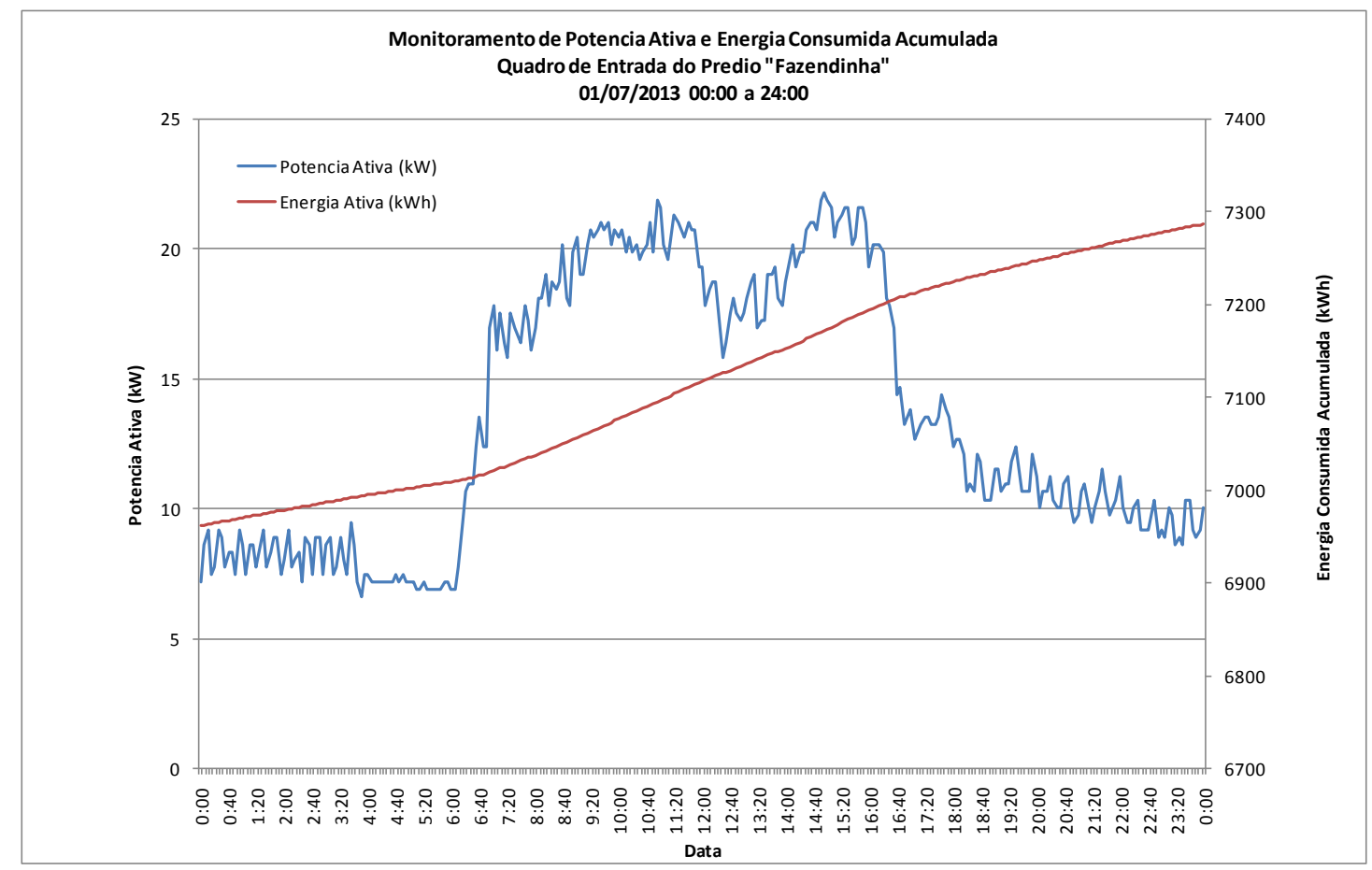

Figura 42- Medição da potência ativa e energia dia típico da semana em horário comercial.

Durante um dia de final de semana (Figura 43) nota-se uma carga base constante de $6 \mathrm{~kW}$, composta principalmente por cargas de refrigeração, ar condicionado, equipamentos do CPD e consumo stand by de equipamentos de escritório. A carga aumenta durante a noite por causa da iluminação exterior.

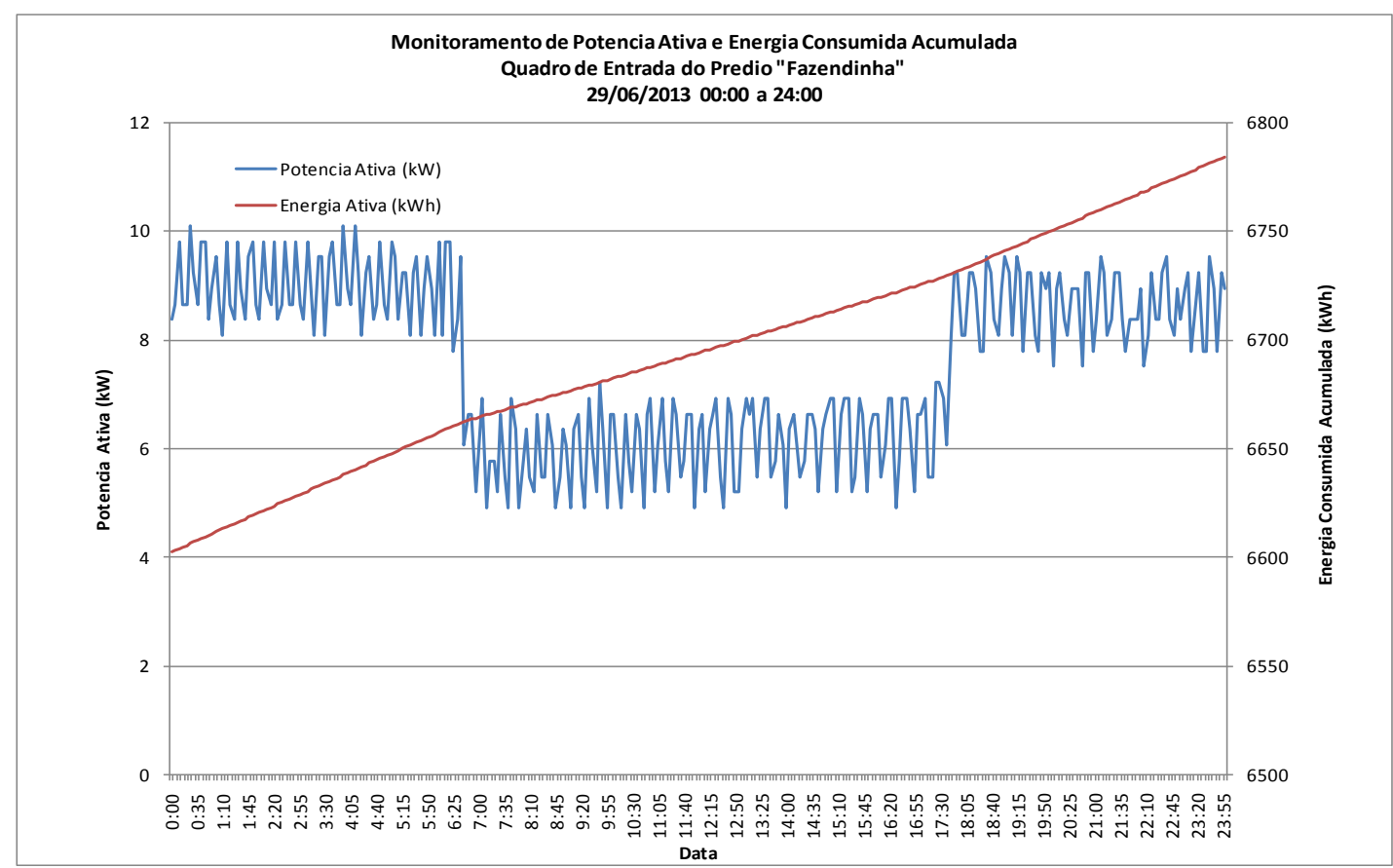

Figura 43- Medição da potência ativa e energia de um dia típico de final de semana. 
Como dito anteriormente, a edificação conta com uma central de computadores que, apesar de pequena, representa um consumo importante no comportamento energético do prédio da "Fazendinha". Para avaliar a carga da central de forma mais minuciosa, foram realizadas medições no CPD entre os dias 08 e 16 de agosto de 2013. As mesmas são amostradas na Figura 44.

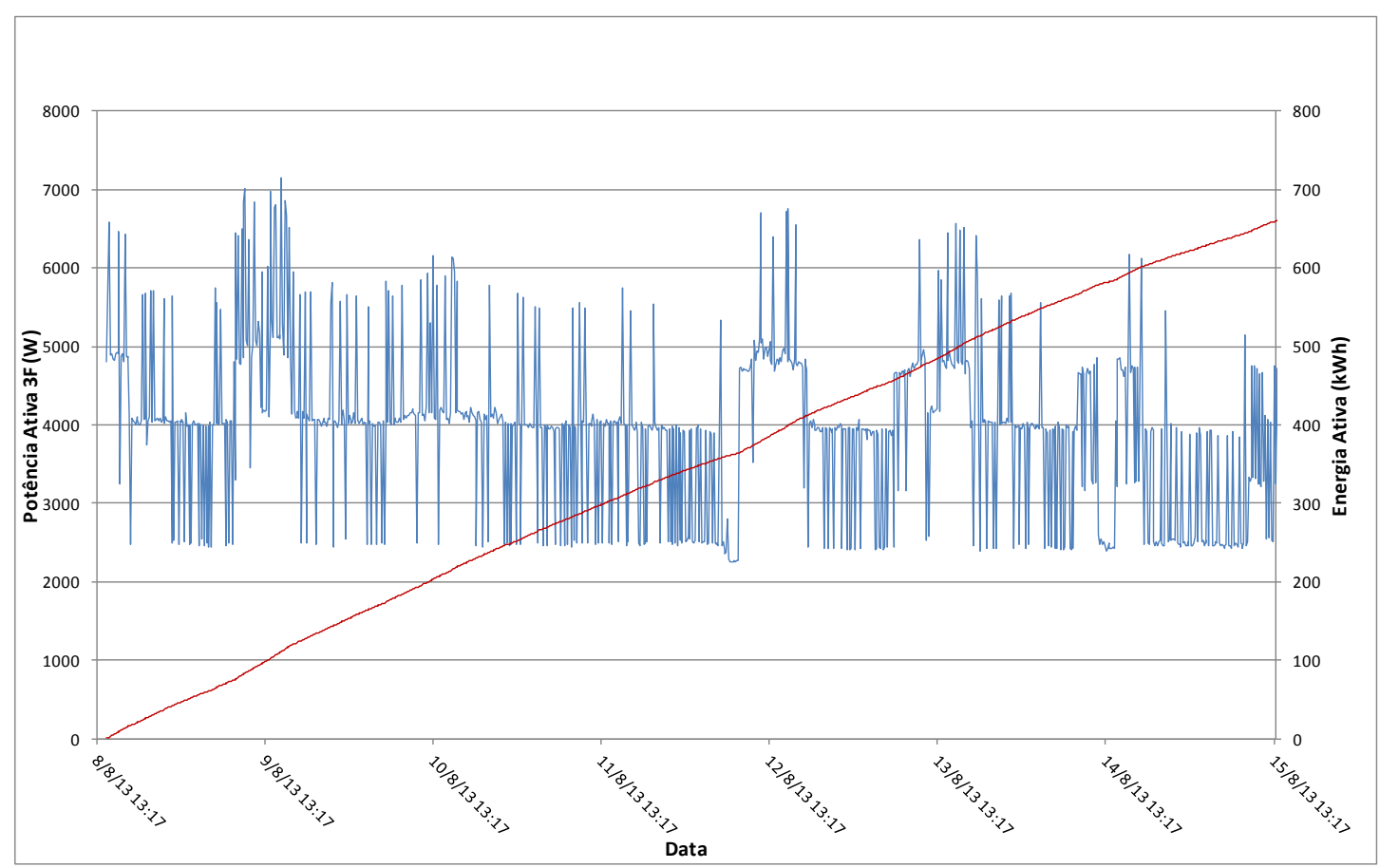

Figura 44- Medição da potência ativa e energia no CPD entre os dias 08 e 16 de agosto de 2013.

A Figura 45 mostra a medição para um dia da semana. Na mesma pode se apreciar uma carga base de $4 \mathrm{~kW}$, que sobe para $5 \mathrm{~kW}$ nos dias de trabalho, uma vez que os servidores são mais requisitados. 


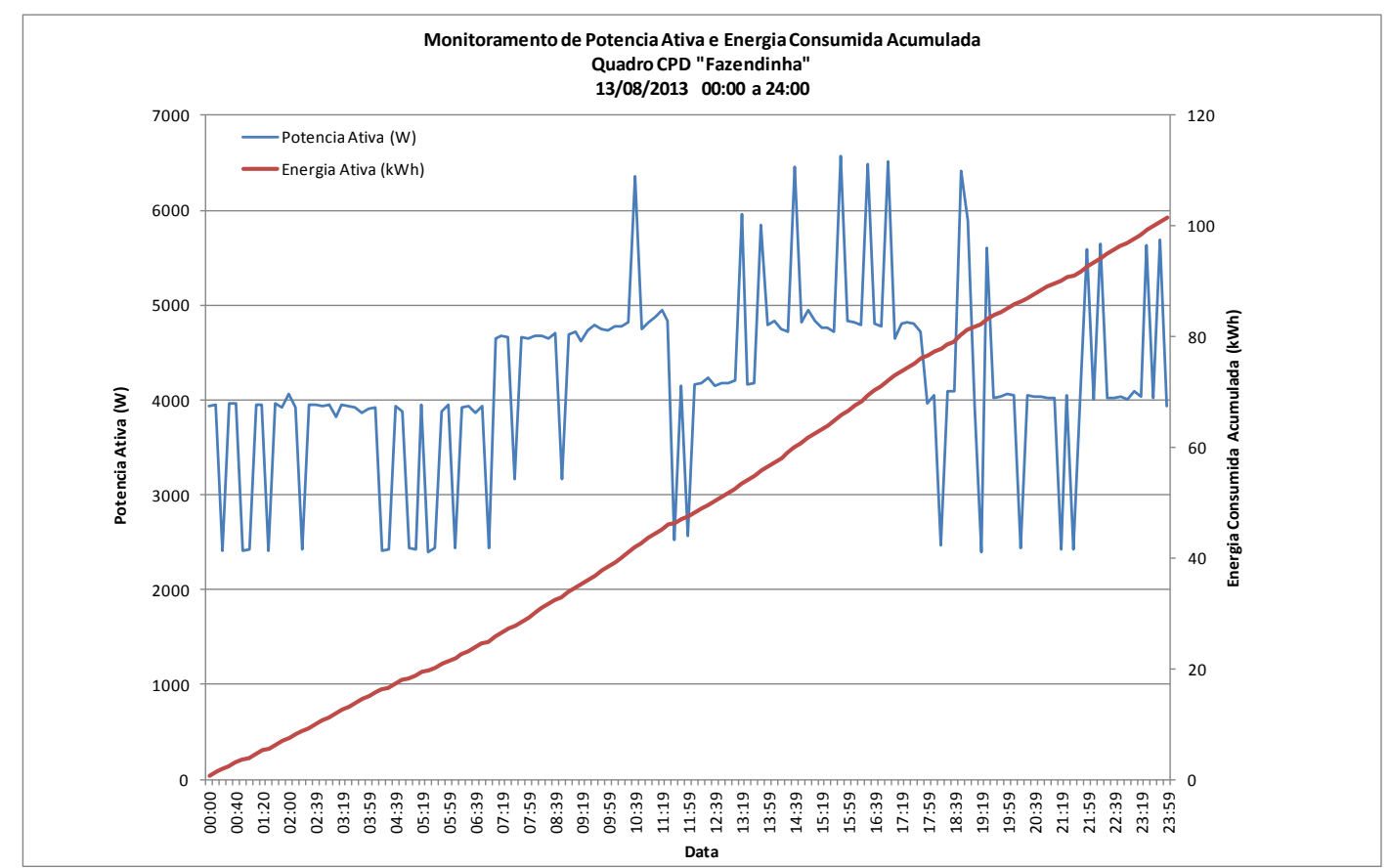

Figura 45- Medição da potência ativa e energia de um dia típico entre semana no CPD.

Nos dias de final de semana a carga é constante entre 3 e $4 \mathrm{~kW}$ sem variações significativas, com exceção das entradas do ar condicionado durante o dia.

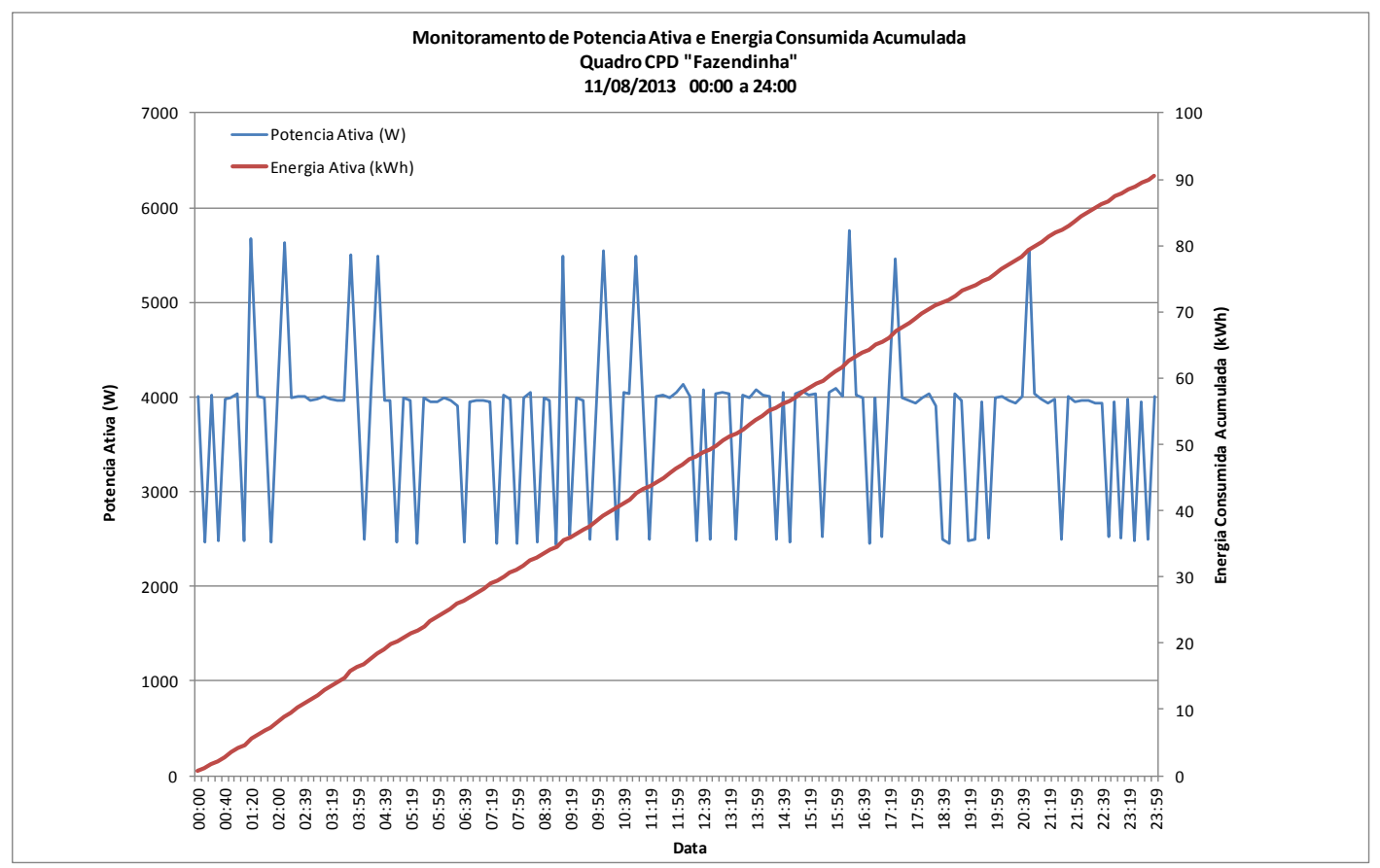

Figura 46- Medição da potência ativa e energia de um dia típico final de semana no CPD. 


\subsubsection{Medições Iluminação}

As medições de iluminância das diferentes áreas do prédio fazendinha foram feitas baseadas na norma NBR 5382: Verificação de Iluminância de Interiores. As mesmas forem realizadas no dia 18 de julho de 2013 pela tarde, com as luminárias ligadas e desligadas, a fim de avaliar o efeito da iluminação natural na iluminância média, e também a iluminância própria do sistema de iluminação artificial. Na tabela 29 encontram-se os valores de iluminância média total das áreas selecionadas e a participação da iluminação natural no total.

Tabela 29- Medições de Iluminância Média e efeito da iluminacao natural no total.

\begin{tabular}{cccc}
\hline & $\begin{array}{c}\text { Iluminância } \\
\text { Media Total } \\
\text { (Lux) }\end{array}$ & $\begin{array}{c}\text { Iluminância } \\
\text { Media Natural } \\
(\text { Lux })\end{array}$ & $\begin{array}{c}\text { \% Iluminância } \\
\text { Natural do } \\
\text { Total }\end{array}$ \\
\hline ESCRITORIO APOIO TECNICO & & & \\
RECEPÇÃO & 977 & 387 & $39.6 \%$ \\
CPD & 1480 & 1098 & $74.2 \%$ \\
LABORATORIO & 514 & 0 & $0.0 \%$ \\
& 474 & 72 & $15.2 \%$ \\
\hline
\end{tabular}

A iluminação natural apresenta uma importante participação nas áreas estudadas. A Recepção possui uma alta iluminação natural, o que permite que praticamente não haja a necessidade de iluminação artificial durante o dia; o Escritório de Apoio Técnico conta com 39,6\% de participação da iluminação natural no total, apontando uma oportunidade de minimizar o consumo de iluminação artificial. O Laboratório também possui um importante componente, de $15 \%$, de iluminação natural que pode ser aproveitado.

Os valores de iluminância média, sem considerar iluminação natural, e a potência de iluminação das diferentes áreas estudadas foi comparada com os valores recomendados nas normas de iluminação e eficiência energética para edificações. Os resultados são mostrados na Tabela 30 .

Tabela 30- Comparação valores existentes com os requeridos nas normas .

\begin{tabular}{|c|c|c|c|c|c|c|c|}
\hline & Área (m2) & $\begin{array}{l}\text { Iluminância } \\
\text { media (Lux) }\end{array}$ & $\begin{array}{c}\text { Iluminância Norma } \\
\text { NBR5413 (Lux) }\end{array}$ & $\begin{array}{c}\text { Potência } \\
\text { Iluminação }(W)\end{array}$ & $\begin{array}{c}\text { DPI } \\
(\mathbf{W} / \mathbf{m} 2)\end{array}$ & $\begin{array}{c}\text { DPI ASHRAE } \\
(\mathrm{W} / \mathrm{m} 2)\end{array}$ & $\begin{array}{c}\text { NPD } \\
(\text { W/m2 } 2 \cdot 100 l u x) \\
\end{array}$ \\
\hline ESCRITORIO APOIO TECNICO & 24 & 590 & 500 & 640 & 26.67 & 11.80 & 4.52 \\
\hline RECEPÇÃo & 21 & 382 & 100 & 320 & 15.24 & 9.60 & 3.99 \\
\hline CPD & 44 & 514 & 500 & 960 & 21.82 & 11.80 & 4.24 \\
\hline LABORATORIO & 72 & 402 & 200 & 1748 & 24.28 & 11.80 & 6.04 \\
\hline
\end{tabular}


No caso da "Fazendinha" os níveis de iluminância média cumprem com os valores estipulados na Norma NBR 5413, mas ao avaliar o consumo energético dos sistemas de iluminação pode se notar que a DPI é extremamente alta comparada com os valores recomendados pelo ASHRAE; além disso, os valores de NPD estão fora dos valores eficientes. A causa parece estar relacionada à alta utilização de luminárias com tubos fluorescentes T12 de 40 watts.

\subsubsection{Levantamento Usos Finais da Energia (PUFE)}

\subsubsection{Distribuição dos usos finais da energia}

O levantamento dos equipamentos e hábitos de uso permitiu definir a participação dos diferentes usos finais da energia no total do consumo do Prédio "Fazendinha". Na figura 47 são apresentados os diferentes usos finais da energia durante o inverno

Prédio "Fazendinha" IEE/USP- Inverno

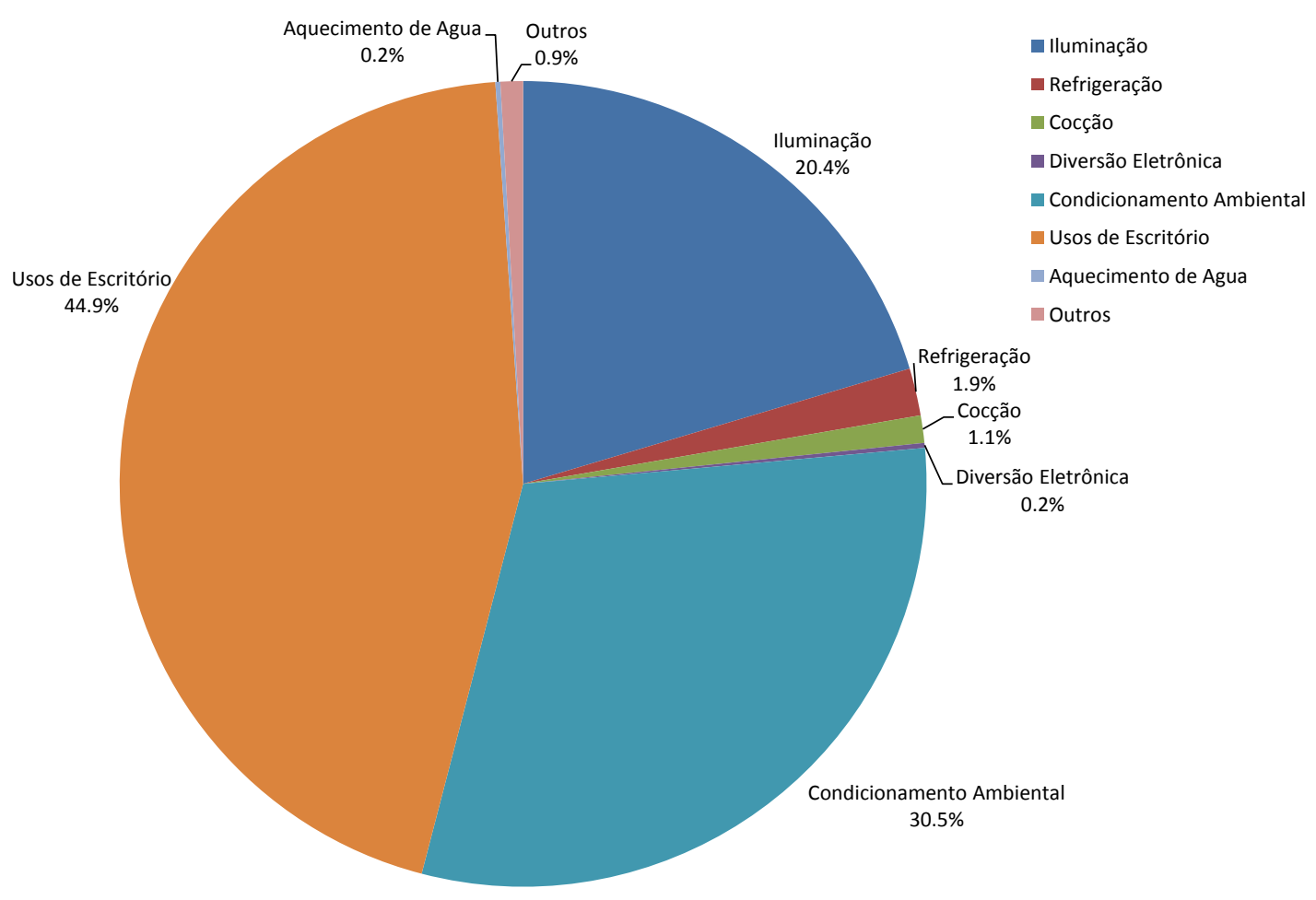

Figura 47- Usos finais da energia Prédio "Fazendinha" no Inverno. 
O uso final mais importante do Prédio "Fazendinha" durante o inverno é o usos de Escritório, representando 44,9\% do total do prédio. A importante carga de equipamentos de computação e redes de dados, operando continuamente no CPD do prédio, é a razão para que este uso final seja o majoritário. O condicionamento ambiental representa $30,5 \%$ do consumo de energia no inverno neste prédio, devido principalmente aos equipamentos de ar condicionado do CPD, os quais operam continuamente para manter a temperatura ótima destes equipamentos eletrônicos.

A iluminação é a seguinte carga em importância com 20,4\% do total; o restante dos usos finais como refrigeração, cocção, aquecimento de água, diversão eletrônica e os outros (próprios dos laboratórios) representa 4,3\% entre todos.

A figura 48 apresenta os diferentes usos finais da energia durante o período do verão no prédio "Fazendinha", e é possível distinguir um aumento no consumo de ar condicionado de $3,7 \%$ sobre o valor do inverno devido ao aumento das temperaturas nesta época do ano.

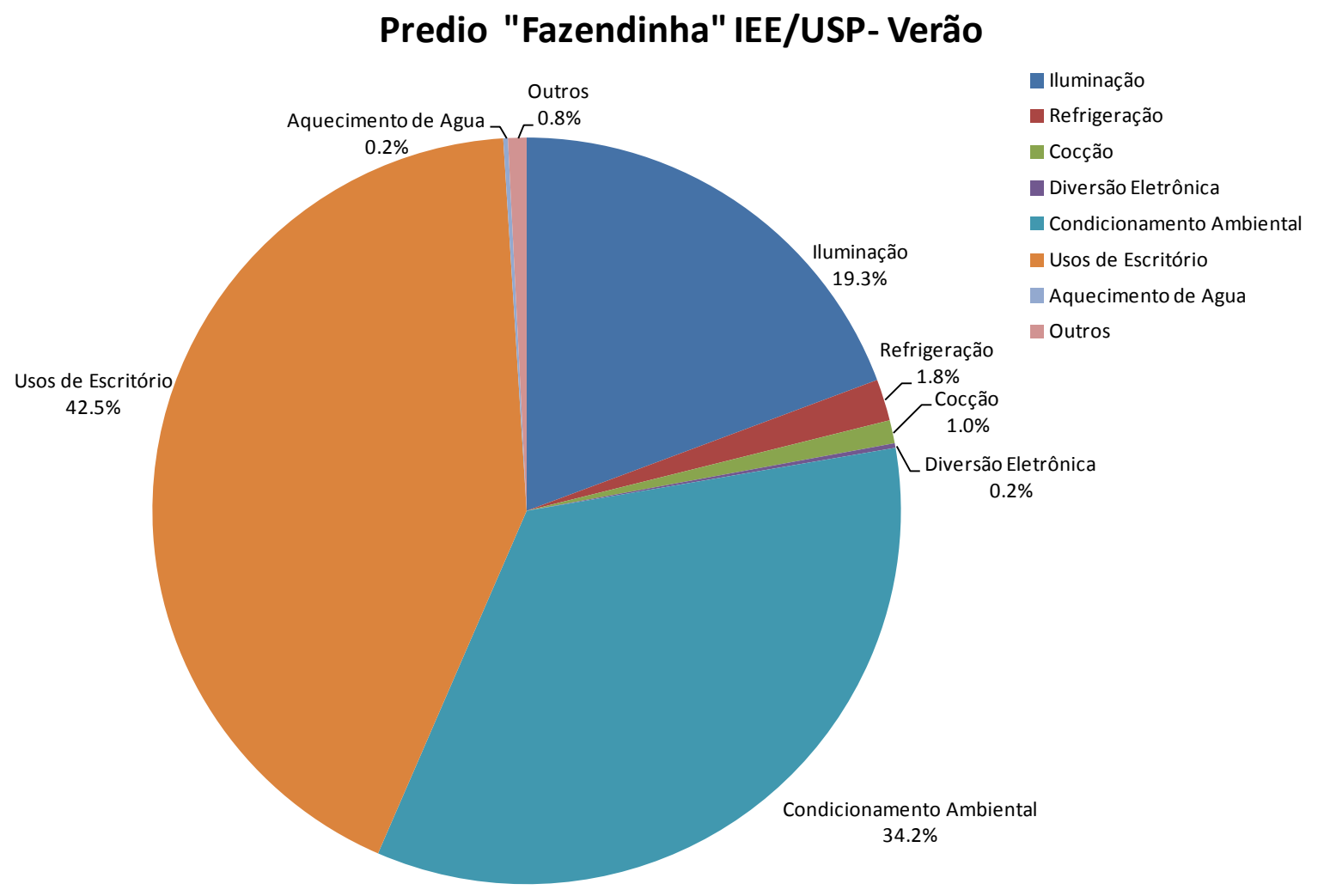

Figura 48- Usos finais da energia Prédio de Energia no Verão.

O consumo de ar condicionado para condicionamento ambiental é o uso com maior variação sazonal, aumentando de $30,5 \%$ no inverno para $34,2 \%$ no verão como foi comentado anteriormente. $\mathrm{O}$ restante dos usos finais permanece com valores 
relativamente similares. Os usos de escritório representam 42,5\%, a iluminação 19,3\%, e o restante de usos finais como refrigeração, cocção, diversão eletrônica, aquecimento de água e os outros (próprios do laboratório) $4 \%$ do total.

\subsubsection{Curva de carga de consumo por uso final}

Com base na medição e nos levantamentos presenciais realizados na edificação, foi possível construir a curva de carga de consumo por uso final. As Figuras 49 e 50 apresentam as curvas para um dia comercial típico e para um dia de pouca atividade (final de semana).

Usando as informações dos levantamentos dos equipamentos e os hábitos de consumo foi estimada a curva média de um dia típico de trabalho, que apresenta uma carga base entre 8 e 10 kW e uma demanda máxima entre 20 e 22 kW.

Por se tratar de uma curva estatística, as cargas aleatórias dos laboratórios são representadas como valores médios e distribuídas ao longo do período de operação. A curva média do dia de trabalho apresenta uma carga base entre 8 e 10kW, constituída por uma carga importante de ar condicionado, iluminação e equipamentos de computação, e outras cargas menores como cargas de refrigeração e equipamentos de escritório em stand by.

Conforme tem início o horário comercial, outras cargas são adicionadas como as cargas dos equipamentos de escritório - principalmente entre às $7 \mathrm{~h}$ e às $20 \mathrm{~h}$. A curva mostra uma demanda máxima média de 18 a 22kW nestes horários.

Como dito anteriormente, a iluminação exterior das áreas comuns do Instituto são fornecidas pelo quadro elétrico da "Fazendinha", somando uma carga de aproximadamente $1,5 \mathrm{~kW}$ durante a noite de todos os dias. 


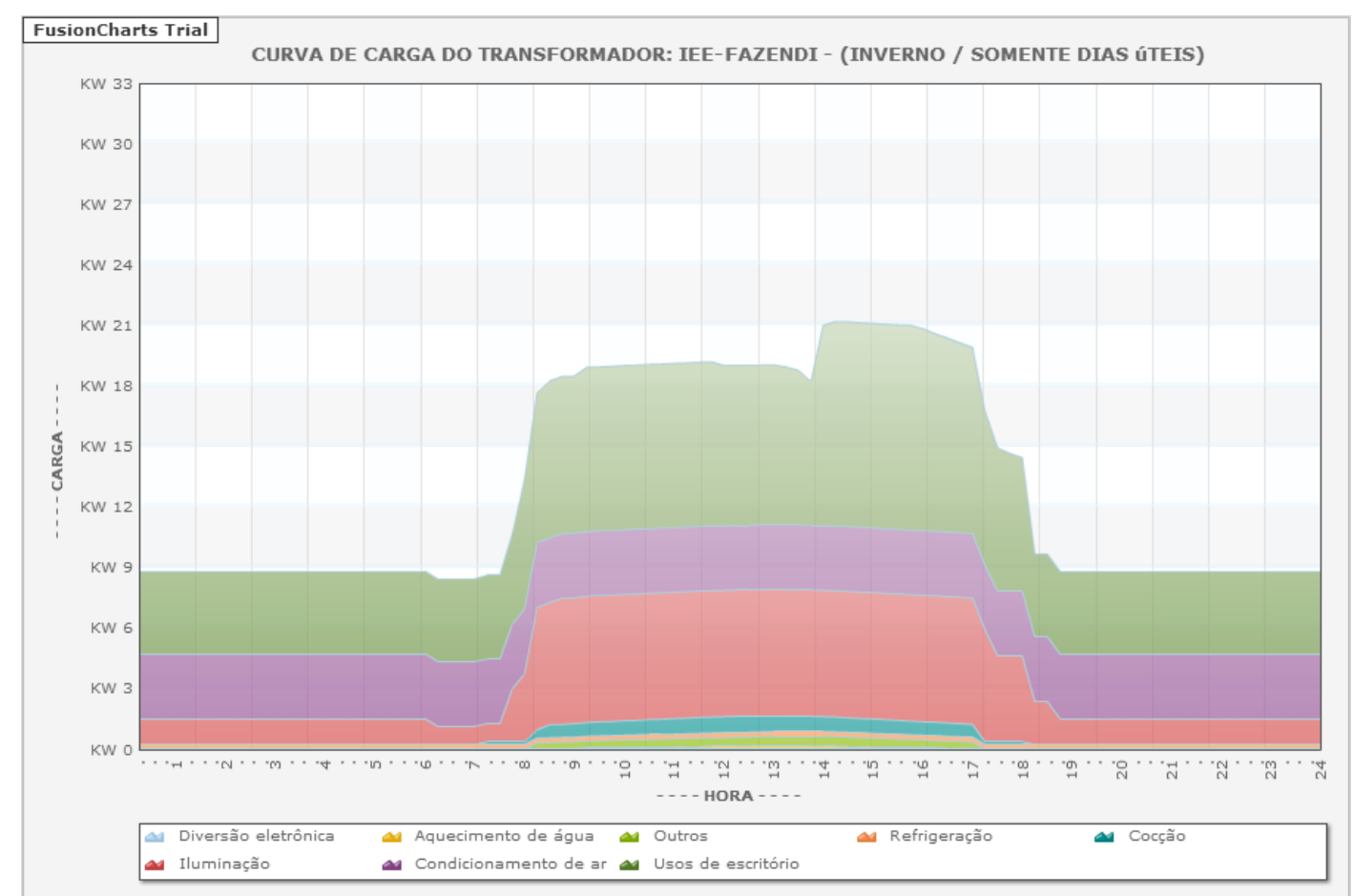

Figura 49- Curva de demanda de energia por uso final para um dia típico da semana no inverno, segundo o PUFE.

No final de semana, com o surgimento da luz natural, as luminárias externas são desligadas e a carga base do prédio fica constante em aproximadamente $7 \mathrm{~kW}$. O comportamento do final de semana no Prédio Fazendinha pode ser apreciado na Figura 50 .

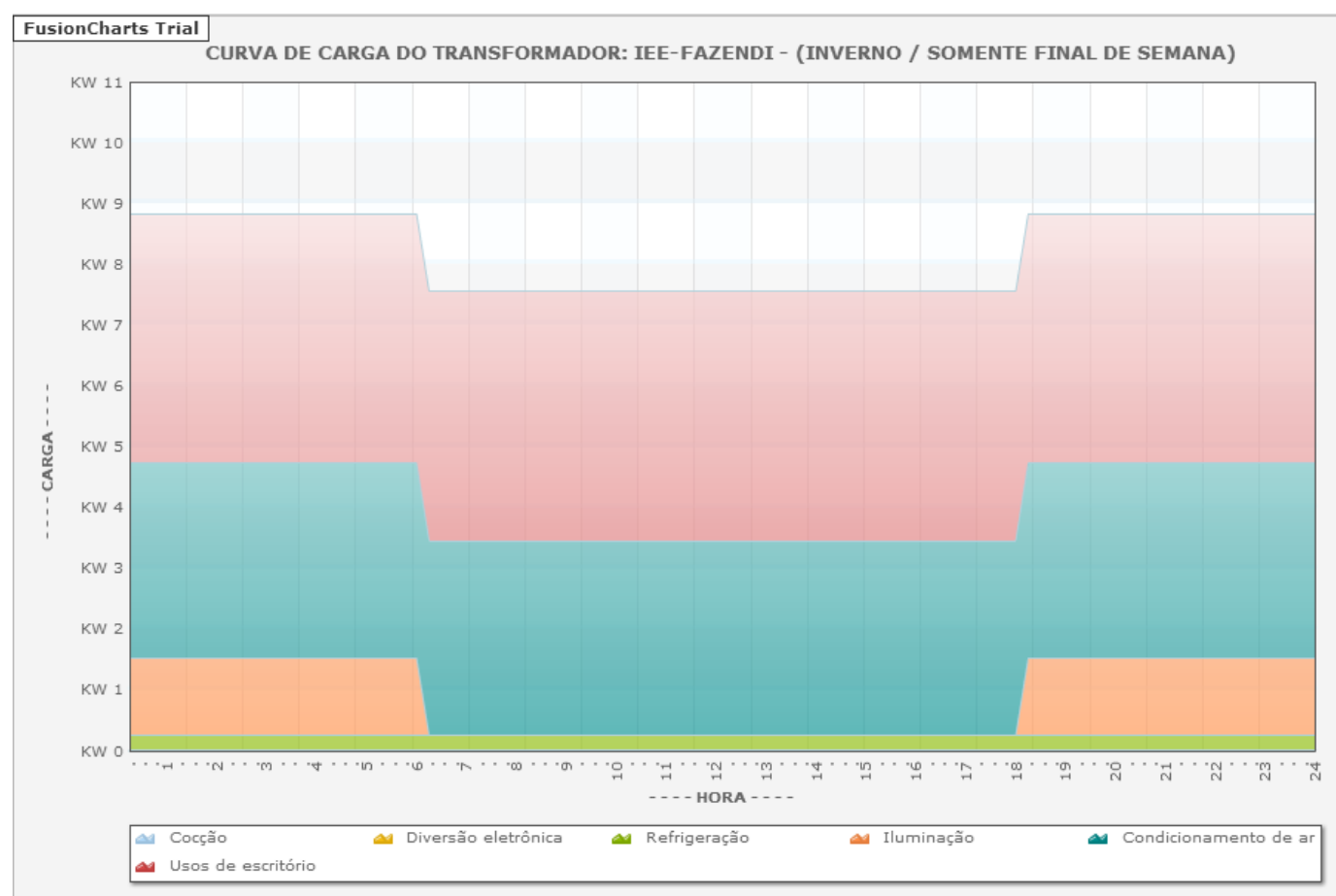

Figura 50- Curva de demanda de energia por uso final para um dia típico final de semana no inverno, segundo o PUFE. 


\subsubsection{Cálculos e Dados Paramétricos}

O consumo mensal total de energia, segundo a medição, foi de $9308,7 \mathrm{kWh} / \mathrm{mês}$ do dia 07/06/2013 a 07/07/2013, enquanto o consumo mensal total de energia segundo o PUFE foi de $9203,84 \mathrm{kWh} /$ mês. A diferença entre os resultados indica uma variação de $1,12 \%$.

Com base nas medições e na curva de carga construída com o PUFE foi possível determinar os dados paramétricos da edificação, fundamentais para determinar os padrões de consumo. Os dados também permitiram a identificação de indicadores, poderiam ser utilizados no futuro para avaliar a eficiência energética da edificação.

Tabela 31- Dados utilizados para o cálculo dos indicadores energéticos.

\begin{tabular}{lc}
\hline \multicolumn{2}{c}{ Dados para calculo dos indicadores } \\
\hline Área Total & $980 \mathrm{~m} 2$ \\
Área CPD & $44 \mathrm{~m} 2$ \\
Funcionários & 30 \\
Demanda Máxima Media & $\sigma=3,88$ \\
Consumo Energia Mensal Medido & $9309 \mathrm{kWh} / \mathrm{mês}$ \\
Consumo Energia Inverno (PUFE) & $9204 \mathrm{kWh} / \mathrm{mês}$ \\
Consumo Energia Verão (PUFE) & $9718 \mathrm{kWh} / \mathrm{mês}$ \\
Consumo Ar Condicionado no Inverno & $2808 \mathrm{kWh} / \mathrm{mês}$ \\
Consumo Ar Condicionado no Verão & $3332 \mathrm{kWh} / \mathrm{mês}$ \\
Demanda de Potencia para Iluminação & $8,8 \mathrm{~kW}$ \\
\hline
\end{tabular}

Com base nos dados acima foi possível determinar a intensidade energética e a demanda máxima mensal da edificação. Os indicadores foram divididos em quatro tipos: Indicadores baseados na medição (Tabela 32); Indicadores baseados no PUFE (Tabela 33), Indicadores próprios do CPD (Tabela 34) e outros indicadores energéticos que poderiam ser de utilidade (Tabela 35).

Tabela 32- Indicadores Energéticos baseados na medição.

\begin{tabular}{lc}
\hline \multicolumn{2}{c}{ Indicadores Energéticos ( Medição Total) } \\
\hline Intensidade Energética por Área & $9,5 \mathrm{kWh} / \mathrm{m} 2$ \\
Intensidade Energética por Funcionário & $310,3 \mathrm{kWh} / \mathrm{funcionário}$ \\
Demanda Máxima Mensal por Área & $24 \mathrm{~W} / \mathrm{m} 2$ \\
Demanda Máxima Mensal por Funcionário & $774 \mathrm{~W} /$ funcionário \\
\hline
\end{tabular}


Tabela 33- Indicadores Energéticos baseados no PUFE.

\begin{tabular}{lc}
\hline \multicolumn{2}{c}{ Indicadores Energéticos (PUFE) } \\
\hline Intensidade Energética por Área (Inverno) & $9,4 \mathrm{kWh} / \mathrm{m} 2$ \\
Intensidade Energética por Funcionário (Inverno) & $306,8 \mathrm{kWh} / \mathrm{funcionário}$ \\
Intensidade Energética por Área (Verão) & $9,91 \mathrm{kWh} / \mathrm{m} 2$ \\
Intensidade Energética por Funcionário (Verão ) & $323,9 \mathrm{kWh} / \mathrm{funcionário}$ \\
\hline
\end{tabular}

Tabela 34- Indicadores Energéticos CPD.

\begin{tabular}{lc}
\hline \multicolumn{2}{c}{ Indicadores Energéticos ( Medição CPD) } \\
\hline Consumo Energético Medição Semanal & $697,6 \mathrm{kWh}$ \\
Estimação Consumo Energético Mensal & $2790,4 \mathrm{kWh}$ \\
Intensidade Energética por Área & $63 \mathrm{kWh} / \mathrm{m} 2$ \\
Densidade de Energia do Ar Condicionado CPD (Inverno/Verão) & $55 \mathrm{kWh} / \mathrm{m} 2$ \\
\hline
\end{tabular}

Tabela 35- Outros Indicadores Energéticos.

\begin{tabular}{lc}
\hline \multicolumn{2}{c}{ Outros Indicadores Energéticos } \\
\hline Densidade de Energia do Ar Condicionado (Inverno) & $2.9 \mathrm{kWh} / \mathrm{m} 2$ \\
Densidade de Energia do Ar Condicionado (Verão) & $3,4 \mathrm{kWh} / \mathrm{m} 2$ \\
Densidade de Potência de Iluminação & $8,1 \mathrm{~W} / \mathrm{m} 2$ \\
\hline
\end{tabular}

\subsubsection{Dificuldades Encontradas}

No prédio de laboratórios do IEE-USP se encontrou diferentes dificuldades para a auditoria energética. $\mathrm{O}$ prédio possui diferentes atividades com regime de consumo energético distinto, o que exigiu uma análise minuciosa para o mapeamento e a construção da curva com o software PUFE.

Apesar disso, a curva de demanda construída no PUFE apresenta um erro de 1,12\%, o que é considerado aceitável. Além dos laboratórios, o prédio possui uma central de computadores, conhecida como CPD. Este espaço de $44 \mathrm{~m}^{2}$ representa um consumo importante, uma vez que os servidores e switchs de rede ficam permanentemente ligados, assim como ar condicionado que mantém o controle da temperatura da sala. Para o cálculo dos indicadores desta área foi preciso estimar o consumo mensal baseado na medição semanal realizada, o que torna difícil avaliar as incertezas dos valores. 
Os laboratórios instalados na edificação, apesar de não possuírem fontes de alta potência, apresentam um padrão de uso irregular, o que também representou um desafio para reconstrução da curva de usos finais.

As áreas de escritório apresentam funcionamento comercial comum das $7 \mathrm{~h}$ às 18h com usos finais típicos de equipamentos de escritório e iluminação. Uma carga diferencial ao prédio é a iluminação exterior nas áreas comuns do Instituto. Esta carga foi determinada pela medição e representa uma potência de $1,5 \mathrm{~kW}$.

Finalmente, é importante mencionar o problema de qualidade de energia com os desequilíbrios observados nas diferentes fases, tanto na edificação como um todo, quanto no CPD. As cargas devem ser redistribuídas para garantir a segurança e a vida útil dos equipamentos elétricos.

\subsubsection{Proposta de cenários de conservação de energia e melhora iluminação}

O consumo de energia para o sistema de iluminação no prédio da fazendinha do IEE, representa, dependendo da estação climática, entre 20,4 e 19,3\% do consumo total do prédio. O indicador de Densidade de Potência de Iluminação, para o prédio completo, tem um valor de $8,1 \mathrm{~W} / \mathrm{m}^{2}$ o qual é baixo comparado com o de $10,9 \mathrm{~W} / \mathrm{m}^{2}$ recomendado mas uma avaliação espaço por espaço (Tabela 3) aponta que muitas áreas da edificação possuem DPI maior que o recomendado pelo ASHRAE, além de níveis de iluminância aceitáveis. Esses dados sugerem a oportunidade de se realizar um processo de delamping, que consiste em utilizar menos tubos nas luminárias.

A tecnologia de iluminação dominante neste prédio é a T12 de $40 \mathrm{~W}$, com luminárias de 4 tubos fluorescentes, juntos todos estes fatos permitem definir como a principal proposta de conservação de energia neste prédio a melhora da tecnologia de iluminação. Foi proposto um retrofit do sistema atual, T12/40W, por outras tecnologias de menor consumo energético utilizando menos tubos (2 em vez de 4), como os T5/54W e LED/22W. Para as simulações da tecnologia T5 foram avaliadas a utilização de 2 tubos de 54 watts nas luminárias, por seu maior fluxo luminoso, e no caso das simulações com LED foram avaliadas a utilização de 4 tubos LED tubulares. Esta proposta foi avaliada do ponto de vista da redução do consumo de energia e dos efeitos luminotecnicos que poderia acarretar. 


\subsubsection{Substituição do sistema de iluminação atual}

A substituição do sistema de iluminação atual pelas tecnologias de menor consumo energético T5 e LED foram primeiro simuladas no software Dialux, para avaliar o comportamento luminotecnico do sistema com as tecnologias comentadas. Para a simulação foram utilizadas lâmpadas T5 de 54 W (4400 lúmenes) e lâmpadas tubulares LED de 22 W (1900 lúmenes). Os reatores das lâmpadas não foram considerados nas simulações.

As áreas selecionadas foram áreas típicas da utilização deste prédio. O fator de manutenção, para considerar a depreciação do fluxo luminoso e sujeira nas lâmpadas, foi de 0,8 . As refletividades utilizadas foram: Teto $80 \%$, Paredes $50 \%$, chão $20 \%$.

Para o prédio da fazendinha as áreas selecionadas são o CPD e o escritório de Apoio Técnico. Para as análises as características físicas das salas foram reproduzidas criando um modelo computacional com o software Dialux. A figura 51 apresenta os modelos computacionais comentados.

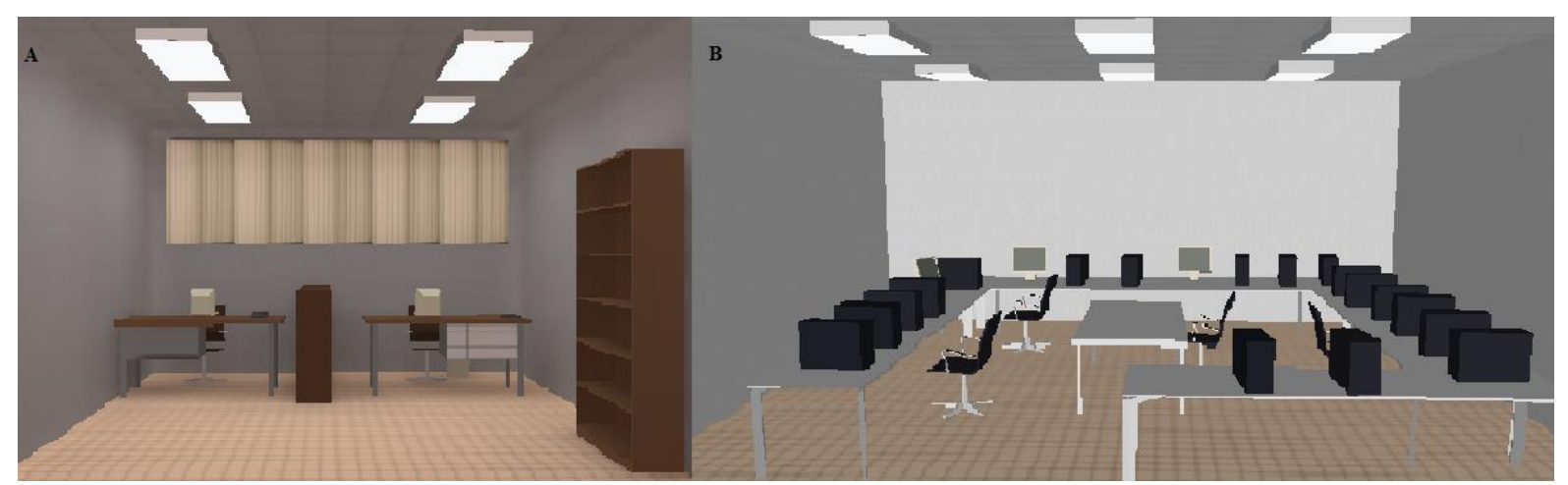

Figura 51- Modelo Computacional Apoio Técnico (A) CPD (B).

Os resultados das simulações das áreas da biblioteca são apresentados na Tabela 36.

Tabela 36- Simulacoes no Dialux para salas representativas do Prédio Fazendinha.

\begin{tabular}{ccccccc}
\hline & \multicolumn{2}{c}{ ESCRITORIO APOIO TECNICO } & \multicolumn{3}{c}{ CPD } \\
\hline & Existente & T5 & LED & Existente & T5 & LED \\
Área (m2) & 24.00 & 24.00 & 24.00 & 44.00 & 44.00 & 44.00 \\
Iluminância media (Lux) & 590 & 566 & 540 & 514 & 547 & 522 \\
Potência Iluminação (W) & 640 & 432 & 352 & 960 & 648 & 528 \\
DPI (W/m2) & 26.67 & 18.00 & 14.67 & 21.82 & 14.73 & 12.00 \\
NPD (W/m2· 100lux) & 4.52 & 3.18 & 2.72 & 4.24 & 2.69 & 2.30 \\
Fluxo Luminoso Útil (klm) & 14.16 & 13.58 & 12.96 & 22.62 & 24.07 & 22.97 \\
\hline
\end{tabular}


Os resultados mostram que nas salas estudadas do prédio da fazendinha, os sistemas tubular LED tem a menor DPI e portanto, o menor consumo energético. Ao considerar as qualidades luminotecnicas dos sistemas, esta tecnologia apresenta o menor NPD sendo assim a opção com melhor balanço entre eficiência energética e qualidade luminotecnica. Além disso, as simulações mostram que a iluminância média dos cenários simulados com as diferentes tecnologias atinge o valor solicitado na norma brasileira NBR 5413 (Ver Tabela 2).

\subsubsection{Avaliação Econômica}

Foi realizada uma análise de economia de energia para determinar se a substituição da distribuição atual de luminárias com sistemas T8 por sistemas de tecnologia T5 e LED seria economicamente viável.

Para esta análise foram consideradas a totalidade das luminárias do prédio; tempo de analise de 10 anos; uso diário médio de 7,3 horas; taxa de desconto de 12\%; o custo unitário da energia elétrica utilizado foi de USD 0.099/kWh (Custo Médio Mensal Energia Elétrica Campus USP Capital); um tempo de vida das lâmpadas de 20000h para a T8/T12, 30000h para o sistema T5, e de 40000h para o sistema LED.

Os custos referentes às lâmpadas, reatores e mão de obra para a execução dos projetos de troca de tecnologia de iluminação são apresentados na seguinte tabela.

Tabela 37- Custos Equipamentos e Mão de Obra.

\begin{tabular}{cccc}
\hline & T8/T12 & T5 & LED \\
\hline Custo Lâmpadas (USD) & 484 & 1114 & 9680 \\
Custo Reatores (USD) & 1089 & 1452 & 0 \\
Custo Mão de Obra (USD) & 666 & 1089 & 968 \\
Custo Total (USD) & $\mathbf{2 2 3 9}$ & $\mathbf{3 6 5 5}$ & $\mathbf{1 0 6 4 8}$ \\
\hline
\end{tabular}

Com os valores comentados anteriormente e os custos da Tabela 37 as figuras de mérito de viabilidade financeira foram calculados. Os resultados são amostrados na tabela 38 . 
Tabela 38- Avaliação econômica da sustitução das lâmpadas atuais por lâmpadas da tecnologia T5 e LED.

\begin{tabular}{ccc}
\hline & Retrofit A (Atual vrs T5) & Retrofit B (Atual vrs LED) \\
\hline Economia de Energia Anual (kWh) & 3803,6 & 9926,4 \\
Payback Simple (Anos) & 9.6 & 10,7 \\
TIR (\%) & 27 & 5 \\
LCC (USD) & 9273,4 & 10522,2 \\
ALCC (USD) & 1641,2 & 1862,3 \\
CEC ( USD/kWh) & 0,05 & 0,31 \\
\hline
\end{tabular}

No prédio Fazendinha, como nos outros prédios estudados, foi realizada uma avaliação considerando a totalidade das figuras de mérito estudadas. Os resultados demonstram que o projeto Retrofit A apresenta viabilidade econômica, mesmo com um alto payback, apresentando um TIR aceitável (27\%) e um custo de energia conservada menor que o custo da tarifa elétrica. É importante mencionar que o custo da energia elétrica utilizado possui um valor consideravelmente menor do que a tarifa para um cliente comercial com caraterísticas similares, portanto os resultados são influenciados por esse fato.

Estas figuras de mérito calculadas, permitiram ainda comparar economicamente os dois retrofit e portanto, as duas tecnologias. Neste caso, o Retrofit A (Atual vrs T5) apresenta as melhores condições por possuir o menor LCC (USD 9273,4), ALCC (USD 1641,2) e CEC (0,05 USD/kWh). 


\subsection{Centro de Computação Eletrônica (CCE/USP)}

\subsubsection{Descrição Arquitetônica}

O Centro de Computação Eletrônica (CCE) da USP executa as principais funções de coordenadoria de informática e comunicação de dados da Universidade de São Paulo, prestando também serviços de informática à comunidade universitária da USP. Localizado nas imediações da Escola Politécnica, dentro da Cidade Universitária Armando Salles de Oliveira, o CCE inclui em suas dependências um estúdio e sala de teleconferências, auditório, oficina de manutenção de equipamentos de informática, central de processamento de dados (data center), salas de escritório e áreas técnicas, perfazendo $4.950 \mathrm{~m}^{2}$.

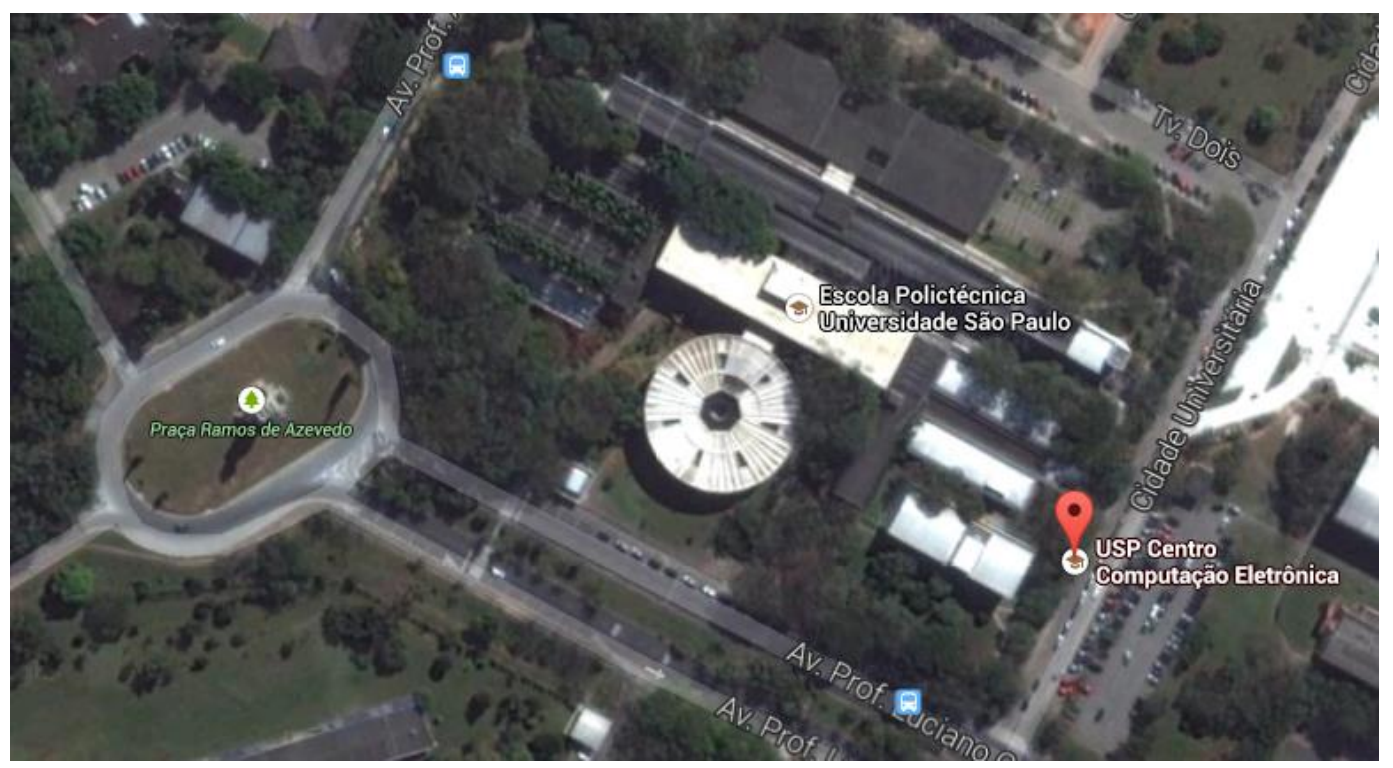

Figura 52- Posicionamento do Prédio CCE USP.

A edificação é composta por 4 blocos, organizados de acordo com diferentes usos, como apresentado na Tabela 39. 
Tabela 39- Divisões e Atividades do CCE USP.

\begin{tabular}{|c|c|c|}
\hline & Quan tidade Funcion ários (T otal do CCE) & Atividades \\
\hline Bloco A & & $\begin{array}{l}\text { - Recepção; } \\
\text { - Teste de software; } \\
\text { - Auditório; } \\
\text { - Sanitários; } \\
\text { - Estúdio e sala de teleconferências. }\end{array}$ \\
\hline Bloco B & & $\begin{array}{l}\text { - Depósitos eáreas de apoio; } \\
\text { - Administrativo; } \\
\text { - Sala de reuniões; } \\
\text { - Copa; } \\
\text { - Laboratório científico }\end{array}$ \\
\hline Bloco C & 283 & $\begin{array}{l}\text { - CPD (Central de Proces samento de Dados); } \\
\text { - Áreas técnicas; } \\
\text { - Núcleos de administração (sala de controle). }\end{array}$ \\
\hline Bloco D & & $\begin{array}{l}\text { - Portaria da oficina; } \\
\text { - Oficina de manutenção de informática; } \\
\text { - Almoxarifado; } \\
\text { - Administração da oficina; } \\
\text { - Refeitório; } \\
\text { - Sala de reunião; } \\
\text { - Sanitários; } \\
\text { - Áreas de apoio. }\end{array}$ \\
\hline
\end{tabular}

Nota-se na Figura 53 que o Bloco D tem sua fachada orientada para a face norte, enquanto os blocos A, B e C, tem a maior parte de suas fachadas orientadas a face sul.

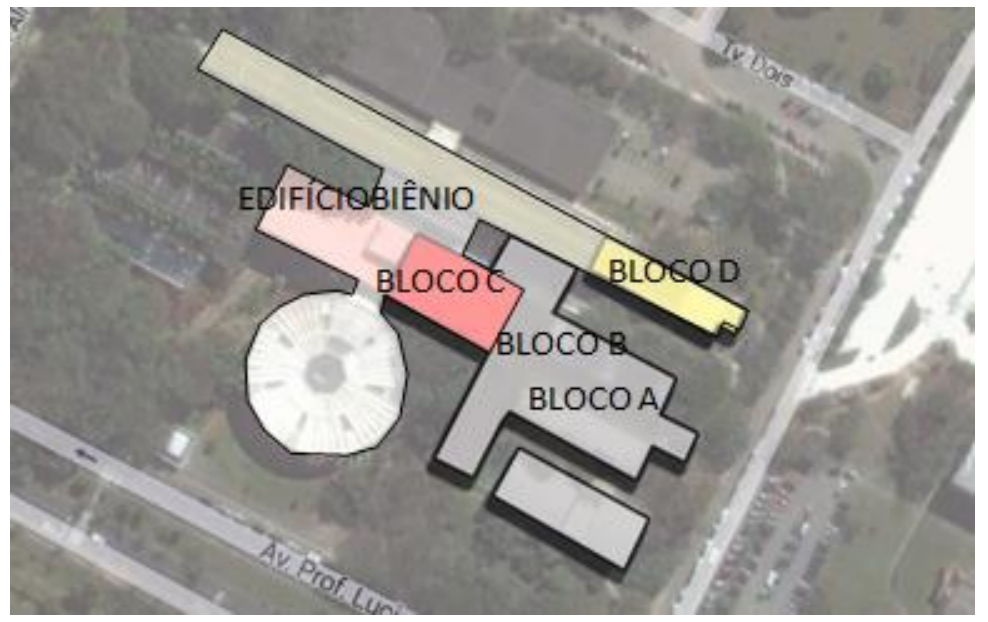

Figura 53- Posicionamento do Prédio CCE USP.

A estrutura de todos os blocos é em concreto armado. As vedações externas são em bloco de concreto, revestido por plaquetas cerâmicas ou tinta branca; ambos revestimentos oferecem algum tipo de resistência à passagem do calor. A considerável diversidade arquitetônica entre os blocos do CCE é explicitada a seguir: 
O bloco A, que abriga a entrada do complexo, é uma ala térrea, composta por um corredor no meio de dois blocos de salas, um à esquerda e outro à direita. A captação de luz solar por esse corredor dá-se por aberturas zenitais, as quais também promovem a iluminação necessária para os jardins internos no corredor citado. O bloco possui o revestimento externo em plaquetas cerâmicas. A vedação da cobertura é feita por meio de telhas de fibrocimento no corredor e por cobertura metálica elevada nas alas laterais. Amplas janelas laterais promovem a iluminação dentro das salas laterais.

Já o bloco B, que abriga o setor administrastivo, possui dois andares, cobertura de telhas de fibrocimento não protegida e revestimento em pintura branca. Janelas amplas no térreo são protegidas por brise soleils horizontais, o que confere bloqueio de insolação direta às horas mais quentes do dia. Já o primeiro andar possui janelas menores, porém sem proteção direta. A fragmentação do espaço em várias salas, em média com $25 \mathrm{~m}^{2}$ cada, é dada por divisórias fixas.

O bloco $\mathrm{C}$ abriga a central de processamento de dados (datacenter), núcleos administrativos e ambientes de apoio (áreas de ar condicionado, geradores, no-breaks). A estrutura apresenta dois andares, sendo o primeiro piso ocupado pelo CPD e apoio, e o segundo piso, pelos núcleos de administração. Por conta do seu posicionamento dentro da edificação, o bloco C é bastante protegido da influência externa das intempéres, não recebendo radiação solar direta em praticamente nenhuma de suas fachadas. O CPD está instalado no piso térreo de uma ala com dois pisos, além de ser inserido entre dois ambientes com larguras entre 3 e 2,5 metros, o que lhe confere isolamento do exterior.

O bloco D (oficina de manutenção de informática) ocupa um braço do edifício Biênio. Apresenta dois andares, ambientes pouco compartimentados e amplas aberturas não protegidas. O térreo é ocupado majoritariamente pela oficina e almoxarifado, enquanto as salas de administração e pessoal localizam-se no segundo piso.

A Figura 54 apresenta diferentes imagens do prédio do CCE para se apreciar as caraterísticas comentadas anteriormenente. 


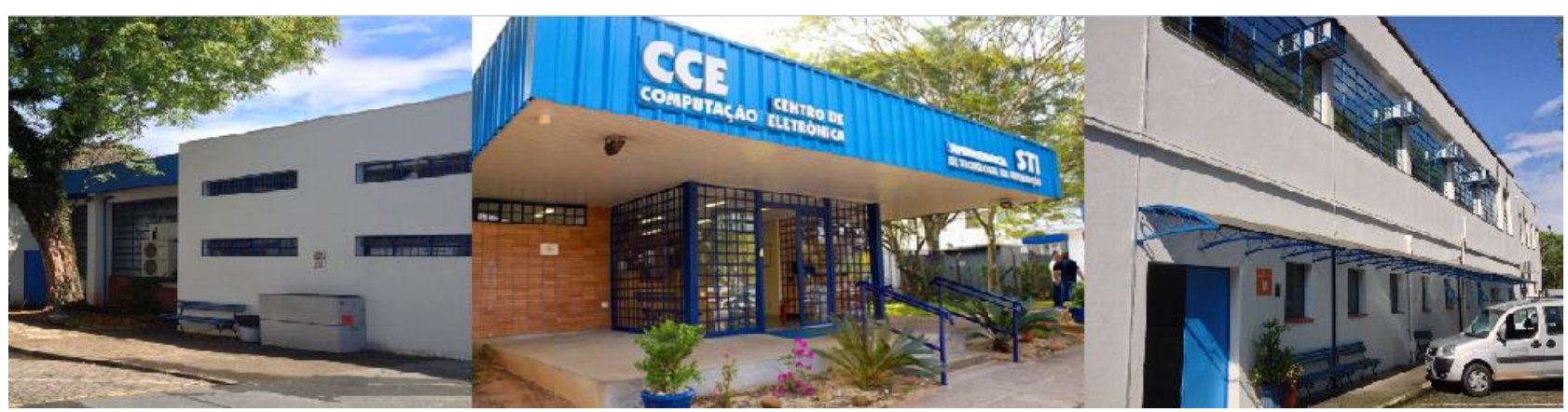

Figura 54- Imagens CCE USP.

\subsubsection{Descrição Geral dos Sistemas Energéticos}

\subsubsection{Condicionamiento Ambiental}

O consumo de ar condicionado para condicionamento ambiental tem sistemas tipo split, de janela, e um sistema de água gelada com chiller e fan coils para o CPD. Os sistemas tipo split e de janela são utilizados nas diferentes áreas com atividade de escritório e em sua maioria funcionam durante o horário comercial das $8 \mathrm{~h}$ as $17 \mathrm{~h}$, em alguns casos durante o inverno e verão e em outros somente durante o verão.

A área do CPD é condicionada artificialmente, sendo ajustada a temperatura em torno de 23 a $24^{\circ} \mathrm{C}$. O condicionamento é realizado através de dois chillers elétricos com potência de 100TR cada, sendo que um é mantido em regime de stand by. Existem sete fan coils para ventilação, sendo quatro de 15TR cada e 3 de 20TR. Desses, um de 15TR e um de 20TR são mantidos desligados e funcionam como backup. A circulação do ar é realizada por dutos abaixo do piso que insuflam o ar para a parte frontal dos racks dos computadores. Os racks recebem o ar frio pela parte frontal e dispensam o ar quente pela parte traseira. De forma a melhorar a eficiência do processo, são formados corredores frios (duas fileiras de racks frente a frente) e corredores quentes (duas fileiras de racks traseira com traseira). 


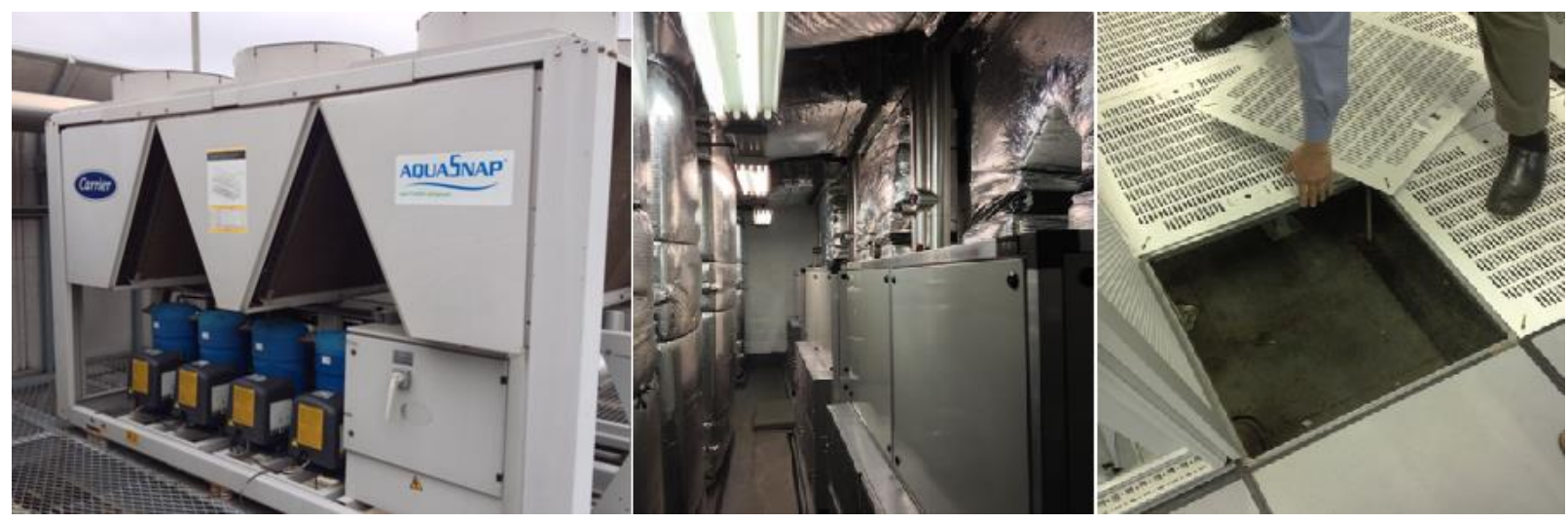

Figura 55- Chiller, Fan Coils e duto de circulacao de ar no CPD do CCE.

\subsubsection{Iluminação}

A iluminação esta composta de luminárias com sistema fluorescente tubular T8 de 32 W. A iluminação é mantida ligada no período de atividade das diferentes áreas, algumas no horário comercial normal de segunda a sexta das $7 \mathrm{~h}$ às $18 \mathrm{~h}$, em outros casos de forma intermitente apenas quando a sala está ocupada como no CPD e sala de roteadores. Também foram verificadas salas com ocupação em todos os dias da semana $24 \mathrm{~h}$.

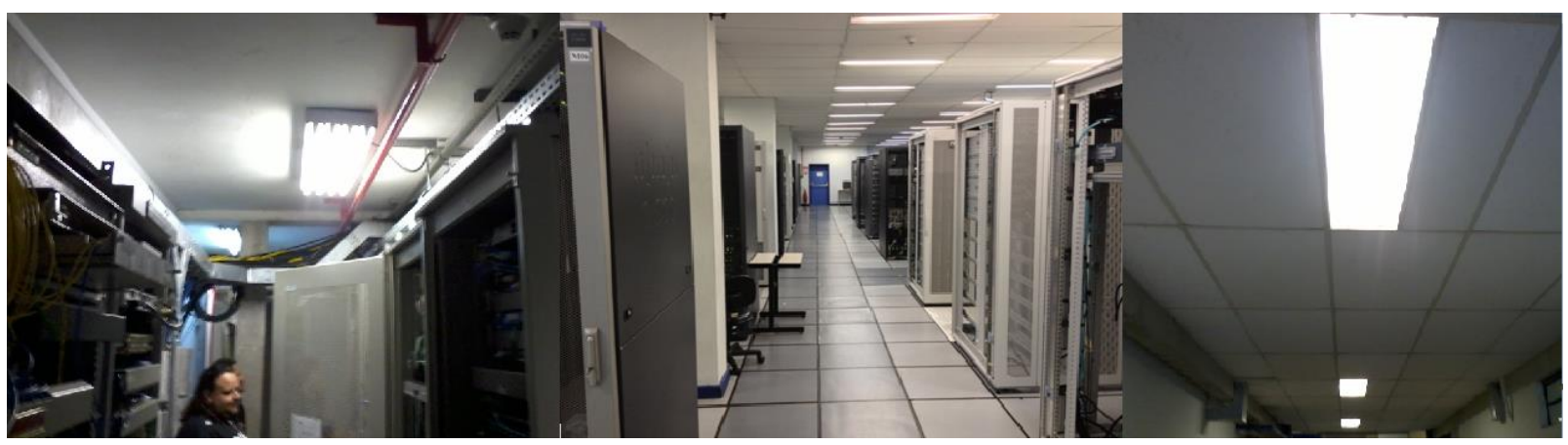

Figura 56- Fotos do sistema de iluminação do CCE.

\subsubsection{Medições}

\subsubsection{Medições de Energia}

Medições de variáveis elétricas foram realizadas dos dias 21 de julho a 18 de agosto de 2013. As medições permitiram conhecer o comportamento energético do prédio e validar o modelo criado no software de usos finais - PUFE. 
Nas Figuras 57, 58 e 59 são apresentados os dados completos da medição de 21 de julho a 18 de agosto de 2013, bem como a medição de um dia comercial durante a semana e a medição de um dia de final de semana. Os dados da medição foram utilizados para calcular os indicadores de consumo energético mensal por área e consumo energético mensal por funcionário, assim como para validar o modelo do PUFE.

Nota-se uma carga base entre 410 e 420 kW, com alterações na demanda máxima que variam entre dias comerciais e finais de semana. Nos dias comerciais a demanda máxima pode chegar a um valor entre 500 e $520 \mathrm{~kW}$, enquanto no final de semana pode chegar a um valor entre 430 e $450 \mathrm{~kW}$.

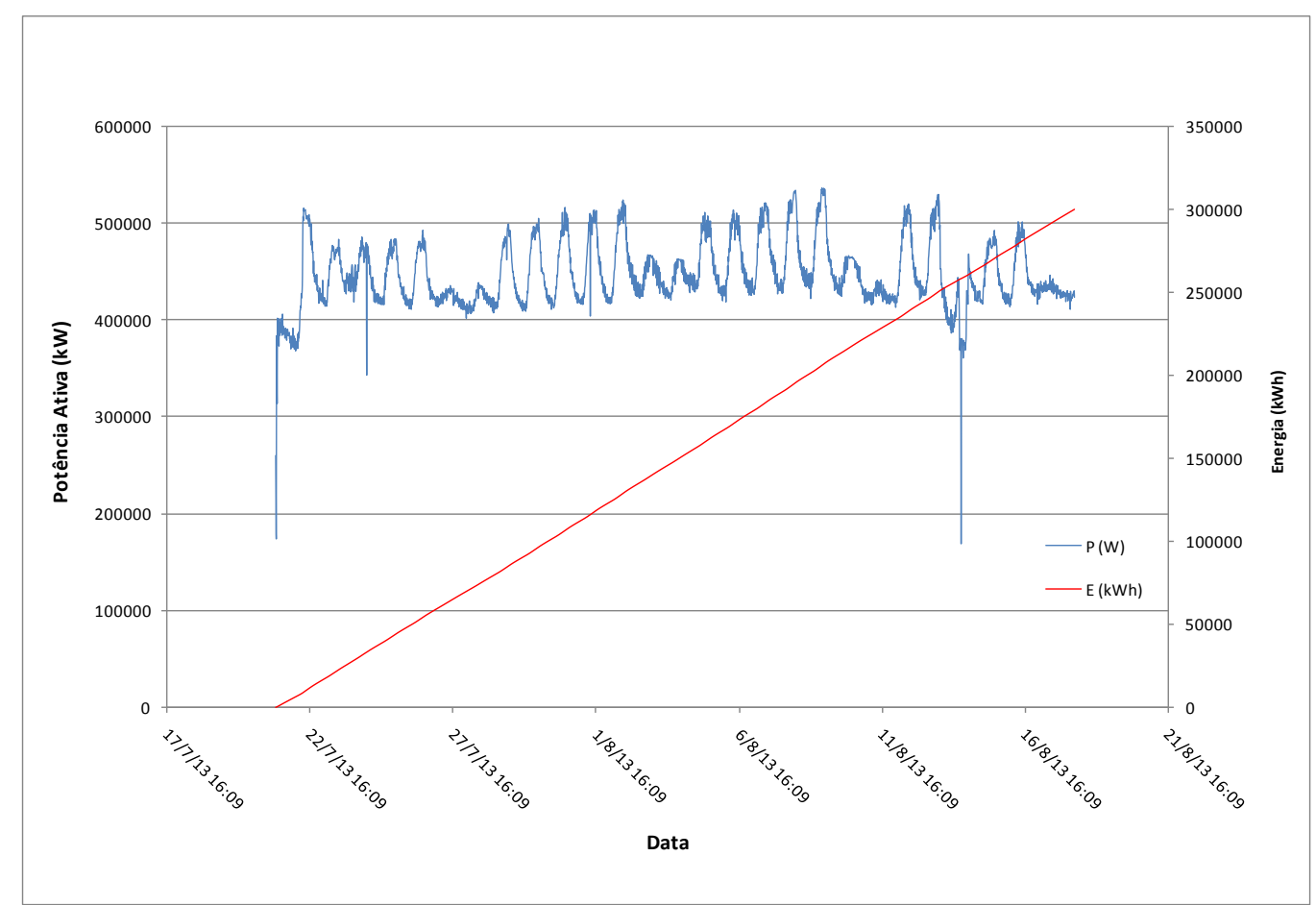

Figura 57- Medição da potência ativa e energia ativa do dia 21/07 ao 18/08 de 2013.

A medição de um dia típico comercial é mostrada na Figura 58. É possível observar a carga base comentada anteriormente, bem como o crescimento na curva ocasionado pelas cargas de iluminação, equipamentos de escritório e ar condicionado (das áreas de escritório), na medida em que o horário comercial se inicia. 


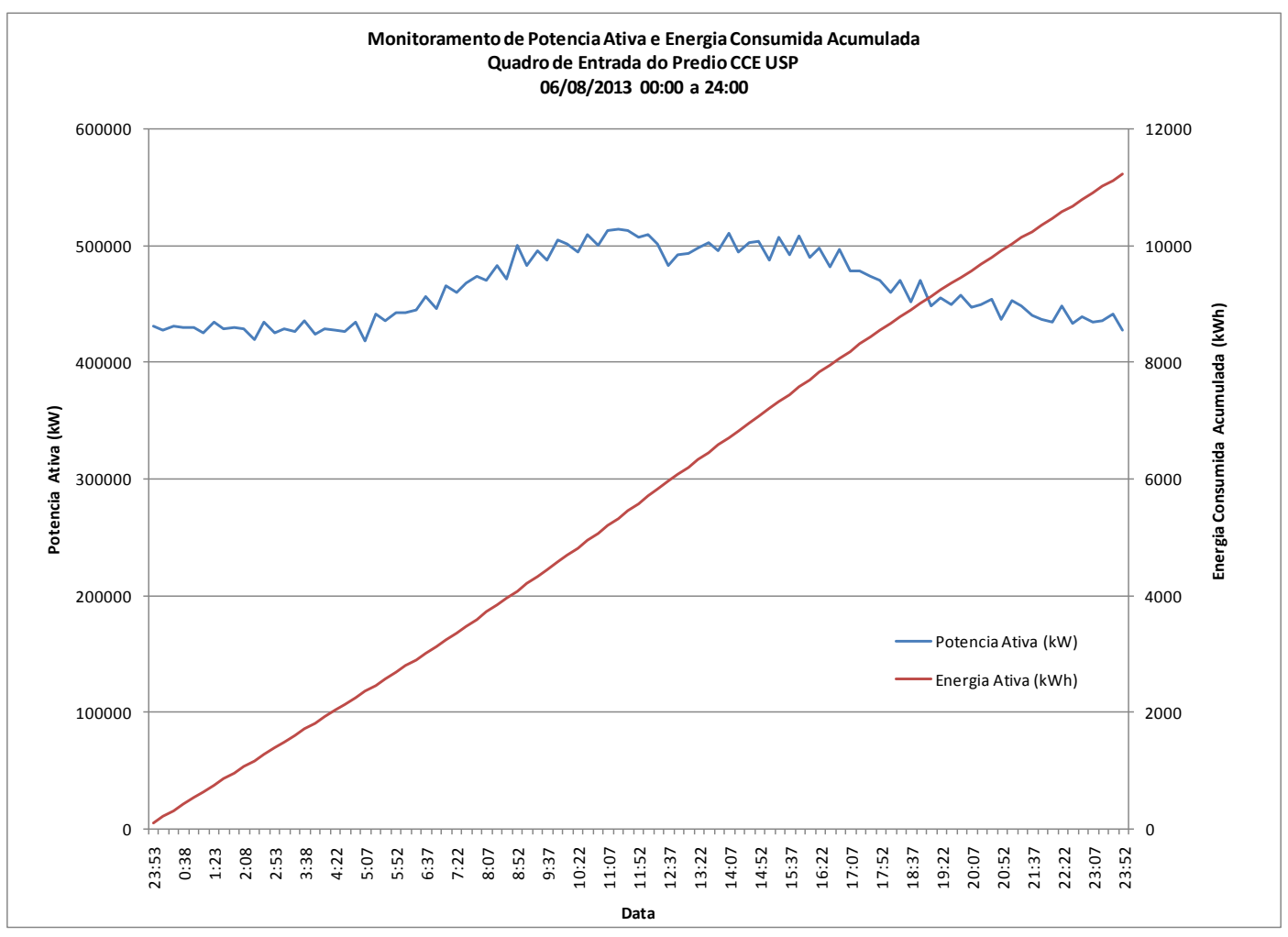

Figura 58- Medição da potência ativa de um dia típico comercial (06/08/2013).

Nos finais de semana, Figura 59, observa-se um aumento menor da carga durante o dia, em função da menor atividade laboral e por tanto, em função da menor circulação de funcionários na edificação e menor atividade da mesma.

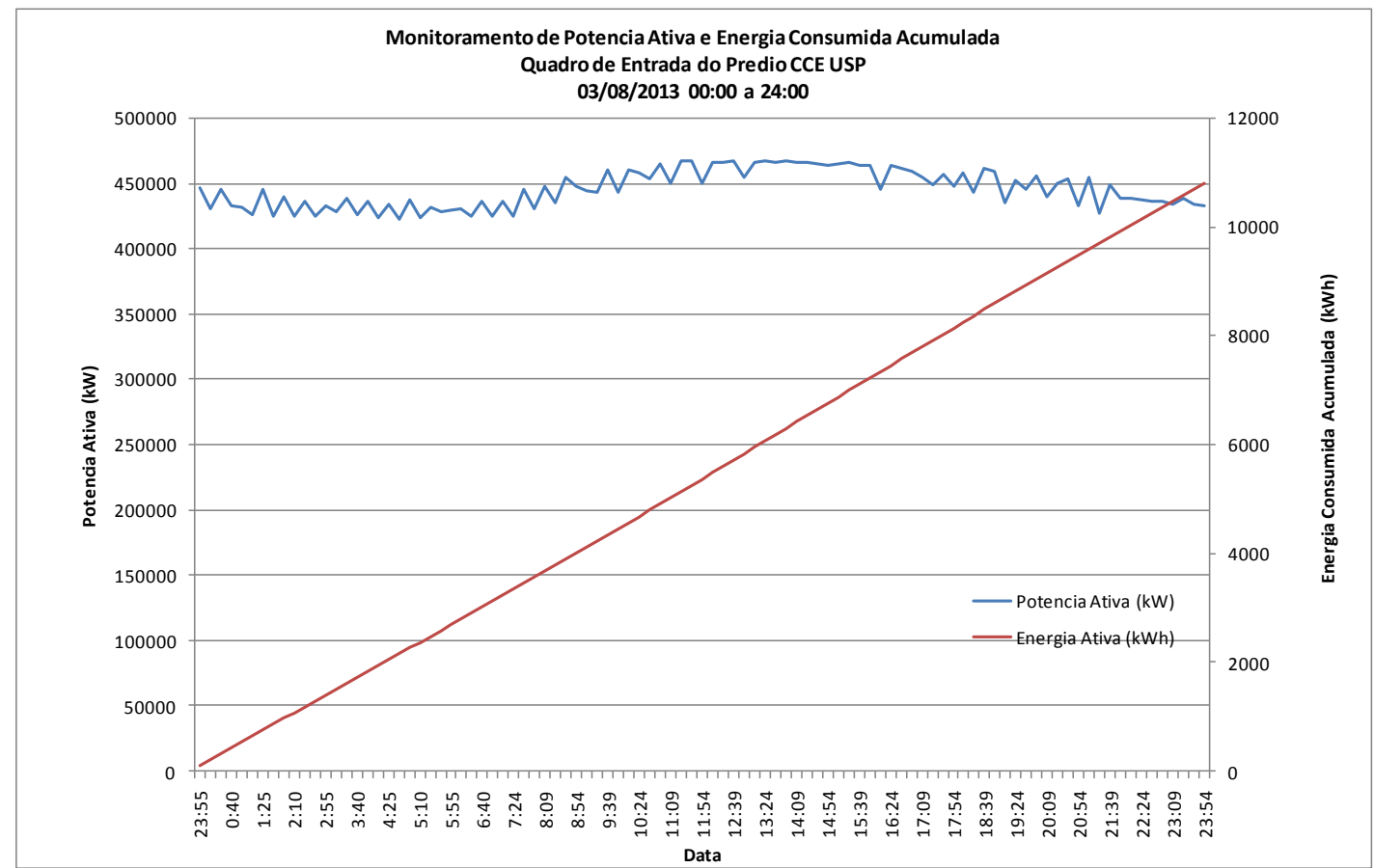

Figura 59- Medição da potência ativa deum final de semana (03/08/2013). 


\subsubsection{Medições de iluminação}

As medições de iluminância das diferentes áreas do prédio de energia foram feitas baseados na norma NBR 5382:Verificação de Iluminância de Interiores. As mesmas forem realizadas no dia 3 de dezembro de 2013 durante a manhã. Neste caso as áreas avaliadas são internas do prédio e não possuem janelas externas, portanto não apresentam influencia da iluminação natural. A tabela 40 apresenta os dados levantados nesta etapa de medições.

Tabela 40- Comparação valores existentes com os requeridos nas normas .

\begin{tabular}{|c|c|c|c|c|c|c|c|}
\hline & Área (m2) & $\begin{array}{l}\text { Iluminância } \\
\text { média (Lux) }\end{array}$ & $\begin{array}{c}\text { Iluminância } \\
\text { Norma NBR5413 } \\
\text { (Lux) } \\
\end{array}$ & $\begin{array}{c}\text { Potência } \\
\text { Iluminação } \\
(W)\end{array}$ & DPI (W/m2) & $\begin{array}{c}\text { DPI ASHRAE } \\
(\mathrm{W} / \mathrm{m} 2)\end{array}$ & $\begin{array}{c}\text { NPD } \\
(\mathrm{W} / \mathrm{m} 2 \cdot 100 l u x)\end{array}$ \\
\hline SALA INFRAESTRUTURA & 32 & 274 & 500 & 320 & 10.00 & 12.90 & 3.65 \\
\hline SALA OPERACAO CPD & 40 & 182 & 500 & 320 & 8.00 & 18.30 & 4.40 \\
\hline SALA CPD-SERVIDORES & 365 & 278 & 500 & 4800 & 13.15 & 11.80 & 4.73 \\
\hline SALA CPD-ROTEADORES & 85 & 184 & 500 & 1600 & 18.82 & 11.80 & 10.23 \\
\hline RECEPÇÃO & 52 & 155 & 100 & 384 & 7.38 & 9.61 & 4.76 \\
\hline
\end{tabular}

As áreas de tipo escritório, como a Sala Infraestrutura e a Sala de Operação e também as salas do datacenter: Sala CPD- Roteadores e Sala CPD-Servidores, tem iluminância menor que a requerida na norma NBR 5413. No caso especifico da Sala de Operação de CPD, a utilização de telas com vídeos de segurança, dados da operação, entre outras informações básicas para o CPD, é utilizada pouca iluminação; mas considerando que tem entre 3 a 4 funcionários trabalhando com níveis de iluminância baixos é importante ter em conta esse fato.

Observa-se também as areas de CPD Servidores e CPD Roteadores , possuem alto DPI, segundo a ASHRAE; o que lhes confere potencial para intervenções de eficiência energética. Da mesma forma, a NPD encontra-se elevada conforme os valores recomendados.

\subsubsection{Levantamento Usos Finais da Energia (PUFE)}

\subsubsection{Distribuição dos usos finais da energia}

O levantamento dos equipamentos e hábitos de uso permitiu definir a participação dos diferentes usos finais da energia no total do consumo do Prédio CCE 
da USP. Na figura 60 são amostrados os diferentes usos finais da energia durante o inverno.

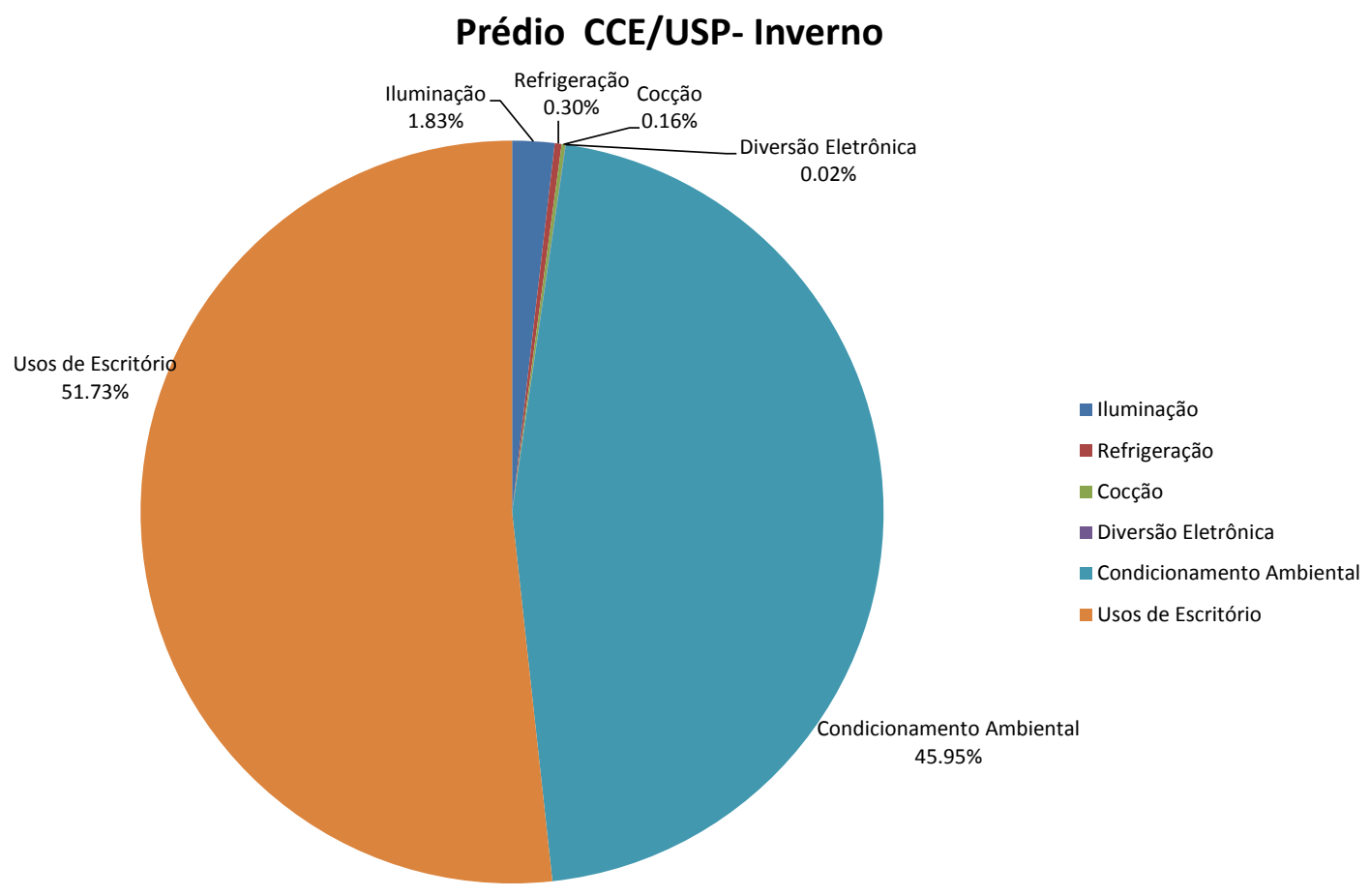

Figura 60- Usos finais da energia Prédio CCE/USP no Inverno.

O prédio do CCE/USP, por possuir um datacenter com equipamentos de alto consumo energético e operando continuamente, apresenta dois usos finais da energia majoritários, os usos de escritório e o condicionamento ambiental. Os usos de escritório representam os servidores, switches, roteadores e outros equipamentos de telecomunicações do CPD e também as cargas de escritório como computadores, impressoras, copiadoras, etc. Estes correspondem a 51,73\% do consumo energético no inverno.

O condicionamento ambiental constituído pelos chillers e fan coils que retiram o calor gerado no CPD do prédio pelos equipamentos de telecomunicações, mas também pelos equipamentos de ar condicionado tipo split e de janela instalados nas áreas de escritório da edificação e que tem alguma operação durante os meses de inverno. Este uso final representa o 45,95\% do consumo nestes meses.

O restante dos usos finais da energia na edificação são pouco significativos comparados às cargas antes comentadas. A iluminação é a seguinte carga em importância com $1,83 \%$ do consumo nos meses de inverno, seguido das cargas de refrigeração com $0,3 \%$, a cocção com $0,16 \%$ e finalmente os equipamentos classificados 
como diversão eletrônica, principalmente televisores, com $0,02 \%$ do consumo do inverno.

A Figura 61 apresenta os diferentes usos finais da energia durante o período do verão no prédio CCE/USP. Nos meses de verão, o consumo de energia para condicionamento ambiental aumenta devido às altas temperaturas atingidas durante o dia e pelo conseqüente aumento na utilização de sistemas de ar condicionado de janela e split nas áreas de escritório.

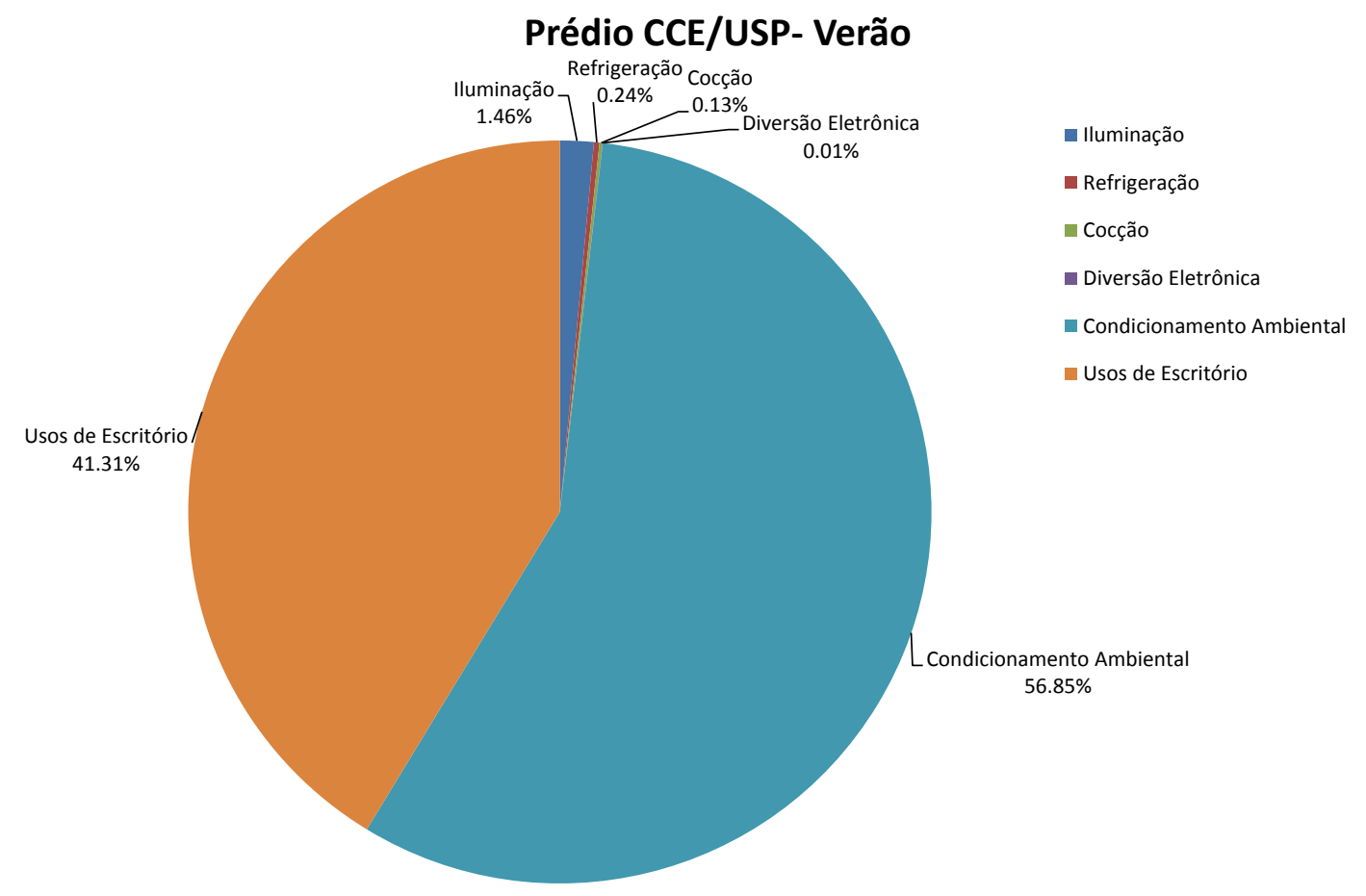

Figura 61- Usos finais da energia Prédio CCE/USP no Verão.

O consumo de energia com o condicionamento ambiental aumenta para 56,85\% nos meses de verão enquanto os usos de escritório diminuem $41,31 \%$ nestes meses. $\mathrm{O}$ restante dos usos finais se mantém com uma baixa taxa representativa tendo a iluminação $1,46 \%$, a refrigeração $0,24 \%$, a cocção o0,13\% e os equipamentos de diversão eletrônica $0,01 \%$ do consumo total.

Considerando que a carga desta edificação esta praticamente dividida entre os usos de escritório e o condicionamento ambiental, o estudo de usos finais foi reformulado considerando outras sub categorias que permitam conhecer com maior detalhe o comportamento energético da edificação e os equipamentos com maior potencial para projetos de eficiência energética. Na Figura 62 é apresentado o estudo de usos finais considerando outras sub categorias, para os meses de inverno. 


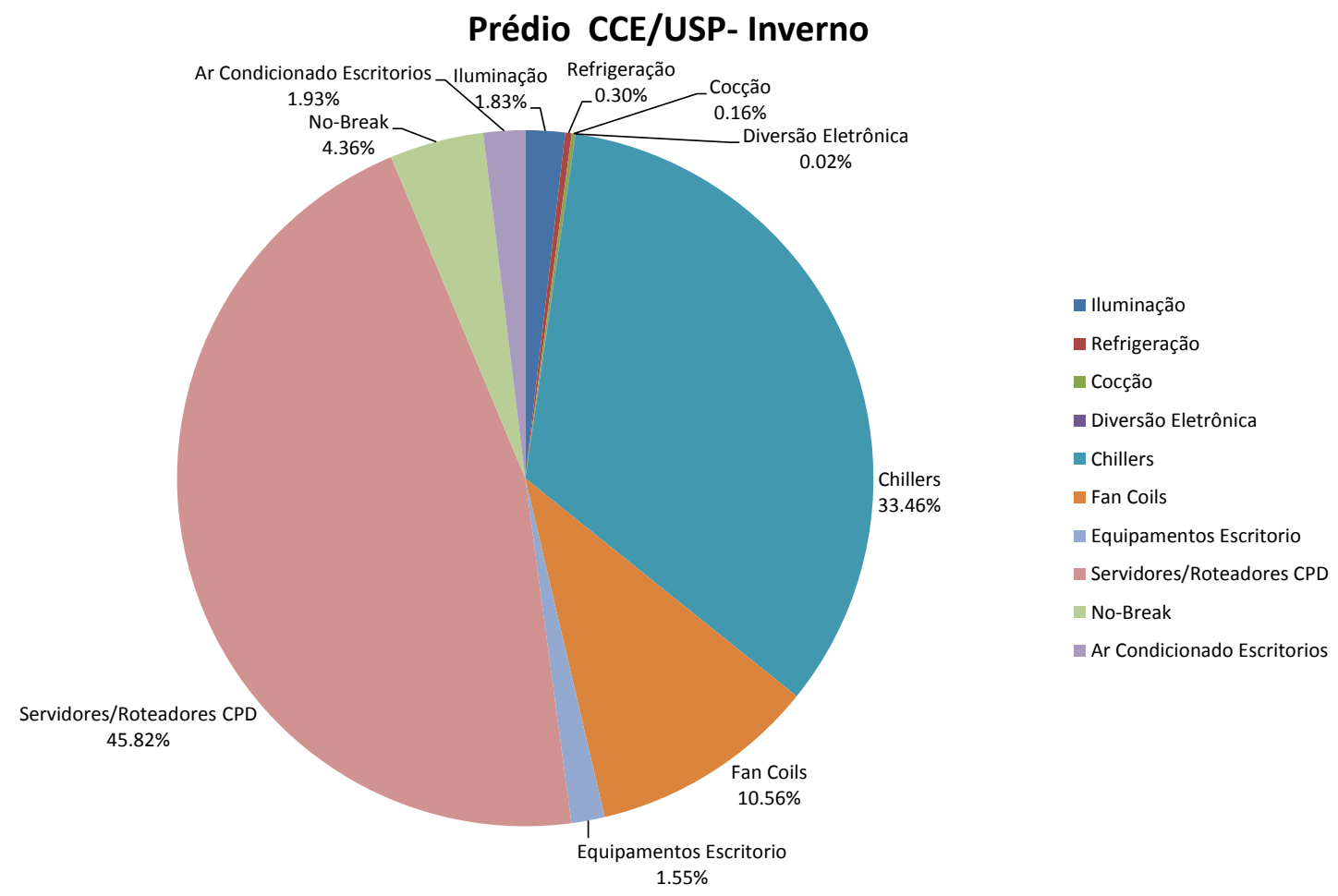

Figura 62- Usos finais da energia Prédio CCE/USP no Inverno.

A carga mais importante durante o inverno é a carga de Servidores e Roteadores no CPD, com 45,82\%. A segunda carga em importância é o Chiller, que realiza a geração de frio para o condicionamento ambiental do CPD, e consome 33,46\% da energia do CCE/USP durante o inverno. Os Fan coils, ventiladores para a distribuição do ar condicionado no CPD, possuem um consumo correspondente a 10,56\% do total. Outro consumo importante são as perdas do No Break do CPD, as quais representam 4,36\%. E finalmente observa-se as cargas menores como o ar condicionado dos escritórios que representa 1,93\%, a iluminação com 1,83\%, os equipamentos de escritório com $1,55 \%$, a refrigeração com $0,3 \%$, a cocção com $0,16 \%$ e diversão eletrônica com $0,02 \%$.

O comportamento dos usos finais da energia, considerando as novas sub categorias foi realizado também para os meses do verão e é apresentado na Figura 63. $\mathrm{Na}$ mesma é possível notar o aumento no consumo energético das categorias relacionadas com o condicionamento ambiental (Chiller, Fan Coils, Ar Condicionado Escritórios) pelo aumento das temperaturas ambientais nesse período. 


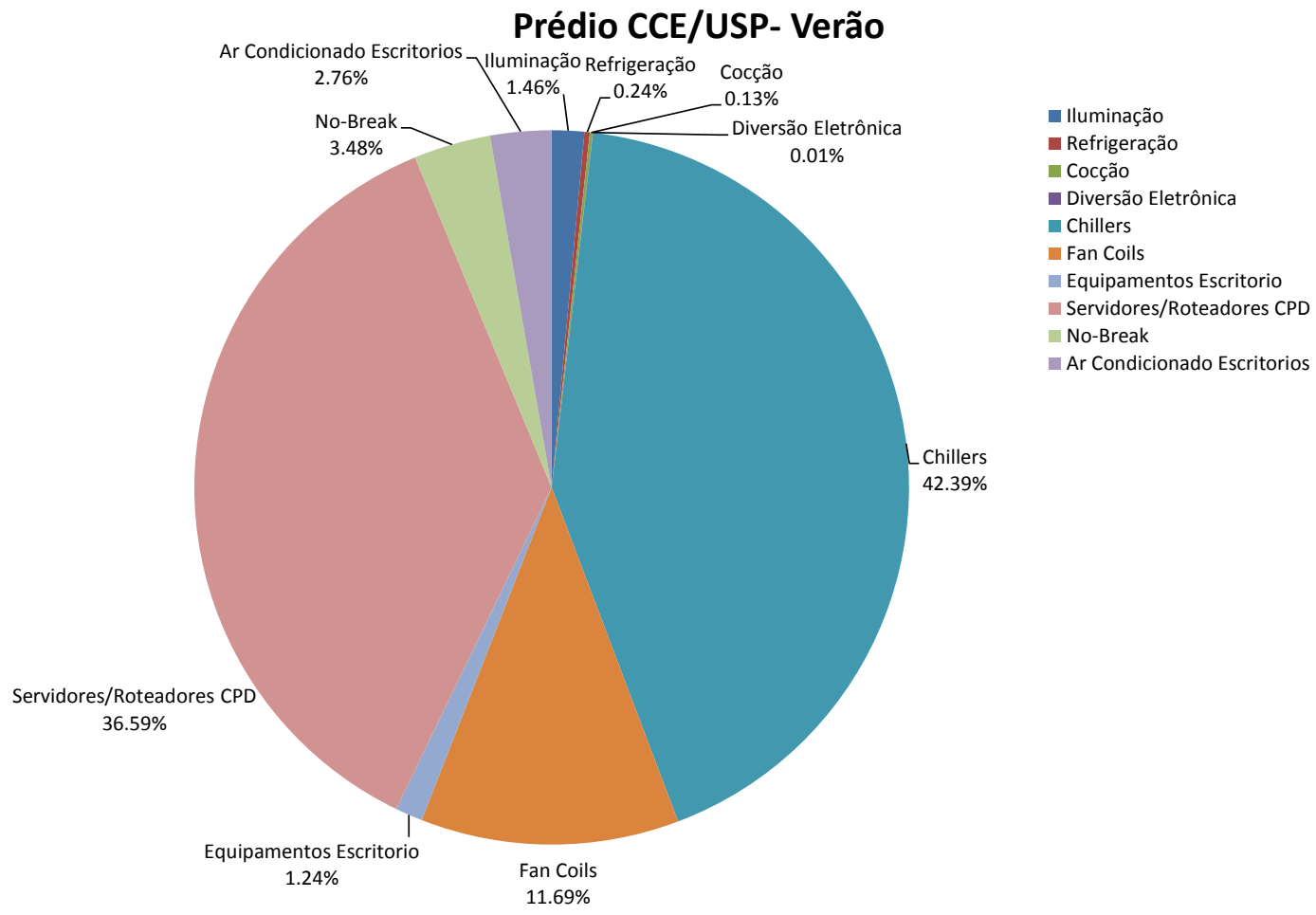

Figura 63- Usos finais da energia CCE/USP no Verão.

A carga mais importante durante o verão são os Chillers representando 42,39\%, seguida da carga de servidores e roteadores do CPD com 36,59\%. Os Fan Coils representam 11,69\% do consumo, as perdas no No-Break 3,48\%, o ar condicionado das áreas de escritórios $2,76 \%$, a iluminação $1,46 \%$, os equipamentos de escritório 1,24\%, a refrigeração $0,24 \%$, a cocção $0,13 \%$ e a diversão eletrônica $0,01 \%$.

\subsubsection{Curva de carga de consumo por uso final}

A curva de demanda estimada estatisticamente pelo software PUFE para um dia comercial e para um dia de final de semana são apresentadas nas Figuras 64 e 65.

Através das informações obtidas nos levantamentos presenciais para avaliação dos equipamentos e hábitos de consumo, foi obtida a curva média para um dia comercial típico, com uma carga base entre 400 e 410 kW e uma demanda máxima entre 510 e 530 kW. Por se tratar de uma curva média, as cargas de caráter aleatório são representadas em valores médios, distribuídos a partir da hora mais provável de ocorrência. 
A curva média de um dia comercial apresenta cargas importantes do sistema de ar condicionado (Chiller e FanCoils) e dos equipamentos do CPD (servidores e roteadores), que compreendem praticamente a carga base do prédio. Outras cargas menores, como as cargas de refrigeração, dos equipamentos de escritório em stand by e da iluminação permanente, também constam na curva, porém com uma contribuição ínfima.

Na curva ainda é possível observar que com o inicio do horário comercial - entre $7 \mathrm{~h}$ e $18 \mathrm{~h}$ - existe um aumento da carga de condicionamento ambiental no CPD, o que pode ser atribuído a três fatores: (1) aumento das temperaturas externas; (2) maior presença de funcionários e (3) maior carga de trabalho dos equipamentos de computação.

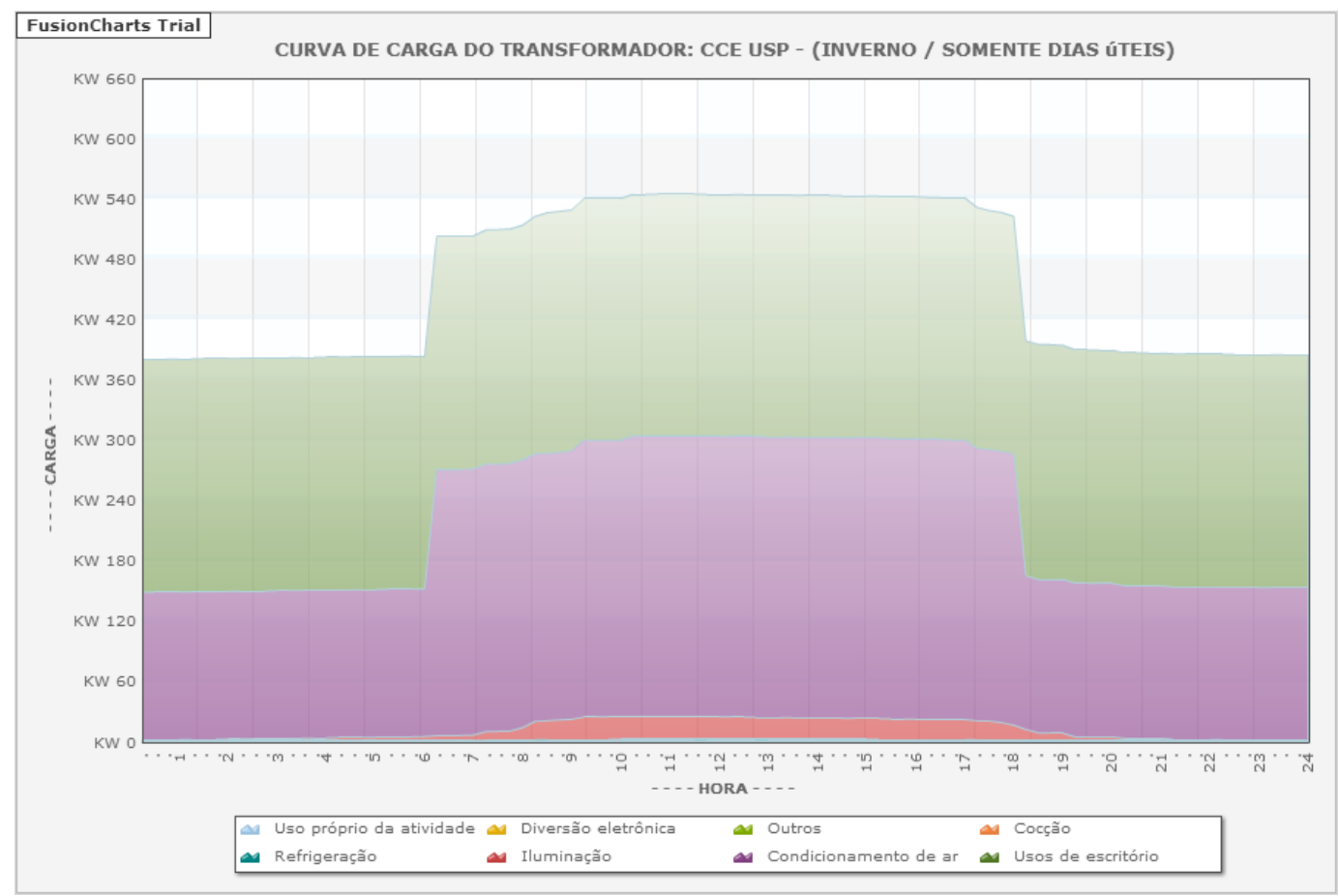

Figura 64- Curva de demanda de energia por uso final para um dia típico da semana no inverno, segundo o PUFE

A curva de demanda estimada no PUFE para o final de semana consiste basicamente da carga de equipamentos de computadores e roteadores, juntamente com o sistema de ar condicionado necessário para retirar a carga térmica gerada no CPD. Somadas a essas cargas, porém, com valores muito inferiores, aparecem as cargas das salas com ocupação permanente, bem como as cargas de refrigeração relacionadas as geladeiras e bebedouros. 
A curva de demanda de energia nos dias de final de semana é apresentada na Figura 65. A carga base dos dias de final de semana é levemente menor que durante a semana, entre 380 e 400 kW e apresenta uma demanda máxima entre 480 e 490 kW.

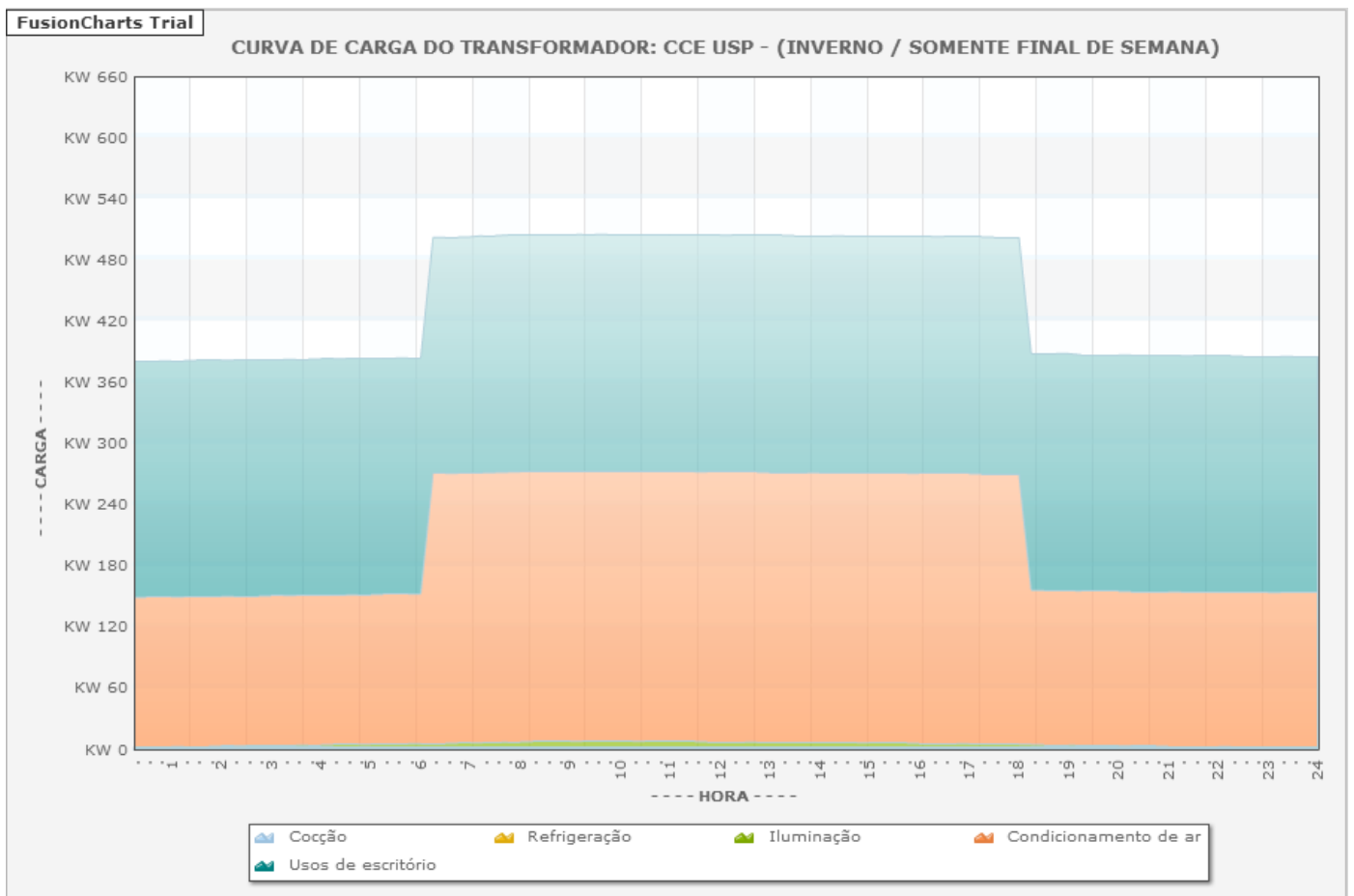

Figura 65- Curva de demanda de energia por uso final para um dia típico de final de semana no inverno, segundo o PUFE.

\subsubsection{Cálculos e Dados Paramétricos}

O consumo mensal total de energia segundo a medição foi de $300.608,70 \mathrm{kWh} / \mathrm{mês}$ do dia 21/07/2013 a 18/08/2013. Para fechar um mês completo (representado do dia 21/07/2013 ao dia 21/08/2013) foi assumido um valor de 10.600,00 kWh para os dois dias comerciais faltantes, contabilizando então um consumo total mensal de $321808,00 \mathrm{kWh} / \mathrm{mês}$. O consumo mensal total de energia segundo o PUFE foi de $328053,00 \mathrm{kWh} / \mathrm{mês}$. A variação observada entre os dois valores mostra um erro de 1,9\%, que é considerado aceitável.

Com base nas medições e na curva de carga construída com o PUFE foi possível determinar os dados paramétricos da edificação, fundamentais para determinar os padrões de consumo. Os dados também permitiram a identificação de indicadores, poderiam ser utilizados no futuro para avaliar a eficiência energética da edificação. 
Tabela 41- Dados utilizados para o cálculodos indicadores energéticos.

\begin{tabular}{lc}
\hline \multicolumn{2}{c}{ Dados para calculo dos indicadores } \\
\hline Área Total & $4950 \mathrm{~m} 2$ \\
Área CPD & $430 \mathrm{~m} 2$ \\
Funcionários & 283 \\
Demanda Máxima Media & $\sigma=30,1$ \\
Consumo Energia Mensal Medido & $321808 \mathrm{kWh} / \mathrm{mês}$ \\
Consumo Energia Inverno (PUFE) & $328053 \mathrm{kWh} / \mathrm{mês}$ \\
Consumo Energia Verão (PUFE) & $411339 \mathrm{kWh} / \mathrm{mês}$ \\
Consumo Ar Condicionado no Inverno (PUFE) & $151633 \mathrm{kWh} / \mathrm{mês}$ \\
Consumo Ar Condicionado no Verão (PUFE) & $234920 \mathrm{kWh} / \mathrm{mês}$ \\
Consumo Ar Condicionado no Inverno CPD (PUFE) & $145260 \mathrm{kWh} / \mathrm{mês}$ \\
Consumo Ar Condicionado no Verão CPD (PUFE) & $223500 \mathrm{kWh} / \mathrm{mês}$ \\
Consumo Energia Inverno CPD (PUFE) & $310860 \mathrm{kWh} / \mathrm{mês}$ \\
Consumo Energia Verão CPD (PUFE) & $389098 \mathrm{kWh} / \mathrm{mês}$ \\
Consumo Energia CPD (Servidores+Roteadores+No-break) & $165600 \mathrm{kWh} / \mathrm{mês}$ \\
Demanda de Potência dos Servidores & $193 \mathrm{~kW}$ \\
Demanda de Potência dos Roteadores & $25 \mathrm{~kW}$ \\
Demanda de Potência Servidores + Roteadores & $218 \mathrm{~kW}$ \\
Demanda de Potência para Iluminação & $38,36 \mathrm{~kW}$ \\
Demanda de Potência para Iluminação sala CPD/Roteador & $6,4 \mathrm{~kW}$ \\
\hline
\end{tabular}

Com base nos dados acima foi possível determinar a intensidade energética e a demanda máxima mensal da edificação. Os indicadores foram divididos em quatro tipos: Indicadores baseados na medição (Tabela 42); Indicadores baseados no PUFE (Tabela 43), Indicadores próprios do CPD (Tabela 44) e outros indicadores energéticos que poderiam ser de utilidade (Tabela 45).

Tabela 42- Indicadores Energéticos baseados na medição CCE/USP.

\begin{tabular}{lc}
\hline \multicolumn{2}{c}{ Indicadores Energéticos ( Medição Total) } \\
\hline Intensidade Energética por Área & $65 \mathrm{kWh} / \mathrm{m} 2$ \\
Intensidade Energética por Funcionário & $1137 \mathrm{kWh} / \mathrm{funcionário}$ \\
Demanda Máxima Mensal por Área & $99,2 \mathrm{~W} / \mathrm{m} 2$ \\
Demanda Máxima Mensal por Funcionário & $1735 \mathrm{~W} / \mathrm{m} 2$ \\
\hline
\end{tabular}

Tabela 43- Indicadores Energéticos baseados no PUFE.

\section{Indicadores Energéticos (PUFE)}

Intensidade Energética por Área (Inverno)

Intensidade Energética por Funcionário (Inverno)

Intensidade Energética por Área (Verão)

Intensidade Energética por Funcionário (Verão )
$66 \mathrm{kWh} / \mathrm{m} 2$

$1154 \mathrm{kWh} /$ funcionário

$83 \mathrm{kWh} / \mathrm{m} 2$ 1452 kWh/funcionário 
Tabela 44- Indicadores Energéticos CPD do CCE/USP.

\section{Indicadores Energéticos CPD/CCE}

Intensidade Energética CPD no inverno

$722,93 \mathrm{kWh} / \mathrm{m} 2$

Intensidade Energética CPD no verão

$904,88 \mathrm{kWh}$

Densidade de Energia do Ar Condicionado CPD no inverno

$337,81 \mathrm{kWh} / \mathrm{m} 2$

Densidade de Energia do Ar Condicionado CPD no verão

$519,76 \mathrm{kWh} / \mathrm{m} 2$

Densidade de Energia Servidores, Roteadores, UPS

$385 \mathrm{kWh} / \mathrm{m} 2$

Densidade de Potência dos equipamentos por rack

$2076 \mathrm{~W} /$ Rack

Densidade de Potência da iluminação CPD

$14,30 \mathrm{~W} / \mathrm{m} 2$

PUE Datacenter

2,33

Tabela 45- Outros Indicadores Energéticos.

\begin{tabular}{lc}
\hline \multicolumn{2}{c}{ Outros Indicadores Energéticos } \\
\hline Densidade de Energia do Ar Condicionado no inverno & $30,63 \mathrm{kWh} / \mathrm{m} 2$ \\
Densidade de Energia do Ar Condicionado no verão & $47,45 \mathrm{kWh} / \mathrm{m} 2$ \\
Densidade de Potência de Iluminação & $7,75 \mathrm{~W} / \mathrm{m} 2$ \\
\hline
\end{tabular}

\subsubsection{Dificuldades Encontradas}

O Centro de Computação Eletrônica (CCE) da USP possui diferentes atividades com regimes de consumo energético distintos, o que exigiu uma análise mais aprofundada para o mapeamento e a construção da curva com o software PUFE. A curva de demanda construída no PUFE apresenta um erro de 1,9\%, que é considerado aceitável.

O prédio do CCE apresenta um consumo diferente quando comparado a um edifício de escritório, já que possuí um datacenter (CPD) em seu interior. O CPD possui área de $430 \mathrm{~m}^{2}$ com um consumo importante, uma vez que os servidores e roteadores de rede ficam permanentemente ligados, assim como o ar condicionado, que mantém os equipamentos refrigerados. O consumo relacionado com esta atividade corresponde de 80 a $85 \%$ do total da edificação, o que representa uma demanda base de aproximadamente $400 \mathrm{~kW}$.

As áreas de escritório são bastante heterogêneas e apresentam diferentes regimes de funcionamento. Algumas áreas possuem horário regular das $7 \mathrm{~h}$ às $18 \mathrm{~h}$, enquanto outras funcionam $24 \mathrm{~h}$ por dia, sete dias por semana. 
Nas áreas de manutenção de equipamentos foram encontradas dificuldades para se estimar o número de computadores em funcionamento. Nas áreas de gravação e edição de TV também foram encontradas dificuldades para se definir o horário de funcionamento dos equipamentos existentes.

\subsubsection{Proposta de cenários de conservação de energia e melhora iluminação}

A partir dos dados do estudo de usos finais, observa-se que o CPD ou datacenter da edificação apresenta um importante consumo de energia para satisfazer as demandas de servidores e roteadores (entre 36,59 e $45,82 \%$ do total) e do chiller para produção de frio (entre 33,46 e 42,39\% do total), já a análise das curvas de demanda da edificação demonstram que este consumo é relativamente constante. Com base nessa informação pode-se dizer que a edificação apresenta um grande potencial para instalação de cogeração, uma vez que as cargas elétricas e térmicas do CPD são constantes ao longo do dia/ano.

De acordo com as análises realizadas, a cogeração foi considerada o cenário de conservação de energia mais importante da edificação, por estar relacionada com o consumo de energia do CPD, o qual representa mais de $90 \%$ do consumo total do prédio. Neste sentido, a principal proposta seria implementar a cogeração a partir do aproveitamento dos rejeitos térmicos da geração local de eletricidade utilizada pelos servidores e roteadores, para acionamento de um ciclo de absorção para geração de frio.

Outros sistemas, como iluminação, ar condicionado tipo split, entre outros, são menos significantes por apresentarem pouca representatividade no consumo total de energia. Contudo, na área de iluminação se identificam possibilidades de melhoria de eficiência energética, com a troca de tecnologia das lâmpadas T8 de 32 Watts por lâmpadas T5 de 28 Watts ou LED de 22 Watts.

\subsubsection{Cogeração}

Para definir os sistemas de cogeração necessários para fornecer a energia elétrica e térmica do CPD, foi considerada a carga térmica necessária para o resfriamento das zonas envolvidas. A carga térmica foi determinada a partir da simulação computacional do prédio no software EnergyPlus, utilizando como valores de simulação os indicadores 
energéticos calculados anteriormente e validando a mesma com os valores de consumo energético do CPD.

O modelo computacional foi composto por 4 zonas térmicas, uma zona para a área dos servidores, uma zona para a área dos roteadores, uma zona perimetral e uma zona de primeiro andar, para dar proteção térmica as zonas do CPD. A Figura 66 mostra o zoneamento no modelo computacional construído com ajuda do software Google Sketchup e do plug-in OpenStudio para EnergyPlus.

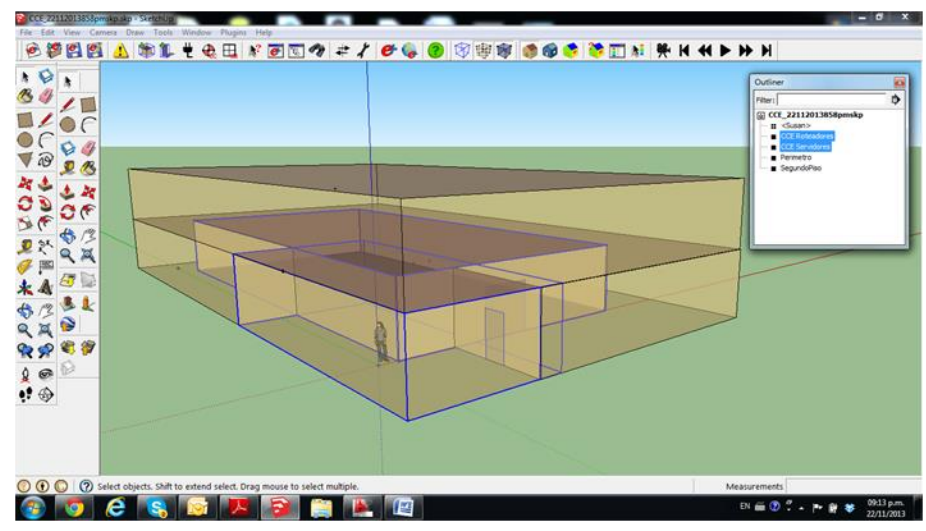

Figura 66. Modelo computacional do CCE en Google Sketchup para simulacao em EnergyPlus.

O modelo construído foi simulado utilizando-se os dados climáticos da cidade de São Paulo e foi validado com os valores de consumo energético mensal obtidos nas etapas anteriores da auditoria energética. Para determinar a carga térmica que o sistema de cogeração devia ser capaz de fornecer para o resfriamento do CPD, foi simulado um dia típico de verão e um dia típico de inverno.

Os resultados da simulação são mostrados na figura 67. Os mesmos permitiram determinar que a carga térmica máxima diária no CPD está entre 62 e 68 TR. Este dado pode foi utilizado para dimensionar o sistema de condicionamento ambiental da cogeração para o CPD.

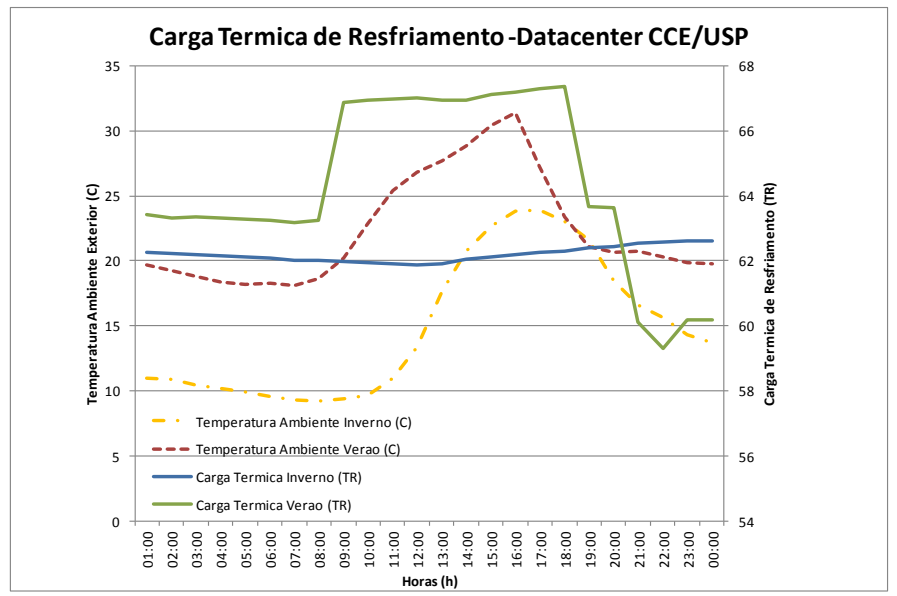

Figura 67. Simulação computacional da carga térmica do CPD num dia de inverno e de verão. 
Neste caso, a proposta é a de implementação de um sistema de cogeração utilizando um sistema topping cycle, no qual a geração de eletricidade tem precedência sobre a geração de calor como indicado na Figura 68. Para isso, foi avaliada, técnica e financeiramente, a possibilidade de utilização de um motogerador de $200 \mathrm{~kW}$ a gás natural ou de uma microturbina de 190kW também a gás natural.

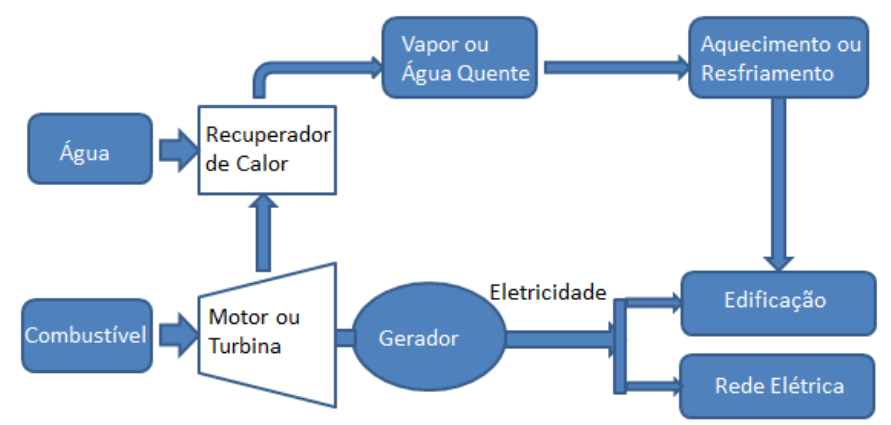

Figura 68. Cogeração com Ciclo Topping (Fonte: Elaboração Própria).

O sistema de ar condicionado atualmente utilizado possui 2 chillers elétricos de 100 TR, sendo um deles para respaldo, e seu uso é de 24 horas por dia, durante todos os dias do ano.

O sistema de cogeração a gás forneceria a potência elétrica total do datacenter sem a participação dos chillers utilizados atualmente; a proposta seria então de empregar um gerador de aproximadamente $200 \mathrm{~kW}$ (dependendo dos valores comerciais disponíveis) para fornecer energia na base da curva de demanda elétrica e utilizar a energia térmica disponível para alimentar um Chiller de Absorção de Água Quente. No caso em que faltasse energia térmica para fornecer a totalidade de energia necessária ao datacenter, ou em momentos de manutenção durante o ano, o chiller elétrico existente poderia suprir essa deficiência.

O presente estudo avaliou e comparou a viabilidade de se empregar um motogerador de $200 \mathrm{~kW}$ a gás natural ou uma microturbina de $190 \mathrm{~kW}$ a gás natural,a fim de apontar qual seria a melhor escolha. Na figura 69 encontra-se representada uma nova curva de demanda elétrica para um dia típico no inverno, na mesma pode-se apreciar a energia gerada localmente com o sistema de cogeração a escolher (Motogerador ou Microturbina) e a estimativa de energia comprada a concessionária 

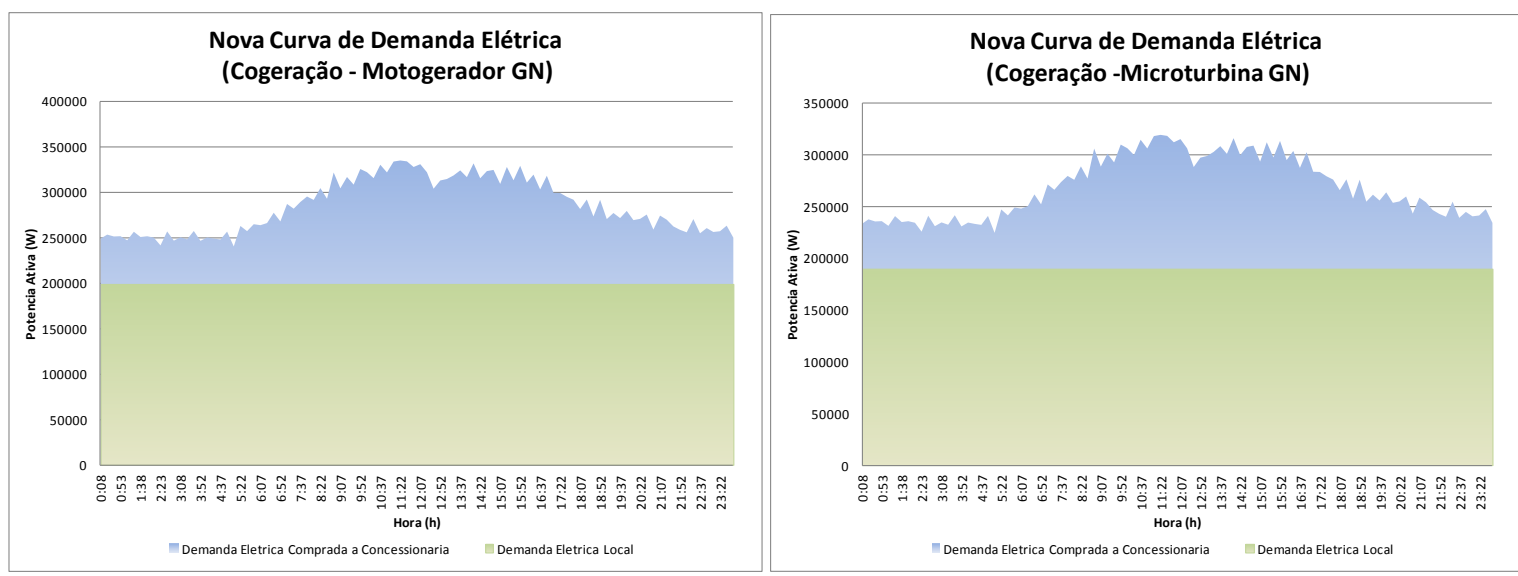

Figura 69. Nova curva de demanda elétrica para um dia típico inverno, energia gerada pelo motogerador e energia comprada a concessionária.

Os dados do balanço energético e o cálculo da energia térmica necessária para a cogeração utilizando o motogerador são apresentados na tabela 46. Para os mesmos foram utilizados os dados de referencia de um Motogerador de $200 \mathrm{~kW}$ a gás natural com eficiência elétrica de 34\% (Andreos, 2013).

Tabela 46. Cálculos Energia Térmica Motogerador 200kW.

\begin{tabular}{cc}
\hline Cálculos Energia Térmica Útil & \\
\hline Consumo Gerador $(\mathrm{Nm} 3 / \mathrm{kWh})$ & 0.2955 \\
Capacidade $(\mathbf{k W e})$ & $\mathbf{2 0 0}$ \\
Eficiência Elétrica $(\%)$ & 34 \\
Vazão horária de Gás Natural $(\mathrm{Nm} 3 / \mathrm{h})$ & 59.1 \\
Poder Calorífico Inferior $(\mathrm{kca} / \mathrm{Nm} 3)$ & 8560 \\
Taxa Energia Entra Gerador $(\mathrm{kcal} / \mathrm{h})$ & 505896 \\
Taxa Energia Entra Gerador $(\mathbf{k W t})$ & $\mathbf{5 8 8}$ \\
Energia Térmica Bloco $(\%)$ & 22 \\
Eficiência do Trocador & 0.95 \\
Taxa Energia Térmica Bloco Útil $(\mathrm{kcal} / \mathrm{h})$ & 105732 \\
Taxa Energia Térmica Bloco Útil $(\mathbf{k W t})$ & $\mathbf{1 2 3}$ \\
Energia Térmica Exaustão $(\%)$ & 23 \\
Eficiência do Trocador & 0.85 \\
Taxa Energia Térmica Bloco Útil $(\mathrm{kcal} / \mathrm{h})$ & 98903 \\
Taxa Energia Térmica Exaustão Útil $(\mathbf{k W t})$ & $\mathbf{1 1 5}$ \\
Energia Térmica Útil Total $(\mathrm{kcal} / \mathrm{h})$ & 204635 \\
Energia Térmica Útil Total $(\mathbf{k W t})$ & $\mathbf{2 3 8}$ \\
\hline
\end{tabular}

$\mathrm{Na}$ tabela 47 encontra-se apresentada a potência de refrigeração que se pode obter utilizando um chiller de absorção do tipo água quente com um COP de 0,8. 
Tabela 47. Cálculos Geração Térmica Chiller de Absorção.

\begin{tabular}{cc}
\hline Capacidade Geração Térmica Chiller de Absorção \\
\hline COP Chiller de Absorção & 0.8 \\
Capacidade Geração Térmica $(\mathrm{kcal} / \mathrm{h})$ & 163708 \\
Capacidade Ge ração Térmica $(\mathbf{k W t})$ & $\mathbf{1 9 0}$ \\
Capacidade Geração Térmica $(\mathbf{T R})$ & $\mathbf{5 4}$ \\
\hline
\end{tabular}

A capacidade de geração térmica para resfriamento deste sistema é de 54 TR, e como observado na figura 67 , a carga térmica de resfriamento necessária para o datacenter esta aproximadamente entre 62 e 67 TR. Portanto, neste caso seria necessária a participação do chiller elétrico durante todo o ano para fornecer entre 8 e 13 TR, com variação dependendo da época do ano e as condições climáticas.

Os dados e o cálculo da energia térmica necessária para a cogeração utilizando a microturbina são apresentados na tabela 48. Para os mesmos foram utilizados os dados de referencia de uma Microturbina de 190 kW a gás natural com eficiência elétrica de $31 \%$ (Capstone, 2013). Contudo, neste caso foi empregada uma eficiência de 29\%, por se considerar que o dado do catalogo é um pouco mais alto do que o real, já que é definida nas condições ISO e não nas condições da cidade de São Paulo.

Tabela 48- Cálculos Energia Térmica Microturbina 190kW.

\begin{tabular}{cc}
\hline Cálculos Energia Térmica Útil & \\
Modelo & C200 Capstone \\
Capacidade $(\mathrm{kWe})$ & $\mathbf{1 9 0}$ \\
Eficiência Elétrica $(\%)$ & 29 \\
Taxa Energia de Entrada Microturbina $(\mathbf{k W t})$ & $\mathbf{6 5 5}$ \\
Poder Calorífico Inferior $(\mathrm{kcal} / \mathrm{Nm} 3)$ & 8560 \\
Vazão horária de Gás Natural $(\mathrm{Nm} 3 / \mathrm{h})$ & 66.16 \\
Eficiência Térmica $(\%)$ & 41 \\
Taxa Energia Térmica Turbina $(\mathrm{kWt})$ & 269 \\
Eficiência do Trocador & 0.95 \\
Taxa Energia Térmica Útil $(\mathbf{k W t})$ & $\mathbf{2 5 5}$ \\
Perdas $(\%)$ & 28 \\
Taxa Energia Térmica Perdida $(\mathbf{k W t})$ & $\mathbf{1 8 3}$ \\
\hline
\end{tabular}

Considerando a utilização de um chiller de absorção do tipo água quente com um COP de 0,8 , os cálculos da potência de refrigeração que se pode obter deste sistema são apresentados na tabela 49 . 
Tabela 49- Cálculos Geração Térmica Chiller de Absorção.

\begin{tabular}{lc}
\hline Capacidade Geração Térmica Chiller de Absorção & \\
\hline COP Chiller de Absorção & 0.8 \\
Capacidade Geração Térmica (kWt) & $\mathbf{2 0 4}$ \\
Capacidade Geração Térmica (TR) & $\mathbf{5 8}$ \\
\hline
\end{tabular}

A capacidade de geração térmica deste sistema para resfriamento é de $58 \mathrm{TR}$, estando abaixo da carga térmica de resfriamento necessária para o datacenter que se encontra aproximadamente entre 62 e 67 TR, como apresentado na figura 67. Portanto, também neste caso seria necessária a participação do chiller elétrico durante todo o ano, fornecendo entre 4 e 10 TR dependendo da época do ano e as condições climáticas.

Com os dados obtidos nos cálculos anteriores e com a simulação computacional no EnergyPlus foi construída uma curva de demanda térmica do datacenter, juntamente com uma curva da capacidade de geração térmica para refrigeração das diferentes tecnologias avaliadas. A análise dessas curvas permite avaliar qual o aporte que cada uma das diferentes tecnologias teria sobre o condicionamento ambiental do datacenter e, portanto, estimar o uso necessário do chiller elétrico do sistema. As curvas para um dia típico de inverno e de verão para cada possível tecnologia encontram-se na figura 70.

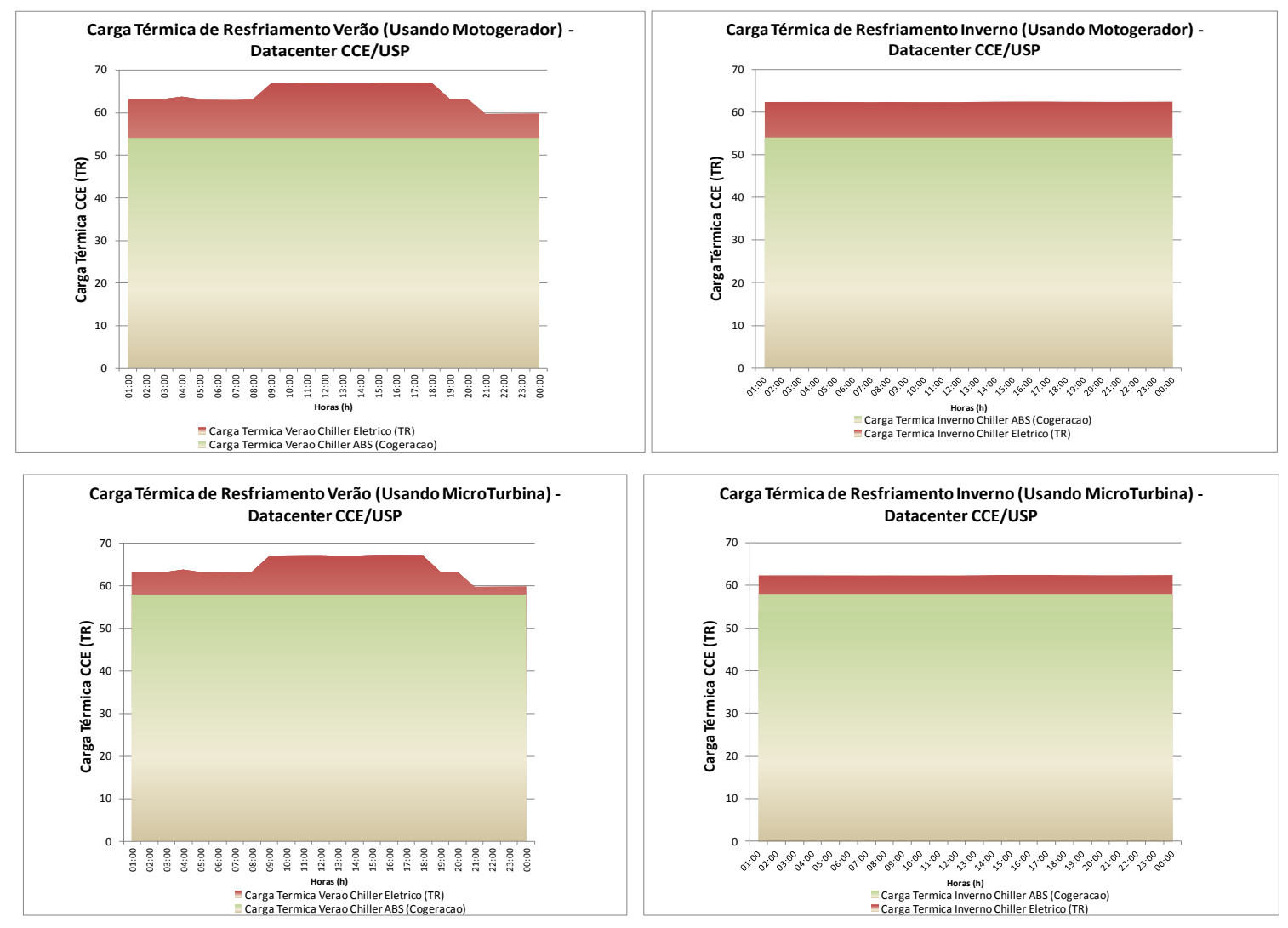

Figura 70. Carga térmica do datacenter e capacidade de geração térmica motogerador e microturbina em dia típico de inverno e verão. 


\subsubsection{Avaliação Econômica}

Foi realizada uma analise de economia de energia usando várias figuras de mérito para determinar se a implementação de um sistema de cogeração a gás natural seria economicamente viável. Para determinar o custo do investimento inicial e de manutenção anual foram utilizados os valores de custo dos equipamentos, de instalação e de manutenção apresentados na tabela 50.

Tabela 50- Custo Equipamentos, instalação e manutenção anuais estimados. (Fonte: Carrier, 2005; Capehart, 2010;Andreos, 2013; Capstone, 2013).

\begin{tabular}{lc}
\hline \multicolumn{1}{c}{ Motoge rador 200 kW } \\
\hline Custo Motogerador (USD/kW) & 373 \\
Custo Instalação (USD/kW) & 228 \\
Custo Manutenção (USD/MWh elétrico gerado) & 22 \\
\hline \multicolumn{2}{c}{ Chiller Absorção 75 TR } \\
\hline \multicolumn{2}{c}{ Microturbina C200 } \\
\hline \multicolumn{2}{c}{682} \\
Custo Chiller Absorção Água Quente (USD/TR) \\
Custo Instalação (USD/TR) \\
\hline \multicolumn{2}{c}{682} \\
\hline Cuntenção Anual (USD/TR) \\
Custo Instalação (USD/kW) \\
Custo Manutenção (USD/MWh elétrico gerado) \\
\hline
\end{tabular}

O seguinte passo foi determinar qual a quantidade de eletricidade que ainda deveria ser comprada da concessionária de energia elétrica em cada caso. A eletricidade comprada à concessionaria foi calculada considerando um uso do sistema de cogeração de 8600 horas/ano (devido à manutenção). Esta energia elétrica foi também estimada com ajuda das medições de variáveis elétricas, do cálculo de consumo mensal no PUFE e dos cálculos das novas curvas de demanda elétrica representados na figura 69

A tarifa utilizada foi tomada do Sistema Contaluz Web "Sistema de Gestão de Faturas da USP", o qual mostrou que a média mensal do custo unitário de energia elétrica do campus USP da Capital, registrado nos últimos doze meses, é de R \$212,00/ MWh, porém, para considerar os valores nas mesmas unidades que as auditorias anteriores, o custo unitário de energia elétrica utilizado foi de $\$ 0,099 / \mathrm{kWh}$. Os resultados do cálculo estão apresentados na tabela 51 . 
Tabela 51. Custo mensal de eletricidade comprada a concessionária.

\begin{tabular}{ccc}
\hline & Inverno & Verão \\
\hline Consumo Eletricidade Mensal Atual (kWh) & 328053 & 411339 \\
Custo Eletricidade Mensal Atual (USD) & $\$ 32733.128$ & $\$ 41043.405$ \\
Custo Eletricidade Mensal (USD) & 56148 & 62747 \\
Consumo Eletricidade Mensal Concessionária - Cogeração Motogerador (kWh) & $\$ 5602.447$ & $\$ 6260.896$ \\
Consumo Eletricidade Mensal Concessionária - Cogeração Microturbina (kWh) & 51749 & 58347 \\
Custo Eletricidade Mensal (USD) & $\$ 5163.515$ & $\$ 5821.864$ \\
\hline
\end{tabular}

Com os dados da vazão horária de gás natural para cada cenário proposto, nas tabelas 46 e 48, foi calculado o consumo mensal de gás natural, que foi igual a 41773 $\mathrm{m}^{3} / \mathrm{mês}$ no caso do motogerador e de $46763 \mathrm{~m}^{3 /}$ mês no caso da microturbina. Para o calculo econômico financeiro foram utilizados os valores da tarifa da COMGAS para abril de 2014, para o termo variável e o termo fixo, com os impostos respectivos, e os mesmos são apresentados na tabela 52.

Tabela 52- Custo mensal do gás natural para geração elétrica nos diferentes cenários.

\begin{tabular}{|c|c|c|c|c|c|c|c|}
\hline v & & $\begin{array}{c}\text { Motoge rador } \\
(\mathrm{m} 3)\end{array}$ & $\begin{array}{c}\text { Microturbina } \\
(\mathrm{m} 3)\end{array}$ & $\begin{array}{c}\text { Tarifa } \\
(\mathbf{R} \$ / \mathbf{m} 3)\end{array}$ & $\begin{array}{c}\text { Tarifa } \\
(\mathrm{USD} / \mathrm{m3})\end{array}$ & $\begin{array}{c}\text { Custo GN } \\
\text { Motogerador (USD) }\end{array}$ & $\begin{array}{c}\text { Custo GN } \\
\text { Microturbina (USD) }\end{array}$ \\
\hline 1 & Até $5.000,00 \mathrm{~m}^{3}$ & 5000 & 5000 & 0.423225 & 0.192375 & 961.9 & 961.9 \\
\hline 2 & $5.000,01$ a $50.000,00 \mathrm{~m}^{3}$ & 36773 & 41763 & 0.332366 & 0.151075 & 5555.5 & 6309.4 \\
\hline 3 & $50.000,01$ a $100.000,00 \mathrm{~m}^{3}$ & & & 0.286124 & 0.130056 & 0.0 & 0.0 \\
\hline 4 & $100.000,01$ a $500.000,00 \mathrm{~m}^{3}$ & & & 0.217348 & 0.098795 & 0.0 & 0.0 \\
\hline 5 & $500.000,01$ a $2.000 .000,00 \mathrm{~m}^{3}$ & & & 0.224677 & 0.102126 & 0.0 & 0.0 \\
\hline 6 & $2.000 .000,01$ a $4.000 .000,00 \mathrm{~m}^{3}$ & & & 0.203365 & 0.092439 & 0.0 & 0.0 \\
\hline 7 & $4.000 .000,01$ a $7.000 .000,00 \mathrm{~m}^{3}$ & & & 0.177947 & 0.080885 & 0.0 & 0.0 \\
\hline 8 & $7.000 .000,01$ a $10.000 .000,00 \mathrm{~m}^{3}$ & & & 0.152526 & 0.069330 & 0.0 & 0.0 \\
\hline 9 & $>10.000 .000,00 \mathrm{~m}^{3}$ & & & 0.126515 & 0.057507 & 0.0 & 0.0 \\
\hline \multicolumn{4}{|c|}{$\begin{array}{r}\text { Termo Variavel } \\
\end{array}$} & & & 6517.4 & 7271.2 \\
\hline \multicolumn{4}{|c|}{ Termo Fixo } & 0.956564 & 0.4348018 & 18163.1 & 20332.8 \\
\hline \multicolumn{4}{|c|}{ Total } & & & 24680.5 & 27604.1 \\
\hline
\end{tabular}

Utilizando os valores de custo mensal de eletricidade da tabela 51 e os valores de custo mensal para geração de eletricidade com gás natural da tabela 52, foram estimadas as despesas anuais para esses itens. Considerando os valores de custo de equipamentos, custo de instalação, custo de manutenção anual, custo de eletricidade anual e custo para geração elétrica com gás natural anual dos diferentes sistemas, junto com uma taxa de desconto do $12 \%$, as figuras de mérito do payback simple e TIR foram calculadas e são mostradas na tabela 53. 
Tabela 53- Avaliação Econômica da implementacao de cogeração no CCE.

\begin{tabular}{|c|c|c|c|}
\hline & Caso Atual (USD) & Caso Motoge rador (USD) & Caso Microturbina (USD) \\
\hline Custo Equipamento & & 74600 & 170000 \\
\hline Custo Instalação & & 45600 & 68000 \\
\hline Custo Manutenção Anual Equipamento & & 18738 & 13490 \\
\hline Custo Chiller de Absorção & & 51150 & 51150 \\
\hline Custo Instalação Chiller de Absorção & & 51150 & 51150 \\
\hline Custo Manutenção Anual Chiller Absorção & & 2700 & 2700 \\
\hline Custo Manutenção Anual Chiller Elétrico & 2000 & 2000 & 2000 \\
\hline Custo Eletricidade Anual Concessionária & 442659 & 71180 & 65912 \\
\hline Custo Geração Elétrica (Gás Natural) & & 296165 & 331249 \\
\hline Custo Total Equipamentos e Instalação & & 222500 & 340300 \\
\hline Custo Anual Atual Energia e Manutenção & 444659 & & \\
\hline Novo Custo Anual Energia e Manutenção & & 390783 & 415351 \\
\hline Payback & & 4.1 & 11.6 \\
\hline TIR & & $20 \%$ & $-4 \%$ \\
\hline
\end{tabular}

Os resultados mostram como a implementação de um sistema de cogeração com um motogerador a gás natural de $200 \mathrm{~kW}$ e um chiller de absorção de água quente de 75 TR é uma opção técnica e financeiramente viável por apresentar um tempo de payback de 4,1 anos e uma taxa interna de retorno de $20 \%$.

No caso da microturbina de $190 \mathrm{~kW}$ a gás natural, mesmo que tecnicamente é viável, devido a possibilidade em fornecer boa parte da demanda elétrica e térmica do datacenter, o alto custo de investimento e o maior custo de geração elétrica com gás natural inviabilizam o projeto ao ter um tempo de payback de 11,6 anos e uma taxa interna de retorno negativa de $-4 \%$. 


\section{CONCLUSÕES}

A partir das auditorias energéticas realizadas foi possível conhecer com detalhe o comportamento energético das edificações estudadas, permitindo propor soluções específicas para as características de uso de cada uma delas. Neste sentido, foi possível através do estudo de usos finais nas edificações, visualizar com maior clareza os sistemas que apresentam as melhores oportunidades de conservação de energia.

Com base nas medições e estudo de usos finais foram calculados indicadores energéticos cujo uso permite comparar diferentes edificações específicas ou com um benchmarking de edificações a fim de determinar se o consumo energético, ou determinados parâmetros, estão de acordo com os valores considerados eficientes. No caso da presente pesquisa, ante a ausência de um benchmarking de consumo energético de edificações brasileiras, as comparações não foram aplicadas, contudo os indicadores recolhidos no trabalho serão de grande utilidade quando um benchmarking de edificações esteja disponível. Dessa forma, será possível saber se o consumo das edificações estudadas esta dentro, acima ou abaixo da média de consumo de outras edificações do país.

Ainda como parte da metodologia de auditoria energética aplicada, a utilização de medição de variáveis elétricas juntamente com a construção do perfil de carga no software PUFE possibilitou a geração de informações valiosas, validadas com dados reais como são as medições. Utilizar ferramentas de simulação computacional para predizer parâmetros energéticos ou de iluminação, permitiu determinar o comportamento de determinadas tecnologias de forma a comprovar qual é a melhor opção de soluções para determinado projeto, evitando assim experimentações desnecessárias.

Como parte das auditorias energéticas, a questão da auditoria de iluminação foi abordada pela importância em avaliar não só o tema energético como também a qualidade deste uso final, já que este apresenta grande importância ao proporcionar aos usuários melhorar suas condições de trabalho e/ou estudo. Na presente pesquisa foram encontrados espaços com iluminância menor do que a recomendada pela norma NBR 5413; por problemas com a distribuição das luminárias ou por falta de luminárias no ambiente. Nas edificações que apresentaram níveis de iluminância menores que os recomendados na norma, sugere-se a utilização de Task Lighting por ser esta uma opção 
válida técnica e economicamente e não necessitar de alterações de tecnologia de iluminação ou adição de luminárias a uma área determinada.

Por possuírem características similares, necessidade de melhora da iluminação e um consumo considerável deste uso final, para os prédios de energia, administração e laboratórios ("Fazendinha") foram propostas soluções relacionadas a trocas de tecnologia de iluminação. A avaliação tecnologica das auditorias de iluminação evidenciou que a tecnologia LED possui na totalidade dos casos um valor de DPI (Densidade de Potência de Iluminação) menor que as outras tecnologias, contudo ao considerar a parte luminotécnica, o LED ainda não obtém um desempenho que permita superar as outras tecnologias estudadas.

Além disso, financeiramente a tecnologia LED ainda não compete com as outras tecnologias pelo alto investimento inicial que necessita atualmente; assim, mesmo que apresente maior tempo de vida útil que as demais, o desempenho luminotécnico não justifica o investimento nesta tecnologia. Neste sentido, a tecnologia tubular T5 apresenta as melhores condições técnicas e econômicas no momento atual, para a implementação de um projeto de iluminação para as edificações do setor estudado.

As propostas de eficiência energética formuladas para os prédios de Administração e Fazendinha demonstraram um tempo de payback alto; contudo, a análise das outras figuras de mérito, como o TIR e o CEC, indicaram a viabilidade financeira destas propostas. Já no Prédio de Energia, a proposta de eficiência energética sugerida foi considerada inviável economicamente por apresentar tempos de payback alto e TIR baixo.

Os valores obtidos se devem á utilização de um custo de energia em média tensão, menor que as tarifas comerciais atuais, e também pelas caraterísticas de uso diário médio das luminárias dos prédios. Este último ponto evidencia a importância e as vantagens da realização de uma auditoria energética, já que esta permite realizar projeções baseadas em valores mais próximos aos reais e de maneira mais específica, gerando cálculos financeiros mais fidedignos e evitando que projetos sejam executados baseados em suposições.

Outro ponto importante das auditorias foi o datacenter, como o estudado no CCE da USP. Por apresentar uma demanda elétrica e térmica relativamente constante durante as 24 horas do dia e os 365 dias do ano, a cogeração aparece como uma opção interessante para um melhor aproveitamento da energia primária e, portanto, para uma diminuição dos custos para o usuário final. As opções estudadas para cogeração foram a 
utilização de um motogerador de 200kW com um chiller de absorção de $75 \mathrm{TR}$ ou a utilização de uma microturbina de $190 \mathrm{~kW}$ com um chiller de igual capacidade que o anterior. O resultado da avaliação técnica permitiu apontar que com ambas as tecnologias estudadas é possível fornecer grande parte da energia elétrica e térmica necessária ao CCE; porém em relação ao aspecto econômico financeiro a opção da microturbina fica inviável devido ao alto custo do equipamento e da instalação, e ao maior consumo de gás natural mensal utilizado, que não é equilibrado em relação a economia de energia elétrica conseguida. Portanto a proposta de cogeração utilizando tecnologia de combustão interna com o motogerador fica atrativa ao ter um tempo de payback menor a 5 anos e um TIR de 20\%, desta forma, seria interessante aprofundar a possibilidade desta opção em futuras pesquisas de energia relativas ao datacenter.

Como uma conclusão final do trabalho, a diminuição do consumo energético nos diferentes setores da sociedade é um tópico importante na atualidade, principalmente pelos altos custos econômicos da energia que podem prejudicar a competitividade de diferentes setores produtivos e também pelo impacto ambiental do consumo desmedido de energia no nosso planeta. Por essa razão a auditoria energética aparece como uma opção destacável no sentido de se alcançar soluções eficientes de conservação de energia em cada caso específico.

Um tema interessante relacionado com ao presente trabalho para futuras pesquisas, seria o estudo energético do setor dos datacenter já que este setor apresenta um consumo diferenciado e com constante aumento. Outros temas para trabalhos futuros seriam a auditoria energética como forma de promover a integração das energias renováveis nas edificações como uma estratégia de conservação de energia, por exemplo, utilizando vidros fotovoltaicos em edificações que possuem fachada de vidro ou mesmo módulos solares no telhado. Também o estudo da utilização da auditoria energética no mercado das Empresas de Conservação de Energia (ESCO) no Brasil comparada com outras latitudes. 


\section{REFERÊNCIAS}

ALAJMI A. Energy audit of an educational building in a hot summer climate em Energy and Buildings, v47, pp.122-130, 2012

ALVAREZ André Luiz. Uso racional e eficiente da energia elétrica: Metodologia para determinação dos potenciais de conservação dos usos finais em instituições de ensino e similares . Dissertação submetida para obtenção do título de Mestre em Engenharia da Escola Politécnica da Universidade de São Paulo. São Paulo: USP, 1998.

ANDREOS Ronaldo. Estudo de viabilidade técnico-econômica de pequenas centrais de cogeração a gás natural no setor terciário do estado de São Paulo . Dissertação submetida para obtenção do título de Mestre em Ciências do Instituto de Eletrotécnica e Energia da Universidade de São Paulo. São Paulo: USP, 2013

ART ISPIRAZIONE E PRATICA. Pagina Web. www.3Dart.it. Revisada em 09/10/2013.

ASHRAE. Guideline 14-2002 Measurement of energy and demand savings, USA, 2002.

ASHRAE. Procedures For Commercial Building Energy Audits , USA, 2004.

ASHRAE. Advanced Energy Design Guide for K-12 School Buildings, USA, 2011.

ASHRAE. Advanced Energy Design Guide for Large Hospitals, USA, 2012.

ASHRAE. Standard 90.1-2007 Energy Standard for Buildings Except Low-Rise Residential Buildings, USA, 2007.

ASSOCIAÇÃO BRASILERA DE NORMAS TECNICAS. NBR 5461 TB23 Iluminação, Terminologia, p.40, part. 3.5.51. Rio de Janeiro, 1991.

ASSOCIAÇÃO BRASILERA DE NORMAS TECNICAS. NBR 5413 Iluminância de Interiores. Rio de Janeiro, 1992.

ATTIA S. State of the Art of Existing Early Design Simulation Tools for Net Zero Energy Buildings: A Comparison of Ten Tools, Université Catholique de Louvain, Belgica, 2011.

AVELAR V. Guidance for Calculation of Efficiency (PUE) in Data Centers em White Paper 158, Schneider Electric Data Center Science Center , 2014.

BARGHINI, A. Manual para la realización de Estudios sobre Usos Finales de electricidad, São Paulo, 1996.

BEGGS C. Energy: Management, Supply and Conservation, Elsevier Science, Second Edition,UK, 2009. 
CAPEHART B.- Microturbines em Whole Building Design Guide , National Institute of Buildings Science, 2010.

CAPSTONE TURBINE CORPORATION. Pagina Web. www.capstoneturbine.com. Revisada em 07/04/2014.

CARRIER CORPORATION. Product Data:16LJ Single-Effect, Low Temperature Hot Water,Hermetic Absorption Liquid Chiller, USA, 2005.

COMGAS. Pagina Web Tarifas Cogeração Atualizadas Deliberação ARSESP $\mathrm{n}^{\circ}$ 455, www.comgas.com.br/pt/nossosServicos/Tarifas/Paginas/coogeracao. aspx, Revisada em $10 / 04 / 2014$.

DEPARTMENT OF ENERGY (DOE). Pagina Web. EnergyPlus Energy Simulation Software. www.eere.energy.gov/buildings/energyplus/ . Revisada em 02.11.2013.

DEPARTMENT OF ENERGY AND CLIMATE CHANGE- Energy Consumption in the UK-Service Sector Data Tables, United Kingdom, 2012.

DIAL. Pagina Web. Dados Software. www.dial.de . Revisada em 30/10/2013.

DILUX-HELP. Pagina Web. Dados Software. www.dialux-help.ru . Revisada em 31.10.2013.

DUBOIS M.C., BLOMSTERBERG A. Energy saving potential and strategies for electric lighting in future North European, low energy office buildings: A literature review em Energy and Buildings, v.43, pp.2572-2582, 2011.

ENERGY INFORMATION AGENCY. 2003 Commercial Building Energy Consumption and Expenditures End-Uses , Table E1A - E2A, USA, Set, 2008.

EPE-EMPRESA DE PESQUISA ENERGÉTICA EPE. Balanço Energético Nacional 2013, Rio de Janeiro, 2013.

FEDERAL ENERGY MANAGEMENT PROGRAM (FEMP). Measurement and Verification for Federal Energy Projects, Version 3.0 ,USA, 2008.

FULLER S.K, PETERSEN S.R. Life Cycle Costing Manual for the Federal Energy Management Program in U.S. Department of Commerce, USA, 1995.

GARD ANALYTICS-Lecture 1: An Overview of Simulation and EnergyPlus, DOE, 2003.

JAYAMAHA L. Energy efficient building systems, McGraw Hill Professional, USA, 2007.

KRARTI M. Energy audit of building systems: an engineering approach, CRC Press, $2^{\text {nd }}$ edition, USA, 2011. 
LIN J. A light diet for a giant appetite: An assessment of China's fluorescent lamp standard em Energy, v. 30, pp.1873-1887, 2005.

LUZETC LOJA ONLINE. Revisão preços lâmpadas tubulares. www.luzetc.com.br . Revisada em 28/09/2013.

MAHLIA T.M.I, ABDUL RAZAK H.,NURASHIDA M.A. Life Cycle Cost Analysis and Payback period of lighting retrofit at the University of Malaya em Renewable and Sustainable Energy Reviews, v.15,pp. 1125-1132, 2011.

MELO A.P, BARCELOS M. Curso de Simulação Computacional-EnergyPlus. Apostila Curso. São Paulo, 2013.

PEREZ-LOMBARD L., ORTIZ J., POUT C. A review on buildings energy consumption information" em Energy and Buildings, v.40,pp.394-398, 2008.

PROCEL. Pesquisa de posse de equipamentos e hábitos de uso- ano base 2005 , em Relatório Setorial Instituições de Ensino, 2005.

PUFE Programa Usos Finais da Energia Projeto Comgas. Pagina Web www. pufe.iee.usp.br/newcomgas/, Instituto de Energia e Ambiente, USP, Revisada em 08/09/2013.

RYCKAERT W.R., SMET K.A.G, ROELANDTS I.A.A, VAN GILS M, HANSELAER P. Linear LED tubes versus fluorescent lamps: An evaluation em Energy and Buildings, v.49, pp.429-436, 2012.

SAIDEL M.A., FAVATO L.B, MORALES C. Indicadores energéticos e ambientais: Ferramenta importante na gestão da energia elétrica, PURE USP, São Paulo, 2005.

SAIT H.H. Auditing and analysis of energy consumption of an educational building in hot and humid area em Energy Conversion and Management, v.66, pp.143-152, 2013.

SANTAMOURIS M., BALARAS C.A., DASCALAKI A., ARGIRIOU A., GAGLIA A.-"Energy Consumption and the potential for energy conservation in school buildings in Hellas" em Energy, v. 19,pp.653-660, 1993.

SAUER I. Notas de Classe: Disciplina Usos Finais e Demanda de energia, Instituto de Energia e Ambiente, USP, 2012.

SENTELHAS Robespierre. Instrumento de Software para apoio á pesquisa de posse de equipamentos e hábitos de uso de energia elétrica. Dissertação submetida para obtenção do título de Mestre em Ciências do Instituto de Eletrotécnica e Energia da Universidade de São Paulo. São Paulo: USP, 2004.

SERVITENGE. Pagina Web. www.servitenge.com.br, Revisada em 02/12/2013.

TARGET ILUMINACAO LOJA ONLINE. Revisão preços lâmpadas tubulares. http://www.targetiluminacao.com.br/ . Revisada em 28/09/2013 
UNIVERSIDADE DE SÃO PAULO. Anuário Estatístico USP 2011, São Paulo, 2012. US DEPARTMENT OF ENERGY EERE- 2012 Annual Report: Commercial Building Energy Alliance, Outubro ,2012.

WARD I., OGBONNA A., ALTAN H. Sector review of UK higher education energy consumption em Energy Policy, v.36, pp.2939-2949, 2008.

YAMAMURA LOJA ONLINE. Revisão preços lâmpadas tubulares. www.yamamura.com/br . Revisada em 28/09/2013

ZILLES R. Sistemas Fotovoltaicos. Apostila-Curso de Pós-graduação em Energia, Instituto de Energia e Ambiente, USP, 2013. 


\section{APENDICE A: EQUAÇÕES FINANCEIRAS}

\section{A.1 Retorno do Investimento Simple (Payback Simple)}

O Payback Simple mede o tempo requerido para recuperar o investimento inicial de determinado projeto. Para projetos de eficiência energética o mesmo pode ser calculado utilizando a Equação (A.1).

$$
\text { Payback Simple }=\frac{I_{o}}{\left(C E_{i}-C E_{j}\right)}
$$

Considerando $\mathrm{I}_{\mathrm{o}}$ como o Investimento Inicial, $\mathrm{CE}_{\mathrm{i}}$ o custo anual de energia para a tecnologia a substituir, e $\mathrm{CE}_{\mathrm{j}}$ o custo anual de energia para a tecnologia eficiente.

\section{A.2 Taxa Interna de Retorno (TIR)}

A Taxa Interna de Retorno ou TIR é a taxa de desconto hipotética que, quando aplicada a um fluxo de caixa, faz com que os valores das despesas, trazidos ao valor presente, seja igual aos valores dos retornos dos investimentos, também trazidos ao valor presente. Para encontrar o valor da TIR, deve se calcular a taxa que satisfaz a equação (A.2):

$$
V P L=0=\sum_{t=1}^{n} \frac{F_{C}}{(1+T I R)^{t}}-I_{0}
$$

Considerando VPL como Valor Presente Liquido, $\mathrm{I}_{\mathrm{o}}$ como o Investimento Inicial, $\mathrm{t}$ o tempo de desconto de cada entrada de caixa, $\mathrm{n}$ tempo de desconto do ultimo fluxo de caixa.

\section{A.3 Avaliação de Custo de Ciclo de Vida (LCCA)}

A Avaliação de Custo de Ciclo de Vida (LCCA) permite organizar e computar os custos de adquirir, possuir, operar, manter e finalmente descartar de uma edificação ou um sistema da edificação. A formula simplificada para o cálculo do LCC de projetos de energia e água nas edificações é apresentada na Equação (A.3). 


$$
L C C(\$)=I_{0}+R e p l-R e s+E+W+O M \& R
$$

Considerando, LCC é o custo de ciclo de vida total em valor presente para determinada alternativa, , $\mathrm{I}_{0}$ como o Investimento Inicial, Repl como o custo em valor presente de reposição, Res como o valor residual em valor presente, E como o custo de energia em valor presente, $\mathrm{W}$ o custo da água em valor presente ( Não aplica para este trabalho) e $\mathrm{OM} \& \mathrm{R}$ os custos não energéticos, manutenção e reparação em valor presente.

\section{A.4 Custo de Ciclo de Vida Anualizado (ALCC)}

Devido às diferentes expectativas de vida dos sistemas avaliados, o LCC precisa ser anualizado para que os custos sejam comparáveis. O cálculoé mostrado na Equação (A.4).

$$
\operatorname{ALCC}(\$)=F R C \cdot L C C
$$

Considerando, ALCC é o Custo de Ciclo de Vida Anualizado, FRC é o Fator de Recuperação de Capital e LCC o Custo de Ciclo de Vida.

\section{A.5 Custo de Energia Conservada ( CEC)}

O Custo de Energia Conservada é calculado conforme a Equação (A.5).

$$
\operatorname{CSE}\left(\frac{U S \$}{k W h}\right)=\frac{\left[\left(I_{i}+\operatorname{Repl}_{i}-\operatorname{Res}_{i}\right)-\left(I_{j}+\operatorname{Repl}_{j}-\operatorname{Res}_{j}\right)\right]}{E_{i}-E_{j}}
$$

Considerando CSE como o Custo de Energia Conservada, $\mathrm{I}_{\mathrm{i}}$ como o investimento inicial para a tecnologia eficiente $i, I_{j}$ como o investimento inicial para a tecnologia $i, R_{e p l}$ como os custos de reposição em valor presente da tecnologia i, Repl $_{\mathrm{j}}$ como os custos de 
reposição em valor presente da tecnologia $\mathrm{j}$, Res $\mathrm{R}_{\mathrm{i}}$ como o valor residual em valor presente da tecnologia $\mathrm{i}, \operatorname{Res}_{\mathrm{j}}$ como o valor residual em valor presente da tecnologia $\mathrm{j}, \mathrm{E}_{\mathrm{i}}$ como o consumo energético anual $(\mathrm{kWh})$ para a tecnologia eficiente i e $\mathrm{E}_{\mathrm{j}}$ o consumo energético anual $(\mathrm{kWh})$ para a tecnologia substituída j. 